\title{
Die Funktion von Geminin beim Übergang von Neuro- zu Gliogenese in der Maus
}

\author{
Dissertation \\ zur Erlangung des Doktorgrades \\ der Mathematisch-Naturwissenschaftlichen Fakultäten \\ der Georg-August-Universität zu Göttingen
}

\author{
vorgelegt von \\ Yvonne Uerlings \\ aus Göttingen
}


D 7

Referent: Prof. Dr. Michael Kessel

Max-Planck-Institut für biophysikalische Chemie Abteilung Molekulare Zellbiologie

Korreferent: Prof. Dr. Ernst Wimmer

Institut für Zoologie, Anthropologie und

Entwicklungsbiologie

Abteilung Entwicklungsbiologie

Universität Göttingen

Tag der mündlichen Prüfung: 
"Solange Kinder klein sind, gib' ihnen Wurzeln, wenn sie groß sind, gib' ihnen Flügel."

(Albert Schweitzer)

Für meine liebe Familie 


\section{Inhaltsverzeichnis}

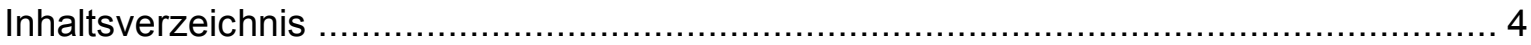

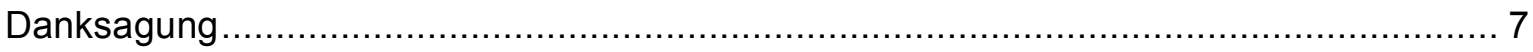

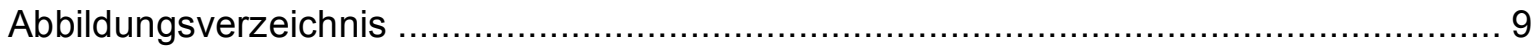

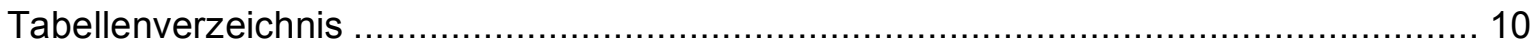

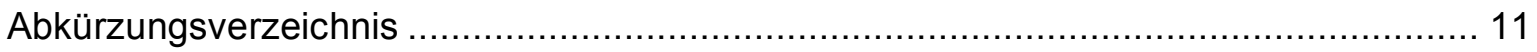

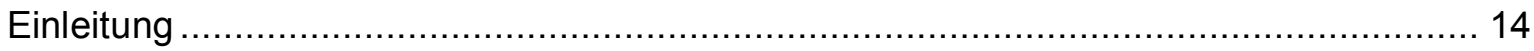

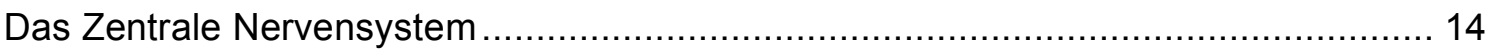

Anatomische Organisation des sich entwickelnden ZNS …............................. 14

Neurale Stamm- und Vorläuferzellen .............................................................. 15

Neuroepitheliale Zellen und radiale Gliazellen .................................................... 17

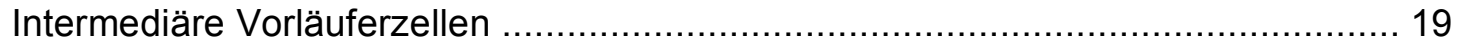

Morphologische Musterung des Cortex in Säugetieren ........................................ 19

Bildung der Schichten des Neocortex in Säugetieren ......................................... 20

Radiale und tangentiale Migration im Neocortex ............................................... 21

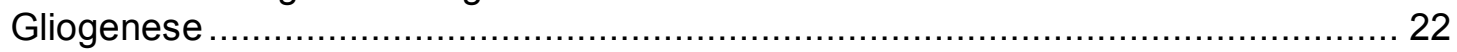

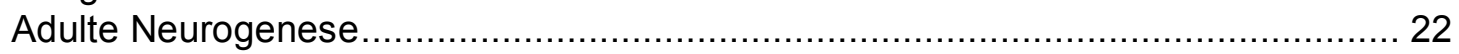

Epigenetische Faktoren in der Neuralinduktion und Neurogenese ....................... 23

Rolle von Geminin in der Embryonalentwicklung ............................................. 26

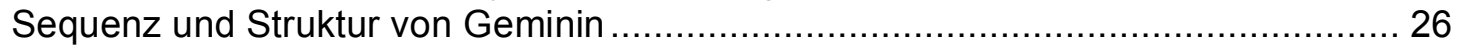

Geminin in der Rolle des Zellzyklusregulators .................................................. 28

Expression von Geminin in proliferierenden Zellen mit neuralem Schicksal............ 30

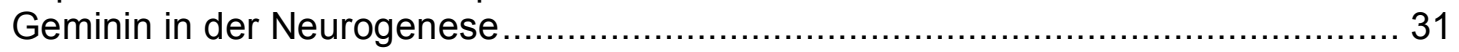

Geminin als Regulator der neuronalen Entwicklung ...................................... 32

Geminin als Regulator von Hox-Gen-Funktionen............................................. 33

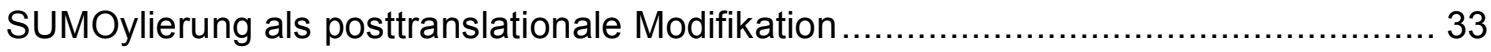

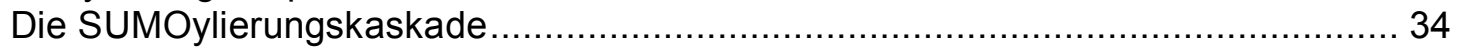

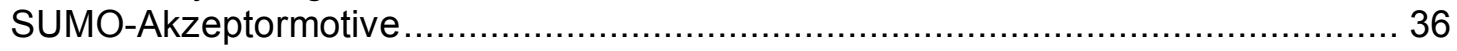

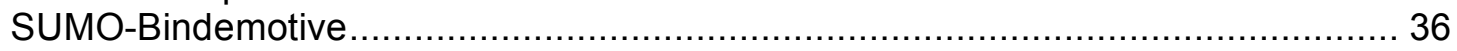

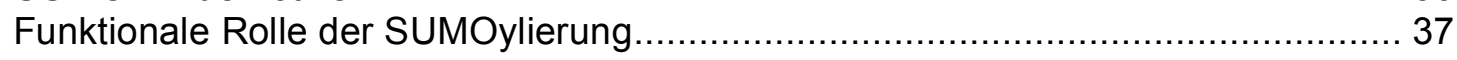

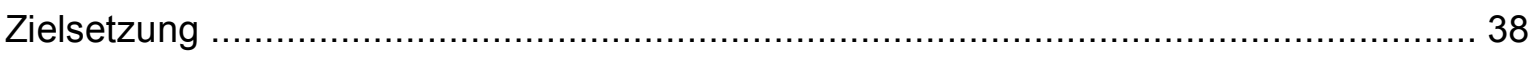

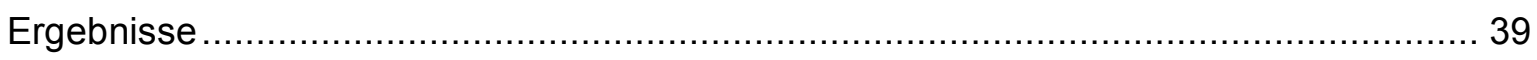

Posttranslationale Modifikation von Geminin mit SUMO1 ….................................... 39

In silico Analyse von dem Geminin-Protein..................................................... 39

Geminin ist bei Anwesenheit von spezifischen SUMO E3-Ligasen in vitro durch

SUMO1 modifizierbar ................................................................................... 40

In vivo SUMOylierung von Geminin in HeLa-Zellen ......................................... 42

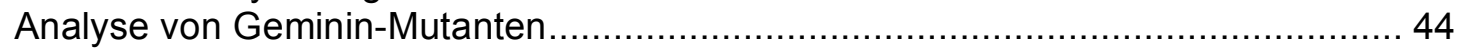

Konditionale Inaktivierung von Geminin in der Maus ............................................. 46

Generierung eines konditionalen Knockout-Konstruktes mittels Recombineering .... 47

Herstellung von homolog rekombinierten ES-Zellen .......................................... 50

Herstellung von Maus-Chimären ............................................................... 52 


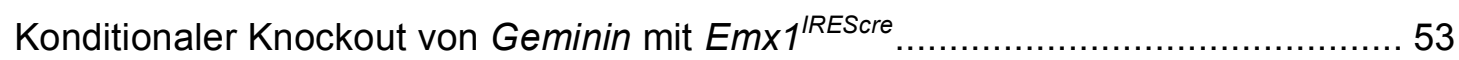

Phänotyp-Analyse von Geminin ${ }^{f / f f \mid} ; E m x 1^{\text {IREScre }}$-Mäusen ........................................... 56

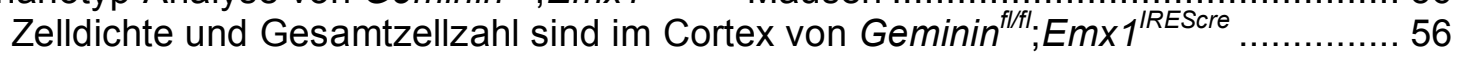

Analyse des mitotischen Zellzyklus im Cortex Geminin-defizienter Mäuse .............. 57

Analyse der Ausbeute an neuronalen Zellen im Cortex von Wt- und

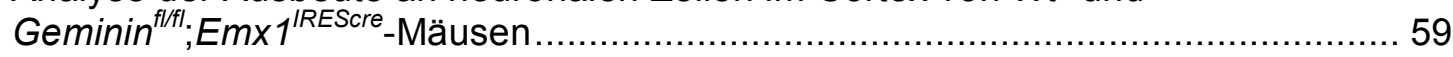

Geminin interagiert mit dem Transkriptionsfaktor Pax6 .................................. 62

Inaktivierung von Geminin mit Emx $1^{\text {RESCre }}$ zeigt keinen Einfluss auf Pax6 und Pax6-

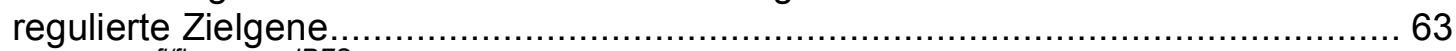

Geminin $^{\text {flffl}} ; E m \times 1^{\text {IRESCre }}$ transgene Mäuse haben eine normale Anzahl intermediärer

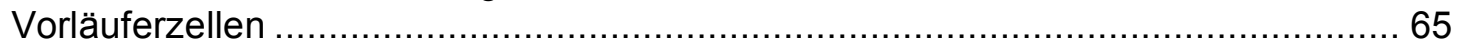

Deletion von Geminin in cortikalen Vorläuferzellen verändert nicht die Expression von

Sox2.

Die tangentiale Migration von Interneuronen ist in Geminin-defizienten Embryonen

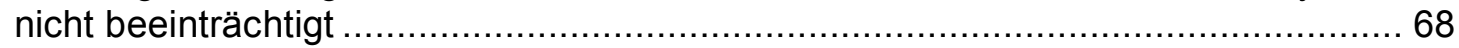

Anreicherung von GFAP-positiven Zellen bei Abwesenheit von Geminin ................ 70

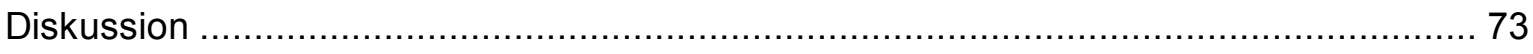

Geminin ist ein neues Zielprotein der SUMOylierung …....................................... 73

Regulation der Funktion von Geminin durch posttranslationale Modifikationen ....... 74

Funktionale Rolle der SUMOylierung von Geminin ............................................ 75

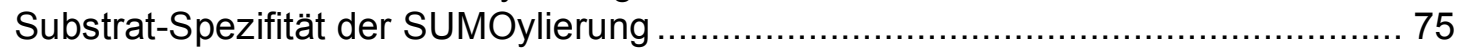

Phänotyp-Analyse der konditional inaktivierten Geminin-Mäuse .............................. 77

Inaktivierung von Geminin erlaubt die normale Proliferation von cortikalen

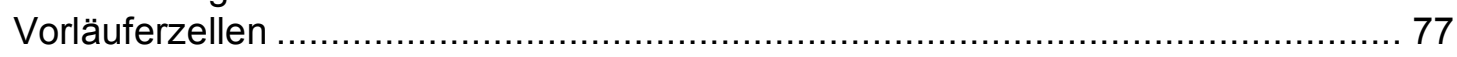

Die frühe neuronale Differenzierung in der Maus hängt nicht von Geminin ab.......... 78

Geminins Rolle in der Neuralinduktion............................................................. 79

Inhibition der Gliogenese in der Periode der Neurogenese ................................... 80

Geminins Rolle in der Regulation der Gliogenese ......................................... 82

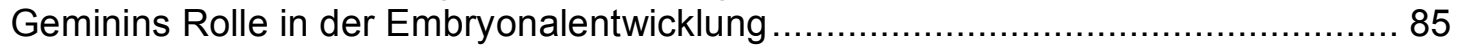

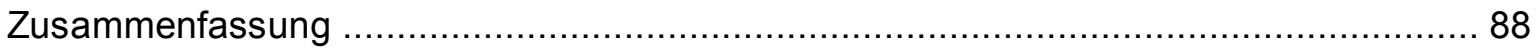

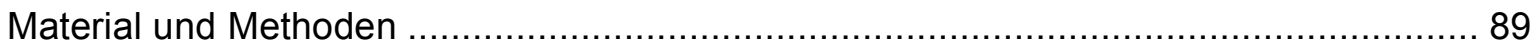

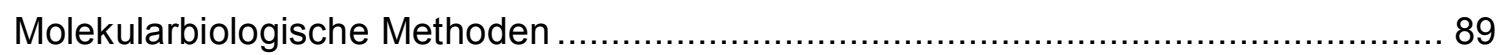

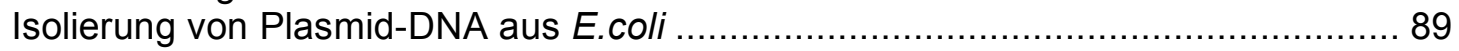

Extraktion von genomischer DNA aus murinem Gewebe .................................... 89

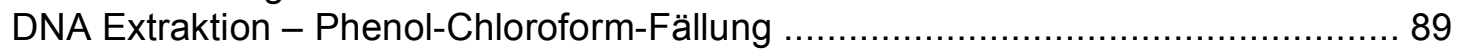

Konzentrationsbestimmung von Nukleinsäuren .............................................. 90

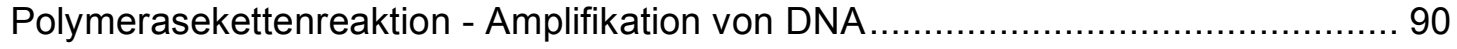

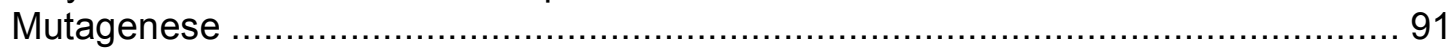

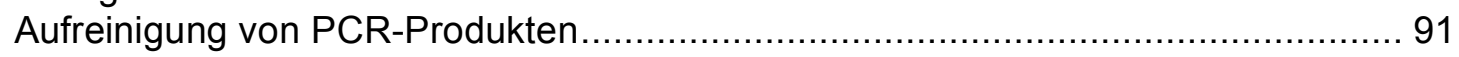

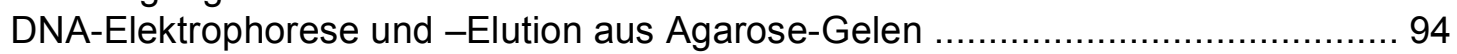

Analytischer und präparativer Restriktionsverdau von DNA ................................ 95

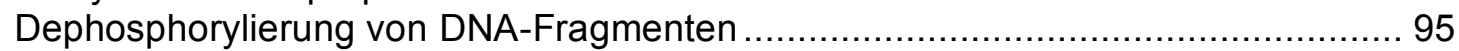

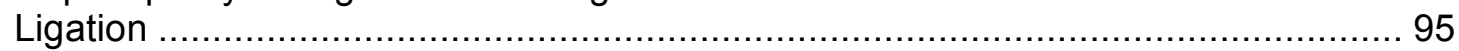

Herstellung chemisch kompetenter E. coli Bakterien .......................................... 98

Transformation in chemisch kompetente E. coli Bakterien................................... 98

Herstellung von elektrokompetenten E. coli Bakterien ......................................... 99

Transformation in elektrokompetente E. coli Bakterien ....................................100

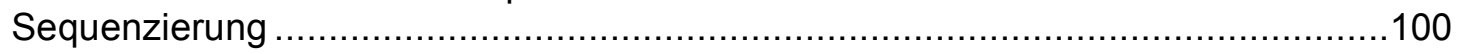


Generierung eines konditionalen Knockout-Konstruktes mittels Recombineering.......100

Isolierung von P1-Phagen Artifiziellen Chromoson-PAC aus E.coli .......................101

Konstruktion der Retrieving- und Targeting-Vektoren .......................................101

Transformation von PAC- und Plasmid-DNA in den E. coli Stamm SW102 ............102

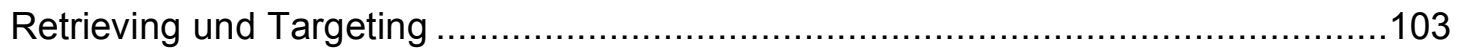

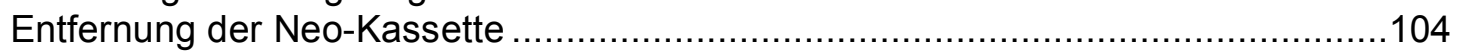

Gen-Targeting in murinen ES Zellen und Produktion der Chimären .......................104

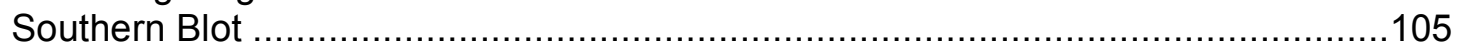

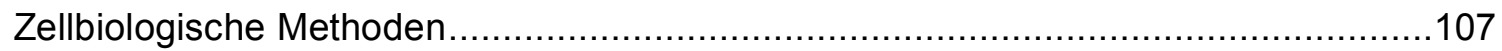

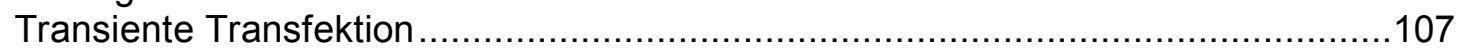

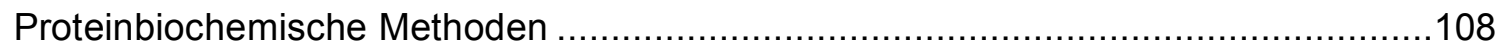

Expression und Aufreinigung rekombinanter Proteine .......................................108

Thrombin-Spaltung von GST-fusionierten Proteinen ......................................110

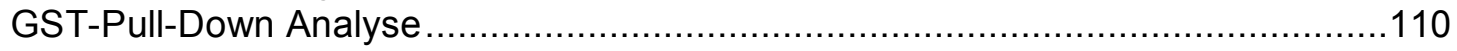

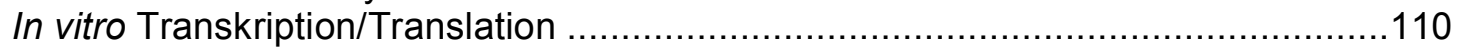

Generierung von Gesamt-Proteinextrakten ................................................111

Konzentrationsbestimmung von Proteinen nach Bradford .................................111

SDS-Polyacrylamidgelelektrophorese (SDS-PAGE) ......................................111

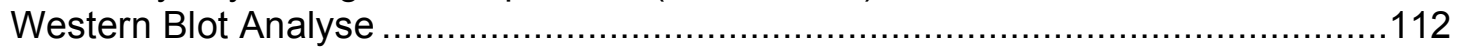

Strippen und Rehybridisierung von Nitrozellulose-Membranen............................114

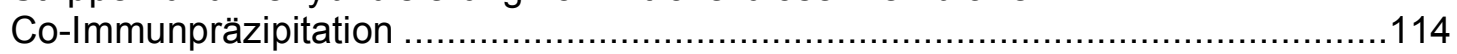

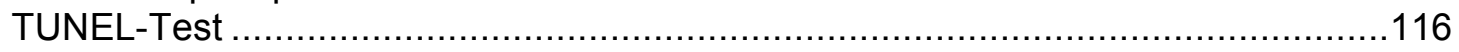

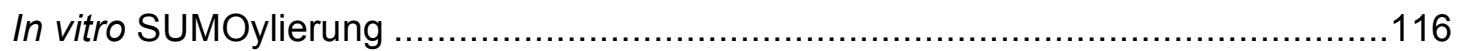

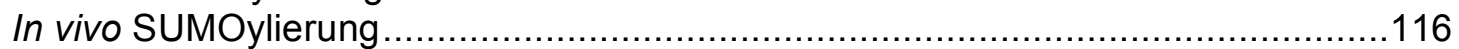

Methanol-Chloroform-( $\left.\mathrm{MeOH} / \mathrm{CHCl}_{3}\right)$ Präzipitation ......................................117

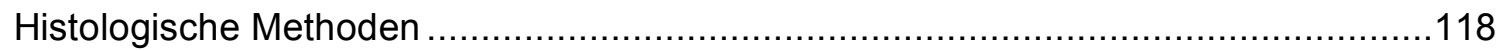

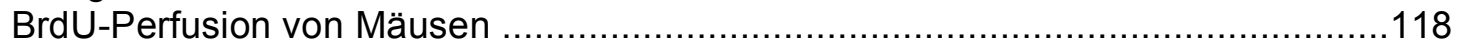

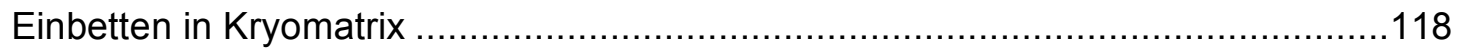

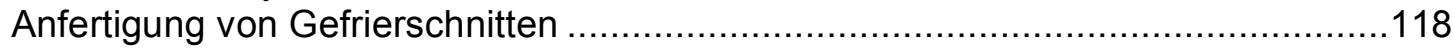

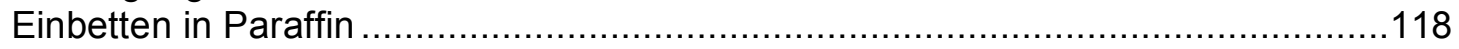

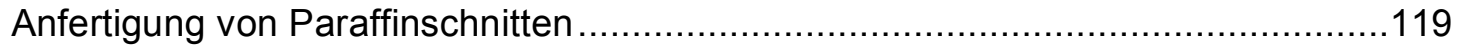

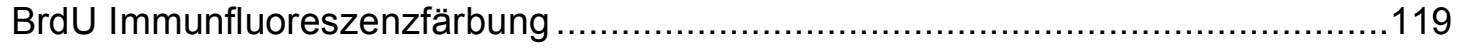

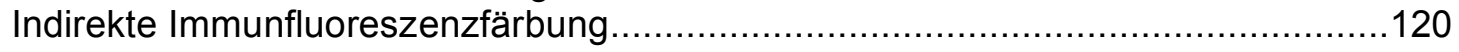

Herstellung von DIG-markierten Antisense-RNA-Sonden .................................120

In situ Hybridisierung von Gefrierschnitten ..................................................121

Cresylviolettfärbung von Paraffinschnitten .....................................................122

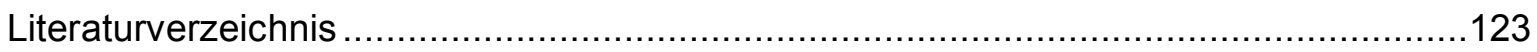

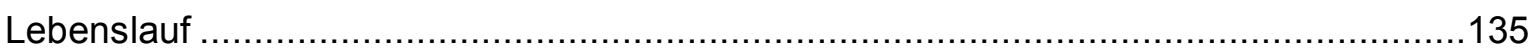




\section{Danksagung}

Mein ganz besonderer Dank gilt Prof. Dr. Michael Kessel, der mir die Anfertigung der Dissertation in seiner Arbeitsgruppe ermöglicht hat. Er hat mich auf meinem Weg in die wissenschaftliche Forschung stets unterstützt, wertvolle Anregungen gegeben und stand mir immer bei Problemstellungen und Fragen zur Seite. Ich hatte die Gelegenheit, meine Arbeit im Labor eigenständig zu gestalten, um mir dadurch ein großes Maß an Selbstständigkeit zu erarbeiten.

Herrn Prof. Dr. E. A. Wimmer möchte ich ebenso recht herzlich für die bereitwillige Betreuung dieser Arbeit als Korreferent danken wie auch den Mitgliedern meiner Prüfungskommission, Prof. Dr. Detlef Doenecke, Prof. Dr. Ralf Heinrich, Prof. Dr. Frauke Melchior und Prof. Dr. Norbert Elsner.

Bei Anastassia Stoykova möchte ich mich bedanken, da Sie mir in vielen Diskussionen die Welt der neuronalen Entwicklung veranschaulicht und mir unzählige Ratschläge gegeben hat.

Ein ganz besonderes Dankeschön geht an Engelchen Petra Rus, die stets zuverlässig war und durch ihre wunderbare technische Assistenz einen entscheidenden Beitrag zu dieser Arbeit geleistet hat. Ihr, wie auch meinen Laborkollegen Naisana Seyed Asli, Dr. Sven Pilarski, Alexander Klimke und ehemals Dr. Mara Pitulescu und Dr. Lingfei Luo möchte ich für die tolle Atmosphäre im Labor danken und die unzähligen Diskussionen und Hilfestellungen. Danke auch an Sabrina Zeddies, die im Rahmen eines Praktikums zu der vorliegenden Dissertation beigetragen und „hervorglänzende“ Arbeit geleistet hat.

Den gesamten Mitarbeitern der Abteilung Molekulare Zellbiologie und des BTL-Teams, im Besonderen aber Sharif Mahsur, Ullrich Franke, Vanessa Paul, Martina Daniel, Dr. Tran Cong Tuoc und meinen Tierpflegerinnen Daniela Wollradt und Jennifer Flemming möchte ich ganz herzlich für jegliche Unterstützung danken und die nette Atmosphäre, die mir den Arbeitsalltag so angenehm gestaltet hat.

Bei Prof. Dr. Frauke Melchior, Tina Lampe und David Ermert aus der Abteilung Biochemie der Universität Göttingen möchte ich mich für die vielen wissenschaftlichen Diskussionen, Ratschläge und die Versorgung mit Arbeitsmaterial bedanken. Ohne Ihre Hilfe hätte ein entscheidender Teil dieser Arbeit nicht entstehen können.

Dr. Heiko Lickert vom Helmholtz Zentrum in München und Etienne Herzog vom MaxPlanck-Institut für experimentelle Medizin in Göttingen danke ich für die wertvollen Ratschläge zur Methode des „Recombineering“. 
Meine Eltern haben eine ganz besondere Umarmung verdient. Ich möchte Ihnen danken, dass Sie immer an mich geglaubt haben, stets für mich da waren und sie einfach wunderbare Eltern sind. Lieben Dank in diesem Zuge auch an mein Schwesterchen Katrin.

Ein ganz großes Danke geht an meinen Freund Lars Reimann. Er hat mich stets unterstützt, motiviert, zum Lachen gebracht und mir neben meiner Arbeit im Labor eine wunderbare und liebevolle Zeit beschert. Einen dicken Kuss für Ihn $\bullet$ Danke. 


\section{Abbildungsverzeichnis}

Abbildung 1. Die frühe Gehirnentwicklung bei Vertebraten.

Abbildung 2. Stammbaum der Neurogenese.

Abbildung 3. Neurone werden durch Abfolge verschiedener neuronalen Teilungen generiert.

Abbildung 4. Formation der neocortikalen Schichten.

Abbildung 5. Der Übergang von Neurogenese zu Gliogenese im sich entwickelnden Neocortex.

Abbildung 6. Schematisierte Struktur des humanen Geminin-Proteins, Darstellung der funktionalen Motive und der Protein-Protein-Interaktionsdomänen.

Abbildung 7. Expressionsmuster von Geminin in der Maus.

Abbildung 8. Die SUMOylierungskaskade in Säugetieren

Abbildung 9. Sequenz-Alignment von Geminin-Orthologen.

Abbildung 10. SUMO1-Modifikation von Geminin in vitro.

Abbildung 11. Überexpression von SUMO1- und Geminin-Plasmid-Konstrukten in HeLaZellen.

Abbildung 12. Geminin kann in Säugerzellen mit SUMO1 modifiziert werden.

Abbildung 13. Herstellung und Analyse der Funktionalität des konditionalen Geminin Knockout Konstruktes.

Abbildung 14. Identifizierung von ES-Zellklonen mit korrekt inseriertem Geminin Targeting-Plasmid.

Abbildung 15. Generierung von konditionalen Knockout-Mäusen mit $E m \times 1^{\text {IREScre }}$.

Abbildung 16. Expression von Geminin im dorsalen Telencephalon in Wt-Mäusen und spezifische Inaktivierung in Geminin ${ }^{f / f l} ; E m \times 1^{\text {RREScre }}$-Mäusen

Abbildung 17. Morphologische Untersuchung von P10 Gehirnen von Wt- und Geminin $^{f / / \pi} ; E m \times 1^{I R E S c r e}$-Mäusen.

Abbildung 18. Analyse der Verteilung von Vorläuferzellen in der M- und S-Phase des Zellzyklus in Cortices von Wt- und Geminin ${ }^{f / / f l} ; E m \times 1^{\text {IREScre }}$ transgenen Mäusen.

Abbildung 19. Vergleichende Darstellung proliferierender gegenüber postmitotischer Zellpopulationen.

Abbildung 20. Inaktivierung von Geminin im dorsalen Telencephalon hat in der frühen Neurogenese keinen Einfluss auf die Ausbeute an Neuronen und resultiert nicht in verstärkter Apoptose.

Abbildung 21. In vitro und in vivo Interaktion von Geminin und Pax6 in HeLa-Zellen.

Abbildung 22. Pax6-RNA und -Protein zeigen keine abweichenden Level im Cortex von Wt- und Geminin ${ }^{\mathrm{f} / f / t} ; E m \times 1^{\text {REESCre }}$-Mäusen in E12.5 und E15.5.

Abbildung 23. Expression von Ngn2 im Telencephalon von Wt- und Geminin-cKOMäusen.

Abbildung 24. Expression von Pax6, Tbr2, Tbr1, NeuroD und Ngn1 im Cortex von E15.5 Wt- und $c K O$-Mäusen.

Abbildung 25. Expression von Sox2 in Wt- und Geminin ${ }^{f l / f l} ; E m \times 1^{\text {IREScre }}$-Mäusen.

Abbildung 26. Identische Expressionsmuster von GAD1 im Telencephalon von Wt- und Geminin-Mausmutanten.

Abbildung 27. Anreicherung von Astrocyten im Cortex Geminin-defizienter Mausmutanten.

Abbildung 28. Vereinfachtes Modell der Regulationsmechanismen bei der Neuralinduktion und der Neurogenese und Gliogenese im Cortex. 


\section{Tabellenverzeichnis}

Tabelle 1. Liste der verwendeten Marker und deren spezifische Expression im Cortex von E15.5 Embryonen.

Tabelle 2. Temperaturprogramm des Thermocyclers für die DNA-Amplifikation.

Tabelle 3. Liste der verwendeten Primer.

Tabelle 4. Agarose-Konzentrationen und die davon abhängigen FragmentlängenTrennbereiche von DNA

Tabelle 5. Plasmidvektoren und im Rahmen dieser Arbeit verwendete und erstellte Plasmidkonstrukte.

Tabelle 6. Liste der gebrauchten Bakterienstämme

Tabelle 7. Liste der verwendeten Zellinien.

Tabelle 8. Verwendete Volumina von Medium und Lipofectamine ${ }^{\mathrm{TM}}$ und Mengen an DNA für transiente Transfektionen.

Tabelle 9. Komponenten und Mengenangaben für Trenn- und Sammelgel für je zwei SDS-PAGE-Gele.

Tabelle 10. Liste der verwendeten Antikörper. 


\section{Abkürzungsverzeichnis}

\begin{tabular}{|c|c|}
\hline$\AA$ & Ångström $\left(1 \AA=100 \mathrm{pm}=10^{-1} \mathrm{~nm}=10^{-4} \mu \mathrm{m}\right)$ \\
\hline APC & (engl.) „Anaphase-Promoting-Complex“ \\
\hline APS & Ammonium Persulfat \\
\hline as & Antisense \\
\hline As & Aminosäure \\
\hline $\mathrm{bp}$ & Basenpaar (engl. „basepair”) \\
\hline BrdU & 5'-Bromo-2'-deoxyuridin \\
\hline $\mathrm{BCIP}$ & 5-Bromo-4-chloro-3-indolylphosphat \\
\hline BSA & Rinderserumalbumin (engl. „bovine serum albumin“) \\
\hline${ }^{\circ} \mathrm{C}$ & Grad Celcius \\
\hline C. elegans & Caenorhabditis elegans \\
\hline Cdk & Cyclin-abhängige Kinase (engl. „Cyclin-dependent kinases“) \\
\hline cDNA & komplementäre DNA (engl. „complementary DNA“) \\
\hline $\mathrm{cKO}$ & konditionaler Knockout (engl. „conditional knockout") \\
\hline CMV & Cytomegalovirus \\
\hline Co-IP & Co-Immunpräzipitation \\
\hline $\mathrm{CP}$ & Cortikale Platte \\
\hline $\mathrm{cpm}$ & Zerfälle pro Minute (engl. „countes per minute“) \\
\hline DAPI & 4,6-Diamidino-2-Phenylindol \\
\hline D-Box & Destruktions-Box \\
\hline DEPC & Diethylpyrocarbonat \\
\hline d. $h$. & das heißt \\
\hline DIG & Digoxigenin-11-UTP \\
\hline DMEM & Dulbecco's Modified Eagle Medium \\
\hline DMEM-10 & DMEM, $10 \%$ FCS und 2 mM L-Glutamin enthaltend \\
\hline DMSO & Dimethylsulfoxid \\
\hline DNA & Desoxyribonukleinsäure (engl. „ deoxyribonucleic acid“) \\
\hline dNTP & Desoxynukleosidtriphosphat \\
\hline $\mathrm{dH}_{2} \mathrm{O}$ & Millipore-Wasser \\
\hline DTT & Dithiothreitol \\
\hline$E$ & Embryonales Stadium \\
\hline engl. & Englisch \\
\hline E. coli & Escherichia coli \\
\hline EDTA & Ethylendiamintetraacetat \\
\hline ES-Zellen & Embryonale Stammzellen \\
\hline Et al. & (lat.) „Et alterae“ (und andere) \\
\hline etc. & (lat.) „et cetera” (und de übrigen) \\
\hline $\mathrm{EtOH}$ & Ethanol \\
\hline FCS & Fötales Kälberserum (engl. „fetal calf serum”) \\
\hline FGF & Fibroblastenwachstumsfaktor (engl. „fibroblast growth factor”) \\
\hline FITC & Fluorescein 5'-Isothiocyanat \\
\hline
\end{tabular}




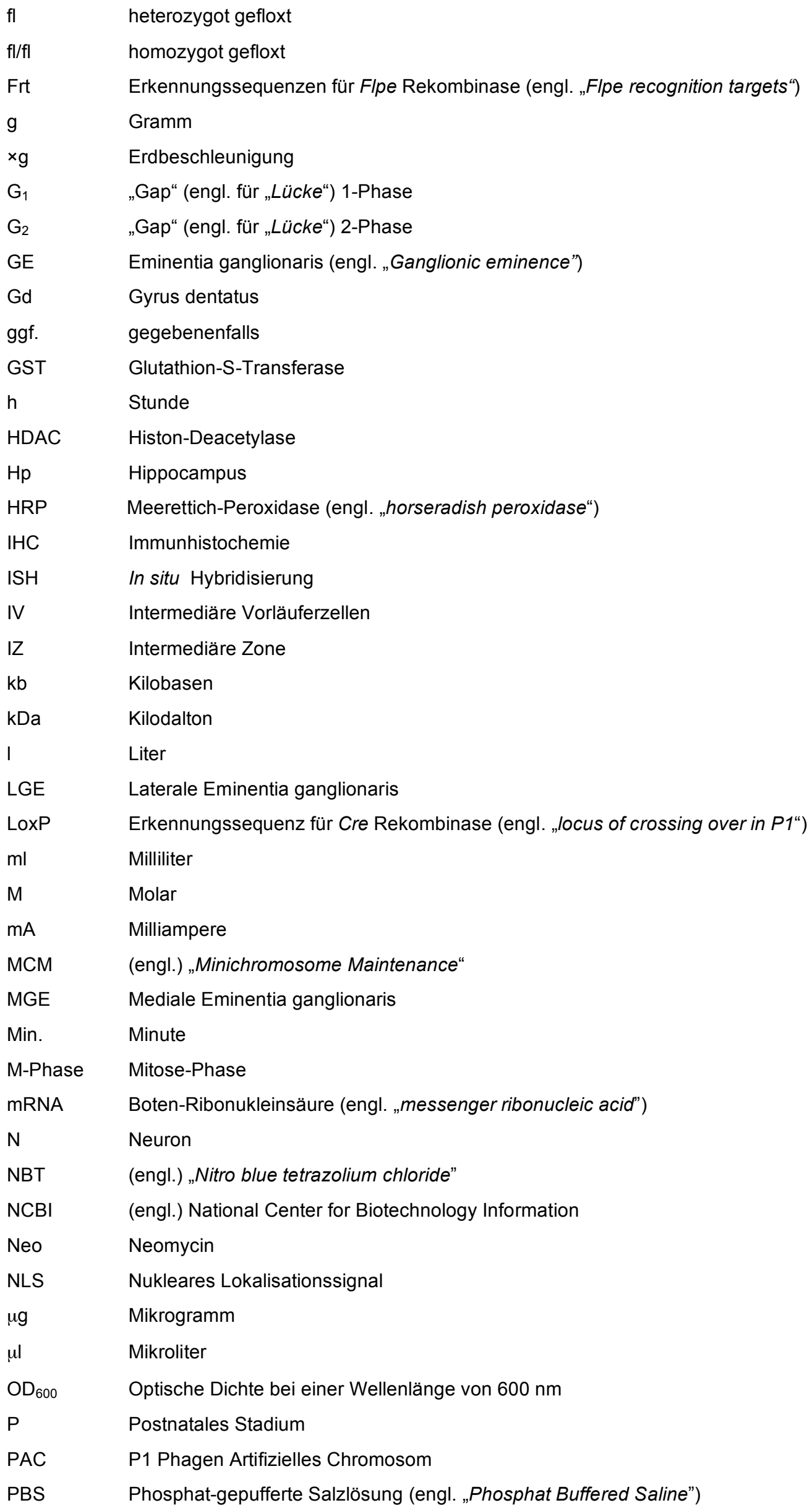


PBT Phosphat-gepufferte Salzlösung mit Tween 20

PCR Polymerase-Kettenreaktion (engl. „Polymerase Chain Reaction“)

PFA Paraformaldehyd

PIAS (engl.) „Protein Inhibitor of Activated STAT")

PMSF Phenylmethylsulfonylfluorid

PP Präplatte

RG Radiale Gliazellen

RNA Ribonukleinsäure (engl. „ribonucleic acid“)

$\mathrm{RPCl} \quad$ Roswell Park Cancer Insitute

rpm Umdrehungen pro Minute (engl. „rounds per minute”)

RT Raumtemperatur

SENP SUMO-spezifische Protease

SDS Natriumdodecylsulfat (engl. „Sodium dodecyl sulfate“)

SGZ Subgranularzone

S-Phase Synthese-Phase

ss

Sense

SSC Natriumchlorid/Natriumcitrat-Saline (engl. „sodium chloride/ sodium citrate”)

SVZ Subventrikularzone

SUMO (engl.) Small Ubiquitin-like Modifier

TBE Tris-Borat-EDTA

TdT Terminale Desoxynukleotidyl-Transferase

TEMED N,N,N',N'-Tetramethyl-Ethylenediamin

TK Thymidin-Kinase

$\mathrm{T}_{\mathrm{M}} \quad$ Schmelztemperatur (engl. „Melting temperature”)

TuJ1 neuronales Klasse III $\beta$-Tubulin

TUNEL (engl.) „Terminal deoxynucleotidyltransferase-mediated dUTP-biotin nick end labeling“

u. a. unter anderem

V Volt

Vol. Volumen

v/v Volumen/ Volumen

VZ Ventrikularzone

WB Western Blot

Wi Wildtyp

w/v Masse/Volumen (engl. „weigth/volume“)

z. B. zum Beispiel

ZNS Zentrales Nervensystem 


\section{Einleitung}

Während der Entwicklung eines Embryos aus einer befruchteten Eizelle laufen eine Vielzahl von Prozessen zeitlich koordiniert ab, so dass die Zellen zum richtigen Zeitpunkt die korrekte Information über ihr Schicksal erhalten, bis sie sich zu dem vielfältigen Gewebe eines Embryos formieren. Die Kontrolle der zeitlichen und räumlichen Koordination wird von einer Fülle von Regulatoren übernommen, die in der Steuerung der Zellproliferation oder in der Zelldifferenzierung involviert sind.

\section{Das Zentrale Nervensystem}

Das Zentrale Nervensystem (ZNS) erfüllt die verschiedensten Aufgaben, wie die Integration von Reizen, die Koordination von motorischen Eigenleistungen und die Regulation aller kognitiven Funktionen. In Säugetieren besteht das ZNS aus Billionen von Neuronen, die zusammen ein Netzwerk zur Verarbeitung, Weiterleitung und Ausführung von Signalen darstellen. Die Entwicklung beruht dabei auf kontrollierten Ereignissen, welche die räumliche und zeitliche Entstehung neuronaler Zellen unterschiedlicher Schicksale steuern. Während die Struktur und Anatomie des ZNS im letzten Jahrhundert ausführlich studiert wurde, sind die molekularen Mechanismen hinter der Entstehung diesen komplexen Systems nur ansatzweise geklärt.

\section{Anatomische Organisation des sich entwickelnden ZNS}

Der erste Schritt bei der Formation des ZNS von Vertebraten ist die Spezifikation von neuralen Vorläufern innerhalb des naiven Ektoderms in einem Prozess, der als Neuralinduktion bezeichnet wird. Dabei geht zunächst aus einem entlang der dorsalen Mittellinie gelegenen verdickten Bereich des Ektoderms die Neuralplatte hervor. Aus dieser entspringt in einem als "Neurulation“ bezeichnetem Prozess eine als "Neuralrinne“ bezeichnete Vertiefung, aus der sich darauf folgend das Neuralrohr und später die verschiedenen Teile des ZNS entwickeln. Das ausgebildete ZNS gliedert sich in das Gehirn und das Rückenmark (Abbildung 1). Das Prosencephalon des Gehirns ist neben Mesenund Rhombencephalon eines der drei hauptsächlichen Gehirnvesikel, das in der frühen Embryonalentwicklung formiert wird (Abbildung 1). Es entsteht aus der am weitesten anterior gelegenen Region des Neuralrohrs und besteht aus dem Diencephalon und dem telencephalischen Vesikel. Letzterer evaginiert von der dorsalen Seite des rostralen Diencephalons. Die zwei Hauptregionen des Telencephalons sind das dorsal gelegene Pallium und das ventral angeordnete Subpallium. Das Subpallium besteht aus den drei primären Regionen Striatum, Pallidum und rostralem Telencephalonstiel. Die Anlage von Striatum 
und Pallidum wird als „Eminentia ganglionaris“ (engl. „Ganglionic eminence“, GE) bezeichnet. Aus der lateralen GE (LGE) geht das Striatum, aus der medialen GE (MGE) geht das Pallidum hervor. In der weiteren Entwicklung des ZNS gehen aus dem Pallium Cortex und Hippocampus hervor und aus dem Subpallium entspringen die Interneurone, die auch als Basalganglien bezeichnet werden. Der Bulbus olfactorius (Riechkolben) entwickelt sich letztlich durch bilaterale Evagination einer Region der Neuralplatte des Prosencephalons (Rubenstein et al., 1998).

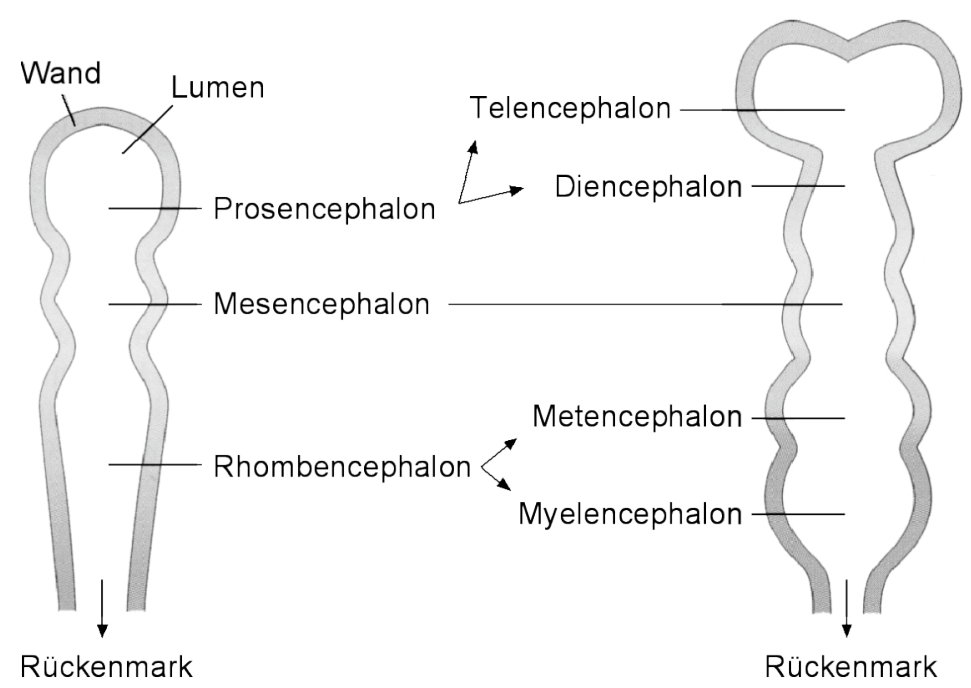

Abbildung 1. Die frühe Gehirnentwicklung bei Vertebraten. Die drei primären Gehirnvesikel (links) und die Unterteilung der Strukturen in voranschreitender Entwicklung (rechts) sind schematisch dargestellt (modifiziert nach Gilbert, 2000).

\section{Neurale Stamm- und Vorläuferzellen}

Stammzellen werden durch zwei Kriterien charakterisiert: Zum einen besitzen sie die Fähigkeit zur Selbsterneuerung, d. h. sie durchlaufen eine unbeschränkte Anzahl von Zellteilungen, zum anderen zeichnen sie sich durch ihre Potenz, d. h. die Fähigkeit in eine Vielzahl von verschiedenen Zelltypen zu differenzieren, aus. Totipotente Stammzellen entstehen bei der Fusion von Ei und Spermienzelle und können in jedes embryonale und extraembryonale Gewebe differenzieren. Pluripotente Zellen sind Abkömmllinge der totipotenten Zellen, welche aber nur in Derivate der drei Keimschichten differenzieren können. Multipotente Stammzellen besitzen eine noch eingeschränktere Potenz, da sie ausschließlich in eine bestimmte Gruppe von verwandten Zelltypen differenzieren können. Aus unipotenten Stammzellen kann letztlich nur ein bestimmter Zelltyp hervorgehen. Dennoch besitzen sie die Fähigkeit zur Selbsterneuerung.

Die so genannten neuralen oder neuroepithelialen Stammzellen des ZNS zählen zu den multipotenten Stammzellen. Während der Entwicklung eines Säugetieres gehen aus diesen Stammzellen alle verschiedenen neuronalen Subtypen des ZNS hervor. Es ist 
bisher jedoch ungeklärt, bis zu welchem Ausmaß sich derartige Stammzellen mit der Fähigkeit zur Multipotenz im sich entwickelnden Gehirn befinden. Der Begriff wird in diesem Fall zur Beschreibung der Eigenschaft der Selbsterneuerung, aber nicht notwendigerweise für das Vermögen, eine unbeschränkte Anzahl von Zellteilungen durchzuführen, verwendet. Die Bezeichnung Vorläuferzelle beschreibt zwar auch einen multi- oder unipotenten Zelltyp mit der Fähigkeit zur Selbsterneuerung, aber Vorläuferzellen befinden sich im Vergleich zu Stammzellen in einem spezialisierteren Stadium der Differenzierung.

a

Direkte Neurogenese

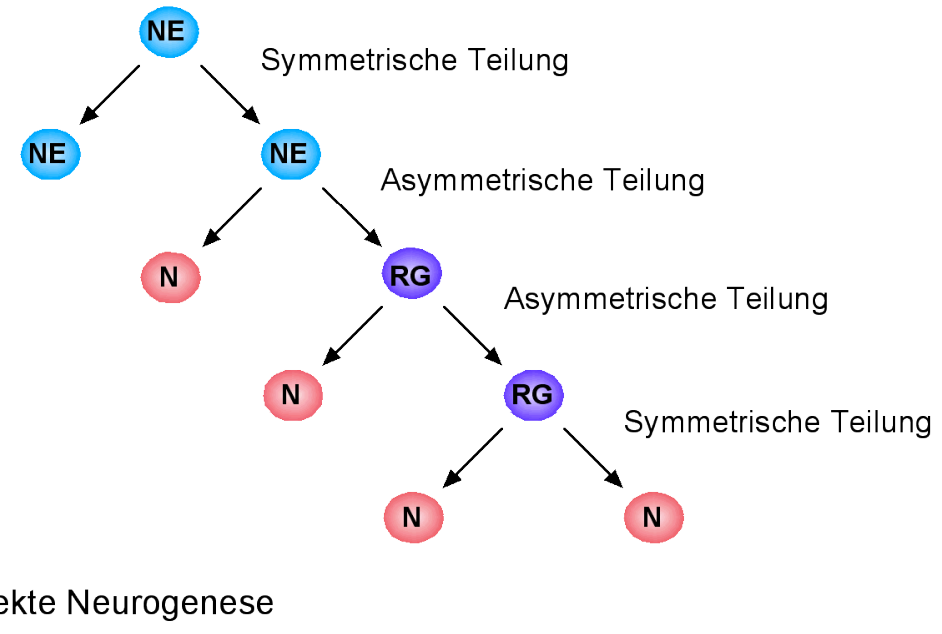

b Indirekte Neurogenese

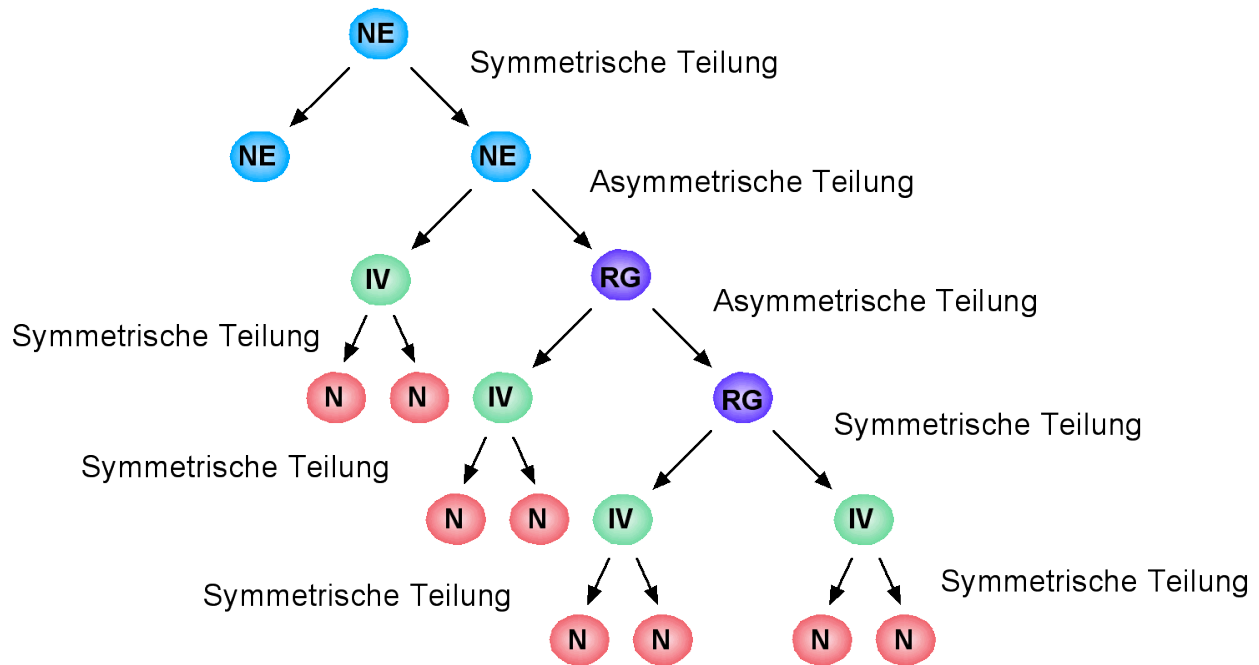

Abbildung 2. Stammbaum der Neurogenese. Der Stammbaum veranschaulicht ein vereinfachtes Modell des Verhältnisses zwischen Neuroepithelialen Zellen (NE), Radialen Gliazellen (RG) und Neuronen (N) (a) ohne und (b) unter Einbezug intermediärer Vorläuferzellen (IV) bei der Generierung von Neuronen. Die Art der Zellteilung ist miteinbezogen (verändert nach Götz and Huttner, 2005).

Die Selbsterneuerung von Stamm- und Vorläuferzellen kann entweder durch symmetrische Teilung geschehen, wobei zwei identische Tochterzellen generiert werden, oder asymmetrisch, wobei eine Zelle identisch mit der Mutterzelle ist und die andere einen zweiten Zelltyp darstellt (Rakic, 1995; McConnell, 1995). Eine neuroepitheliale 
Stammzelle durchgeht zunächst eine oder mehrere symmetrische, proliferative Teilungen und danach folgen mehrere asymmetrische Zellteilungen, woraus jeweils eine neue Stammzelle und eine postmitotische Zelle (N, Neuron; Abbildung 2a) oder eine weiter differenzierte Vorläuferzelle, die so genannte radiale Gliazelle (RG; Abbildung 2a) hervorgeht. Radiale Gliazellen besitzen ebenso wie Stammzellen die Fähigkeit zur Selbsterneuerung, indem sie eine asymmetrische Teilung durchlaufen, bei der eine weitere radiale Gliazelle und eine postmitotische Zelle gebildet wird (Abbildung 2a). Die symmetrische Teilung dieser radialen Gliazelle bringt letztlich zwei weitere terminal differenzierte, postmitotische Zellen hervor (Abbildung 2a). Sowohl aus neuroepithelialen Zellen wie auch aus radialen Gliazellen können durch asymmetrische Teilungen eine postmitotische Zelle und eine so genannte intermediäre Vorläuferzelle (IV; Abbildung 2b) hervorgehen, wobei letztere dann durch Teilung zur Bildung von je zwei postmitotischen Zellen beiträgt (Abbildung 2b). Die Vorläuferzellen des Cortex in Säugetieren stellen somit keine homogene Population von Zellen dar, sondern bestehen vielmehr aus bestimmten Subtypen, aus denen verschiedene Abkömmlinge hervorgehen.

\section{Neuroepitheliale Zellen und radiale Gliazellen}

Vor Initiation der Neurogenese besteht die Neuralplatte und das Neuralrohr von Vertebraten aus einer einzelnen Schicht neuroepithelialer Zellen, dem so genannten Neuroepithel, welches sowohl die basale wie auch apikale (ventrikuläre) Oberfläche des Neuralrohr kontaktiert. Neuroepitheliale Zellen weisen eine polare Organisation von apikal nach basal auf. Die Kerne der Zellen des Neuroepithels unterliegen während ihres Zellteilungszyklus einer interkinetischen Kernmigration. Sie migrieren entlang der apikalbasalen Achse, wobei die Teilung der Zellen an der apikalen Oberfläche erfolgt (Abbildung 3; Sauer, 1935; Takahashi et al., 1993). Mit Beginn der Generierung von Neuronen ab dem embryonalen Stadium 9 (E9) in Mäusen transformiert sich das Neuroepithel in ein Gewebe mit zahlreichen Zellschichten (Misson et al., 1988). Die Zone proliferativer Aktivität, welche am meisten apikal gelegen ist, wird als Ventrikularzone (VZ) bezeichnet. Aus den neuroepithelialen Zellen des Cortex gehen die radialen Gliazellen hervor, welche einen mit den Zellen des Neuroepithels verwandten Zelltyp darstellen, dessen Schicksal jedoch beschränkter ist als das der multipotenten Neuroepithelzellen. Als Konsequenz entstehen die meisten Neurone des Gehirns direkt oder indirekt aus radialen Gliazellen (Abbildung 3; (Malatesta et al., 2000). Radiale Gliazellen weisen im Vergleich zu neuroepithelialen Zellen ebenso eine interkinetische Kernmigration auf (Götz and Huttner, 2005). Die Kerne unterziehen sich der Mitose an der apikalen Oberfläche der VZ und migrieren für die S-Phase des Zellzyklus in Richtung der basalen Oberfläche (Abbildung 3). 
a Direkte Neurogenese

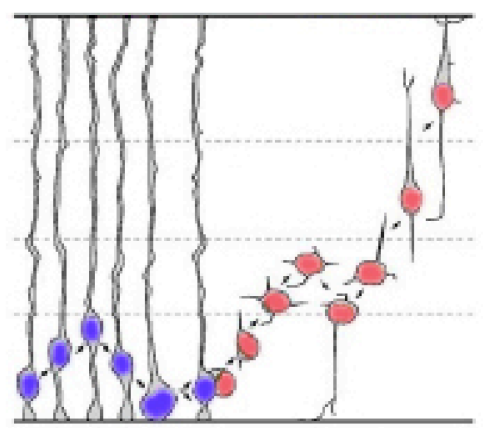

Zellzyklus

Zelltyp

Migrationsphase
$G_{1} S G_{2} M_{a}$ postmitotisch

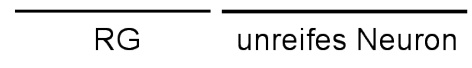

b Indirekte Neurogenese

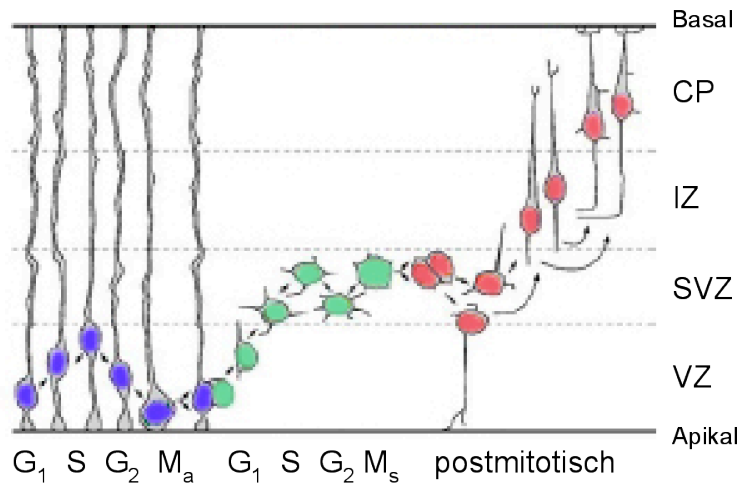

RG

IV unreifes Neuron

$\frac{7}{2} \frac{7}{3} \overline{4}$

Abbildung 3. Neurone werden durch Abfolge verschiedener neuronalen Teilungen generiert. Die radialen Gliazellen (RG, blau) weisen in Abhängigkeit der Phasen des Zellzyklus eine interkinetische Migration auf. Die Bildung von Neuronen findet hauptsächlich von E12 bis E18 statt. (a) Bei der direkten Neurogenese entsteht in frühen Stadien der cortikalen Entwicklung durch symmetrische mitotische Teilung $\left(M_{a}\right)$ einer radialen Gliazelle in der Ventrikularzone (VZ) ein Neuron (rot; Haubensak et al., 2004). (b) Bei der indirekten Neurogenese gehen aus einer radialen Gliazelle 2 bis 4 postmitotische Neurone hervor. Die radiale Gliazelle produziert eine intermediäre Vorläuferzelle (IV), welche sich dann in der Subventrikularzone (SVZ) ein weiteres Mal (oder in einigen Fällen zweimal) symmetrisch in der Mitose $\left(M_{s}\right)$ teilt, so dass 2 (bzw. 4) postmitotische Neurone generiert werden. Dieser Weg dominiert in späteren Phasen der Neurogenese (Miyata et al., 2004). CP, cortikale Platte; $G_{1}, G_{2}$, „Gap“ (engl. für „Lücke“)-Phase; IZ, intermediäre Zone; S, SynthesePhase; Abbildung modifiziert nach Hevner et al., 2006).

Einige Merkmale von neuroepithelialen Zellen, wie die Expression von spezifischen Markern wie der des Intermediärfilament-Proteins Nestin oder die der apikalen-basalen Polarität, bleiben den radialen Gliazellen erhalten. Im Gegensatz zu neuroepithelialen Zellen besitzen radiale Gliazellen aber verschiedene Eigenschaften von so genannten Astrogliazellen oder Astrocyten (Kriegstein and Gotz, 2003). Sie exprimieren während der Neurogenese Proteine wie den Astrocyten-spezifischen Glutamat-Transporter (GLAST), das $\mathrm{Ca}^{2+}$-bindende Protein S100 $\beta$, Vimentin, BLBP (engl. „brain-lipid-binding protein“), und außerhalb des Cortex auch GFAP (engl. "glial fibrillary acidic protein“), die charakteristisch für die Gliogenese sind. (Hartfuss et al., 2001; Noctor et al., 2002). In Bezug auf inr Potential sind radiale Gliazellen vergleichend zu Neuroepithelzellen in der Regel auf die Generierung von einem spezifischen Zelltyp, entweder Astrocyten oder Oligodendrocyten oder, wie in den meisten Fällen, Neurone, beschränkt. In transgenen Mauslinien, in denen ein Teil des Nestin-Promotors oder das regulatorische Element des BLBP-Gens benutzt wurde, um die Expression einer Cre Rekombinase in frühen embryonalen Stadien wie E9/10 zu steuern, wurde die Rekombination der Zielgene vermittelt, bevor die radialen Gliazellen in Erscheinung traten und die rekombinierten Gene sich in allen Zellen des 
ZNS fanden (Anthony et al., 2004). Im Gegensatz dazu geschah bei einer transgenen Mauslinie mit der Cre Rekombinase unter Kontrolle des humanen GFAP-Promotors die Rekombination zum Zeitpunkt der Differenzierung der radialen Gliazellen (Malatesta et al., 2003). In diesem Fall waren die Nachkommen der Zellen, welche die Rekombination vererbt bekommen hatten, stärker beschränkt in Bezug auf ihre Zellidentität. So waren nur Zellen wie beispielsweise die cortikalen Projektionsneurone, aber nicht die aus dem ventralen Telencephalon hervorgehenden Interneurone (siehe unten) in einer spezifischen Region des ZNS zu lokalisieren. Zusammengefasst erfolgt der Übergang von neuroepithelialen zu radialen Gliazellen in den meisten Regionen des Gehirns zwischen E10 und E12. Während die Nachkommenschaft von frühen Neuroepithelzellen sehr breit gefächert ist, stellen die Abkömmlinge der radialen Gliazellen eine stärker eingegrenzte Population von Zelltypen dar. Beide Arten von Zellen stellen jeweils nur einen Teil der im ZNS vorhandenen Vorläuferzellen dar.

\section{Intermediäre Vorläuferzellen}

Neben den primär erscheinenden Neuroepithelzellen und den daraus entstehenden radialen Gliazellen wird während der frühen Neurogenese im Cortex ein weiterer Typ von Vorläuferzellen, die so genannten basalen oder intermediären Vorläuferzellen (IV), gebildet (Noctor et al., 2004; Haubensak et al., 2004). Im Gegensatz zu den ersten beiden Zelltypen, die an der apikalen Oberfläche des Neuroepitheliums bzw. der VZ die Mitose eingehen, durchlaufen intermediäre Zellen die Mitose an der basalen Seite der VZ (Noctor et al., 2004; Haubensak et al., 2004). Sie entstehen durch asymmetrische Teilung der neuroepithelialen und radialen Gliazellen (Abbildung $2 b$ und Abbildung $3 b$ ). Im Telencephalon und anderen Regionen des ZNS bilden die IV neben der VZ ab E13.5 eine zweite Proliferationszone, die so genannte Subventrikularzone (SVZ), welche sich an der basalen Seite der VZ befindet. IV teilen sich symmetrisch und bilden dabei zwei neuronale Tochterzellen (Abbildung 3b). Die IV tragen somit durch die zusätzliche Zellteilungen zur Vervielfältigung der ursprünglich von einer radialen Gliazelle abstammenden postmitotischen Zelle bei (Abbildung 2b). Die Anzahl der intermediären Zellen selbst wird dabei von den Zellen der VZ bestimmt. Die direkte und indirekte Neurogenese der verschiedenen Typen von Vorläuferzellen stellt das primäre Stadium der Formation des Neocortex dar (Abbildung 3).

\section{Morphologische Musterung des Cortex in Säugetieren}

Der cerebrale Cortex ist der größte und komplexeste Teil des Säugergehirns. Er entsteht während der embryonalen Musterbildung aus dem dorsalen Telencephalon und wird in verschiedene Regionen unterteilt. Der Neocortex stellt dabei den größten Anteil dar. Er ist 
zwischen dem den Hippocampus einschließenden Archicortex und dem Paläocortex positioniert. Der Neocortex trägt in höher entwickelten Arten stark zu der Zunahme der Größe und Komplexität des Gehirns bei (Krubitzer and Kaas, 2005). Im Vergleich zu den anderen Bereichen des Telencephalons unterscheidet sich der Neocortex durch seine geschichtete Organisation. Charakteristisch sind hauptsächlich sechs radial organisierte Schichten, von denen jede aus einer heterogenen Population von Neuronen, die morphologisch, verbindend und funktional verschieden von den anderen Schichten sind. In tangentialer Dimension wird der Neocortex in Areale unterteilt, die funktional einmalig sind, da sie sich voneinander durch Abweichungen in der Zellstruktur, Chemoarchitektur, (engl.) „Input" und „Output" -Verbindungen und Genexpressionsmustern unterscheiden. Besonders in adulten Organismen können diese Bereiche, beispielsweise durch ihre Architektur und die Verteilung von Projektionsneuronen, gegeneinander abgegrenzt werden. Diese Eigenschaften bestimmen die funktionalen Spezialisierungen, die die Areale des Neocortex charakterisieren. Für die Etablierung eines derartig komplexen Aufbaus bedarf es einer Vielzahl von Molekülen und genetischer Mechanismen, die das Schicksal cortikaler Vorläuferzellen und ihrer Nachkommen bestimmen.

\section{Bildung der Schichten des Neocortex in Säugetieren}

Der Neocortex (Abbildung 4b) besteht, wie bereits erläutert, aus sechs Schichten von Neuronen, die verschiedene morphologische und funktionale Identitäten besitzen. Die Formation der Schichten findet in der Maus zwischen E11 und E18 statt (Bayer et al., 1991). Im Stadium E11 besteht der Neocortex vornehmlich aus proliferierenden Vorläuferzellen, die in der VZ arrangiert sind (Abbildung 4c). Eine Reihe von postmitotischen Neuronen wandert dann aus der VZ heraus und bewegt sich in radialer Richtung der basalen Oberfläche entgegen, um dort eine als Präplatte (PP) bezeichnete neue neuronale Schicht zu bilden. In Stadium E13.5 bildet sich die in Richtung basaler Ober-fläche gelegene SVZ (Abbildung 4c). Aus den Vorläuferzellen der VZ und SVZ gehen in der fortschreitenden Neurogenese weitere postmitotische Neurone hervor, welche radial von der VZ weg migrieren und die Präplatte in eine oberflächliche Marginalzone (MZ) und in eine tiefer gelegene Subplatte (SP) spalten. Zwischen diesen beiden Schichten entsteht dann aus den migrierenden Neuronen die cortikale Platte (CP; Abbildung 4c). Im Laufe der weiteren Entwicklung, zwischen E14 und E18, verlassen weitere, neu gebildete postmitotische Neurone die VZ und SVZ, um die Subplatte zu durchqueren und um in sequentieller Abfolge die Schichten der cortikalen Platte zu bilden (Abbildung 4c). Die Positionierung der Zellen in der cortikalen Platte geschieht nach dem (engl.) „inside-out"-Prinzip, d. h. Neurone, welche zuerst und in der VZ generiert werden, bilden die tieferen Schichten der cortikalen Platte und Neurone, welche später und in der SVZ gebildet werden, etablieren 
die der Oberfläche nahe gelegenen, höher liegenden Schichten (Angevine and Sidman, 1961). Nachdem die cortikale Platte vollständig etabliert wurde, degeneriert die Subplatte und hinterlässt den sechsschichtigen Neocortex, der durchgehend im adulten Gehirn bestehen bleibt (Abbildung 4c).

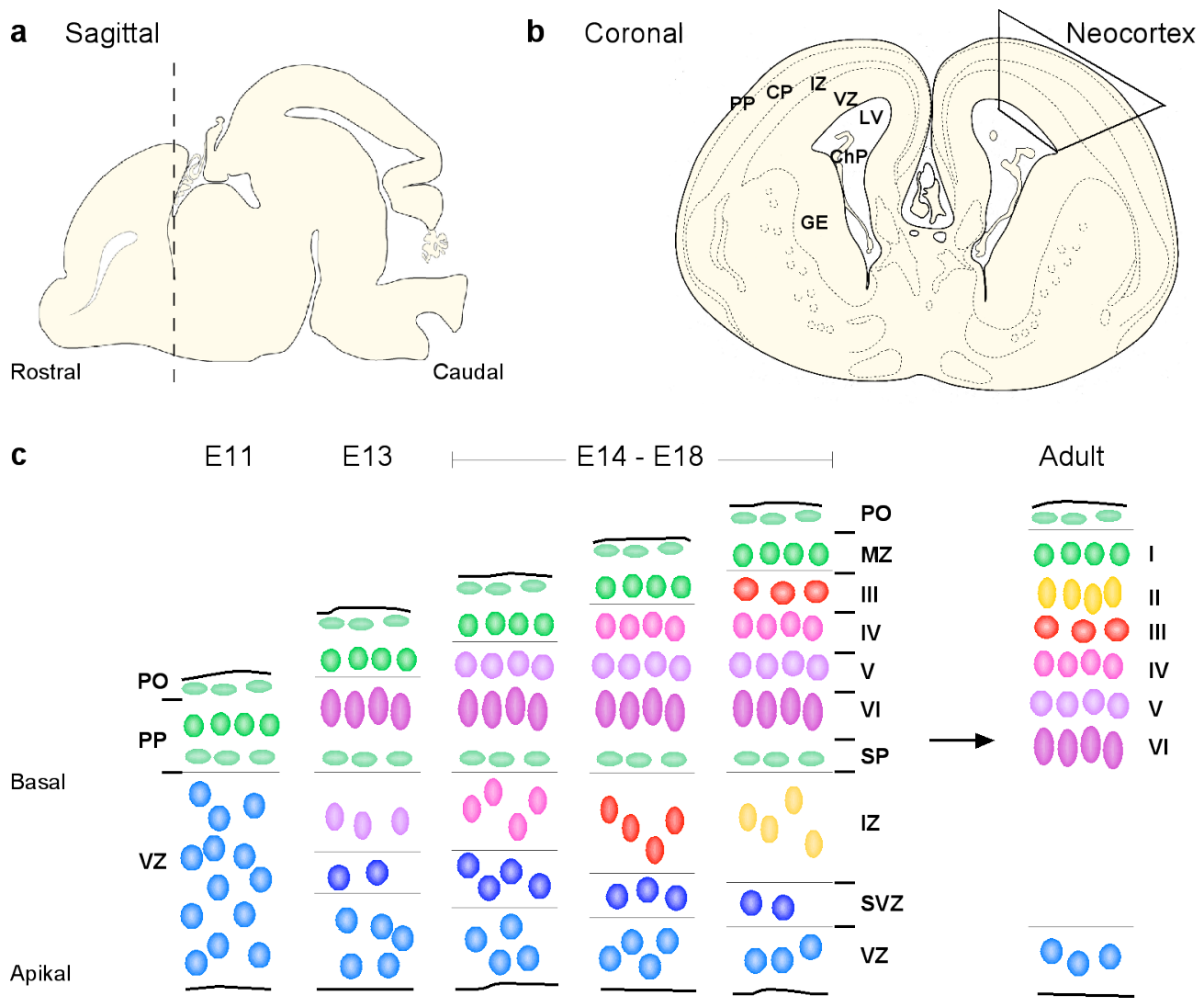

Abbildung 4. Formation der neocortikalen Schichten. (a) Sagittale Ansicht eines Schnittes von Stadium E16 (links), bei dem die gestrichelte Linie die Schnittebene des in (b) dargestellen coronalen Schnittes kennzeichnet. Der Bereich des Neocortex ist markiert. (c) Schematische Darstellung der Organisation des adulten Neocortex (rechts) und die vorherige Etablierung der Schichten von E11 bis E18 (links; ChP, Choroid Plexus; CP, cortikale Platte; GE, Eminentia ganglionaris; IZ, intermediäre Zone; MZ, Marginalzone; PO, Piale Oberfläche; PP, Präplatte; SP, Subplatte; SVZ, Subventrikularzone; VZ, Ventrikularzone; Abbildung modifiziert nach Gupta et al., 2002).

\section{Radiale und tangentiale Migration im Neocortex}

Die Entwicklung der neuronalen Schichten des Neocortex setzt die Migration der Neurone in radialer und tangentialer Richtung $\mathrm{zu}$ ihrer finalen Position voraus. Die meisten Neurone unterliegen dabei der radialen Migration, bei der die Zellen vom Bereich der Vorläuferzellen in Richtung der Oberfläche des Gehirns in radialer Anordnung zum Neuralrohr migrieren. Dieses betrifft in erster Linie die glutamatergen Neurone der Vorläuferzellen des dorsalen Telencephalons, dem Pallium (Marin and Rubenstein, 2003).

Bei der tangentialen Migration bewegen sich die Zellen orthogonal zur Richtung der radialen Migration. Eine große Anzahl der Vorläuferzellen, welche in der GE des ventralen 
Telencephalons, dem Subpallium, generiert wird, migriert tangential in Richtung des Cortex und Hippocampus. Aus der Mehrheit dieser Zellen gehen inhibitorische Interneurone, die den Neurotransmitter $\gamma$-Aminobuttersäure (GABA, engl. „ $\gamma$-amino butyric acid") ausschütten, hervor (Anderson et al., 1997; Marin and Rubenstein, 2003). Durch Integration der über radiale und tangentiale Migration ankommenden Neurone formieren sich die meisten Strukturen des Vorderhirns, wodurch die zelluläre Komplexität des ZNS erhöht wird.

\section{Gliogenese}

Aus radialen Gliazellen können sowohl Neurone als auch Gliazellen hervorgehen (Gotz and Barde, 2005). Zu den am häufigsten vorkommenden Klassen von Gliazellen zählen Oligodendrocyten, Schwann-Zellen und Astrocyten. Die Neurogenese im Cortex der Maus (Mus musculus) hält von E10 bis E18 an, während die ersten Astrocyten im Rahmen der Gliogenese um E18 erscheinen und erst in der neonatalen Periode terminal differenziert werden (Abbildung 5a). Ausdifferenzierte Oligodendrocyten sind frühestens postnatal nachweisbar (Bayer, 1991). Diese zeitlich versetzte Entstehung ist auch in Kultur zu beobachten. Aus Primärkulturen von E10 bis E12 cortikalen Stamm- und Vorläuferzellen, auch als Neurosphären bezeichnet, gehen in den ersten Tagen ausschließlich Neurone hervor, während die sequentielle Entstehung von Astrocyten und Oligodendrocyten folgt (Qian et al., 2000). Diese Beobachtung läßt sich auf Klone einzelner Vorläuferzellen zurückführen, d. h. diese multipotenten Vorläufer ändern in Abhängigkeit von der Zeit ihr Verhalten und das Genexpressionsmuster und generieren zunächst erst Neurone und danach Gliazellen. Es findet der Übergang von Neurogenese zu Gliogenese statt (Abbildung 5a).

\section{Adulte Neurogenese}

Zu Beginn des 19. Jahrhunderts wurde erstmals beschrieben, dass die Neurogenese im ZNS auf embryonale Stadien beschränkt ist (Ramón y Cajal, 1913). Bis in die frühen 1990ern wurden alle Bereiche des adulten Säugergehirns als „nicht-neurogen“ und unfähig zur Regeneration beschrieben. Heute ist bekannt, dass Neurone auch im adulten Gehirn kontinuierlich generiert werden (Reynolds and Weiss, 1992). Während ein Teil der neugebildeten Neurone unmittelbar nach ihrer Geburt absterben, werden einige funktional in das umliegende Gewebe integriert. Es gibt mindestens zwei Regionen, in denen noch proliferierende Vorläuferzellen vorliegen, welche das gesamte Leben durch der Bildung von Neuronen und Gliazellen dienen. Bei den Regionen adulter Neurogenese handelt es sich zum einen um die dem lateralen Ventrikel anliegende Subventrikularzone (SVZ), deren neu generierte Zellen über den Rostralen Migrationsstrom (RMS) zum Bulbus 
olfactorius wandern. Zum anderen werden in der Subgranularzone (SGZ) als Teil des Gyrus dentatus des Hippocampus Neurone neu gebildet (Eriksson et al., 1998). Die Präsenz von neuralen Stammzellen in einer dritten Region des Gehirns, dem Neocortex, wurde bislang nur anhand kontroverser Belege und in einem sehr geringen Maße gezeigt (Gould, 2007; Gould et al., 1999; Gould et al., 2001).

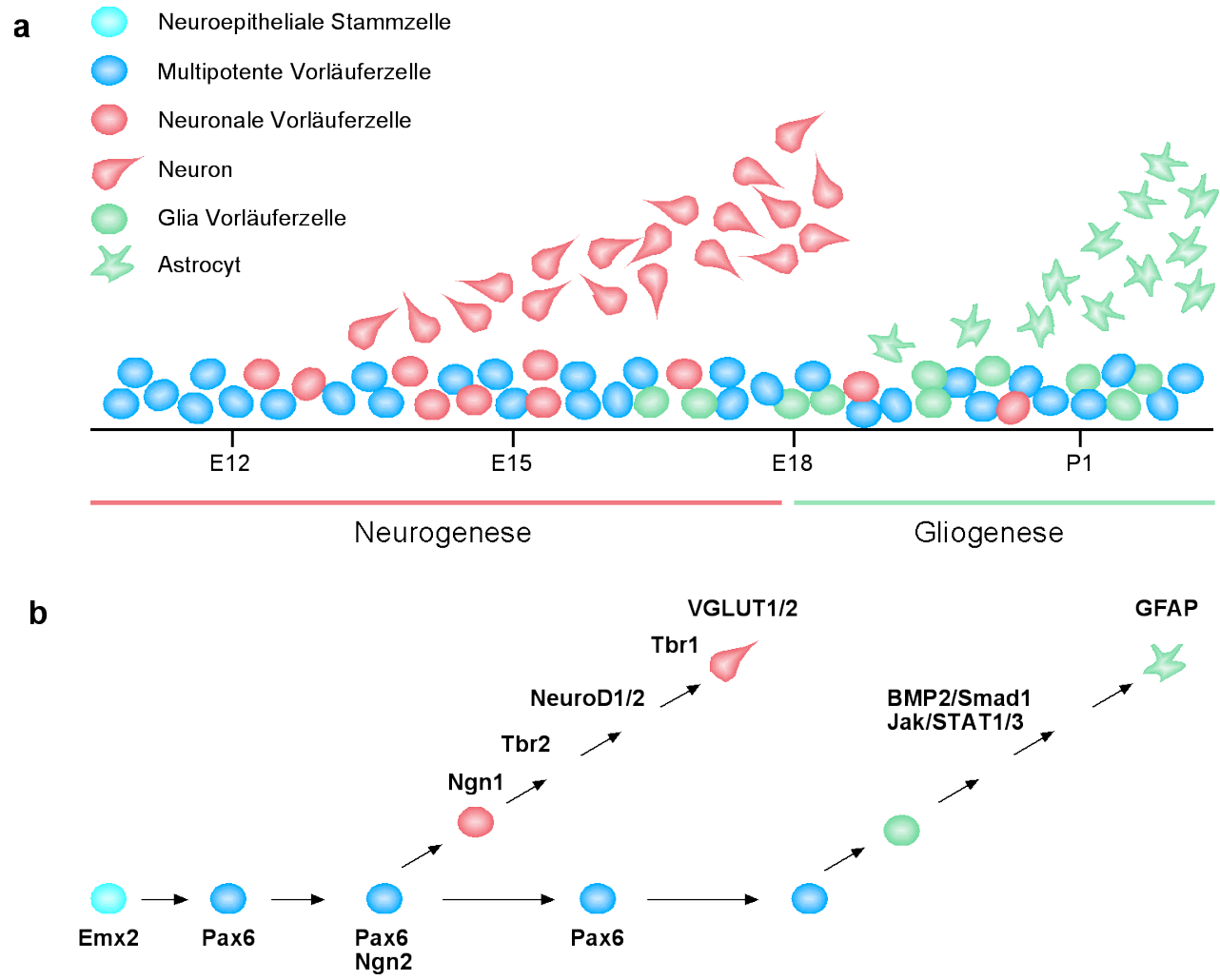

Abbildung 5. Der Übergang von Neurogenese zu Gliogenese im sich entwickelnden Neocortex. (a) Im murinen ZNS gehen von ungefähr E12 bis E18 aus multipotenten Vorläuferzellen postmitotische Neurone hervor. Vorläufer von Gliazellen werden ab E16 gebildet aus denen ab E18 Astrocyten hervorgehen. (b) Für die Differenzierung von Vorläuferzellen in cortikale Neurone bedarf es der Pax6-regulierten Aktivierung von Ngn2. Infolgedessen werden verschiedene Transkriptionsfaktoren in sequentieller Abfolge exprimiert, welche letztlich zur Bildung terminal differenzierter Neurone führen. Ab E18 werden diese neuronalen Signale reprimiert und gliogene Signale bewirken die Differenzierung der Vorläuferzellen in GFAP-positive Astrocyten (Abbildung 5a verändert nach Miller and Gauthier, 2007).

\section{Epigenetische Faktoren in der Neuralinduktion und Neurogenese}

Bei der Spezifikation von neuralen Vorläufern innerhalb des naiven Ektoderms im Kontext der Neuralinduktion und bei der Bestimmung des Schicksals neuronaler Vorläuferzellen in der Neurogenese ist eine Vielzahl von epigenetischen Faktoren involviert. Das Telencephalon geht so z. B. aus Zellen der rostralen Begrenzung der Neuralplatte hervor, einer Region, die unter dem Einfluss extrazellulärer Signale steht, welche sowohl die anteroposteriore als auch die dorsoventrale Musterung des Neuralgewebes steuern. Eingeschlossen sind Mitglieder der Fgf- (engl. „fibroblast growth factor") und Wnt- 
(engl. „wingless-type MMTV integration site family") Familie, Shh (engl. „sonic hedgehog"), BMPs (engl. „bone morphogenic proteins“), Nodal und Retinoide (reviewed in Wilson and Rubenstein, 2000).

Während der Entwicklung der cortikalen Schichten sind Proliferation und Spezifizierung des neuronalen Schicksals Schlüsselereignisse, die in der VZ und SVZ ablaufen, während Differenzierung und Migration die entscheidenden Ereignisse in der IZ sind und die Reifung der Neuronen in der CP abläuft. Da viele Transkriptionsfaktoren ein regional begrenztes Expressionsmuster in der VZ, der SVZ, der IZ oder der CP aufweisen, wird diese Tatsache in direkten Zusammenhang mit den besagten Schicht-spezifischen Ereignissen der Neurogenese gebracht (Hevner et al., 2006). Neuroepitheliale Zellen der VZ werden beispielsweise durch die Expression einer Reihe von Genen, wie Foxg1 (engl. „Forkhead box G1"), Lhx2 (engl. „LIM homeobox 2“), Emx2 (engl. „Empty spiracles homologue 2“) und Pax6 (engl. „Paired box 6“), induziert, radiale Gliazellen zu werden (Molyneaux et al., 2007). Der Transkriptionsfaktor Emx2 unterstützt symmetrische, proliferative (vertikale) Teilungen (Heins et al., 2001), Pax6 dagegen fördert asymmetrische, neurogene Zellteilungen (Heins et al., 2002), d. h. die beiden Transkriptionsfaktoren regulieren das Schicksal der Zellen in Koordination.

Sowohl neuroepitheliale als auch radiale Gliazellen exprimieren Nestin und RC2. Die Genexpressionsmuster von radialen Gliazellen sind im ZNS regional verschieden, was vermutlich die Unterschiede hinsichtlich der postmitotischen Nachkommen beeinflusst. Cortikale radiale Gliazellen von Säugetieren erfordern für ihre normale Entwicklung den zur Pax-Gen-Familie gehörigen Transkriptionsfaktor Pax6. Die Expression von Pax6 beginnt im sich entwickelnden Gehirn in E8.5 und ist im dorsalen Telencephalon auf die Vorläuferzellen der VZ beschränkt (Walther and Gruss, 1991; Stoykova and Gruss, 1994). In E13.5 repräsentiert die Mehrheit der Vorläuferzellen (88\%) radiale Gliazellen, welche spezifisch Pax6 und RC2 co-exprimieren (Götz et al., 1998). In der weiteren Entwicklung wurde die Expression von Pax6 auch in geringem Maße in der SVZ nachgewiesen (Hevner et al., 2006). Bei Abwesenheit von Pax6 weisen die radialen Gliazellen u. a. morphologische Defekte und einen abnormalen Zellzyklus auf und es werden nur 50\% der neuronalen Nachkommen gebildet (Götz et al., 1998; Estivill-Torrus et al., 2002; Malatesta et al., 2000). Pax6 wurde daher als Schlüsselelement der radialen Gliazellen charakterisiert.

Vorläuferzellen in der SVZ und der IZ zeichnen sich im Vergleich zu den anderen Subtypen von neuronalen Vorläuferzellen durch die Expression von anderen Sets von Genen, wie den Transkriptionsfaktoren Tbr2 (Englund et al., 2005), Cux1 (engl. „Cut-like homeobox 1“) und Cux2 (Nieto et al., 2004; Zimmer et al., 2004), aus. 
In der CP werden einige Transkriptionsfaktoren nur in bestimmten Schichten exprimiert, so dass innen eine Rolle in der spezifischen Differenzierung der einzelnen Schichten zugeschrieben wird (reviewed von Guillemot et al., 2006). Pax6, Ngn2, Tbr2, NeuroD und Tbr1 werden sowohl in der embryonalen wie auch der adulten Neurogenese in allen Regionen des Gehirns, mit Ausnahme einiger Modifikationen im Cerebellum in sequentieller Abfolge exprimiert (Abbildung 5b; Hevner et al., 2006). Die Expressions-muster dieser Transkriptionsfaktoren sind überlappend, so dass auch in individuellen Zellen die Transkriptionsfaktoren co-exprimiert werden, was letztlich zur Entscheidung über das neuronale Schicksal der Zelle bei der Musterung der cortikalen Schichten führt.

Eine weitere Gruppe von Transkriptionsfaktoren, die für die Initiierung der Entwicklung von neuronalen Zelllinien erforderlich sind, sind die zu den basisch-Helix-Loop-Helix (bHLH) gehörenden proneuralen Gene (Jan and Jan, 1994). Genetische Studien in Drosophila zeigten, dass in der zweiten Phase der Entwicklung des ZNS die Proliferation der neuralen Vorläuferzellen in der Expansion der Neuralplatte resultierte und einige Zellcluster begannen, die proneuralen Gene zu exprimieren, welche unmittelbar das Schicksal der Zellen neural zu werden einleiten. Die Aktivität dieser Gruppe von Transkriptionsfaktoren bedarf der Aktivierung des Notch-Signalweges. In Vertebraten dagegen werden proneurale Gene zuerst in neuroepithelialen Zellen exprimiert, welche bereits neural spezifiziert sind und sich selbst erneuern. Die Aktivierung dieser proneuralen Gene resultiert in dem neuronalen Schicksal der Abkömmlinge der Vorläuferzellen, statt das Schicksal einer Gliazelle anzunehmen.

Zu den proneuralen Genen in der Maus zählen Mash1, Mash2, Olig2 sowie Neurogenin (Ngn1, Ngn2) und NeuroD. Ngns aktivieren die Transkription durch Rekrutierung von Co-Faktoren wie p300/CBP (CREB-binding protein) und PCAF (p300/CBP-assozierter Faktor; Koyano-Nakagawa et al., 1999). Sie bewirken die Aktivierung von anderen Genen, welche den Austritt aus dem Zellzyklus und die neuronale Differenzierung im Cortex fördern (Abbildung 5b). Die proneuralen Gene Ngn1 und Ngn2 dienen beispielsweise auf diesem Wege der Etablierung der unteren Schichten. Die Aktivierung von Ngn2 unterliegt dabei der direkten Regulation durch Pax6 (Abbildung 5b). Mash1 unterliegt der Repression durch die Ngn-Mitglieder. Es wird vornehmlich im ventralen Telencephalon exprimiert und ist durch Transaktivierung von GAD1/2 an der Differenzierung der subcortikalen Bereiche, den Interneuronen, beteiligt. Das Zusammenspiel der proneuralen bHLH-Proteine hat eine bedeutende Rolle bei der Generation sämtlicher Vorläufer des cerebralen Cortex (Abbildung 5b).

Transkriptionsfaktoren der SoxB1-Familie wie Sox1, Sox2 und Sox3 sind entscheidend für die Erhaltung von neuralen Vorläufern in dem Proliferationsstatus. Konstitutive Expression 
von Sox2 inhibiert die neuronale Differenzierung, resultierend in der Erhaltung von neuronalen Vorläuferzellen (Graham et al., 2003). Die Differenzierung in Astrocyten ist dagegen nicht beeinflusst (Bani-Yaghoub et al., 2006). Es sind keine direkten transkriptionellen Zielgene von Sox2 in neuralen Zellen bekannt, jedoch wurde durch konstitutive Expression des Transkriptionsfaktors die Notch-Signalkaskade aktiviert (BaniYaghoub et al., 2006). Inhibition der Sox2-Genexpression hat dagegen den Austritt von Vorläufer-zellen aus dem Zellzyklus zur Folge (Graham et al., 2003).

Zusammenfassend lässt sich sagen, dass es bestimmter genetischer Programme bedarf, die zu verschiedenen Stadien der Cortexentwicklung zur Spezifizierung der Eigenschaften aller cortikalen Neurone operieren. Das Zusammenspiel extrinsischer Signale in der Umgebung der Vorläuferzellen und die Kombination der Transkriptionsfaktoren determinieren das Schicksal dieser Zellen. Inwiefern die Regulation des Zellzyklus proliferierender Zellen mit der Einleitung des neuralen bzw. neuronalen Schicksals und der Spezifizierung in zellulären Subtypen in koordinierter Weise gesteuert wird, ist bislang noch unzureichend verstanden.

\section{Rolle von Geminin in der Embryonalentwicklung}

Geminin wurde ursprünglich als bifunktionales Protein mit einer Rolle bei der Kontrolle des Zellzyklus wie auch bei der Regulation der embryonalen Entwicklung des Nervensystems charakterisiert. Geminin wurde in einem Screen für Proteine, die in Abhängigkeit des Zellzyklus degradiert werden, entdeckt (McGarry and Kirschner, 1998). Außerdem wurde Geminin zeitgleich in einer Expressionsanalyse von Proteinen von Xenopus identifiziert, welche bei Überexpression einen Einfluss auf die Formation des Nervensystems haben sollten (Kroll et al., 1998). Die Struktur des Geminin-Proteins gibt Aufschluss über seinen multifunktionalen Charakter. Bevor auf die verschiedenen biologischen Funktionen von Geminin im Zellzyklus und in der Zelldifferenzierung und die daran beteiligten Faktoren eingegangen wird, werden daher im Folgenden zunächst die biochemischen Eigenschaften des Proteins erläutert.

\section{Sequenz und Struktur von Geminin}

Humanes Geminin besteht aus 209 Aminosäuren (As) und besitzt ein vorhergesagtes Molekulargewicht von $23 \mathrm{kDa}$. Die vollständige Struktur von Geminin wurde mittels Elektronenmikroskopie bei einer Auflösung von 17,5 $\AA$ aufgeschlüsselt (Okorokov et al., 2004). Das Geminin-Oligomer erscheint in einer Schlüssel-ähnlichen Form mit einem flexiblen, N-Terminalen „Kopf“ (As 1-80), einer „Hals“-Domäne (As 80-110), einem zentralen Körper (As 110-160) und einem C-terminalen „Schwanz“ (As 160-209; Abbildung 6). 
Der N-terminale „Kopf“ umfasst die für Xenopus gezeigte Aktivität als neuralisierendes Molekül (As 28-79 in humanem Geminin). Der zentrale Körper korrespondiert mit einer fünf Hepta-Aminosäurewiederholungen enthaltenden Leucin-Zipper coiled-coil Domäne, welche zur Formation eines parallelen coiled-coil Dimers mit sich selbst assoziiert (Thépaut, 2004; Saxena et al., 2004; Lee et al., 2004). Die Geminin-Homodimere formieren sich zu einem Tetramer, wie durch Vernetzungs- (engl. „crosslinking“) Experimente belegt wurde (Okorokov et al., 2004).

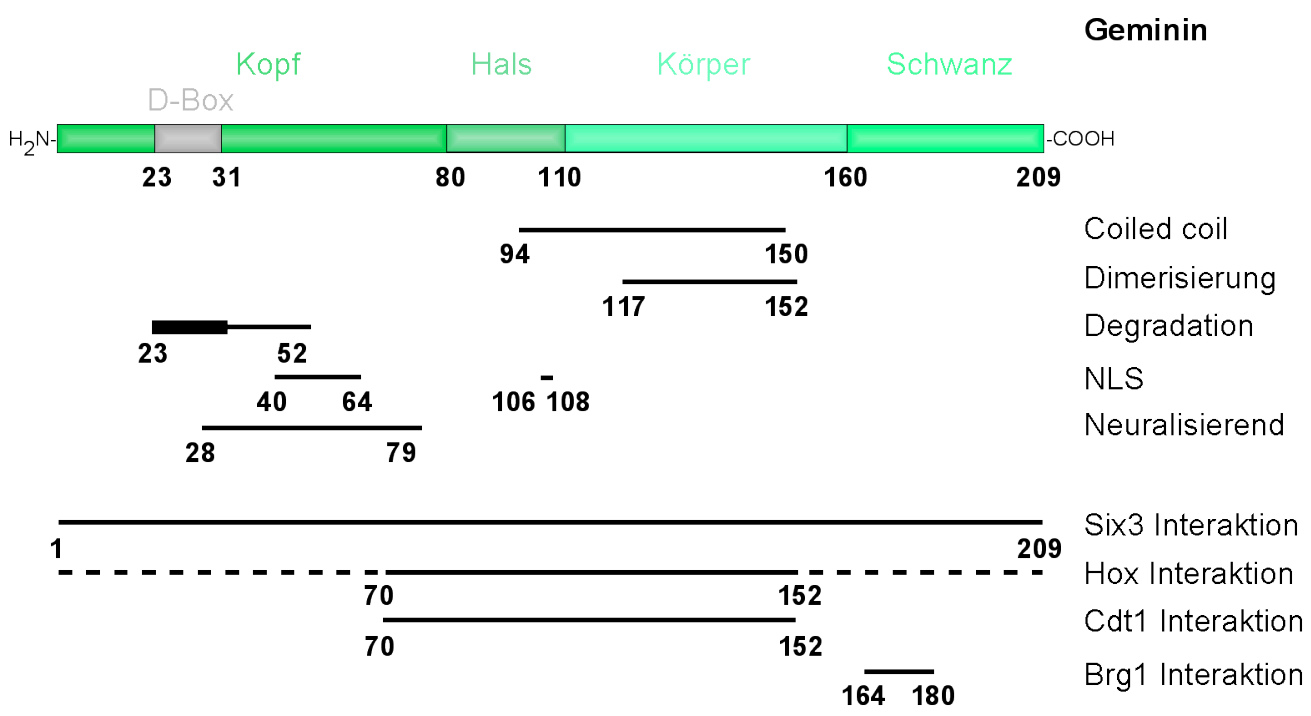

Abbildung 6. Schematisierte Struktur des humanen Geminin-Proteins, Darstellung der funktionalen Motive und der Protein-Protein-Interaktionsdomänen. Von der zur Degradation erforderlichen Sequenz (As 23-52) ist die D-Box durch eine verstärkte Linie gekennzeichnet. Für Xenopus Geminin wurden zwei zweiteilige nukleare Lokalisationssignale (NLS; RTK+KRK oder KRK+KKAK) beschrieben (Benjamin et al., 2004; Yoshida et al., 2005; Boos et al., 2006). In der Sequenz von humanem Geminin umfasst die N-terminale Region (As 40-64) dieses Motiv, jedoch handelt es sich um nur eines dieser Motive (KRK). Ein alternatives Motiv (RRK) ist von As 106-108 lokalisiert (Boos et al., 2006). Die Geminin-Hox Interaktion bedarf der durch eine durchgehende Linie angedeuteten Domäne; die gestrichelte Linie weist auf die bisher nicht kartierte Sequenz hin (Abbildung modifiziert nach Kroll, 2007).

Geminin interagiert mit einer Vielzahl von Proteinen, die in verschiedenen Regulationsprozessen involviert sind. Zusammen mit dem „Hals“ stellt der „Kopf“ der Geminin-Struktur den mit Cdt1 interagierenden Part dar (Abbildung 6). Die negativen Ladungen auf der Oberfläche der coiled-coil Domäne sind für elektrostatische Wechselwirkungen mit dem zentralen Part von Cdt1 erforderlich. Das „Hals“-Segment von Geminin ist ebenfalls in der Inhibition der DNA-Replikation involviert, indem es eine weitere Interaktionsoberfläche für den N-Terminus von Cdt1 darstellt. Die N-terminalen Teile der coiled-coil Domäne sind flexibel und scheinen die Interaktion zwischen Geminin und Cdt1 zu stabilisieren. Homeodomän-Proteine wie Hox und Six3 kompetetieren mit Cdt1 um die Bindung an Geminin (Luo et al., 2004; Del Bene et al., 2004). Die Interaktionsmotive der Transkriptionsfaktoren überlappen mit der Cdt1-Interaktionsdomäne (Abbildung 6). In in vitro Analysen und Primärzellkulturen konnte so beispielsweise gezeigt werden, dass bei direk- 
ter Interaktion von Hoxa11 und Geminin Cdt1 von dem Komplex entfernt wird, so dass die Initiation der DNA-Replikation nicht mehr gegeben ist (Luo et al., 2004).

Bei der Analyse verschiedener Deletionsmutanten von Geminin wurde in der N-terminalen Domäne eine Destruktionsbox- (D-Box) Konsensussequenz identifiziert (McGarry and Kirschner, 1998), die eine Sequenz-Homologie zu der der mitotischen Cycline aufweist (Glotzer et al., 1991). In der humanen Sequenz des Geminin-Proteins ist die D-Box zwischen den Aminosäuren 23 bis 31 lokalisiert (Abbildung 6). Sie ist Zielsequenz des (engl.) „Anaphase-Promoting-Complex“ (APC), welcher die Degradation des Proteins über den Ubiquitin-Proteasom-Weg vermittelt. Für eine effiziente Degradation bedarf es überdies einer zusätzlichen Sequenz C-terminal von der D-Box. Diese Region enthält in Xenopus zwei Cluster von basischen Aminosäuren, die als nukleares Lokalisationssignal (NLS) des Geminin-Proteins fungieren (Benjamin et al., 2004; Boos et al., 2006; Luo et al., 2007). In der Sequenz des humanen Geminin umfasst die N-terminale Region, Aminosäuren 40 bis 64 , eines dieser Motive und ein alternatives Motiv befindet sich von Aminosäuren 106 bis 108 in der „Hals“-Domäne (Abbildung 6). Letztlich wurde eine Interaktionsdomäne für die katalytische Untereinheit des SWI/SNF-ChromatinRemodellierungkomplexes, Brm, dem Drosophila-Ortholog zu den der Vertebraten, Brg1 und Brm, entdeckt, welche im C-Terminus des Geminin-Proteins lokalisiert ist (Abbildung 6; Seo et al., 2005a).

Während einige der genannten Faktoren um die Bindung zu Geminin kompetetieren, mögen andere simultan binden können. Im Folgenden werden die strukturellen Eigenschaften von Geminin in Bezug auf seine funktionale Rolle im Zellzyklus und in der Embryonalentwicklung erörtert.

\section{Geminin in der Rolle des Zellzyklusregulators}

Die Synthese vom Geminin-Protein beginnt in der frühen S-Phase. Zu diesem Zeitpunkt akkumuliert es unmittelbar im Kern und bindet als Dimer den Replikationsfaktor Cdt1 (Wohlschlegel et al., 2000). Diese Bindung blockiert Cdt1 und verhindert damit die unzulässige Replikationsinitiierung während der S-Phase (Wohlschlegel et al., 2000; Tada et al., 2001). Geminin verbleibt in der $S$ und $G_{2}$-Phase bis zum Ende der Mitose im Kern, wo dann beim Metaphase-Anaphase Übergang die APC-vermittelte Degradation des Proteins erfolgt. Während der $\mathrm{G}_{1}$-Phase des Zellzyklus ist Geminin infolgedessen nicht mehr präsent. Cdt1 veranlasst zur Initiierung der DNA-Synthese daraufhin die Assemblierung des Prä-Replikationskomplexes. Die Formation dieses Komplexes auf dem Chromatin des Replikationsursprungs erfolgt durch Beladung mit einem Komplex aus sechs MCM- (engl. „Minichromosome Maintenance“) Proteinen. Cdt1 hat somit in der $\mathrm{G}_{1}$-Phase des 
Zellzyklus die Lizenz für die kommende Runde der DNA-Replikation erteilt (Nishitani et al., 2000).

In Xenopus wird nur etwa die Hälfte des Geminin-Proteins degradiert, wogegen der verbleibende Teil durch einen unbekannten Mechanismus inaktiviert wird, welcher die Ubiquitinylierung von Geminin involviert (Li and Blow, 2004). Es wurde zum einen belegt, dass inaktiviertes Geminin nicht fähig ist Cdt1 zu binden, so dass die Replikationslizenzierung nicht verhindert wird (Hodgson et al., 2002). Zum anderen wird angenommen, dass Geminin zusammen mit Cdt1 einen Komplex auf dem Chromatin formiert, welcher zunächst die Lizenzierung der Replikation erlaubt. Nur bei der Veränderung des stöchiometrischen Verhältnisses von Geminin zu Cdt1 wird Cdt1 in seiner Aktivität bei der Formierung des Prä-Replikationskomplexes blockiert. Während in der $\mathrm{G}_{1}$-Phase der aktive Geminin-Cdt1-Komplex die Replikation erlaubt, wird in der S-Phase die Lizenzierung der Replikation durch Anreicherung von Geminin auf dem Chromatin blockiert (Lutzmann et al., 2006). Diese Inhibition scheint gegeben, sobald die in Abhängigkeit vom Kernimport stehende Reaktivierung von Geminin vollzogen wurde (Hodgson et al., 2002; Lutzmann et al., 2006).

In Säugetieren wurde ein weiterer Mechanismus zur Regulation der Rereplikation

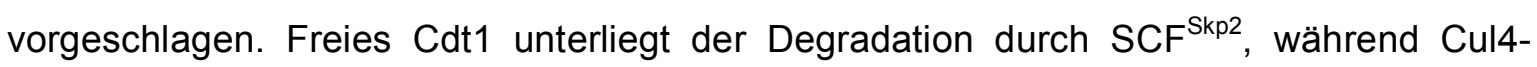
$D d b 1^{C d t 2}$ sowohl freies wie auch an Geminin gebundenes Cdt1 eliminiert. In der S-Phase werden somit alle Formen von Cdt1 degradiert. In der $\mathrm{G}_{2}$-Phase wird Cul4-Ddb1 ${ }^{\mathrm{Cdt} 2}$ inaktiviert und Cdt1-Geminin beginnt zu akkumulieren. Geminin beschützt somit Cdt1 vor der Degradation. Die Assemblierung des Prä-Replikationskomplexes wird dabei in der M-Phase durch Geminin reprimiert bis das Protein in der Anaphase durch den APC zerstört wird (Arias and Walter, 2005).

Die Aktivität von Geminin unterbindet eine erneute Runde der DNA-Synthese, die so genannte Rereplikation. In humanen Zellkultursystemen und in Drosophila resultierte die Herunterregulierung des Expressionslevels von Geminin mittels RNA Interferenz in Zellen mit vergrößertem Zellkern und einem DNA-Gehalt von $4 \mathrm{~N}$ oder höher (Melixetian et al., 2004; Zhu et al., 2004; Quinn et al., 2001; Mihaylov et al., 2002). Die Zellen waren in der S-Phase akkumuliert und betrieben extensive Rereplikation. In Funktionsverlust-Studien von Geminin in humanen HCT116-Krebszellen wurde ebenfalls eine Zunahme der Replikation durch die Inkorporation von BrdU visualisiert (Yoshida et al., 2004). Da Geminin nicht mehr verfügbar war, wurde Cdt1 nicht mehr an seiner Funktion der Lizenzierung der DNA-Replikation gehindert.

Die vollständige Inaktivierung von Geminin in der Maus resultiere in vorzeitiger Endoreduplikation im 8-Zell-Stadium und embryonaler Lethalität in Stadien vor der Implantation 
(Gonzalez et al., 2006; Hara et al., 2006). Es wurden ausschließlich Zellen der Trophoblasten-Zelllinie generiert, ohne dass sich die für die Embryonalentwicklung erforderliche innere Zellmasse formierte. Geminin ist somit ein bedeutendes Element in der embryonalen Entwicklung, das die Rereplikation in proliferierenden Zellen von Eukaryoten inhibiert und das zur Aufrechterhaltung der Pluripotenz die Endoreduplikation verhindert.

\section{Expression von Geminin in proliferierenden Zellen mit neuralem Schicksal}

Geminin ist weit verbreitet in proliferierenden Vorläuferzellen, vornehmlich in neuralem und davon abgeleitetem Gewebe, in adulten Gonaden und in endoreplizierenden Zellen wie bei Drosophila und Caenorhabditis elegans (Kroll et al., 1998; Quinn et al., 2001; Seo et al., 2005a; Yanagi et al., 2005; Xouri et al., 2004; Wohlschlegel, 2002; Montanari et al., 2005). Bei der Entwicklung von Xenopus laevis ist maternale Geminin-mRNA von Beginn an in den Oozyten-Stadien präsent, während die Expression von zygotischem Geminin mit einsetzender Gastrulation von Signalen des dorsalen Mesoderms, dem Spemann Organisator, induziert wird. Zu den Induktoren zählen die BMP-Antagonisten Chordin und Noggin, die die stärkste Expression von Geminin im zukünftigen Neuralgewebe initiieren (Kroll et al., 1998). In der fortlaufenden Entwicklung markiert Geminin Populationen neuraler Vorläuferzellen, ein Expressionsmuster, das mit dem der SoxB1-Familie von Transkriptionsfaktoren, Sox2 und Sox3, vergleichbar ist (Kroll et al., 1998; Seo et al., 2005a). In späten embryonalen Stadien ist eine erhöhte Expression von Geminin in Gehirn, Auge, Ohr und in nasalen Strukturen zu verzeichnen.

Sox2 ist der erste Marker der Neuralplatte, aus welcher das gesamte ZNS hervorgeht. Im Huhn wurde gezeigt, dass Geminin zu Beginn der Entwicklung der Neuralplatte die Expression des Sox2-Gens durch Aktivierung des N2-Enhancer auslöst (Papanayotou et al., 2008). Dieser Mechanismus involviert die Interaktion von Geminin mit dem SWI/SNFChromatin-Remodellierungskomplex, dessen katalytische Untereinheit an den N2-Enhancer des Sox2-Gens gebunden ist. Diese Interaktion wird durch die Heterochromatin-Proteine HP1 $\alpha$ und HP1 $\gamma$ reprimiert (Papanayotou et al., 2008).

Die Überexpression von Geminin in Xenopus Embryonen führte zur Expansion der Neuralplatte auf Kosten des angrenzenden Neuralkamms und der Epidermis (Kroll et al., 1998). Injektion von Geminin-mRNA in Embryonen im Zwei-Zell-Stadium löste im frühen Neurula-Stadium eine Hypertrophie des Neuralgewebes aus wie durch Expression neuraler und neuronaler Marker, wie N-Tubulin, Otx2, Pax6 und Delta-1, angezeigt wurde. Im Gastrula-Stadium verursachte die Missexpression von Geminin-mRNA im Ektoderm die Induktion der ektopischen Expression von Neuralgewebe. Diese Effekte wurden ebenfalls 
beobachtet, sofern ausschließlich die N-terminale „neuralisierende“ Domäne von Geminin in Xenopus überexprimiert wurde (Kroll et al., 1998).

Vergleichbar mit der in Xenopus beschriebenen Expression von Geminin ist die Expression im embryonalen ZNS des japanischen Medaka Fisches (Oryzias latipes). Ektopische Überexpression von Geminin im Medaka Fisch resultierte in einem Phänotyp mit kleineren Augen, Zyklopie oder rief den Verlust der vollständigen Vorderhirnstruktur hervor (Del Bene et al., 2004). Diese Erscheinung war einhergehend mit einer abnehmenden Anzahl proliferierender Zellen und vorzeitiger Neuralinduktion in den optischen Vesikeln. Geminin wies eine inhibitorische Wirkung bei der frühen Augen-entwicklung auf, was mit der Rolle von Geminin in der Zellzyklusregulation und Neurogenese korreliert. Reduktion des Expressionslevels von Geminin durch Morpholino Oligonukleotide führte zu einer erhöhten Anzahl mitotisch aktiver Zellen und somit vergrößerten Augen. Die Beobachtungen waren auf eine direkte Interaktion mit dem Homeodomän-Protein Six3 zurückzuführen, welches zuvor bereits als ein Faktor der Augenentwickung beschrieben worden war (Del Bene et al., 2004). Die starke Interaktion von überexprimiertem Geminin und Six3 blockierte das Protein in seiner eigentlichen Funktion bei der Entwicklung der Augen und führte zu dem erläuterten reduzierten Augen-Phänotyp. Co-Injektion von Geminin-RNA und Anti-Six3 Morpholinos konnte den Wildtyp-Phänotyp wiederherstellen (Del Bene et al., 2004). Geminin ist somit neben der Rolle als Zellzyklusregulator des Weiteren an der Determination des Schicksals neuraler Vorläuferzellen beteiligt.

\section{Geminin in der Neurogenese}

Die Expression von Geminin während der Entwicklung von Säugetieren weist eine mit anderen Vertebraten und Invertebraten vergleichbare Anreicherung im sich formierenden Nervensystem auf (Kroll et al., 1998; Spella et al., 2007). Im ZNS von E12.5 und E15.5 Mäusen wurde mittels In Situ Hybridisierung (ISH) Geminin-mRNA in der VZ und SVZ des Cortex und in der GE des Telencephalons detektiert (Abbildung 7; Spella et al., 2007). Weiter posterior ist eine Expression in der den dritten Ventrikel umliegenden VZ des Neuroepitheliums, aus der der Thalamus, Hypothalamus und das Diencephalon hervorgeht, aber auch im Mittelhirn und in der VZ des sich entwickelnden Rückenmarks nachweisbar. In allen Bereichen ist die Expression von Geminin auf die die proliferierenden Vorläuferzellen enthaltenen Regionen beschränkt. Das Expressionsmuster von Geminin in der frühen Embryogenese weist auf eine Rolle des Proteins in der Spezifizierung des Schicksals neuronaler Vorläuferzellen hin. Auch in adulten Gehirnen ist die Expression von Geminin auf Zonen aktiv teilender Vorläuferzellen beschränkt: Die SGZ des zum Hippocampus gehörigem Gyrus dentatus und die SVZ. 
Zusammenfassend korreliert die Expression von Geminin somit in allen fast jedem zellulärem Kontext mit sich aktiv teilenden Zellen, während sie bei Austritt aus dem Zellzyklus oder Zellzyklusarrest herunterreguliert wird.

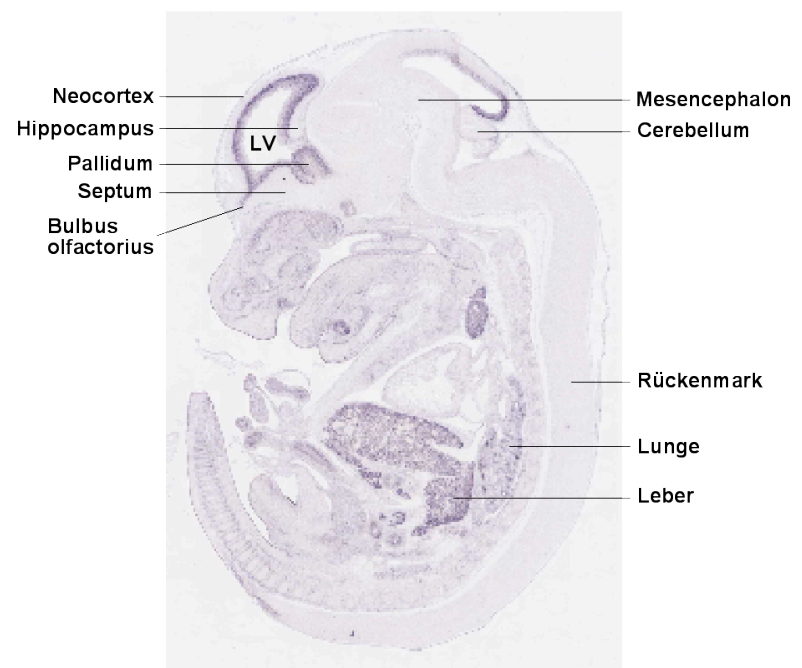

Abbildung 7. Expressionsmuster von Geminin in der Maus. In situ Hybridisierung mit Geminin auf einem sagittalen Schnitt durch einen Embryo des Stadiums E14.5 (LV, lateraler Ventrikel; Abbildung übernommen von www.genepaint.org).

\section{Geminin als Regulator der neuronalen Entwicklung}

Während Geminin in der Gastrulation das Schicksal einer Zelle neural zu werden, durch seine N-terminale Domäne reguliert, wirkt sich die Regulation durch die C-terminale Domäne auf die später ablaufende Neurogenese aus. Das Fortschreiten von einer frühen neuroepithelialen Zelle bis zum differenzierten postmitotischen Neuron scheint der Kontrolle einer geordneten Abfolge von Ereignissen zu unterliegen, welche durch die Expression von Stadien-spezifischen Genen vermittelt wird. Die Regulation der Sets von Transkriptionsfaktoren wird dabei durch große Enzymkomplexe gesteuert, welche den Zugang zur Transkriptionsmaschinerie des Chromatins modifizieren. Der SWI/SNFChromatin-Remodellierungskomplex ist ein derartiger Komplex. Er besteht aus etlichen Untereinheiten, welche zur Familie der Brahma-zugehörigen Gene (engl. „Brahma-related gene“; Brg) / Brahma- (Brm) assoziierte Faktoren (engl. „Brahma-associated factor"; BAF) Komplexe zählen. Die Komposition der Untereinheiten variiert in Bezug auf den Zelltyp (Olave et al., 2002; Wang et al., 1996). So bestimmt auch im sich entwickelnden ZNS die präzise Zusammensetzung des SWI/SNF-Komplexes aus den einzelnen Co-Faktoren, ob sich ein Zelle weiterhin teilt oder ob sie differenziert (Lessard et al., 2007). Die ChromatinAssemblierung steuert dabei das Schicksal der Zelle. Die BAFs vermitteln möglicherweise die Repression der transkriptionellen Aktivierung von Zielgenen, indem die den SWI/SNFKomplex daran hindern, an Promotor-gebundene Transkriptionsfaktoren zu binden.

Ein derartiger Mechanismus wurde so auch für Geminin vorgeschlagen. Geminin wurde in einer Yeast-Two-Hybrid Analyse als Interaktionspartner der katalytische Untereinheiten 
des ATP-abhängigen SWI/SNF-Komplexes Brg1 und Brahma identifiziert (Seo et al., 2005a). Die funktionalen Studien in Xenopus und murinen P19-Zellen belegten, dass die Interaktion zwischen Brg1 und Geminin zur Aufrechterhaltung des undifferenzierten Zellstatus beiträgt, indem verhindert wird, dass Brg1 mit transkriptionellen Regulatoren der bHLH-Familie interagiert. Zusätzlich konnte gezeigt werden, dass bei Reduktion des Geminin-Expressionslevels eine vorzeitige Neurogenese eingeleitet wird (Seo et al., 2005a). Das Ergebnis war einhergehend mit der Beobachtung, dass das Level von Geminin bei Differenzierung in neurales Gewebe abnimmt. Die Repression des SWI/SNFKomplexes durch Geminin wird aufgehoben und zuvor reprimierte Transkriptionsfaktoren werden aktiviert. Der Antagonismus von Geminin und Brg1 dient der Erhaltung neuronaler Vorläuferzellen und reguliert zeitlich die neuronale Differenzierung. Der ausführliche molekulare Zusammenhang, in dem Geminin während der Neurogenese zu stehen vermag, ist noch nicht aufgeklärt.

\section{Geminin als Regulator von Hox-Gen-Funktionen}

Im Rahmen der Musterung von Vertebraten wurde Geminin als Interaktionspartner von Mitgliedern der Hox-reprimierenden Polycomb-Familie entdeckt (Luo et al., 2004). Überexpressions- und Funktionsverlust-Studien im Neuralrohr demonstrierten die Polycomb-ähnliche Aktivität von Geminin. Die Assoziation von Geminin mit dem Chromatin Hox-regulatorischer DNA-Elemente reprimiert die Transkriptionsaktivierung der Hox-Gene. Darüber hinaus verhindert Geminin die Hox-Funktion durch direkte Bindung an die Homeodomäne der Hox-Proteine. Da die coiled-coil Domäne zum Teil auch mit der Interaktionsdomäne überlappt, an welche Cdt1 bindet, wird Cdt1 durch die Hox-Proteine von seinem Komplex mit Geminin ersetzt (Abbildung 6).

Geminin ist sowohl durch Inhibition der Rereplikation in der Kontrolle des Zellzyklus wie auch in der Regulation der embryonalen Musterung involviert. Aufgrund dieser funktionalen Dualität könnte Geminin ein bedeutendes Element in der Koordination von Zellproliferation und Zelldifferenzierung darstellen. Da diese Prozesse in einem Organismus zeitlich parallel ablaufen, stellt sich die Frage, wie dasselbe Protein gleichzeitig die Kontrolle über derartig verschiedene Regulationsmechanismen zu besitzen vermag. Eine mögliche Erklärung bestünde in der Veränderung der Protein-Eigenschaften durch posttranslationale Modifikationen.

\section{SUMOylierung als posttranslationale Modifikation}

Die räumliche und zeitliche Regulation der Funktion eines Proteins kann durch eine chemische Modifikation verändert werden. Für das Protein Geminin wurde eine Modifikation 
in Form der Anheftung von Phosphatgruppen gezeigt (Kulartz et al., 2003; Kulartz et al., 2004). Die Phosphorylierung ermöglicht weitere Regulationen der Aktivität von Geminin, obwohl bisher die funktionale Relevanz dieser posttranslationalen Modifikation nicht weiter charakterisiert wurde. Acetylierung, Methylierung, Biotinylierung, das Anfügen von Lipiden oder Zuckerresten und andere Modifikationen stellen andere allgemeine Arten von Protein-Modifikationen dar. Sie erfolgen nach der Translation der mRNA und bezeichnen die Addition von funktionalen Gruppen. Posttranslationale Modifikationen wie Ubiquitinylierung und SUMOylierung bedeuten dagegen die kovalente Bindung eines Proteins, Ubiquitin bzw. SUMO.

SUMOylierung bezeichnet die kovalente Modifikation mit Proteinen der (engl.) „Small Ubiquitin-related Modifier" (SUMO) -Familie. Bei SUMO1 handelt es sich um ein aus 101 Aminosäuren bestehendes Protein mit einem Molekulargewicht von 10,9 kDa. In Hefe (Saccharomyces cerevisiae) ist nur eine SUMO-Form namens Smt3 enthalten (Lapenta et al., 1997), wogegen Säugerzellen vier SUMO-Isoformen, SUMO1 bis SUMO4, besitzen.

Das humane SUMO1 besitzt trotz einer Sequenzhomologie von nur 18\% eine sehr hohe Ähnlichkeit in der Tertiärstruktur mit Ubiquitin. Die Tertiärstruktur entspricht der für Ubiquitin typischen $\beta \beta \alpha \beta \beta \alpha \beta$-Struktur (Bayer et al., 1998; Vijay-Kumar et al., 1987). SUMO2 und SUMO3 bestehen aus 95 bzw. 103 Aminosäuren und sind zu 95\% identisch. Sie unterscheiden sich ausschließlich in drei N-terminalen Resten und sind bisher noch nicht funktional voneinander unterscheidbar. Sie teilen eine Sequenzhomologie von $47 \%$ mit SUMO1 (Bayer et al., 1998). SUMO4 ist zu $87 \%$ homolog zu SUMO2 und wurde bisher aber am wenigstens charakterisiert. Bislang wurde es hauptsächlich in der Niere nachgewiesen und es wurde über keine nativen Substrate berichtet (Bohren et al., 2004; Bohren et al., 2007).

\section{Die SUMOylierungskaskade}

Der Weg der SUMOylierung ist analog zu dem der Ubiquitinylierung (Johnson, 2004), aber die Konjugation von SUMO bedarf eines abweichenden Sets von Enzymen. Die SUMO-Isoformen werden als inaktive Vorstufen generiert, und erst durch Abspaltung des C-Terminus durch die enzymatische Aktivität der SUMO-spezifischen Proteasen (SENPs; Ulps (engl. „Ubiquitin-like processing proteases“) in Hefe) wird das C-terminale GlycinGlycin Motiv zugänglich, welches zur Bindung der Zielproteine erforderlich ist (Abbildung 8). In Säugetieren werden die SUMO-Proteine in Abhängigkeit von ATP dann durch den aktivierenden E1-Heterodimer Aos1 und Uba2 (SAE1 und SAE2 (engl. „SUMO-Activating Enzyme“;) in Hefe) aktiviert (Abbildung 8; Desterro et al., 1999; Johnson et al., 1997). Über die zwischen E1 und SUMO neu gebildete Thioesterbindung wird SUMO 
anschließend auf das Ubiquitin-konjugierende Enzym 9 (Ubc9) übertragen (Johnson et al., 1997). Im Gegensatz zu der großen Anzahl von Ubiquitin-E1-Enzymen ist Ubc9 das einzige bisher bekannte SUMO-E2-Enzym. Ubc9 kann dann direkt an das Substrat binden und SUMO darauf übertragen. Wie zur Übertragung von Ubiquitin sind zum Teil aber auch bei der SUMOylierung E3-Ligasen erforderlich, die letztlich die Konjugation von SUMO an das Zielprotein katalysieren (Abbildung 8). Die Siz-Proteine aus Hefe wurden als erste SUMO-spezifische E3-Ligasen entdeckt (Johnson and Gupta, 2001; Takahashi et al., 2001). Die Homologen der Siz-Proteine in Säugetieren sind die PIAS- (engl. „Protein Inhibitor of Activated STAT") Proteine (Kahyo et al., 2001). Andere E3-Ligasen in Säugern schließen RanBP2 (engl. „Ran binding protein 2“; Pichler et al., 2002) und ein Mitglied der Polycomb-Familie, PC2 (engl. „polycomb protein 2“; Kagey et al., 2003), ein.

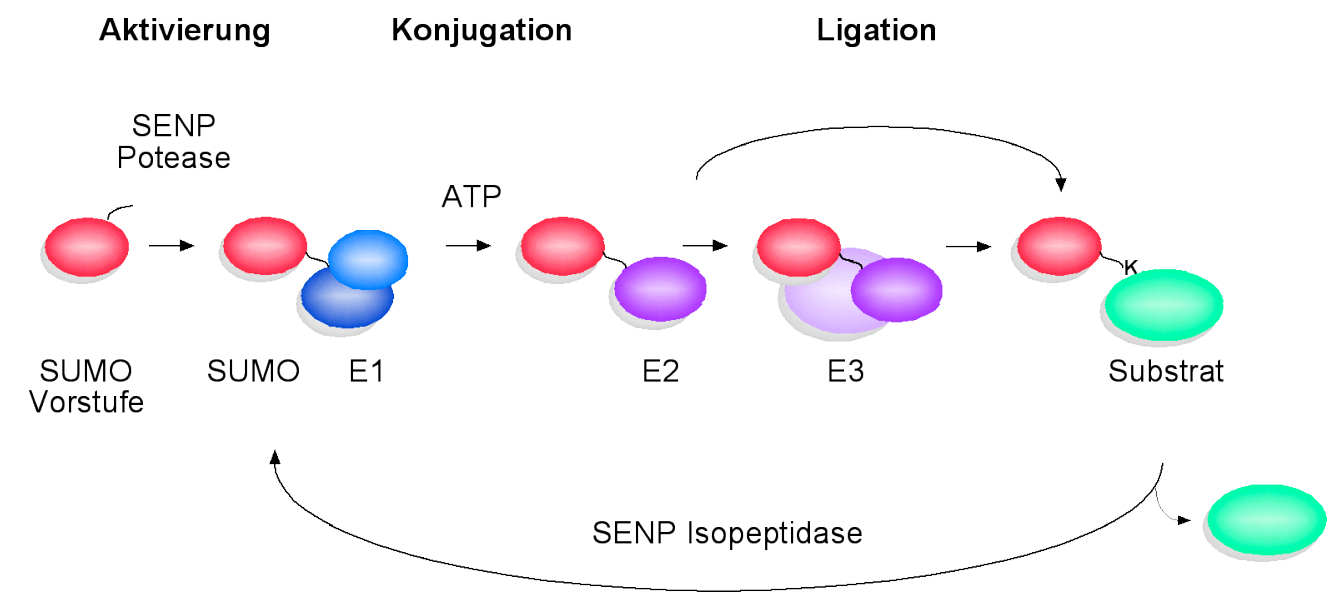

Abbildung 8. Die SUMOylierungskaskade in Säugetieren. SUMO wird als Vorstufe synthetisiert und reift durch die Hydrolase-Aktivität von spezifischen SUMO-Proteasen (SENPs). In Abhängigkeit von ATP wird durch das aktivierende Enzym E1 (Uba2/Aos1) eine Thioesterbindung zu SUMO formiert. Das aktivierte SUMO wird an E2 (Ubc9) konjugiert, welches SUMO dann direkt oder in Verbindung mit einer E3-Ligase (z. B. PIAS, RanBP2, PC2) auf das Lysin (K) des Zielsubstrats überträgt. Die Bindung von SUMO an das Substrat kann durch die Isopeptidase-Aktivität der SENPs aufgehoben werden.

Bei der Modifikation mit SUMO handelt es sich um einen reversiblen und hochdynamischen Prozess. Die kovalente Bindung von SUMO an das Substrat kann durch die Isopeptidase-Aktivität der SENPs aufgehoben werden. (Abbildung 10; Reviews Bossis and Melchior, 2006; Mukhopadhyay and Dasso, 2007). Der SUMOylierungsDeSUMOylierungs-Zyklus kann zum einen eine Veränderung der Eigenschaften des Substrat-Proteins bewirken, die bei DeSUMOylierung bestehen bleiben (Hardeland et al., 2002). Zum anderen kann die SUMOylierung stöchiometrisch ablaufen, d. h. das Ausgangsstadium des Substrats (Konformation, Funktionalität etc.) wird nach Dissoziation von SUMO wiederhergestellt. Während SUMO1 stets als Monomer an das Substrat konjugiert, können SUMO2 und SUMO3 auch in Ketten gebunden werden (Tatham et al., 2001). 


\section{SUMO-Akzeptormotive}

SUMO wird über eine kovalente Isopeptidbindung an die $\varepsilon$-Aminogruppe eines Akzeptorlysins in dem Zielprotein geknüpft. Die SUMOylierung eines Proteins geschieht vorzugsweise an das Kernkonsensus-Motiv $\psi-\mathrm{K}-\mathrm{x}-[\mathrm{D} / \mathrm{E}]$, wobei $\psi$ jeder größere hydrophobe Aminosäurerest sein kann, wie bei Isoleucin (I), Valin (V) oder Leucin (L), K das Ziel-Lysin ist, $x$ jeder Rest und D/E Aspartat oder Glutamat darstellen. Analysen von SUMOSubstraten lassen annehmen, dass die die Kernsequenz flankierenden Regionen ebenso entscheidend für die Bindung von SUMO sind. Es wurden daraufhin mehrere erweiterte SUMO-Motive definiert (Subramanian et al., 2003; Hietakangas et al., 2006; Yang et al., 2006a). Die Interaktion von SUMO und einem Protein ist nur möglich, sofern das Konsensus-Motiv durch Einbettung in eine $\beta$-Faltblatt oder Schlaufen- (engl. „loop") Struktur exponiert wird und in einer gestreckten Konformation vorliegt. Es sind zudem aber einige SUMO-Akzeptormotive entdeckt worden, die nicht das beschriebene Motiv enthalten. So stellen beispielsweise K164 in S. cervisiae PCNA (engl. „proliferating cell nuclear antigen“) als Teil der Sequenz einer Haarnadel- (engl. „hairpin“) Struktur und K14 im humanen Protein E2-25K, welches in eine $\alpha$-Helix eingebettet ist, abweichende SUMOAkzeptorstellen dar (Hoege et al., 2002; Pichler et al., 2005).

\section{SUMO-Bindemotive}

Die SUMOylierung eröffnet dem modifizierten Protein neue Interaktionsmöglichkeiten. Die kovalente Bindung von SUMO kann eine konformative Änderung des Substrats hervorrufen, so dass neue Interaktionsmöglichkeiten gegeben sind, oder es können neue Interaktionen durch SUMO selbst geschehen. Eine vergleichende Analyse SUMO-assoziierter Proteine identifizierte ein kurzes Motiv, das nicht-kovalent mit SUMO interagiert. Bei den so genannten SBM- (SUMO-Bindemotive) Motiven [V/I]-x-[V/I]-[V/I]-[V/I] oder [V/I] [V/I]$\mathrm{x}$-[V/I/L] (weitere SBMs siehe Reviews Martin et al., 2007; Geiss-Friedlander and Melchior, 2007) handelt es sich um einen hydrophoben Kern x, der N- oder C-terminal von sauren und/oder phosphorylierbaren Serin-Resten flankiert wird (Minty et al., 2000; Song et al., 2004). Das Bindemotiv formiert einen $\beta$-Strang, welcher in paralleler oder antiparalleler Orientierung zwischen der $\alpha$-Helix und einem $\beta$-Strang von SUMO bindet. Zu den wenigen bisher beschriebenen Proteinen, die ein derartiges Motiv besitzen, zählen PML und der Transkriptionsrepressor Daxx (Shen et al., 2006; Lin et al., 2006). Die funktionalen Eigenschaften dieser Proteine werden durch die Bindung von SUMO verändert. 


\section{Funktionale Rolle der SUMOylierung}

Im Gegensatz zur Modifikation mit Ubiquitin, die häufig die Degradation der Substratproteine fördert, kann die SUMOylierung diesen Prozess antagonisieren. Die Modifikation mit SUMO ist in der Kontrolle einer Vielzahl von Mechanismen innerhalb des Zellkerns etabliert. Viele Transkriptionsfaktoren und Co-Faktoren werden durch Mutation des SUMO-Akzeptorlysins zu einem Arginin deutlich aktiviert, d. h. die SUMOylierung vermittelt die Repression der transkriptionellen Aktivität. Mit der nicht-kovalenten Bindung von SUMO an Daxx wurde beispielsweise gezeigt, dass sie für die repressive Aktivität des Transkriptionsfaktors erforderlich ist. Sumoyliertes Daxx reprimiert andere sumoylierte Transkriptionsfaktoren (Lin et al., 2006). Die Modifikation mit SUMO dient des Weiteren der Regulation von Protein-Protein-Interaktionen, der subzellulären Lokalisation, dem Transport durch den Kernporenkomplex und der Regulation der Aktivität von weiteren Transkriptionsfaktoren, Histonen und Chromatin-assoziierten Proteinen (siehe Reviews Melchior, 2000; Muller et al., 2001; Hay, 2005). SUMO hat somit eine bedeutende Rolle bei der Kontrolle von diversen zellulären Prozessen. Es vermag eine entscheidende Rolle bei der Vermittlung zwischen regulatorischen Elementen und Molekülen bei diesen Ereignissen haben. 


\section{Zielsetzung}

Das Protein Geminin ist charakterisiert durch seine funktionale Dualität, da es sowohl an der Kontrolle des Zellzyklus als auch an der Steuerung der Zelldifferenzierung beteiligt ist. Geminin wurde zuerst als ein Schlüsselelement bei der Kontrolle des Zellschicksals bei der Formation des Nervensystems entdeckt, während seine Rolle im Laufe der Zeit auf weitere Prozesse wie die Steuerung von Hox-Gen-Funktionen und der Regulation der neuronalen Differenzierung erweitert wurde.

Die molekularen Mechanismen, die hinter der Kontrolle dieser vielfältigen Prozesse durch Geminin stecken, sind bisher nur teilweise charakterisiert. Posttranslationale Modifikationen von Proteinen ermöglichen oftmals eine Vervielfältigung der Funktionen eines Proteins, indem dessen räumliche und zeitliche Regulation verändert wird. Die SUMOylierung stellt eine derartige posttranslationale Modifikation dar, welche in einer Vielzahl von zellulären Prozessen involviert ist. Die Modifikation mit SUMO vermag möglicherweise einen schnellen Wechsel der Funktionalität von Geminin bewirken, der bei der inhibitorischen Wirkung von Geminin auf Cdt1 im Zellzyklus erforderlich ist. Mit dieser Arbeit wurde es angestrebt, Geminin als mögliches Substrat der SUMOylierung zu untersuchen und den Effekt dieser Modifikation auf die Regulation Geminins hinsichtlich der beschriebenen Interaktionspartner zu analysieren.

Die regulatorischen Eigenschaften von Geminin sind in einer Vielzahl von Modellorganismen, einschließlich Drosophila, Xenopus, dem Medaka Fisch, dem Huhn und verschiedenen Zellkultursystemen beschrieben worden. Das Ziel der vorliegenden Arbeit lag des Weiteren in der eingehenden Analyse der funktionalen Bedeutung von Geminin bei der embryonalen Musterung eines höher entwickelten Vertebraten, der Maus.

Da die Annahme bestand, dass ein konventioneller Knockout des Geminin-Gens frühe embryonale Lethalität hervorrufen könnte wie inzwischen auch durch eine Gruppe um R. A. Laskey bestätigt werden konnte (Gonzalez et al., 2006), wurde es in dieser Arbeit angestrebt, mittels der Methode des (engl.) „Recombineering“ einen konditionalen Knockout zu generieren. Um das Verständnis der Rolle von Geminin in der neuronalen Entwicklung zu erweitern, bestand das Ziel dieser Arbeit darin, mittels des Cre/LoxP Rekombinationssystems mit einsetzender Neurogenese eine spezifische Inaktivierung von Geminin im Cortex von Mäusen zu generieren. Die Analyse der transgenen Mäuse war im Besonderen auf die Zellzykluscharakteristika der Geminin-inaktivierten proliferierenden Vorläuferzellen ausgerichtet. Es galt zu untersuchen, ob der Funktionsverlust von Geminin in Rereplikation resultieren würde, inwiefern das neuronale und gliogene Schicksal der cortikalen Vorläuferzellen bei der Bildung des Neocortex beeinflusst sein würde und welche Bedeutung Geminin beim Übergang von Neuro- zu Gliogenese hat. 


\section{Ergebnisse}

\section{Posttranslationale Modifikation von Geminin mit SUMO1}

Um die Eigenschaft der Funktionalität des Geminin-Proteins bei der Kontrolle des Zellzyklus und bei der Regulation der Zelldifferenzierung besser zu verstehen, wurde Geminin als mögliches Substrat der posttranslationalen Modifikation mit SUMO untersucht. Die SUMOylierung vermag möglicherweise eine Veränderung der Funktionalität von Geminin bei der zeitlichen und räumlichen Koordination der zeitgleich ablaufenden Prozesse bewirken.

\section{In silico Analyse von dem Geminin-Protein}

Die SUMOylierung von Substratproteinen geschieht in der Regel an einen Lysin-Rest (K), welcher sich innerhalb der Konsensussequenz $\psi-K-x-[D / E]$ befindet. Das humane Geminin Protein setzt sich aus 209 Aminosäuren zusammen, von denen 20 Lysine sind, welche eine potentielle Akzeptorstelle für SUMO darstellen. Mit Hilfe der online verfügbaren Software SUMOplot ${ }^{\mathrm{TM}}$ Prediction (http://www.abgent.com/tool/sumoplot) wurde die Primärsequenz von Geminin auf mögliche SUMO-Konsensusmotive überprüft. Für humanes Geminin ließen sich zwei Motive ausmachen, die der Konsensussequenz entsprechen. Motiv 1 befindet sich am N-terminus von Geminin, aufwärts der D-Box, und besteht aus den Aminosäuren QKQE (Abbildung 9). Das Lysin K8 ist mit Ausnahme vom Huhn (Gallus gallus) und Xenopus konserviert. In Xenopus liegen zwei weitere Aminosäuren innerhalb dieses Motivs. Das zweite Motiv besteht in der Sequenz von humanem Geminin aus den Aminosäuren LKKE. Das Lysin K135 an zweiter Position des Motivs (LKKKE) ist hochkonserviert und wurde mit Ausnahme für die Maus (Mus musculus) als potentielles SUMO-Akzeptormotiv vorhergesagt. Das zweite Lysin (LKKKE) tritt nur in den Sequenzen vom Mensch und in der Maus auf. Motiv 2 befindet sich innerhalb einer der fünf HeptaAminosäurewiederholungen der coiled-coil Domäne, eingebettet in einer Schlaufenstruktur (Abbildung 9). Das Motiv liegt daher in einer gestreckten Konformation vor und macht somit erst die Interaktion zwischen SUMO und Geminin möglich (Lee et al., 2004). Eines der für andere SUMO-Substrate beschriebenen SUMO-Bindemotive konnte nicht in der Sequenz von Geminin identifiziert werden. Die Analyse der Aminosäure-sequenz von humanem Geminin mit dem PEST-Find Algorithmus (http://www.at.embnet.org/embnet/tools/bio/PESTfind; Rogers et al., 1986) offenbarte außerdem zwei so genannte PEST-Sequenzen, die in einer Reihe von SUMOZielproteinen neben dem Konsensusmotiv vorhanden sind (Abbildung 9). PEST-Sequenzen sind Abschnitte von mindestens 12 Aminosäuren, die vornehmlich 
Prolin, Glutamat, Aspartat, Serin und Threonin, aber keine positiv geladenen Aminosäuren enthalten (Rechsteiner and Rogers, 1996).

Zusammengefasst wurden mit Hilfe der in silico Analyse zwei potentielle Akzeptormotive in der Aminosäure-Sequenz von humanem Geminin ausgemacht, an die SUMO konjugieren könnte. Die Präsenz zweier möglicher PEST-Sequenzen ist ein weiteres Indiz für eine Modifikation mit SUMO. Da die Sequenz von Geminin zudem sehr reich an Lysinen ist, ist die Wahrscheinlichkeit der kovalenten Bindung von SUMO um ein Weiteres erhöht, da theoretisch jedes Lysin eine potentielle Angriffstelle für SUMO bedeutet. Im Folgenden wurde überprüft, ob sich diese theoretischen Überlegungen in vitro und in vivo bestätigen lassen.

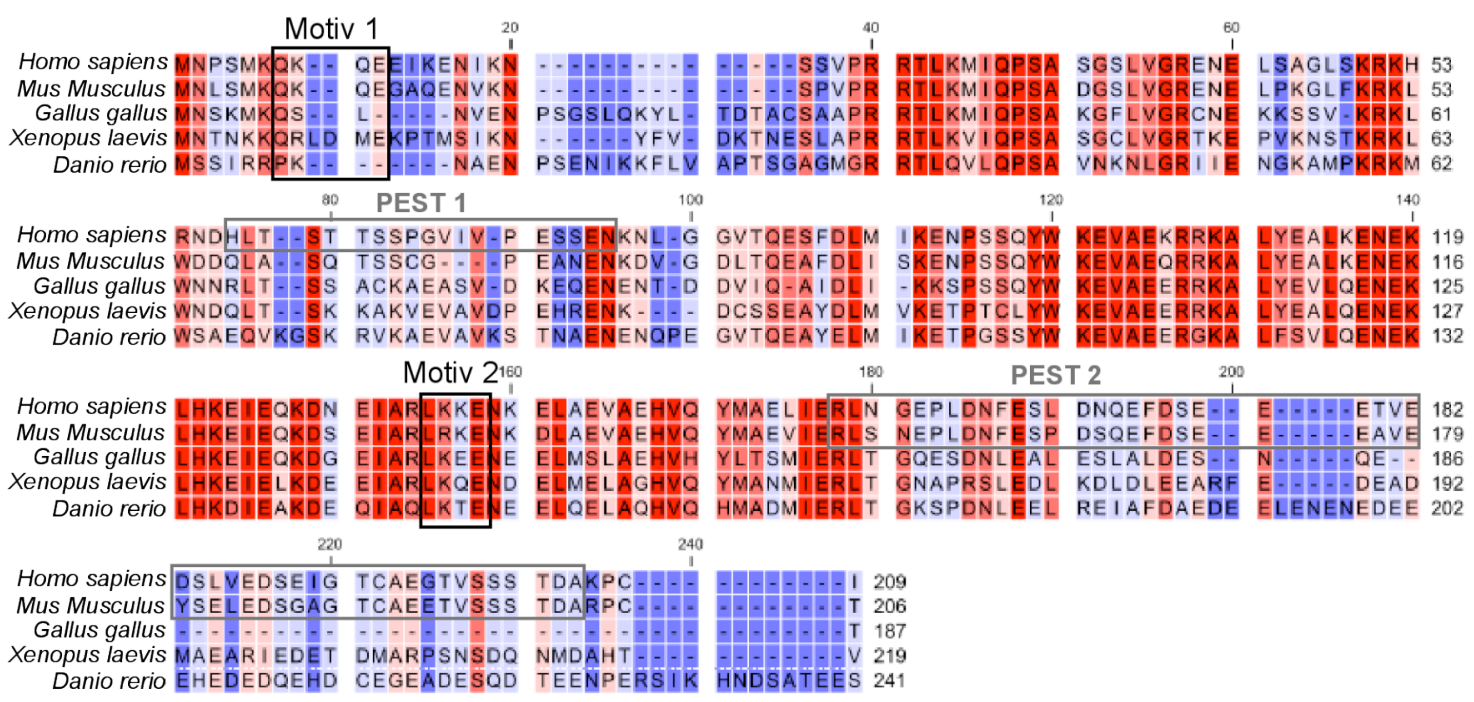

Abbildung 9. Sequenz-Alignment von Geminin-Orthologen. Die Proteinsequenz von Homo sapiens Geminin wurde mit den Orthologen aus Maus (Mus musculus), Huhn (Gallus gallus), Frosch (Xenopus laevis) und Zebrafisch (Danio rerio) aligniert und zeigt die zwei potentiellen SUMO-Akzeptormotive (Motiv 1 und 2) und zwei PEST-Sequenzen. PEST-Element 2 ist in der Sequenz von Mensch und Maus vorhanden. Die Hintergrundfarbe der Aminosäuren variiert von blau (nicht-konservierte Reste) bis rot (konservierte Reste).

\section{Geminin ist bei Anwesenheit von spezifischen SUMO E3-Ligasen in vitro durch SUM01 modifizierbar}

Die posttranslationale Modifikation eines Proteins durch Konjugation an SUMO1 veranlasst, dass das modifizierte Protein in einem Acrylamid-Gel mit höherem Molekulargewicht migriert als das unmodifizierte mit dem normalen Molekulargewicht. Das sumoylierte Molekül lässt sich dann mittels SDS-PAGE und Western Blot Analyse durch einen Verlagerung der herkömmlichen Proteinbande um etwa 11 bis 20 kDa nachweisen.

Um zu überprüfen, ob Geminin in vitro sumoyliert werden kann, wurde rekombinantes Geminin zusammen mit ATP, rekombinantem SUMO1, E1- (Aos1/Uba2) und E2-Enzym (Ubc9) inkubiert und eine Western Blot Analyse vorgenommen. 
Der Anti-Geminin-Antikörper detektierte unmodifiziertes Geminin bei $32 \mathrm{kDa}$. In der Negativ-Kontrolle ohne ATP und E3-Ligase (Abbildung 10a, Spur 2) wurden keine weiteren Proteinbanden im höhermolekularen Bereich detektiert (Abbildung 10a, Spur 3).

a

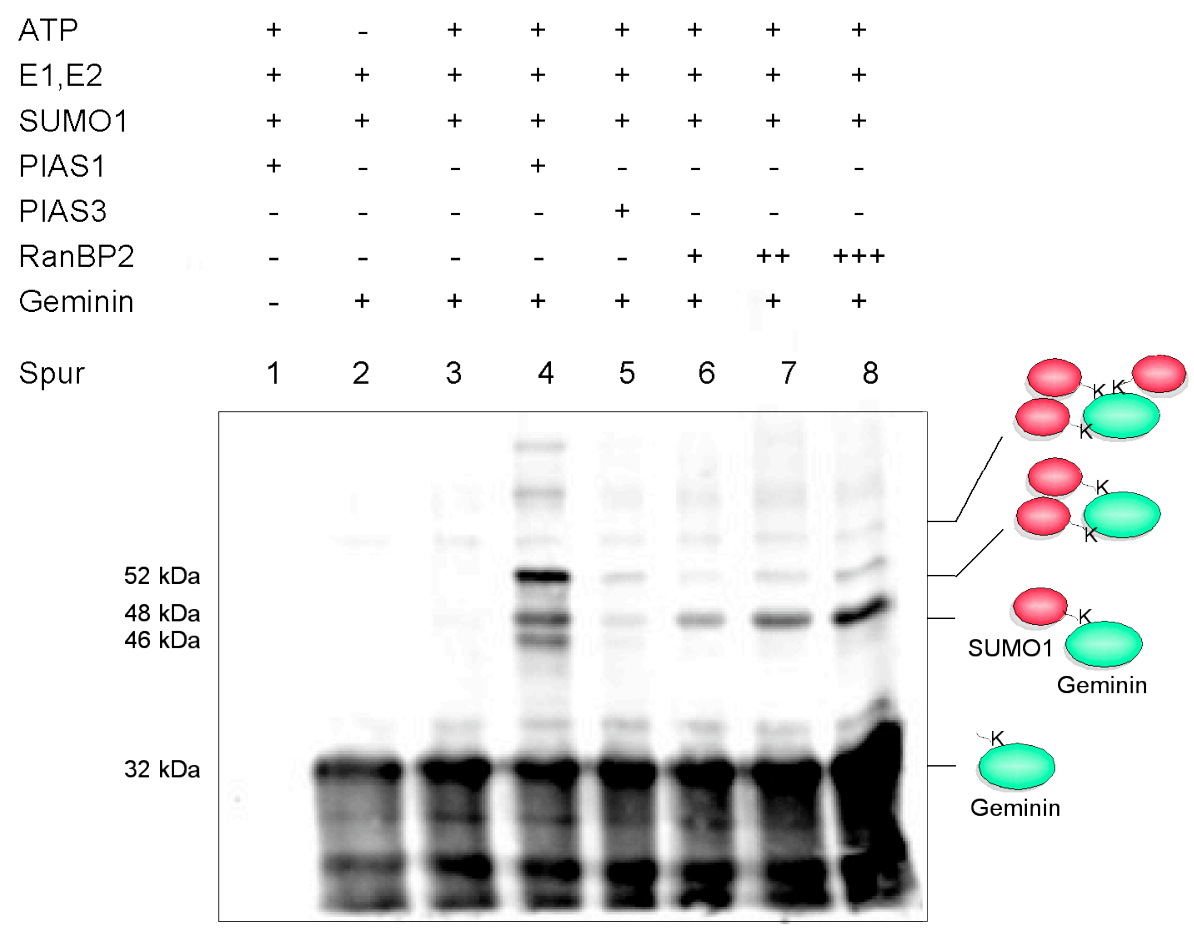

b

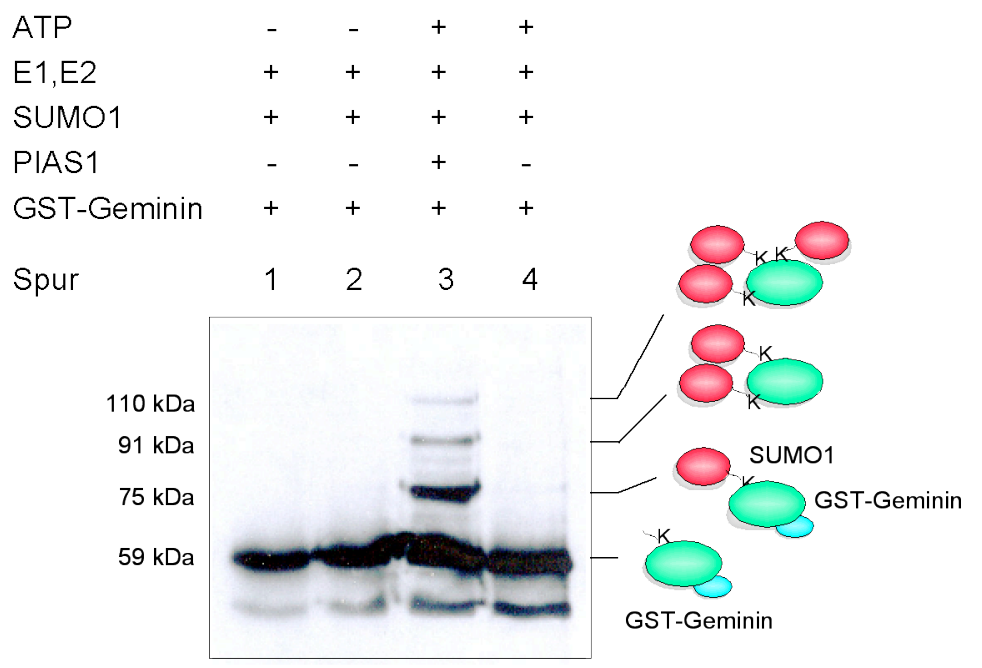

Abbildung 10. SUMO1-Modifikation von Geminin in vitro. (a) Rekombinantes Geminin und (b) GSTGeminin wurden als Substrat in Gegenwart von ATP und den aufgereinigten Komponenten SUMO1, E1, E2 und verschiedenen E3-Ligasen (PIAS1, PIAS3 und RanBP2) in vitro sumoyliert. Die Produkte wurden mittels SDS-PAGE und Western-Blot mit Anti-Geminin-Antikörper analysiert. (++) bzw. (+++) bedeutet die Zugabe der doppelten bzw. dreifachen Konzentration der Komponente, in diesem Fall RanBP2.

Bei Anwesenheit einer E3-Ligase im Reaktionsansatz wurde dagegen höher migrierendes Geminin-Protein registriert (Abbildung 10a, Spuren 4 bis 8). Die dominierende Bande lag bei Anwesenheit von PIAS1 bei 52 kDa und zwei weitere stärkere Banden erschienen bei 
46 und 48 kDa (Abbildung 10a, Spur 4). Die SUMOylierungsansätze mit zunehmender Konzentration an RanBP2 führten alle zur Detektion der höher migrierenden Bande von $48 \mathrm{kDa}$, bei der es sich vermutlich um SUMO1-konjugiertes Geminin handelte, da sich die unmodifizierte Bande von Geminin um 16 kDa verlagert hatte (Abbildung 10a, Spuren 6 bis 8). Noch weiter höher migrierende Banden wiesen auf die Anheftung mehrerer SUMO1-Proteine hin. Der Effekt von PIAS3 war nur sehr schwach (Abbildung 10a, Spur 5). PIAS1 und RanBP2 fungierten gegenüber Geminin somit als SUMO-E3-Ligasen und resultierten in der in vitro SUMOylierung von Geminin. Die Analyse wurde mit GSTfusioniertem Geminin wiederholt, um das Ergebnis zu unterlegen. Den Erwartungen entsprechend konnte auch GST-fusioniertes Geminin von PIAS1 mit SUMO1 in vitro modifiziert werden (Abbildung 10b).

\section{In vivo SUMOylierung von Geminin in HeLa-Zellen}

Um zu bestimmen, ob Geminin auch in vivo sumoyliert werden kann, wurde in humanen HeLa-Zellen die transiente Überexpression von SUMO1 vorgenommen. Da im Allgemeinen die Detektion von SUMO-konjugierten Substraten oft schwierig ist, da der prozentuale Anteil des zellulär in modifizierter Form vorliegenden Substrats sehr gering ist, wurde zudem ein durch den CMV-Promotor gesteuertes Plasmid mit inserierter Geminin-cDNA mit SUMO1 co-exprimiert. Als Negativ-Kontrolle fungierte SUMO1- $\triangle$ C7YFP, welches SUMO1 ohne das zur Konjugation an ein Substrat erforderliche GlycinGlycin-Motiv darstellt. Aktives SUMO1 wurde durch SUMO1- $\triangle$ C4-YFP repräsentiert, wobei es sich um das bereits prozessierte SUMO1 handelt, welches ebenso wie SUMO1HA die Fähigkeit zur Konjugation an ein Akzeptorlysin hat. Die Aufbereitung der Zellen zur Proteinextraktion wurde unter Standardbedingungen durchgeführt. Unmodifiziertes Geminin wurde bei $32 \mathrm{kDa}$ detektiert, aber es wurde weder für endogenes noch für exogenes Geminin eine zusätzliche, höhermolekulare Form von Geminin visualisiert (Abbildung 11a). Die über 52 kDa migrierenden Banden wurden unter den angewendeten Bedingungen für die Proteinextraktion stets detektiert und schienen eine unspezifische Reaktion des Geminin-Antikörpers mit den Proteinen des Zelllysats zu sein (Abbildung 11a). Proteinbanden, welche unterhalb der $32 \mathrm{kDa}-B a n d e$ von Geminin laufen, sind Resultat der Spaltung durch Caspase-3 (Roukos et al., 2007). Diesen kürzeren Varianten von Geminin fehlen mehrere Aminosäuren des C-Terminus (Roukos et al., 2007).

Da es für die in vitro SUMOylierung von Geminin der Anwesenheit einer E3-Ligase bedurfte, das Expressionslevel von PIAS1 in HeLa-Zellen jedoch ausgesprochen gering war, wurde im Folgenden die Co-Expression von der E3-Ligase PIAS1 und FLAGGeminin vorgenommen. 
a

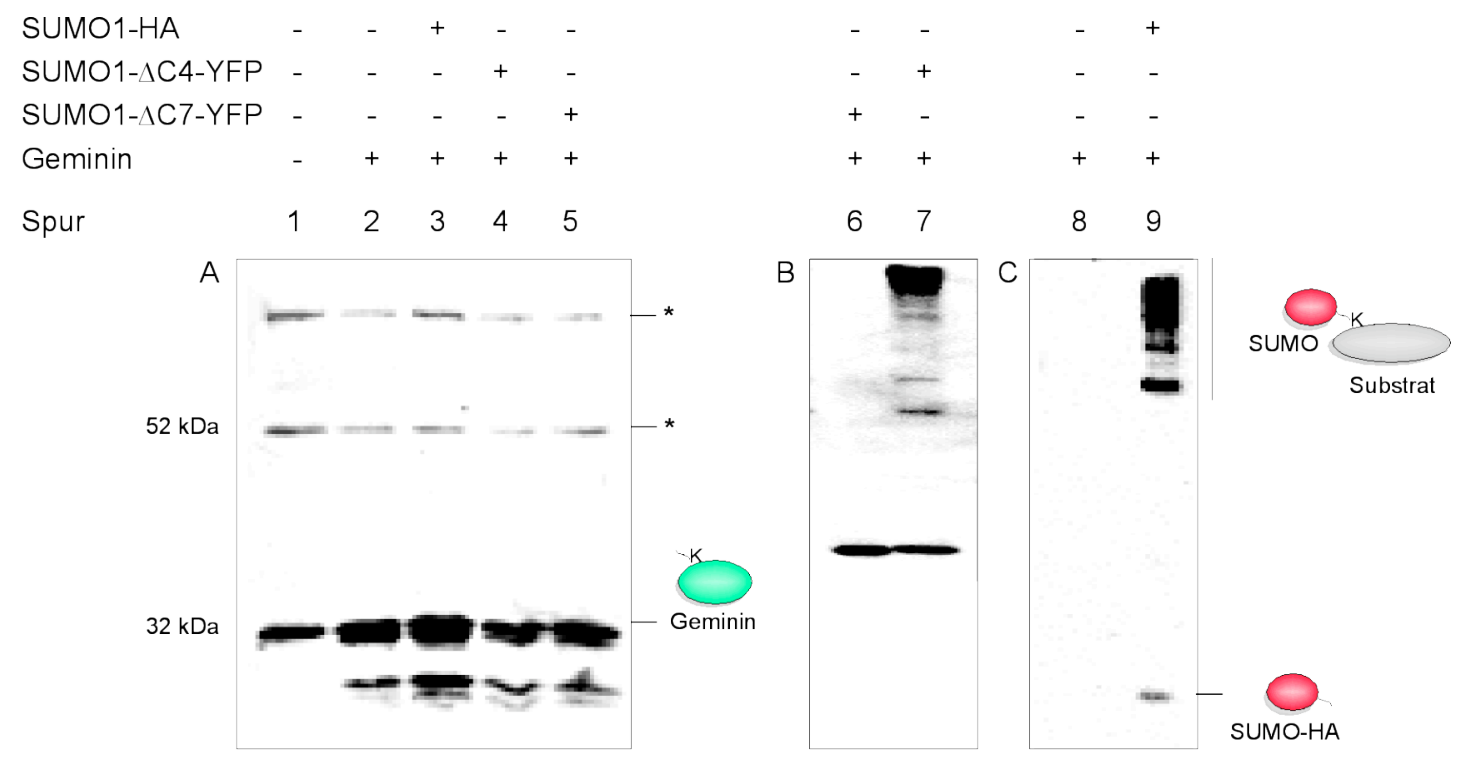

b

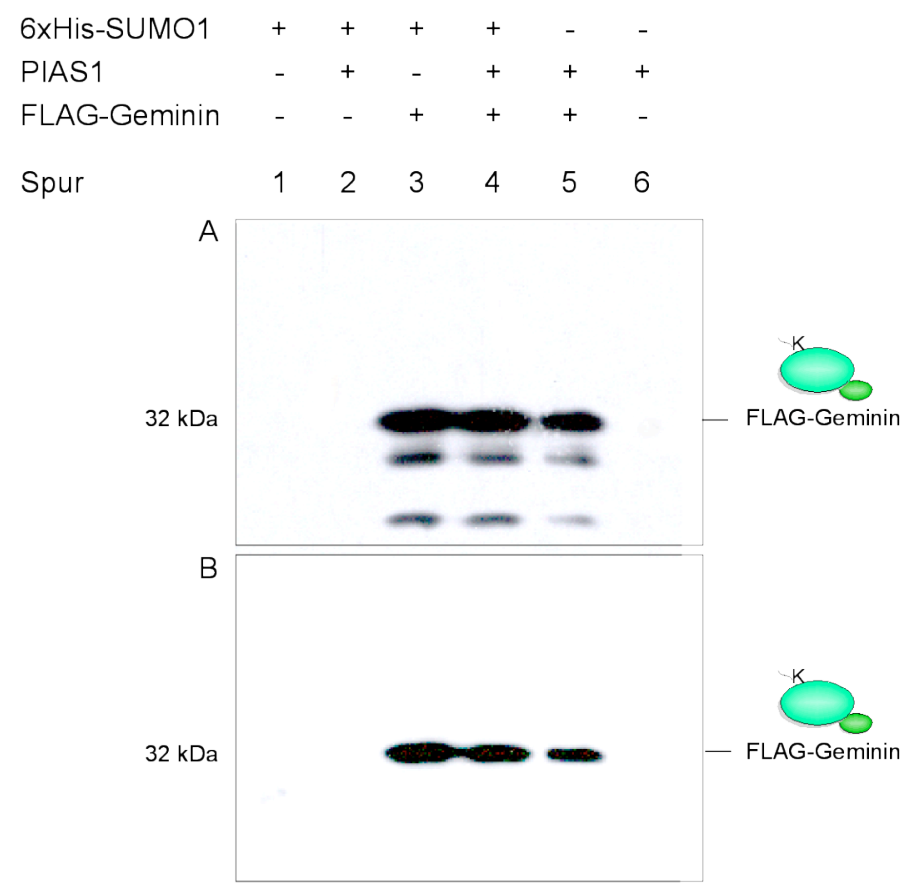

Abbildung 11. Überexpression von SUMO1- und Geminin-Plasmid-Konstrukten in HeLa-Zellen. (a) Western Blot Analyse von HeLa-Extrakten nach transienter Transfektion von SUMO1-YFP, HA-SUMO1 und Geminin mit (A) Anti-Geminin-, (B) Anti-GFP- (detektiert auch YFP) und (C) Anti-HA-Antikörper. (B) und (C) dienen als Kontrolle und weisen in Spur 7 bzw. 9 sämtliche, an SUMO1- konjugierte Substrate nach. SUMO1$\Delta \mathrm{C} 7$ stellt die inaktive Form von aktivem SUMO1- $\Delta \mathrm{C} 4$ dar und dient als Negativ-Kontrolle. ( $\left.{ }^{*}\right)$ kennzeichnen unspezifische Reaktionen des Anti-Geminin-Antikörpers (b) Western Blot Analyse von Proteinextrakten aus HeLa-Zellen nach Überexpression von 6xHis-SUMO1, FLAG-Geminin und PIAS1 mit (A) Anti-Geminin- und (B) Anti-FLAG-Antikörper. Die Reaktionen wurden jeweils mit den entsprechenden Leervektoren aufgefüllt.

Trotz Überexpression von PIAS1 konnte jedoch kein SUMO1-modifiziertes Geminin mittels Western Blot Analyse und Detektion mit Anti-Geminin- und Anti-FLAG-Antikörper nachgewiesen werden (Abbildung 11b). Ebenso konnte durch Zugabe von 
N-Ethylmaleimid zur Reprimierung der Isopeptidase-Aktivität der SENPs der Nachweis von sumoyliertem Geminin nicht erbracht werden (Daten nicht gezeigt).

In einer Zelle liegt zu einer bestimmten Zeit nur ein kleiner Prozentsatz der SUMOSubstrate in modifizierter Form vor, da der Prozess der SUMOylierung reversibel und hochdynamisch ist. Um dennoch die modifizierte Form von Geminin in vivo nachweisen zu können, wurde ein zelluläres SUMOylierungssystem verwendet, bei dem HeLa-Zellen ein in ihr Genom stabil integriertes 6xHis-SUMO1 besitzen (Girdwood et al., 2003). Nach transienter Transfektion mit CMV-gesteuertem Geminin oder dem Leervektor wurden die HeLa-Zellen mit dem chaotropen Salz Guanidiumhydrochlorid lysiert. Die stark denaturierenden Bedingungen bei dieser Methode der Lyse verhindern die proteolytische Aktivität der Isopeptidasen. Die mit 6xHis-SUMO1 modifizierten Proteine wurden dann mittels Bindung an eine Nickel-NTA-Agarose-Matrix aufgereinigt. Der Erfolg der Aufreinigung von 6xHis-SUMO1-Substraten wurde am Beispiel der vollständigen SUMOylierung von RanGAP1, welches bereits in der Zelle in modifizierter Form vorliegt (Mahajan et al., 1997), belegt. Unmodifiziertes RanGAP1 läuft bei $70 \mathrm{kDa}$ (Abbildung 12b, Spur 2), an SUMO1konjugiertes RanGAP1 migriert bei 90 kDa im SDS-Gel (Abbildung 12b, Spur 2 und 4)

Die Western Blot Analyse eluierter Proteine ließ im Falle des transient überexprimierten Geminins eine um 16 kDa verlagerte Bande von 48 kDa detektieren (Abbildung 12a, Spur 6). Während die Modifikation mit 6xHis-SUMO1 von exogen angereichertem Geminin belegt werden konnte, konnte kein Nachweis für die SUMOylierung von endogenem Geminin erbracht werden, wie in Abbildung 12b, Spur 5, zu sehen ist. Die Spezifität dieses Ergebnisses wurde dabei durch eine zeitgleiche Durchführung der Prozedur mit herkömmlichen HeLa-Zellen, welche nicht 6xHis-SUMO1 enthalten, demonstriert (Abbildung 12a, Spur 1 und 4). Es konnte gezeigt werden, dass Geminin bei Co-Expression mit SUMO1 auch in vivo sumoylierbar ist.

\section{Analyse von Geminin-Mutanten}

Die Konjugation von SUMO geschieht an ein Lysin des Akzeptorproteins. Um herauszufinden, welches Lysin in der Aminosäure-Sequenz von humanem Geminin modifiziert wird, wurden mehrere Konstrukte mit einzelnen Punktmutationen konstruiert, bei denen das entsprechende Lysin durch ein Arginin ersetzt wurde. Von den insgesamt 20 Lysinen der Aminosäure-Sequenz von humanem Geminin wurden 12 mutiert. Des Weiteren wurde ein Konstrukt generiert, bei dem beide Lysine in dem vorhergesagten SUMO-Motiv 2 (Abbildung 9) mutiert waren. Zudem wurde ein Konstrukt ohne die N-terminalen 17 Aminosäuren, welche das potentielle SUMO-Akzeptormotiv 1 beinhalten, generiert. 
a

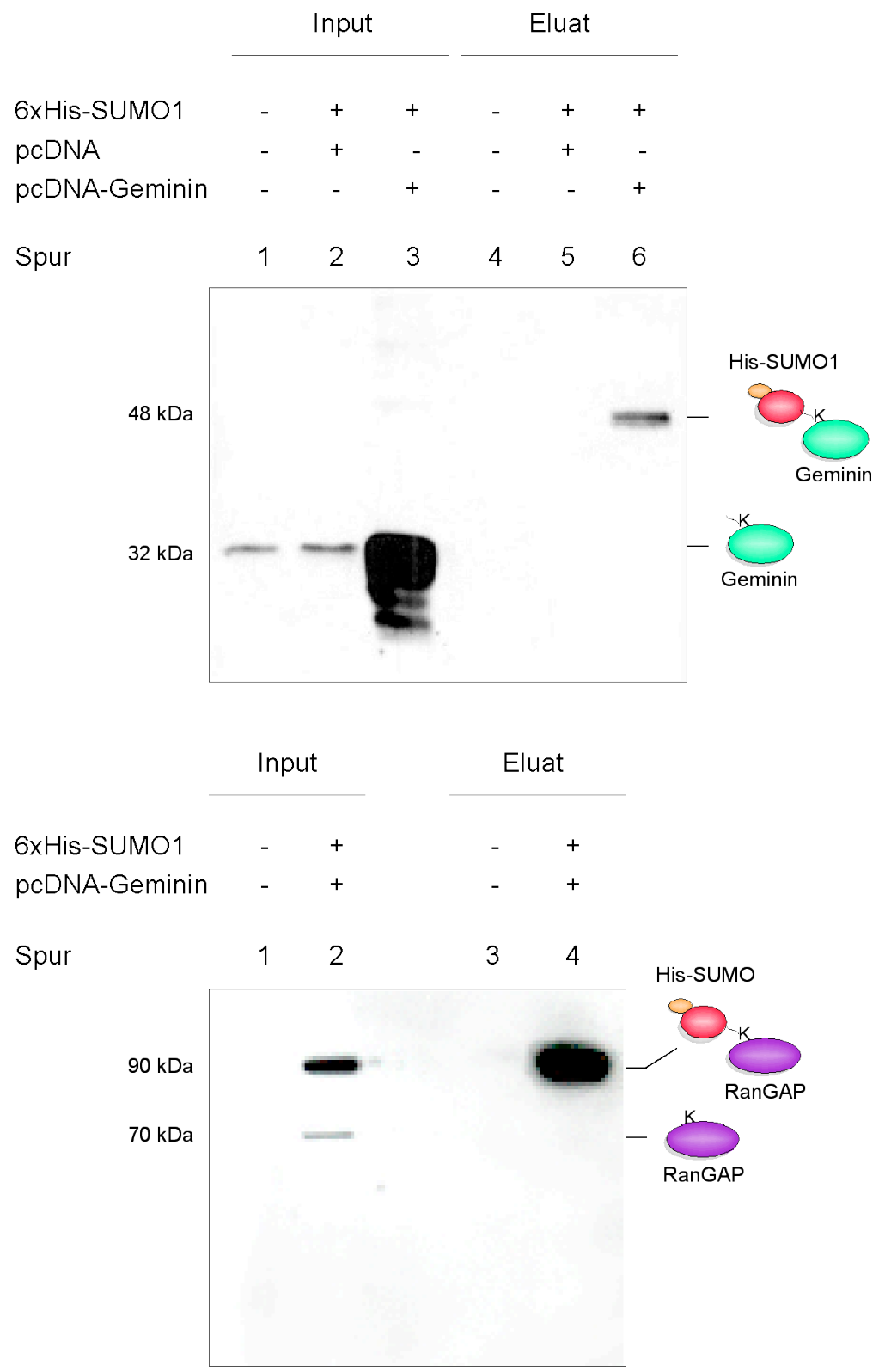

Abbildung 12. Geminin kann in Säugerzellen mit SUMO1 modifiziert werden. (a) Western Blot Analyse der In vivo SUMOylierung von Geminin mit stabil in HeLa-Zellen integriertem 6xHis-SUMO1. Der zur Detektion verwendete Antikörper ist gegen Geminin gerichtet und erkennt Geminin bei 32 kDa. Während 6xHis-SUMO1-gebundenes endogenes Geminin nicht nachgewiesen werden konnte, wurde transient überexprimiertes Geminin bei 48 kDa detektiert und war damit mit SUMO1 modifiziert. Als Kontrolle wurde der leere pcDNA-Vektor überexprimiert. Der Input entspricht $0,33 \%$ des initialen Volumens der lysierten Zellen vor Aufreinigung von SUMO1-His und Substraten. (b) Western Blot Analyse mit Anti-RanGAP1 tail-Antikörper zur Überprüfung der Aufreinigung.

Die Mutante, welche nicht das für die spezifische Konjugation von SUMO1 erforderliche Lysin besitzt, sollte dementsprechend auch nicht modifiziert werden. Die PlasmidKonstrukte wurden in dem mit stabil inseriertem 6xHis-SUMO1 HeLa-Zellkultursystem überexprimiert und der Aufreinigung über den $6 \times$ His-Tag unterzogen. Alle Mutanten wurden in den HeLa-Zellen sumoyliert (Abbildung nicht gezeigt). Da bei keiner der Mutanten ein vollständiger Verlust der SUMOylierung nachgewiesen werden konnte, 
konnte nicht ermittelt werden, welches Lysin spezifisch für die Konjugation von SUMO1 an Geminin ist.

Das bzw. die Akzeptorlysin(e) kann auch mittels Sequenzanalyse von sumoyliertem Geminin durch Massenspektometrie ermittelt werden. Zu Sequenzierung bedarf es dabei einer adäquaten Menge des modifizierten Proteins. Zur Herstellung von sumoyliertem Geminin wurde Rahmen dieser Arbeit daher ein Expressionssystems in E. coli angewendet, das die Herstellung von mit SUMO-modifiziertem rekombinantem Protein ermöglicht (Uchimura, 2004). Mit Hilfe dieser Methode konnte jedoch kein SUMO1Geminin gewonnen werden (Daten nicht gezeigt), da in dem System keine E3-Ligasen vorhanden sind, welche zur SUMOylierung von Geminin erforderlich sind. Es wurde gezeigt, dass Geminin in vitro und in vivo sumoylierbar ist, aber das mit SUMO1 modifizierte Lysin des Geminin-Proteins konnte nicht identifiziert werden.

\section{Konditionale Inaktivierung von Geminin in der Maus}

Um einen Einblick in die funktionale Rolle von Geminin während der Embryonalentwicklung in Säugetieren zu gewinnen, wurde eine gezielte Inaktivierung des GemininGens mit Hilfe eines konditionalen Knockouts in der Maus vorgenommen. Vor Erstellung eines Knockout-Konstruktes des Geminin-Gens wurde in Erwägung gezogen, dass homozygote Mäuse möglicherweise einen embryonal lethalen Phänotyp haben, da Geminin eine globale Funktion in verschiedenen Prozessen der Zellproliferation wie auch -differenzierung besitzt. Ein Einblick in die Embryonalentwicklung oder Analyse von adulten Tieren wäre hierbei nicht möglich. Es wurde daher die Generierung eines konditionalen Knockout-Konstruktes gewählt, um das Geminin-Allel in einem spezifischen Gewebe zu einem bestimmten Zeitpunkt zu deletieren. Zur Klonierung eines konditionalen Targeting-Vektors wurde das Cre/LoxP System eingesetzt (Sauer, 1998). Im Allgemeinen bedarf es dazu zweier transgener Mauslinien. Die erste Linie trägt das Gen von Interesse, welches vollständig oder von dem nur ein Segment mit zwei in derselben Orientierung vorliegenden LoxP-Sequenzen flankiert wird (gefloxtes Gen). Die normale Gen-Aktivität sollte durch diese 34 bp langen Sequenzen nicht gestört sein. Die LoxP-Sequenzen sind Erkennungssequenzen für die so genannte Cre Rekombinase, welche durch homologe Rekombination die LoxP-Stellen lokalisiert und das dazwischen liegende Fragment deletiert. Die zweite Mauslinie beinhaltet ein Transgen, welches die Expression der Cre Rekombinase unter Kontrolle eines ausgewählten Promotors oder Enhancer-Elements steuert. Bei Kreuzung beider Linien wird das gefloxte Allel deletiert, sobald die Cre Rekombinase exprimiert wird. Die Null-Mutation geschieht somit in Abhängigkeit der regula- 
torischen Einheit der Cre Rekombinase ausschließlich in ausgewählten Zellen oder Geweben.

Der genomische Bereich des Maus-Geminin-Gens ist auf Chromosom 13 zwischen 24.843.714 bp bis 24.853.806 bp lokalisiert (NCBI: NC_000079.5; Ensembl Gen ID: ENSMUSG00000006715). Das Gen umfasst insgesamt 10,09 kb und setzt sich aus sieben Exons zusammen. Die Länge des Transkripts beträgt 1.127 bp (206 As). Es ist eine Isoform von Geminin-mRNA bekannt, bei der es sich möglicherweise um eine alternative Splicevariante handelt, deren Translationsprodukt bisher vornehmlich jedoch nur im Testis detektiert wurde. Während Maus-Geminin mit einem vorhergesagten Molekulargewicht von 23,3 kDa (Homo sapiens: 23,6 kDa) im Western Blot bei $32 \mathrm{kDa}$ (Homo sapiens: $33 \mathrm{kDa}$ ) läuft, wurde die besagte Isoform bei $20 \mathrm{kDa}$ detektiert (Eward et al., 2004). Eine detaillierte Analyse der online zur Verfügung stehenden Datenbanken (NCBI; Ensembl) bot keinen ersichtlichen Hinweis auf Enhancer oder andere cis-regulatorische Elemente in der genomische Sequenz des Geminin-Gens oder in angrenzenden Regionen.

Das Start-Codon (ATG) befindet sich im zweiten Exon. Um zu gewährleisten, das keine verkürzte Variante des Geminin-Gens hergestellt werden kann, wurden die LoxPSequenzen 143 bp aufwärts von dem zweiten, das Start-Codon einschließende, Exon und 182 bp abwärts von dem dritten Exon inseriert. Die komplette, von LoxP-Sequenzen flankierte und später deletierte Region schloss dabei das Start-Codon ein und umfasste eine Sequenz von insgesamt 2947 bp.

\section{Generierung eines konditionalen Knockout-Konstruktes mittels Recombineering}

Um DNA von dem gewünschten Geminin-Lokus zu erhalten, wurde eine Maus PAC-Bank gescreent (Osoegawa et al., 2000). Nach erfolgreicher Hybridisierung der Phagen-Bank mit einer radioaktiv markierten Sonde von Geminin-cDNA wurden vier individuelle Klone identifiziert. Die Klone wurden mittels PCR-Amplifikation von den genomischen GemininLokus flankierenden DNA-Fragmenten überprüft. Detaillierte Angaben zu dem gesamten Verfahren sind im Abschnitt „Material und Methoden“ erläutert. Drei der fünf PAC-Klone enthielten den gewünschten genomischen Bereich. Einer dieser positiven Klone (RPCIP711F02244Q2) wurde letztlich verwendet, um das konditionale KnockoutTargeting-Konstrukt zu klonieren.

Der Targeting-Vektor wurde nach der Methode des (engl.) „Recombineering” oder „Recombinogenic Engeneering” hergestellt (Zhang et al., 2000; Ellis et al., 2001; Muyrers et al., 2001; Copeland et al., 2001). Das System zur Subklonierung von DNA beruht auf homologer Rekombination in E. coli, vermittelt durch die Red-Proteine des Bakteriophagen Lambda. Im Vergleich zur konventionellen Klonierung bedarf es für das 
Recombineering keiner einzigartigen Restriktionsschnittstellen oder DNA-Ligasen (Zhang et al., 2000; Muyrers et al., 2001; Copeland et al., 2001).

Im ersten Schritt wurde ein Fragment von 16,5 kb, die Target-Region des Geminin-Gens beinhaltend, aus dem ausgewählten PAC-Klon via Recombineering in das Retrieval Plasmid PL253 subkloniert (Abbildung 13a; Retrieving). PL253 basiert auf dem pBluescript-Vektor und enthält eine durch den MC1 Promotor gesteuerte ThymidinKinase-(TK) Kassette, welcher der Negativ-Selektion in den ES-Zellen dient. Der Prozess der homologen Rekombination zur Subklonierung von PAC-DNA in pBluescript nennt sich (engl.) „Gap repair”. Der hierzu verwendete linearisierte Vektor PL253 enthält SequenzHomologien von 300 bis 500 bp, welche den gewünschten DNA-Abschnitt flankieren und homolog zu den zu modifizierenden Regionen sind. Der Austausch der Fragmente konnte so über homologe Rekombination stattfinden.

In einem nächsten Schritt wurde 143 bp aufwärts des zweiten Exons eine von LoxPSequenzen flankierte Neo-Kassette inseriert (Abbildung 13a; Erstes Targeting). Die Kassette wurde durch Expression der Cre Rekombinase in E. coli Zellen entfernt, eine einzelne LoxP-Sequenz hinterlassend. Des Weiteren wurde eine zweite Neo-Kassette 182 bp abwärts des dritten Exons mittels Recombineering eingefügt. In diesem Fall flankierten zwei Frt-Sequenzen das Neo-Gen sowie abwärts der Neo-Kassette und Frt-Sequenz eine weitere LoxP-Sequenz vorhanden war (Abbildung 13a; Zweites Targeting). Bei diesem Konstrukt handelt es sich um den finalen Targeting-Vektor für den konditionalen Knockout.

Die Expression des Neo-Gens verleiht Resistenz gegenüber Geneticin (G418). Durch Zugabe dieses Antibiotikums in das ES-Zellmedium dient die Neo-Kassette der Selektion von Zellen mit positiven Rekombinationsereignissen. Die Neo-Kassette steht unter der Kontrolle des eukaryotischen PgK Promotors sowie unter der des prokaryotischen em7 Promotors, welches die Expression sowohl in E. coli Bakterien wie auch in den eukaryotischen ES-Zellen ermöglichte. Da sich nach Targeting des Allels in einigen Fällen die Expression des Neo-Gens durch den PgK Promotor auf den Phänotyp auswirkt bzw. um transkriptionelle Interferenz mit dem natürlichen Transkriptionsprogramm zu vermeiden, kann sie durch die flankierenden Frt-Sequenzen optional in den ES-Zellen oder den Mäusen entfernt werden. Sofern Geminin ausgeknockt würde, wäre die Deletion der Kassette eingeschlossen.

Um die Funktionalität der Frt-Sequenzen zu überprüfen, wurde das Targeting-Konstrukt in E. coli Zellen transformiert, welche die Flpe Rekombinase exprimieren (Abbildung 13a; Flpe Rekombinase Test). 
a

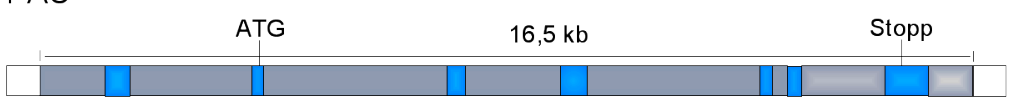

Retrieving
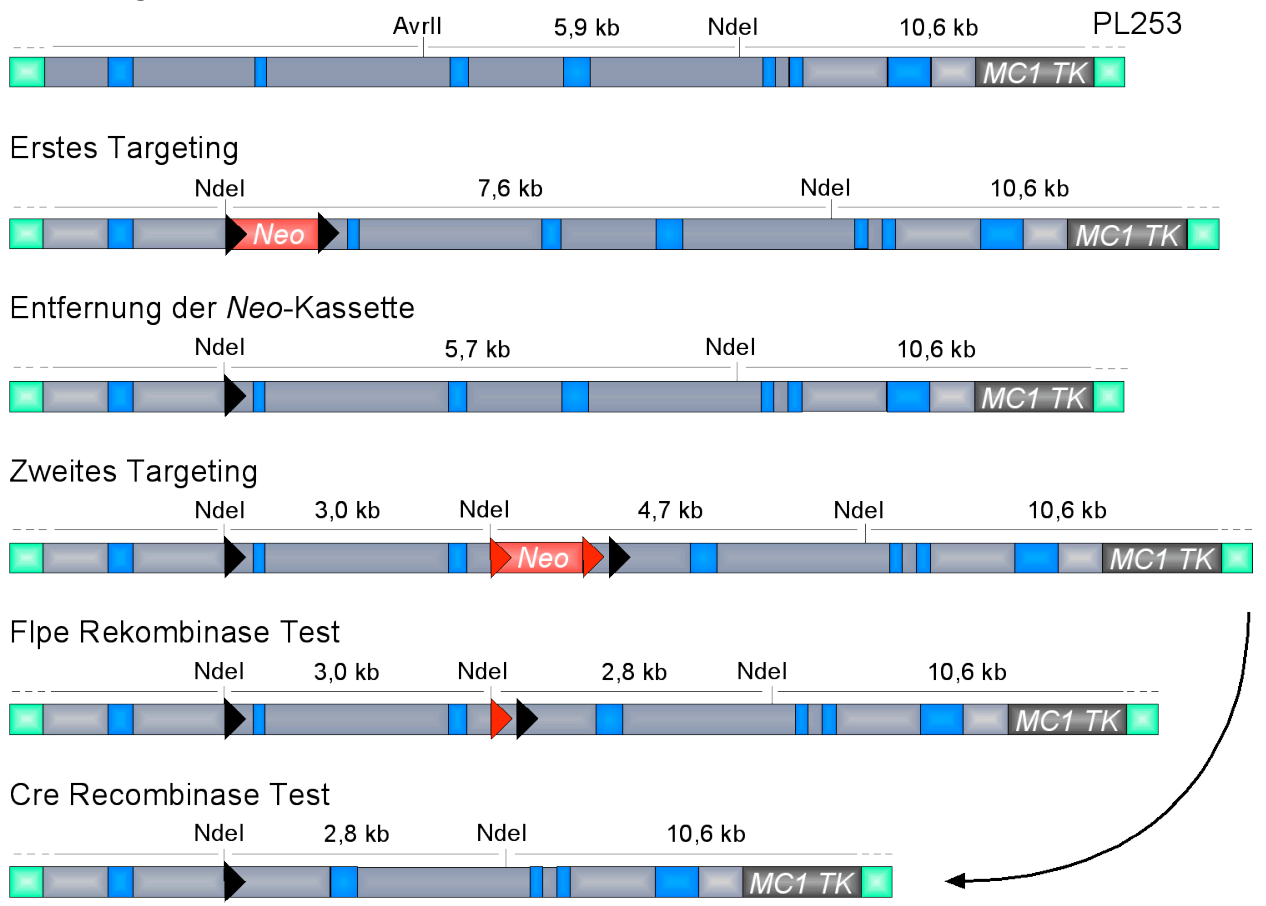

b

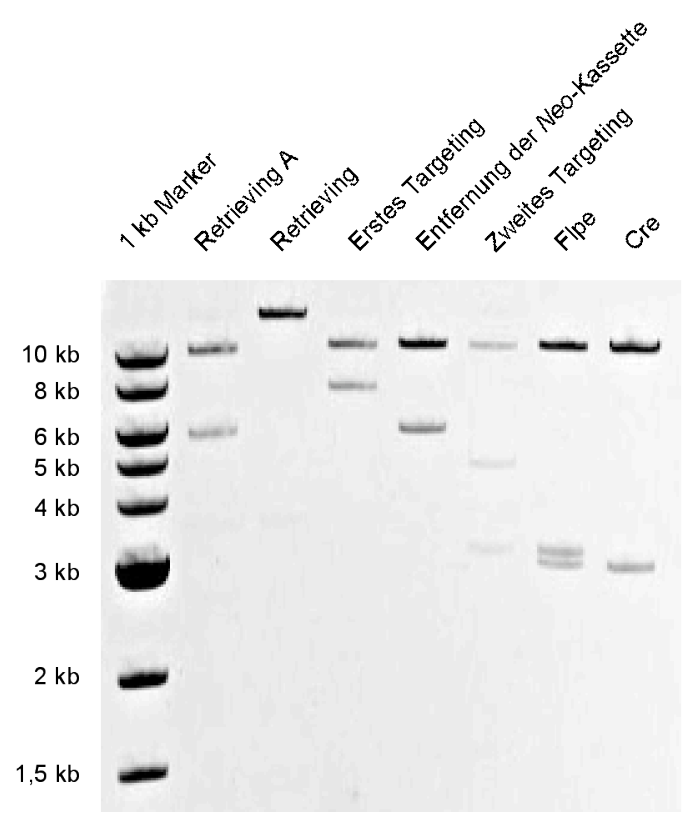

Abbildung 13. Herstellung und Analyse der Funktionalität des konditionalen Geminin Knockout Konstruktes. (a) Ein 16,5 kb Fragment genomische DNA, das vollständige Geminin Gen enthaltend, wurde aus dem PAC-Klon via (engl.) „Gap repair" in den PL253 Vektor subkloniert (Retrieving) und Schritt für Schritt mit den Targeting-Kassetten versehen. Blaue Kästen stellen codierende Exons dar, LoxP-Sequenzen sind durch schwarze Dreiecke, Frt-Sequenzen durch rote Dreiecke gekennzeichnet. (b) Restriktionsverdau der Plasmide mit $\mathrm{Ndel}$ in jedem Stadium der Herstellung des Knockout-Konstruktes. Die Ndel-Schnittstellen sind in (a) markiert und erwartete Fragmentgrößen sind angegeben. Retrieving A zeigt den Verdau des „Gap repair" Plasmides mit Avrll und Ndel. 
Ebenso wurde die Funktionalität der LoxP-Sequenzen analysiert, indem das KnockoutKonstrukt in die die Cre Rekombinase exprimierenden E. coli Zellen elektroporiert wurde (Abbildung 13a; Cre Rekombinase Test). Mit der Einführung der beiden Neo-Kassetten wurden zwei weitere Ndel Schnittstellen in das Targeting-Konstrukt eingebracht. Die einzelnen Schritte zur Klonierung und Überprüfung des Targeting-Vektors wurden mittels Restriktionsanalyse überprüft. Der Verdau mit Ndel ergab für jeden einzelnen Schritt ein spezifisches Restriktionsmuster (Abbildung 13b). Der Restriktionsverdau des Plasmides nach dem Retrieving mit Ndel führte nur zur Linearisierung der DNA und lieferte keine präzise Aussage über die Größe der DNA. Um dennoch eine korrekte Abschätzung der Plasmidgröße zu gewährleisten, wurde zusätzlich ein Doppelverdau mit Ndel und Avrll vorgenommen, welcher das Plasmid in zwei Fragmente von 10,6 und 5,9 kb Länge zerlegte (Abbildung 13a und b; Retrieving A).

Die modifizierten Regionen der verschiedenen Konstrukte wurden außerdem sequenziert, um ggf. Mutationsereignisse zu registrieren. Ebenso wurden das finale KnockoutKonstrukt an allen veränderten Regionen der genomischen Geminin Gensequenz und die Übergänge zum PL253 Vektor sequenziert. Es wurden dabei keine Mutationen festgestellt.

\section{Herstellung von homolog rekombinierten ES-Zellen}

Die Frequenz der homologen Rekombination in ES-Zellen hängt u. a. von der Länge der homologen Bereiche zwischen Konstrukt und Gen-Lokus ab. Um eine hohe Wahrscheinlichkeit von Rekombinationsereignissen zu gewährleisten, wurde das finale KnockoutTargeting-Konstrukt mit einem 3' Arm von einer Länge von 2,7 kb versehen, und die Länge des 5' Armes betrug 6,1 kb (Abbildung 14a).

Das konditionale Geminin-Knockout Konstrukt wurde zur Elektroporation in MPI-II ES-Zellen mit Hpal linearisiert. Es folgte die Selektion der transformierten ES-Zellen mit G418 (Geneticin) und Ganciclovir. Zellen, welche das Targeting-Konstrukt über homologe Rekombination in das Genom inseriert hatten, zeichneten sich aufgrund der vorhandenen Neo-Kassette durch Resistenz gegen G418 aus. Außerdem sollten diese ES-Zellen die TK-Kassette verloren haben, so dass sie in Gegenwart von Ganciclovir überleben konnten (Abbildung 14a).

Um die erfolgreiche homologe Rekombination des Targeting-Konstruktes mit der genomischen DNA der ES-Zellen nachweisen zu können, wurde eine Southern Blot Strategie entwickelt. Mittels PCR wurden zwei Sonden erzeugt, deren komplementäre Sequenzen außerhalb der Regionen des 3' und 5' Arms lagen (Abbildung 14a). 
a
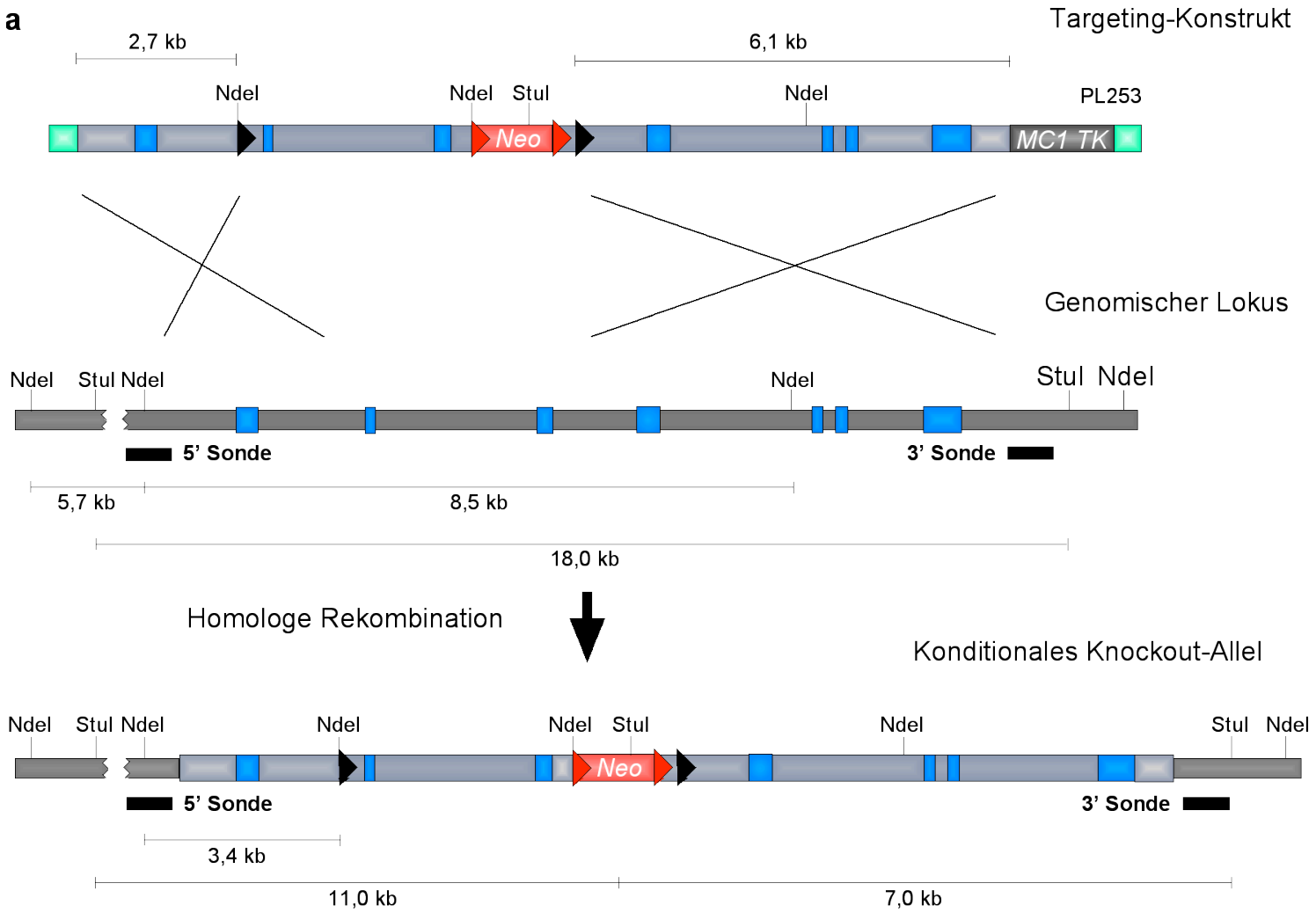

b

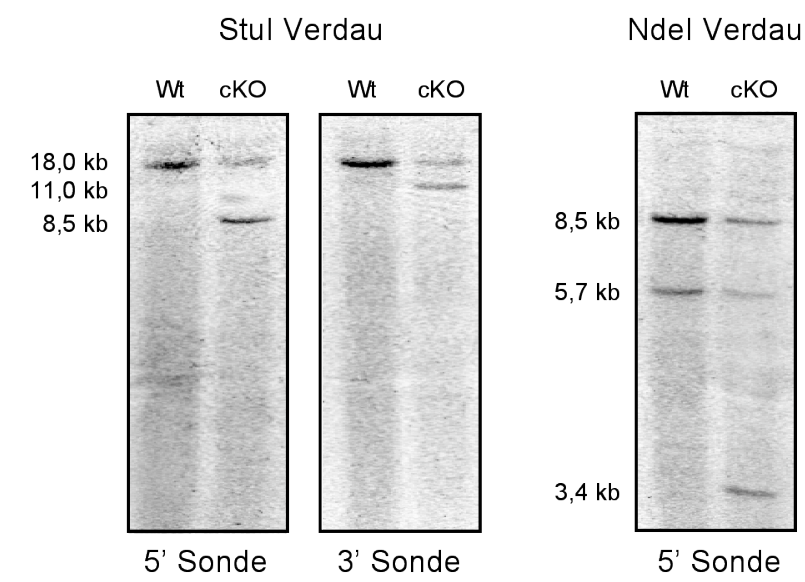

Abbildung 14. Identifizierung von ES-Zellklonen mit korrekt inseriertem Geminin Targeting-Plasmid. (a) Homologe Rekombination zwischen dem Targeting-Konstrukt und dem genomischen Geminin-Lokus. Bei Verdau mit Stul weisen korrekt getargetete ES-Zellen bei Southern Blot Analyse mit der 5' Sonde zusätzlich zu der 18 kb Wt-Bande eine Bande von 8,5 kb (cKO, konditionaler Knockout) auf; Hybridisierung mit der 3' Sonde liefert außerdem eine $11 \mathrm{~kb}$ Bande. Der Verdau mit Ndel und Detektion mit der 5' Sonde ist zu den WtFragmenten von 8,5 und 5,7 kb im Falle des konditionalen Knockout-Allel eine weitere Bande von 3,4 kb zu erwarten. (b) Darstellung des Ergebnisses der Southern Blot Analyse des korrekt inserierten Klons Z3-147.

205 ES-Zell-Klone überstanden die Positiv/Negativ-Selektion mit G418 und Ganciclovir und wurden mit Hilfe der Southern Blot Technik analysiert. Die genomische DNA wurde aus den einzelnen ES-Zell-Klonen isoliert und mittels Restriktionsenzymen verdaut. Es wurden Enzyme vermieden, welche leicht durch CpG-Methylierung in oder in der Nähe von den Restriktionsschnittstellen in ihrer Aktivität hätten blockiert werden können. 
Für die 3' Sonde wurde die DNA mit Stul verdaut und für die 5' Sonde wurde zum einen mit Stul, zum anderen mit Ndel verdaut. Mit Insertion des Targeting-Konstruktes in die ES-Zell-DNA war eine weitere Stul-Schnittstelle vorhanden. Bei korrektem Targeting wurde beim Restriktionsverdau mit Stul und Detektion mit der 5 ' Sonde ein Fragment von 8,5 kb statt wie beim Wt-Allel von 18 kb erwartet. Die Hybridisierung mit der 3' Sonde sollte ein Fragment von $11 \mathrm{~kb}$ Länge statt der $18 \mathrm{~kb}$ von $W t$-ES-Zellen hervorbringen. Die 5' Sonde ist komplementär zu einer eine Ndel-Schnittstelle beinhaltenden Sequenz abwärts vom Geminin-Lokus. Bei Verdau mit Ndel und Southern Blot Analyse mit der 5' Sonde wurden somit in Wt-Zellen zwei Banden (8,5 und 5,7 kb) nachgewiesen. Da in das Targeting-Konstrukt mit der Neo-Kassette aufwärts des zweiten Exons eine weitere $\mathrm{Ndel}$ Schnittestelle eingebracht worden war, war nach homologer Rekombination mit der WtDNA eine weitere Bande von 3,4 kb zu erwarten. Von den ES-Zell-Klonen waren drei Klone sowohl für die 5' als auch für die 3' Sonde positiv (Abbildung 14b). Alle drei Klone (Z3-68, Z3-108 und Z3-147) wurden zur Herstellung von Maus-Chimären verwendet.

\section{Herstellung von Maus-Chimären}

Zur Gewinnung von Maus-Chimären wurden die drei positiven ES-Zell-Klone separat expandiert, mit CD ${ }^{\circledR} / I C R$ Embryonen im 16-Zell-Stadium aggregiert und bis zum Blastozysten-Stadium kultiviert. Die Blastozysten wurden in den Ovidukt scheinschwangerer Mäuse transferiert und die daraus hervorgehenden Jungtiere wurden aufgrund ihrer Fellfarbe selektiert. Da die MPI-II ES-Zellen einem 129er Stamm bräunlich(agouti) gefärbter Mäuse entstammen und die CD ${ }^{\circledR} / \mathrm{ICR}$ Embryonen von Albino-Tieren, sollten chimäre Mäuse eine gemischte Fellfarbe aufweisen. Männliche Chimären mit einem Anteil von 60 bis $70 \%$ agouti Fellfarbe wurden zur Identifikation von KeimbahnChimären mit CD1 Weibchen verpaart. Das erste Zeichen für eine erfolgreiche KeimbahnTransmission ist das Erscheinen von Jungtieren mit einer agouti Fellfarbe. Tiere, welche ausschließlich von Spermien der CD1 Wirtsembryonen entstammen, würden eine weiße Fellfarbe aufweisen. Alle drei zur Aggregation verwendeten ES-Zell-Klone führten zur Übertragung des Geminin-Knockout-Allels über die Keimbahn, was sowohl anhand der agouti Fellfarbe, wie auch mittels PCR-Genotypisierung bestätigt werden konnte (Abbildung 15b). Sofern die heterozygot gefloxten Mäuse (fl) identifiziert worden waren, wurden sie zur Generierung von homozygot gefloxten Tieren ( $f / f l)$ untereinander verpaart. Homozygot gefloxte Mäuse waren lebensfähig, fertil und wiesen ein normales Verhalten und keinen offensichtlichen Phänotyp auf. Die Tiere einer der aus den drei verschiedenen ES-Zell-Klonen hervorgegangenen Mauslinien (Klon Z3-108) wiesen unabhängig vom Genotyp ( $W t, f l, f l / f)$ zum Teil einen Hydrocephalus und Kleinwuchs auf. 
Für weitere Verpaarungen, Rückkreuzung in den $\mathrm{CD} 1^{\circledR} / \mathrm{ICR}$ Hintergrund und den konditionalen Knockout des Geminin-Allels wurde daher im Folgenden ausschließlich die Linie Z3-147 verwendet.

\section{Konditionaler Knockout von Geminin mit Emx $1^{\text {IREScre }}$}

Die Expression von Geminin ist im Neocortex der Maus regional auf die SVZ und VZ beschränkt. In der vorliegenden Arbeit wurde zur gezielten Inaktivierung von Geminin die transgene Emx1/REScre -Mauslinie gewählt, da das Expressionsmuster von Geminin mit dem der Cre-Linie im Neocortex überlappt. Bei der transgenen Emx $1^{\text {IREScre }}$-Linie wurde durch homologe Rekombination ein IRES- (engl. „Internal ribosome entry site“) Cre-Gen in das Exon des Emx1-Gens inseriert, welches die 3' untranslatierte Region codiert (Gorski et al., 2002). Die Expression der Cre Rekombinase sowie das endogene Emx1Gen unterliegen somit beide der Kontrolle des Emx1-Promotors. Emx1 codiert für ein Homeodomän-Protein, das sowohl in Vorläuferzellen des dorsalen Telencephalons wie auch in postmitotischen Neuronen im medialen, dorsalen und lateralen Cortex exprimiert wird. Der die Emx1/REScre Rekombinase steuernde Promotor wird ab E9.5 in den cortikalen Vorläuferzellen aktiviert und die vollständige Rekombination ist in E12.5 gewährleistet (Gorski et al., 2002). Die konditionale Inaktivierung in einer ein gefloxtes Allel tragenden Mauslinie durch Verpaarung mit Emx1 $1^{\text {RESCre }}$ ist somit zu Beginn der Neurogenese gegeben. In adulten Stadien erstreckt sich die Expression von Emx $1^{\text {IREScr }}$ zudem über Strukturen des Hippocampus und die Riechkolben (Gorski et al., 2002).

Zum konditionalen Knockout von Geminin im dorsalen Vorderhirn von Mäusen wurden die homozygot gefloxten Tiere (Geminin ${ }^{\text {fl }}$ ) mit heterozygoten Emx $1^{\text {IREScre }}$ Mäusen verpaart (Abbildung 15a). 25\% der Nachkommen waren wie erwartet sowohl heterozygot für das gefloxte Geminin-Allel wie auch für das die Rekombinase tragende Allel (Geminin ${ }^{f l}$; $\left.E m \times 1^{\text {IRESCre }}\right)$ und stellten damit rein heterozygote Geminin-Knockout-Mäuse dar. Um das Geminin-Gen auf beiden Allelen zu inaktivieren, wurden die Geminin ${ }^{f / f f l} ; E m \times 1^{\text {IREScre }}$ Tiere des weiteren mit homozygot gefloxten Geminin-Mäusen verpaart. Sowohl die heterozygoten, wie auch die homozygoten Embryonen, Neugeborenen und adulten Tiere wiesen äußerlich keine Abnormalitäten auf, verhielten sich normal und waren fertil.

Zur Genotypisierung wurde aus Schwanz-Biopsien DNA extrahiert und mittels PCR wurden ausgewählte Fragmente amplifiziert. Da das Ereignis der Rekombination zwischen dem konditionalen Geminin-Allel und Emx1 $1^{\text {RREScre }}$ durch die spezifische Expression der Cre Rekombinase auf Zellen des Telencephalons beschränkt ist und nicht im gesamten Embryo abläuft, wurde die Genotypisierung stets von dem gefloxten Geminin-Allel und in einer unabhängigen Reaktion von dem Rekombinase-Gen vor- 
genommen. Diese beiden modifizierten Allele sollten in jeder Zelle des Körpers vorhanden sein. Die Kombination der Primer K, N und L erlaubte die Unterscheidung von Wt- (530 bp, Primer $\mathrm{K}$ und $\mathrm{L}$ ) und gefloxtem Allel (740 bp, primer $\mathrm{N}$ und $\mathrm{L}$ ). Primer $\mathrm{K}$ ist komplementär zu einer Sequenz aufwärts vom dritten Exon. Unter den gegebenen PCRBedingungen war es nicht möglich, mit Primer $K$ und $L$ von dem gefloxtem Allel eine weitere, in diesem Fall störende Bande, zu amplifizieren, da dieses Fragment ein Länge von 2,4 kb besäße.

a

Genomischer Lokus (Geminin)

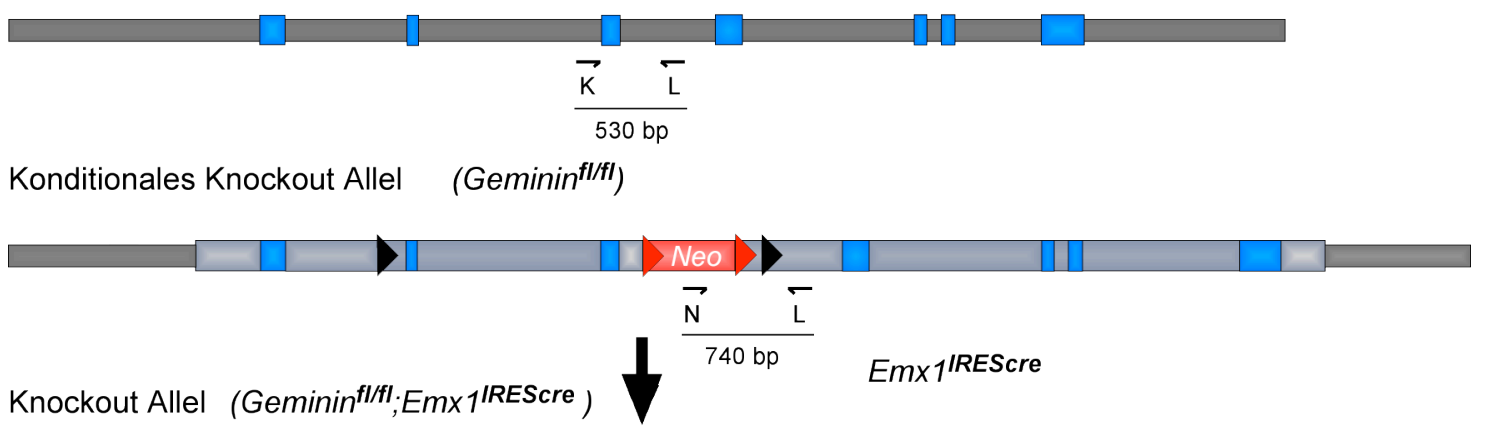

b

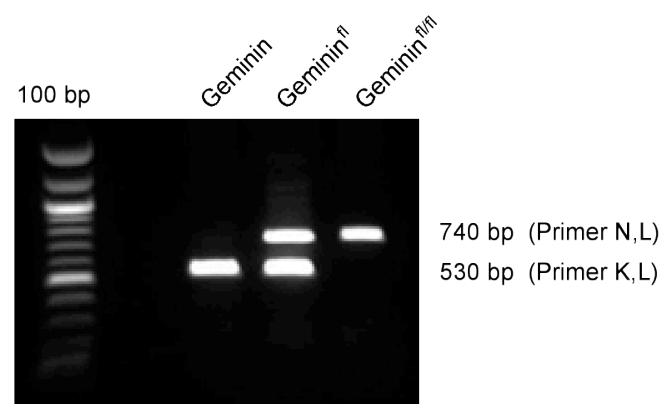

Abbildung 15. Generierung von konditionalen Knockout-Mäusen mit Emx1 ${ }^{\text {IREScre }}$. (a) Heterozygot gefloxte Geminin ${ }^{f l}$;Emx $1^{\text {IREScre }}$-Mäuse wurden mit homozygot gefloxten Geminin ${ }^{\text {fl/fl}}$-Tieren verpaart, um homozygote Tiere $\left(\right.$ Geminin $^{f / f f} ; E m x 1^{\text {IREScre }}$ ) zu erhalten. Primer N und L generieren ein für das Geminin Wt-Allel spezifisches Produkt von 740 bp; Primer K ist komplementär zu einer Sequenz in der Neo-Kassette und produziert bei Amplifikation mit Primer L ein Fragment von 740 bp Länge. (b) Genotypisierung der Wt (Geminin), heterozygot $\left(\right.$ Geminin $\left.^{f l}\right)$ und homozygot $\left(G_{\text {eminin }}^{f / f l}\right)$ gefloxten Tiere mittels PCR mit den Primern K, N und L.

Zur Verifizierung der konditionalen Inaktivierung des Geminin-Gens im dorsalen Telencephalon wurde eine In Situ Hybridisierung (ISH) mit einer gegen Geminin gerichteten RNA-Sonde vorgenommen. Da die Emx $1^{\text {IREScre }}$ Rekombinase erst ab E12.5 die vollständige Aktivität erzielt (Gorski et al., 2002), wurden für den Nachweis coronale Gefrierschnitte von Gehirnen aus Mäusen des Stadiums E12.5, E13.5 sowie E15.5 angefertigt, welche mit einer Geminin-Antisense RNA-Sonde hybridisiert wurden. Wie bereits in dem digitalen Atlas von GenePaint (www.genepaint.org; Abbildung 7) dokumentiert wurde, 
wurde das Transkript des Geminin-Gens in Wt-Mäusen in der proliferierenden Schicht der dem lateralen Ventrikel (LV) anliegenden GE, in der SVZ und in der VZ des Neocortex nachgewiesen (Abbildung 16). Außerdem erstreckt sich die Expression von Geminin über den Hippocampus (Hp; Abbildung 16). In Stadium E15.5 war die Expression von Geminin hauptsächlich auf die SVZ beschränkt (Abbildung 16, C, D und F). In Schnitten von Gemi$n i^{f f / f l} ; E m \times 1^{\text {RREScre }}$-Tieren bestand die Expression von Geminin in der GE, aber es wurde fast keine Geminin-mRNA mittels ISH im Neocortex nachgewiesen (Abbildung 16, A', B', C', D', E' und F'). Die gezielte Inaktivierung von Geminin im Neocortex mit Emx1 $1^{\text {IREScre }}$ konnte somit mittels ISH belegt werden.

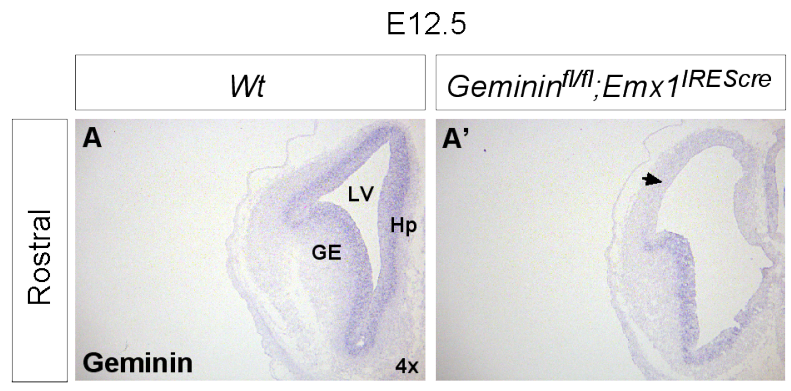

E13.5

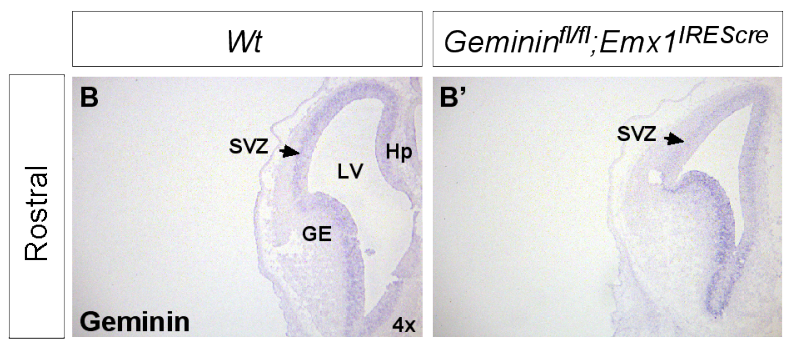

E15.5

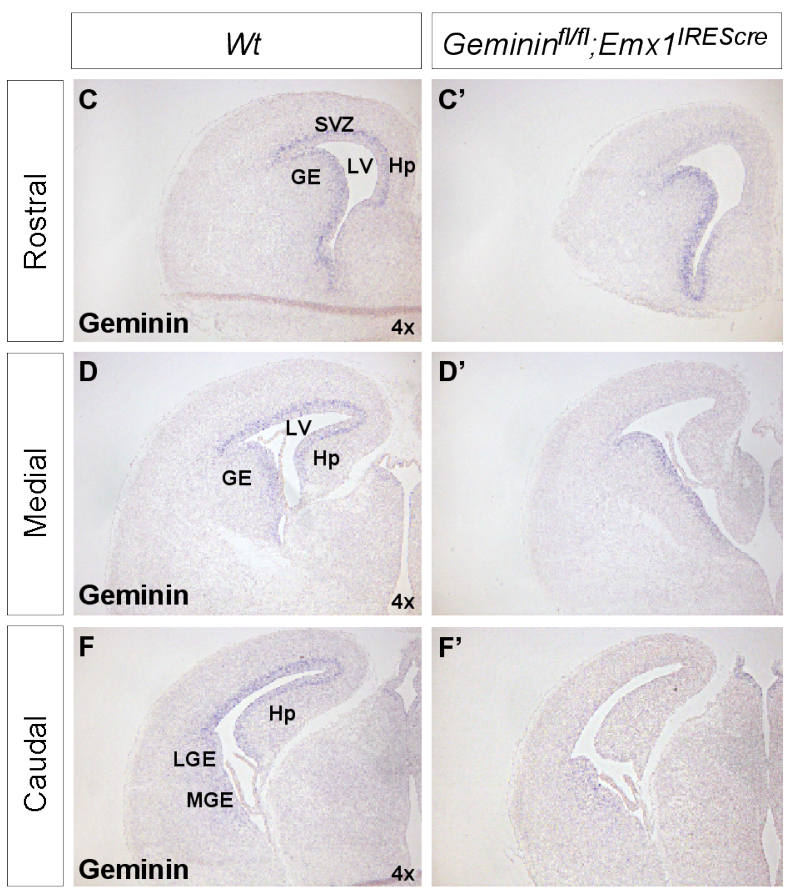

Abbildung 16. Expression von Geminin im dorsalen Telencephalon in Wt-Mäusen und spezifische Inaktivierung in Geminin ${ }^{f / f l}$; Emx $1^{\text {IREScre }}$-Mäusen. ISH von Geminin- mRNA auf coronalen Gewebeschnitten von Wt- und Geminin $^{f l / f l} ; E m \times 1^{I R E S c r e}$-Mäusen der Stadien E12.5 (A, A'), E13.5 (B, B') und E15.5 (C, C', D, D', E, $\left.E^{\prime}\right)$. Dargestellt ist jeweils eine der symmetrischen Hemisphären des Gehirns (CP, cortikale Platte; GE, Eminentia ganglionaris; Hp, Hippocampus; LGE, laterale GE; LV, lateraler Ventrikel; MGE, mediale GE; SVZ, Subventrikularzone). 
Die vergleichende Analyse von Wt und Mäusen mit heterozygot inaktiviertem Geminin $\left(\right.$ Geminin $^{f l} ; E m \times 1^{\text {IREScre }}$ ) offenbarte nie einen Unterschied, so dass im Rahmen dieser Arbeit eine vergleichende Darstellung im Folgenden stets ausschließlich von Wt- und mit $E m \times 1^{\text {IREScre }}$ homozygot deletierten Mäusen vorgewiesen wird.

\section{Phänotyp-Analyse von Geminin ${ }^{f / f l} ; E m \times 1^{\text {IREScre }}$-Mäusen}

Den Mendelschen Regeln zufolge entsprach die Verteilung der Nachkommen aus Verpaarungen von Geminin ${ }^{f / f l}$ - und Geminin ${ }^{f / f l} ; E m \times 1^{\text {IREScre }}$-Mäusen in embryonalen sowie postnatalen Stadien im Allgemeinen den Erwartungen. Jungtiere und adulte Tiere wiesen keinerlei anormales Verhalten auf, waren fertil und es wurden keine Unterschiede zwischen männlichen und weiblichen Tieren festgestellt.

\section{Zelldichte und Gesamtzellzahl sind im Cortex von Geminin ${ }^{f l / f l} ; E m \times 1^{\mid R E S c r e}$}

Da die visuelle Analyse von E13.5, E15.5, E18.5, P10 und P15 Wt- und cKO(konditionaler Knockout) Gehirnen keine Indizien für beständige Unterschiede in Bezug auf Volumen und Morphologie lieferte (Daten nicht dargestellt), wurde eine eingehendere morphologische Untersuchung anhand histologischer Paraffinschnitte und Färbung mit Cresylviolett vorgenommen.

Das Volumen der murinen Gehirne eines Wurfes variierte unabhängig vom Genotyp. Bei vergleichender Analyse verschiedener Würfe konnte keine Tendenz der Geminininaktivierten Gehirne bezüglich der Größe festgestellt werden. Die Musterung der cortikalen Schichten wies bei Vergleich von Wt- und cKO-Gehirnen keine besonderen Abweichungen auf (Abbildung 17). Ebenso zeichneten sich die Strukturen des Hippocampus (Hp; Abbildung 17, C, C') in den Geminin-deletierten Gehirnen nicht durch bestimmte Abweichungen bei Vergleich mit Wt-Gehirnen aus. ISH mit spezifischen Markern für die verschiedenen cortikalen Schichten wie Cux2 (Schicht IV-II; Iulianella et al., 2003), RZR $\beta$ (Schicht IV; Nakagawa and O'Leary, 2003), Er81 (Watakabe et al., 2007) und Gad1 (Behar et al., 1994) erbrachte keinen Hinweis auf eine morphologische Veränderung des Neocortex von P10 mutanten Mäusen (Daten nicht dargestellt). Der Verlust der Aktivität von Geminin im dorsalen Telencephalon resultierte nicht in einer veränderten morphologischen Musterung des geschichteten Neocortex in adulten Stadien. 


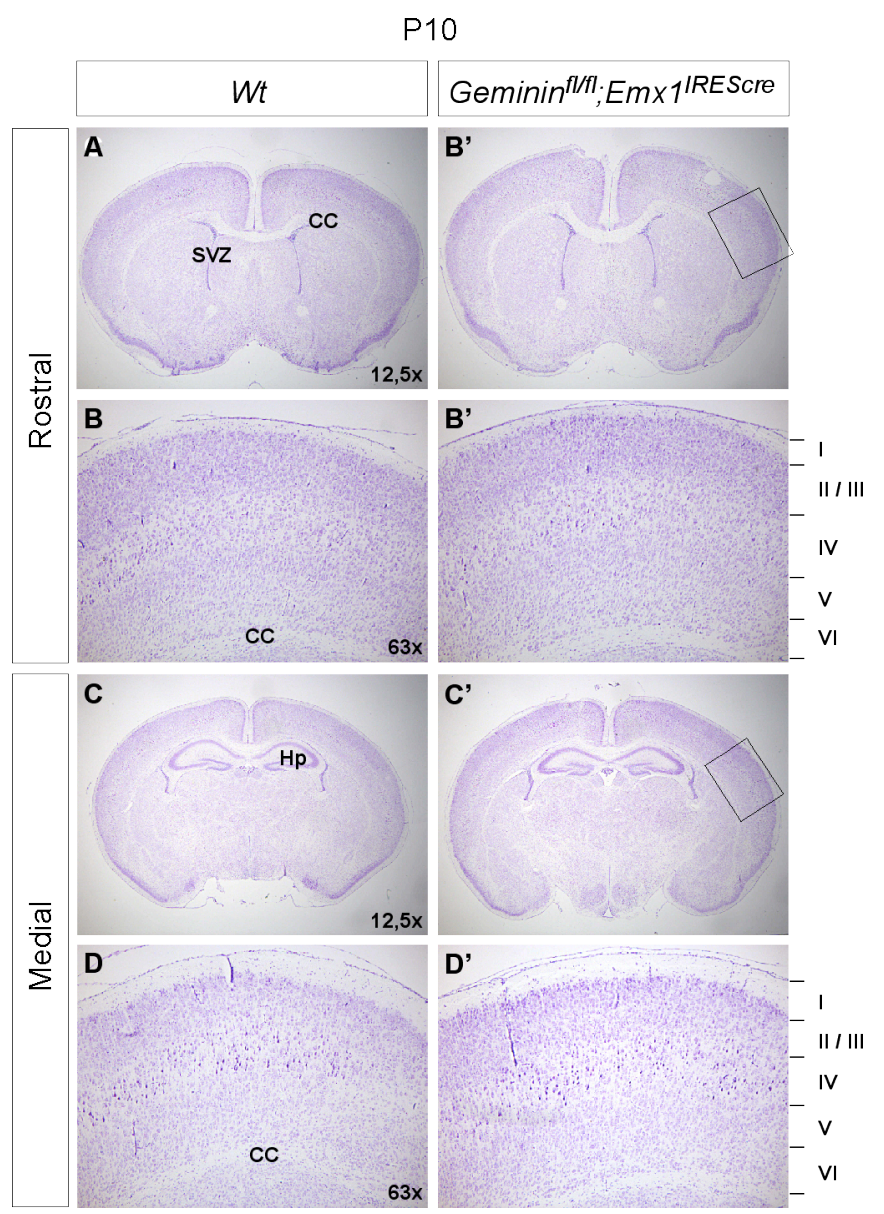

Abbildung 17. Morphologische Untersuchung von P10-Gehirnen von Wt- und Geminin $^{f l / f l} ; E m \times 1^{\text {IREScre }}$-Mäusen. Cresylviolett-Färbung von coronalen ParaffinSchnitten. In den neocortikalen Schichten (I bis IV) von adulten Tieren sind keine Abweichungen zu beobachten (CC, Corpus Callosum; Hp, Hippocampus; SVZ, Subventrikularzone).

\section{Analyse des mitotischen Zellzyklus im Cortex Geminin-defizienter Mäuse}

Während der Neurogenese folgen die proliferierenden Kerne einer interkinetischen Migration. Während die DNA-Synthese in der S-Phase des Zellzyklus an der basalen Seite der cortikalen VZ geschieht, findet die Mitose und Teilung der Zellen an der ventrikulären Oberfläche statt (Sauer, 1935; Takahashi et al., 1993). Da Geminin an der Kontrolle des Zellzyklus beteiligt ist und die Herunterregulierung von Geminin in Zellkultursystemen in den meisten Fällen zu einem Zellzyklusarrest in der $\mathrm{G}_{2} / \mathrm{M}$-Phase und Endoreduplikation führt (Melixetian et al., 2004; Zhu et al., 2004; Tachibana et al., 2005), wurde eine eingehende Analyse der Verteilung von Zellzyklusphasen im dorsalen Telencephalon konditional Geminin-inaktivierter Mäuse vorgenommen.

Zur Bestimmung der Anzahl und Lokalisation mitotischer Zellen wurde ein Antikörper gegen das an Serin 10 phosphorylierte Histon (H3P) eingesetzt (Weissman et al., 2003).

Die Auszählung von H3P-positiven Zellen wurde von jeweils sieben Wt- und

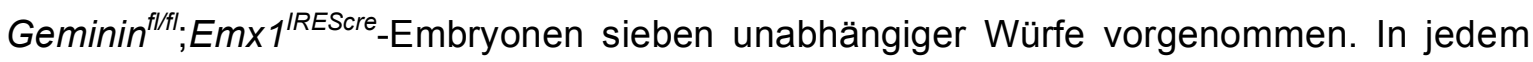
Fall wurden 8 bis 12 coronale Schnitte der einzelnen Embryonen ausgewertet. 


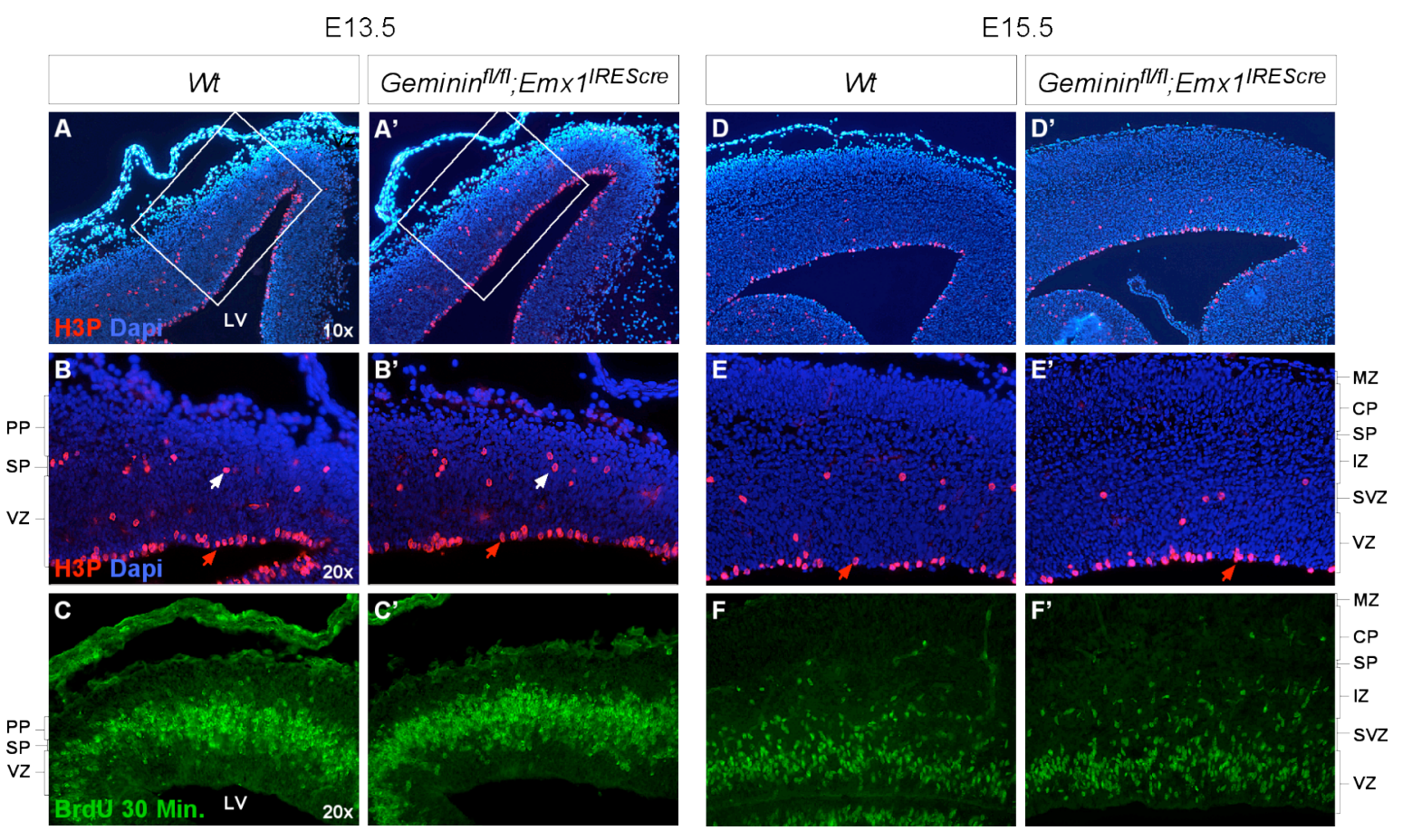

Abbildung 18. Analyse der Verteilung von Vorläuferzellen in der M- und S-Phase des Zellzyklus in Cortices von Wt- und Geminin ${ }^{\text {fl/fl}} ; E m \times 1^{I R E S c r e}$ transgenen Mäusen. Vergleichende Darstellung der IHCAnalysen coronaler Schnitte von E13.5 (A, A', B, B', C' C') und E15.5 (D, D', E, E', F, F') Gehirnen mit AntiH3P (rot) zur Markierung der Zellen in M-Phase und Anti-BrdU (grün) zur Aufnahme von S-Phase-Zellen. BrdU wurde zur Inkorporation in replizierende Zellen 30 Minuten vor Tötung der Muttertiere injiziert (C, C', F, $\left.F^{\prime}\right)$. Weiße Kästen in $A$, und $A^{\prime}$ markieren den in B und B' vergrößert dargestellten Ausschnitt. Die weißen Pfeile in B und B' markieren Zellen in der basalen VZ, an der Grenze zur SP (Dapi in blau; CP, Cortikale Platte; IV, Intermediäre Zone; MZ, Marginalzone; PP, Präplatte; SP, Subplatte; SVZ, Subventrikularzone; VZ, Ventrikularzone).

Zellen in der späten $\mathrm{G}_{2}$ - und $\mathrm{M}$-Phase, immunopositiv für $\mathrm{H} 3 \mathrm{P}$, wurden im Cortex von E13.5 und E15.5 Wt- und Geminin ${ }^{f / f f l} ; E m \times 1^{\text {IREScre }}$-Tieren in gleicher räumlicher Verteilung am Rand der VZ entlang des gesamten lateralen Ventrikels (LV) entdeckt (Abbildung 18 A, A', D, D' rote Pfeile in B, B', E, E'). Zur Initiation der Formation der SVZ in E13.5 akkumulieren mitotische Zellen zudem an der basalen Grenze der VZ (Abbildung 18 B, B'; weißer Pfeil). In E15.5 liegen dann bereits in der neu gebildeten SVZ intermediäre Vorläuferzellen vor, welche ebenfalls aktiv zyklieren und in der M-Phase positiv für H3P sind (Abbildung $18 \mathrm{E}, \mathrm{E}$; rote Pfeile). Da nach rein visueller Begutachtung der IHC mit Anti-H3P kein Unterschied bei Wt- und cKO-Mäusen zu beobachten war, wurden Zellzahlbestimmungen der H3P-positiven Zellen vorgenommen. Obwohl zunächst eine Tendenz von verstärkt H3P-positiven Zellen in der VZ der Knockout-Tieren zu verzeichnen war, erbrachte die Auszählung letztlich keinen signifikanten Unterschied von H3Pimmunoreaktiven Zellen in den cortikalen Zellpopulationen von Wt- und Geminin-cKOMäusen. Das Ergebnis wurde sowohl in E13.5 wie auch in E15.5 vermerkt (Daten nicht gezeigt). 
Die Gliederung der Zellzyklusphasen wurde des Weiteren durch die Inkorporation von BrdU (5'-Bromo-2'-deoxyuridin) in proliferierende Zellen verfolgt. Adulte Weibchen wurden 30 Minuten nach Injektion von BrdU getötet, um die Zellen in der S-Phase des Zellzyklus aufzunehmen. Wie aus Abbildung $18 \mathrm{C}$ und $\mathrm{C}^{\prime}$ ersichtlich, reichern sich die meisten Vorläuferzellen an der dem LV abgewandten, basalen Seite der VZ an. Hinsichtlich der Quantifizierung BrdU-positiver Zellen (siehe Zellzahlbestimmungen für H3Pimmunopositive Zellen) ließ sich keine signifikante Differenz zwischen $W t$ und $c K O$ feststellen (Daten nicht gezeigt).

Zusammenfassend wurde bei Vorläuferzellen, welche das Geminin-Gen nicht exprimieren, keine signifikante Veränderung der Anzahl von Zellen in M- und S-Phase in der frühen cortikalen Entwicklung nachgewiesen.

\section{Analyse der Ausbeute an neuronalen Zellen im Cortex von Wt- und Geminin $^{f l / f l} ; E m \times 1^{\text {IREScre }}$-Mäusen}

Während sich intermediäre Vorläuferzellen in der SVZ zur Bildung von zwei Neuronen vorzugsweise symmetrisch teilen, läuft die Teilung der radialen Gliazellen in der VZ meistens asymmetrisch ab, so dass höchstens ein Neuron entsteht (Abbildung 3). Um einen Eindruck von der Ausbeute an Neuronen im Cortex mit konditional inaktiviertem Geminin zu gewinnen, wurden auf coronalen Gefrierschnitten von E15.5 IHC-Analysen mit Anti-Ki67 und Anti-TuJ1 umgesetzt. Ki67 bezeichnet einen nuklearen Transkriptionsfaktor, der in allen sich aktiv teilenden Zellen von der S- bis zur M-Phase vertreten ist (Scholzen and Gerdes, 2000). Postmitotische Zellen, bei denen bereits die Differenzierung in Neurone initiiert wurde, zeichnen sich dagegen durch die Expression von neuronalem Klasse III $\beta$-Tubulin (TuJ1) aus. Zwischen den Cortices von Wt- und cKO-Tieren in Bezug auf proliferierende und postmitotische Zellpopulationen wurden keine qualitativen Unterschiede festgestellt (Abbildung 19). Die Expression von Ki67 beschränkt sich auf die Schichten proliferierender Vorläuferzellen der VZ, der SVZ (Abbildung 19 A, A') und in geringem Maße der IZ (Abbildung 19 B, B', weiße Pfeile). IHC mit Anti-TuJ1 detektierte das filamentöse Protein in allen postmitotischen, Ki67-immunonegativen Zellen in der IZ, der CP und der PP (Abbildung 19 B, B', C, C'). Das Verhältnis von proliferierender und bereits primär differenzierter Zellpopulation erschien im Cortex von Wt- und cKO-Mäusen identisch. 


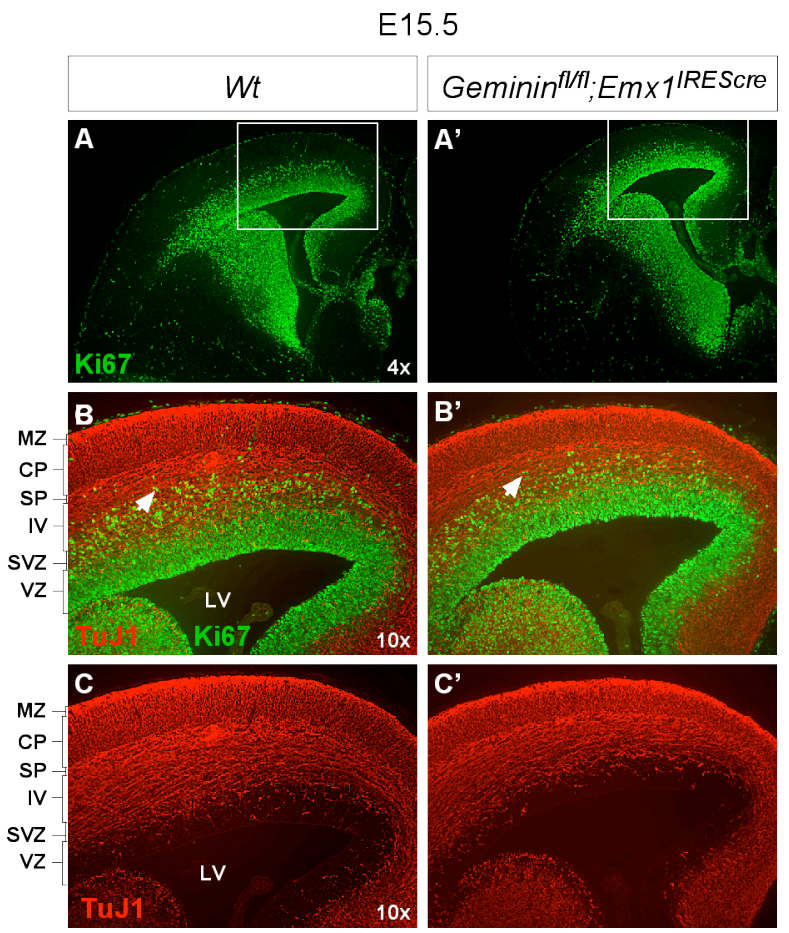

Abbildung 19. Vergleichende Darstellung proliferierender gegenüber postmitotischer Zellpopulationen. IHC mit Anti-Ki67 (A, A', B, B') zur Markierung der proliferierenden Vorläuferzellen und mit Anti-TuJ1 (B, B', C, C') zur Visualisierung von postmitotischen Zellen in coronalen Schnitten von Wt- und Geminin-cKO-Mäusen im Stadium E15.5. Die weißen Kästen in A und A' markieren den in den anderen Aufnahmen dargestellten vergrößerten Bereich und die weißen Pfeile (B, B') weisen auf Vorläuferzellen in der IZ (intermediäre Zone) hin (CP, Cortikalplatte; LV, lateraler Ventrikel; MZ, Marginalzone; SP, Subplatte; SVZ, Subventrikularzone; VZ, Ventrikularzone).

Um dennoch einen möglichen Effekt des Aktivitätsverlusts von Geminin auf das Schicksal der proliferierenden Vorläuferzellen zu dokumentieren, wurde eine Quantifizierung der Ausbeute an Neuronen in Mäusen mit Wt- und Geminin-defizienten Cortices vorgenommen. Dazu wurde im Stadium E15.5, 24 Stunden vor Präparation der Embryonen, ein BrdU-Puls gegeben. BrdU-positive Zellen, welche den Zellzyklus bereits verlassen haben, befinden sich so 24 nach ihrer Markierung mit BrdU an der Grenze von VZ und SVZ oder bereits außerhalb der VZ. Da zwischen den Cortices von Wt- und cKOEmbryonen keine offensichtliche Differenz der BrdU-positiven Zellpopulationen dokumentiert wurde (Abbildung 20a), schien die Inaktivierung von Geminin im Cortex keinen Effekt auf den Austritt der proliferierenden Vorläuferzellen aus dem Zellzyklus und die Initiierung der neuronalen Differenzierung zu haben.

Bei vollständigem Funktionsverlust von Geminin in der Maus wurde nach den ersten embryonalen Teilungen der ES-Zellen Apoptose registriert (Hara et al., 2006). Da bei der Analyse der konditional Geminin-inaktivierten Embryonen zunächst kein Hinweis auf eine Abnormalität der proliferierenden Zellen vorlag, stellte sich die Frage, ob Geminindefiziente Zellen der Apoptose unterlegen sind. Die Durchführung des TUNEL-Tests zur Dokumentation von apoptotischen Zellen auf E15.5 coronalen Schnitten erbrachte im Vergleich zu Wt-Nachkommen desselben Wurfes keine Anzeichen auf eine verstärkte Mortalitätsrate (Abbildung 20b).

Die konditionale Inaktivierung von Geminin im dorsalen Telencephalon mittels Emx1 $1^{\text {IREScre }}$ hat, den vorliegenden Ergebnissen zufolge, keinen signifikanten Einfluss auf die 
Population proliferierender Vorläuferzellen und deren Verteilung im Zellzyklus. Das Verhältnis von differenzierten zu proliferierenden Zellen stimmt in den Geminin-defizienten Mausmutanten mit dem in der Wt-Situation überein.

a E16.5
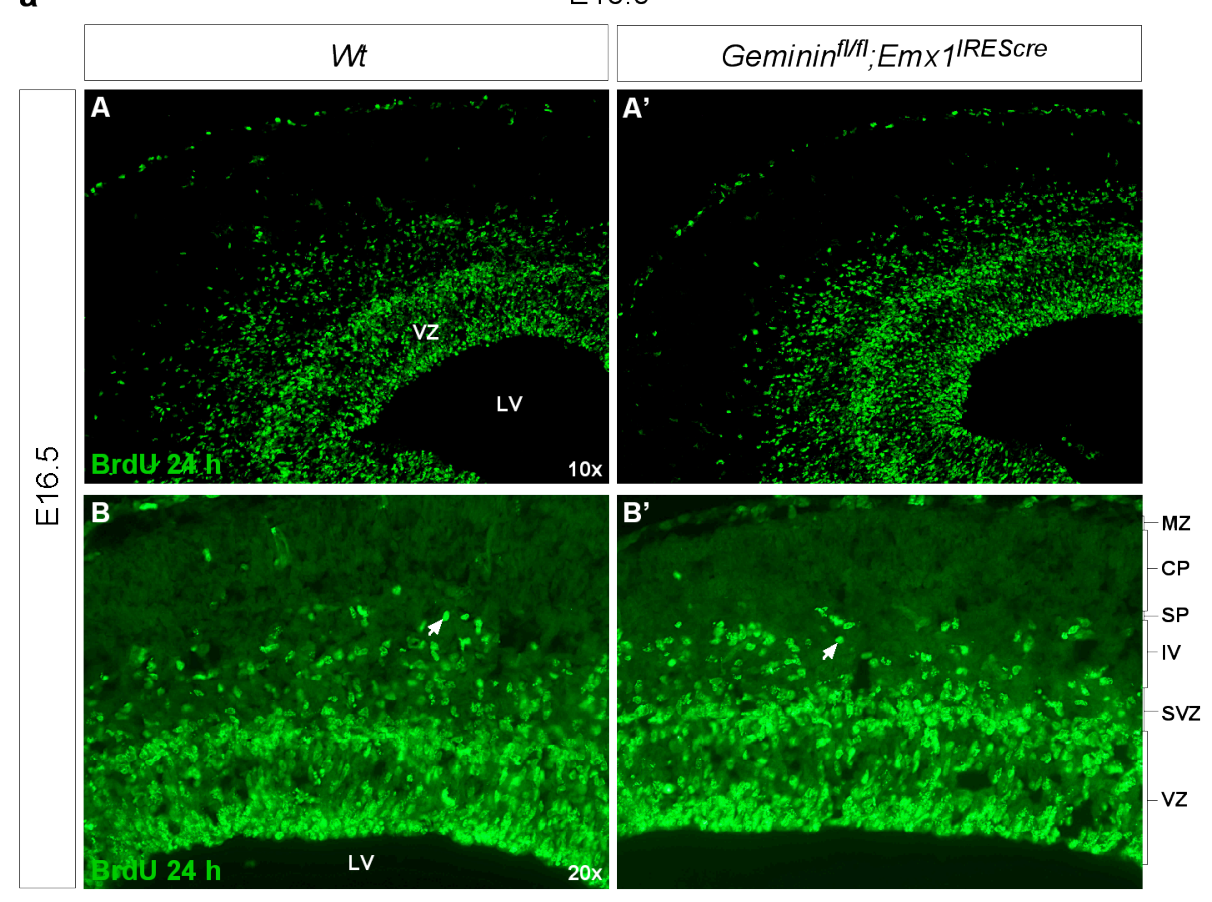

Geminin $^{f / f l]} ; E m \times 1^{\text {IRESCre }}$

b

E15.5

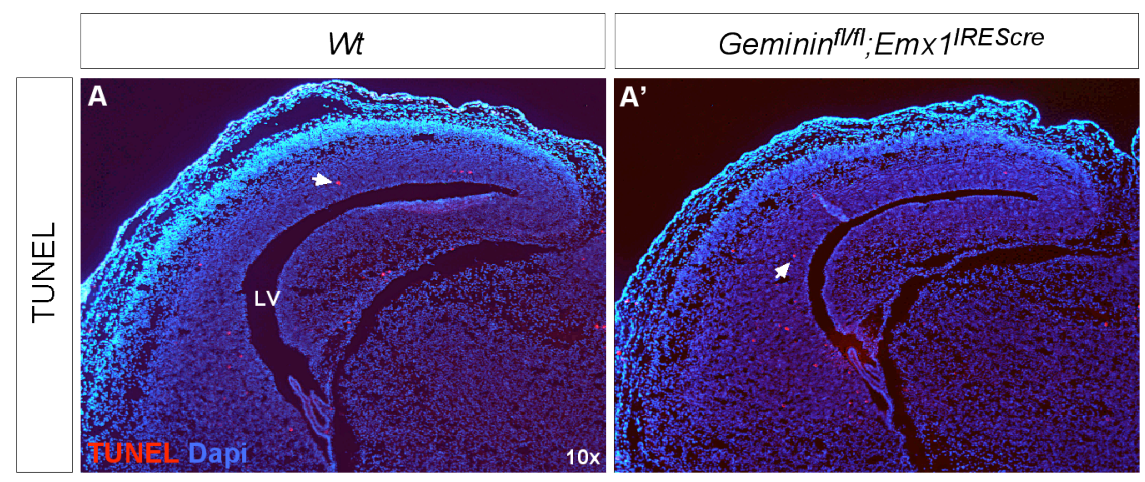

Abbildung 20. Inaktivierung von Geminin im dorsalen Telencephalon hat in der frühen Neurogenese keinen Einfluss auf die Ausbeute an Neuronen und resultiert nicht in verstärkter Apoptose. (a) Markierung der Zellen für 24 Stunden mit BrdU. Weiße Pfeile weisen auf aus der VZ ausgewanderte Zellen hin, die den Zellzyklus möglicherweise bereits verlassen haben. (b) TUNEL-Test auf E15.5 coronalen Gefrierschnitten von (A) Wt- und (A') Geminin ${ }^{\text {fl/fl}} ; E m \times 1^{I R E S c r e}$-Mäusen. Weiße Pfeile markieren einzelne apoptotische Zellen (rot; LV, lateraler Ventrikel; SVZ, Subventrikularzone; VZ, Ventrikularzone). 


\section{Geminin interagiert mit dem Transkriptionsfaktor Pax6}

Pax6 ist eines der Schlüsselelemente der radialen Gliazellen des Neocortex, da es entscheidend an der Spezifizierung des neuronalen Schicksals der Zellen beteiligt ist. Geminin und Pax6 sind in der Mehrheit der Zellen in VZ und SVZ co-exprimiert (Spella et al., 2007). Durch ihre räumliche Nähe in den neuronalen Vorläuferzellen wäre somit eine direkte Interaktion möglich, welche bei der Regulation der Neurogenese eine funktionale Bedeutung haben könnte.

Um zu untersuchen, ob Geminin und Pax6 tatsächlich miteinander interagieren, wurde zunächst ein in vitro GST-Pull-Down Experiment durchgeführt. Rekombinantes, an GSTfusioniertes Geminin-Protein wurde auf seine Bindung an Pax6 getestet. Pax6-Protein wurde dabei durch in vitro Transkription/Translation in Gegenwart von $\left[{ }^{35} \mathrm{~S}\right]$-Methionin hergestellt. Das Pull-Down Experiment belegte, dass Pax6 an GST-Geminin binden kann, aber nicht an GST allein (Abbildung 21a).

a

GST-Pull-Down

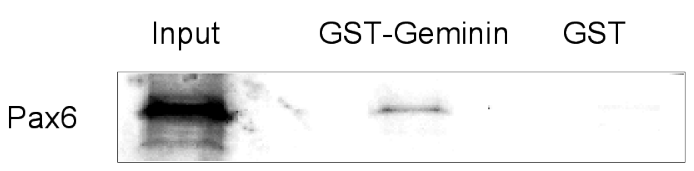

b

Co-Immunpräzipitation

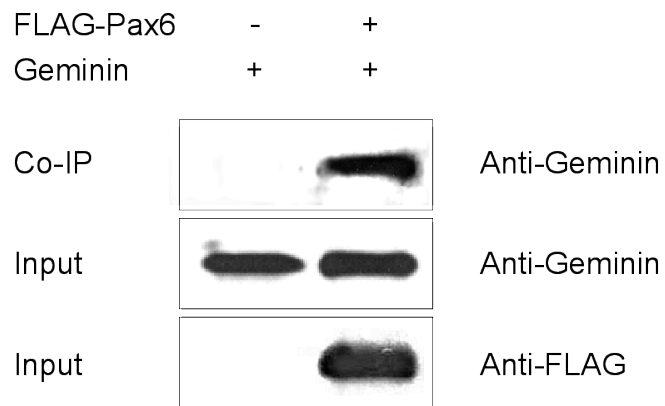

Abbildung 21. In vitro und in vivo Interaktion von Geminin und Pax6 in HeLa-Zellen. (a) GST-Pull-Down Analyse der Interaktion von GST-Geminin mit Pax6-Protein. Pax6 bindet an GST-Geminin aber nicht an GST. Der Input zeigt in vitro transkribiertes/translatiertes Pax6 (Daten freundlicherweise von Naisana S. Asli zur Verfügung gestellt). (b) Western Blot Analyse der Co-Immunpräzipitation (Co-IP) von Geminin mit FLAGPax6. Als Negativ-Kontrolle wurde anstatt FLAG-Pax6 der leere Plasmid-Vektor transfiziert. Der Input entspricht $0,4 \%$ des initialen Volumens vor der Co-IP.

Um tatsächlich die funktionale Rolle einer Protein-Protein-Interaktion zwischen Pax6 und Geminin während der Neurogenese zu untersuchen, wurde es des Weiteren angestrebt, die Interaktion in Säugerzellen zu bestätigen. Für die Co-Immunpräzipitation in einem Zellkultursystem mit humanen HeLa-Zellen wurde ein Plasmid mit N-terminal FLAGgetaggtem Pax6-Protein oder, der als Negativ-Kontrolle fungierende leere Plasmidvektor ohne Insert, zusammen mit einem Expressions-Plasmid für Maus-Geminin transient überexprimiert. Acht Stunden vor Ernte der Zellen wurde das Zellkulturmedium mit $10 \mu \mathrm{M}$ 
des Proteasom-Inhibitors MG132 versetzt, um eine vorzeitige Degradation von Pax6 und Geminin zu verhindern. Von den lysierten Zellextrakten wurde jeweils eine Probe (Abbildung 21b; Input) entnommen, um anschließend mit der Co-Immunpräzipitation fortzufahren. Das mittels FLAG-Antikörper präzipitierte Protein wurde mit Ladepuffer eluiert (Abbildung 21b; Co-IP) und einer Western Blot Analyse mit Anti-GemininAntikörper unterzogen. Wie bereits in vitro dargestellt wurde, wurde auch in vivo verifiziert, dass Geminin mit FLAG-Pax6 spezifisch präzipitiert wird (Abbildung 21b). Die beiden Proteine stehen in dem Zellkultursystem in direkter Interaktion miteinander.

\section{Inaktivierung von Geminin mit $E m \times 1^{\text {IREScre }}$ zeigt keinen Einfluss auf Pax6 und Pax6- regulierte Zielgene}

Die Interaktion zwischen Geminin und Pax6 spielt möglicherweise eine Rolle bei der Expression und Funktionalität von Pax6 im sich entwickelnden Neocortex. Um in den Cortices der konditionalen Knockout-Mäuse eine mögliche Repression oder Erhöhung der Pax6-exprimierenden Zellen durch Deletion von Geminin zu dokumentieren, wurde eine ISH von Pax6-mRNA und IHC mit einem gegen Pax6 gerichteten Antikörper vorgenommen. Die minimalen Größenunterschiede von Wt- und mutanten Gehirnen bzw. der Dicke ihrer cortikalen Schichten, wie in Abbildung $22 \mathrm{E}, \mathrm{F}(W t)$ und E', F' $\left(\right.$ Geminin $\left.^{\text {fl/fl }} ; E m \times 1^{\text {IREScre }}\right)$ zu beobachten, traten nicht konstant auf und waren unabhängig von dem Genotyp der analysierten Tiere. Die Expression von Pax6 wurde in E12.5 und E15.5 hauptsächlich in der VZ detektiert. Anhand der ISH- und IHC-Analysen waren keine Abweichungen der regionalen Pax6-Expression in Wt und Mutante zu verzeichnen. Die Inaktivierung von Geminin hatte keinen Einfluss auf das Expressionsmuster von Pax6.

Ein direktes Zielgen von Pax6 ist das proneurale Gen Ngn2 (Stoykova et al., 2000; Scardigli et al., 2003). Hohe Konzentrationen von Pax6 bewirken die transkriptionelle Aktivierung des Ngn2-Gens. Um zu analysieren, ob die Deletion von Geminin einen direkten oder über Pax6-vermittelten Effekt auf die Expression von Ngn2 in neocortikalen Vorläuferzellen hat, wurde eine ISH von E15.5 Wt- und cKO-Schnitten vorgenommen. Bei Vergleich von Wt und Mutante konnte kein Unterschied in der Expression des proneuralen Gens dokumentiert werden (Abbildung 22). Ngn2 ist sowohl in Wt- wie auch in Geminin $^{f / f l} ; E m \times 1^{\text {IREScre }}$-Mäusen in der VZ des Neocortex angereichert und weist kein unterschiedliches Expressionsmuster auf. 

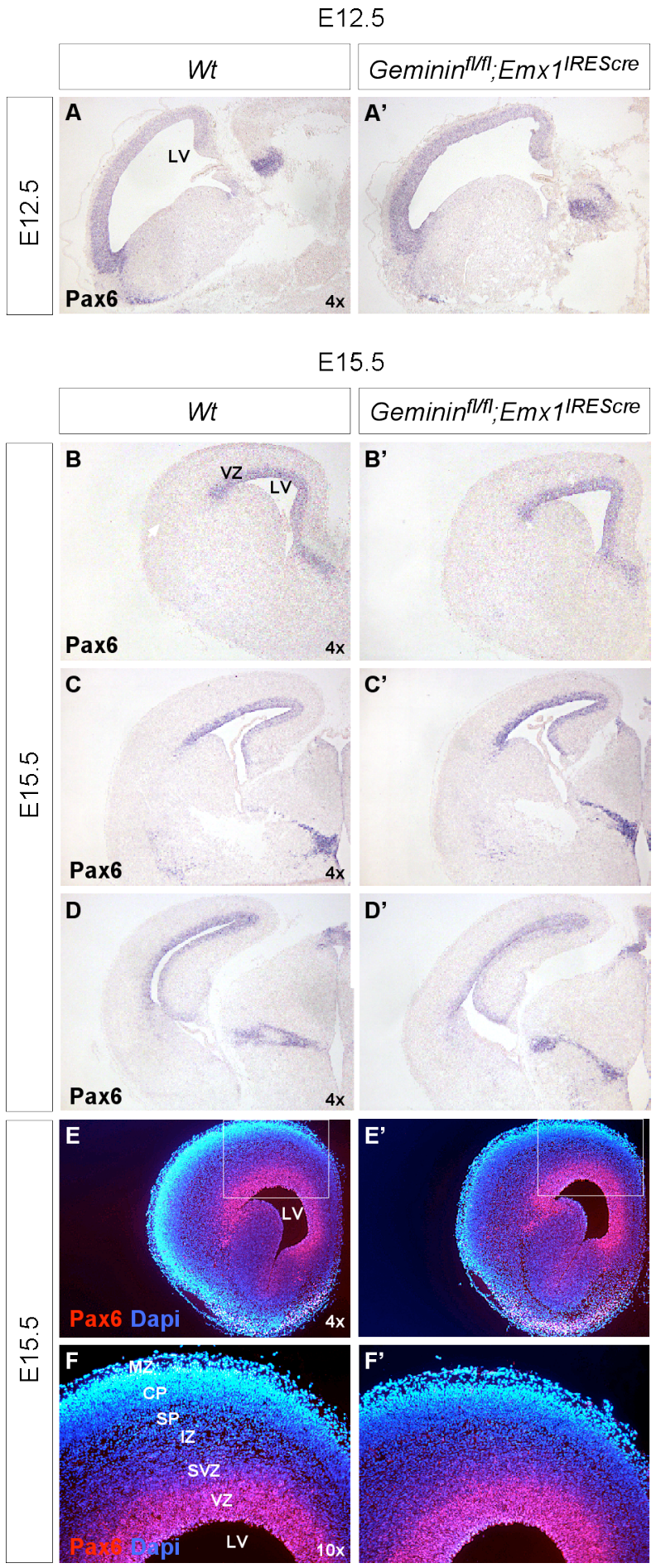

Abbildung 22. Pax6-RNA und -Protein zeigen keine abweichenden Level im Cortex von Wtund Geminin $^{f l / f l} ; E m \times 1^{\text {IREScre }}$-Mäusen in E12.5 und E15.5. ISH-Analysen von Pax6-mRNA auf sagittalen Schnitten von Wt- und mutanten Tieren des Telencephalons von E12.5 (A, A') und von coronalen Schnitten von E15.5 (B bis $F^{\prime}$ ) in der Ventrikularzone $(V Z)$ in rostralen $\left(B, B^{\prime}\right)$, medialen (C, C') und caudalen (D, D') Abschnitten und die Detektion von Pax6 Protein (rot) mittels IHCAnalyse (weiße Kästen in E, E' (4× Vergrößerung) zeigen Ausschnitte in $F, F^{\prime}$ in $10 \times$ Vergrößerung; Dapi in blau; IZ, intermediäre Zone; LV, lateraler Ventrikel; MZ, Mantelzone; SP, Subplatte; SVZ, Subventrikularzone).

Neben der Regulation des Transkriptionsfaktors Ngn2 durch Pax6 sind weitere Faktoren an der Musterung des geschichteten Neocortex und der damit verbundenen Differenzierung von Vorläuferzellen in Projektionsneurone beteiligt, die auch zum Teil in Verbindung mit Pax6 stehen. Viele Transkriptionsfaktoren werden in regional beschränkten Zonen exprimiert, was vermutlich in Verbindung mit den Schlüsselereignissen in der Neurogenese steht (reviewed von Hevner et al., 2006). Die transgene Geminin-cKOMauslinie wurde, wie im Folgenden beschrieben, in Bezug auf diese zonalen 
Expressionsmuster einiger Transkriptionsfaktoren in der VZ, der SVZ, der IZ und der CP untersucht, um einen Einblick in die Rolle von Geminin während der neocortikalen Musterung zu bekommen, insbesondere hinsichtlich einer möglichen Interaktion mit Pax6.

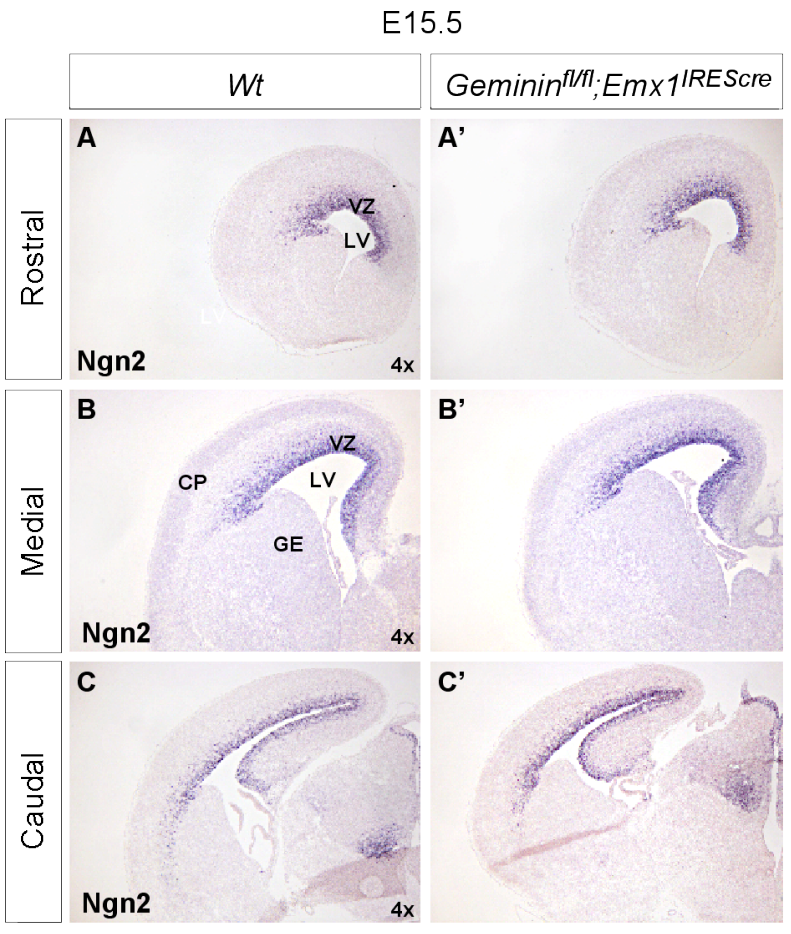

Abbildung 23. Expression von Ngn2 im Telencephalon von Wt- und Geminin-cKO-Mäusen. ISH von E15.5 coronalen Gefrierschnitten durch das Gehirn (CP, cortikale Platte; GE, Eminentia ganglionaris; LV, lateraler Ventrikel; VZ, Ventrikularzone).

\section{Geminin $^{f l / f l} ; E m \times 1^{\text {IREScre }}$ transgene Mäuse haben eine normale Anzahl intermediärer Vorläuferzellen}

Die Expression von Pax6 ist im Neocortex auf die radialen Gliazellen in der VZ beschränkt. Der Übergang von radialen Gliazellen zu intermediären Vorläuferzellen findet statt, sobald die Zellen aus der VZ in die SVZ zu migrieren beginnen. Dieser Vorgang um E11.5 ist mit der Initiation der Aktivierung von Tbr2 assoziiert, dessen Expression auch der Regulation durch Ngn2 unterliegt (Schuurmans et al., 2004). Die Expression der Transkriptionsfaktoren Pax6, Ngn2 und Tbr2 erfolgt in sequentieller Abfolge (Englund et al., 2005).

Um zu analysieren, ob die Inaktivierung von Geminin einen Einfluss auf die Generierung von intermediären Vorläuferzellen hat, wurde eine Co-Lokalisation von Pax6 und Tbr2 mittels IHC in Gewebeschnitten des Stadiums E15.5 vorgenommen (Abbildung 23; Pax6 in rot, Tbr2 in grün). Die Expression von Tbr2 im Neocortex wurde in der VZ, der SVZ und der IZ (Abbildung $23 \mathrm{C}$, weißer Pfeil) registriert, wobei die Zellen hauptsächlich über den Pax6-positiven VZ-Zellen, an der basalen Oberfläche, angereichert waren (Abbildung 23; B, B', C, C'). Zwischen dem Cortex von Wt- und Geminin ${ }^{f / f f l} ; E m \times 1^{\text {IREScre }}$-Mäusen ließ sich kein Unterschied feststellen. Die Entstehung von intermediären Vorläufern scheint durch die Inaktivierung von Geminin nicht beeinträchtigt zu sein. 
a

E15.5
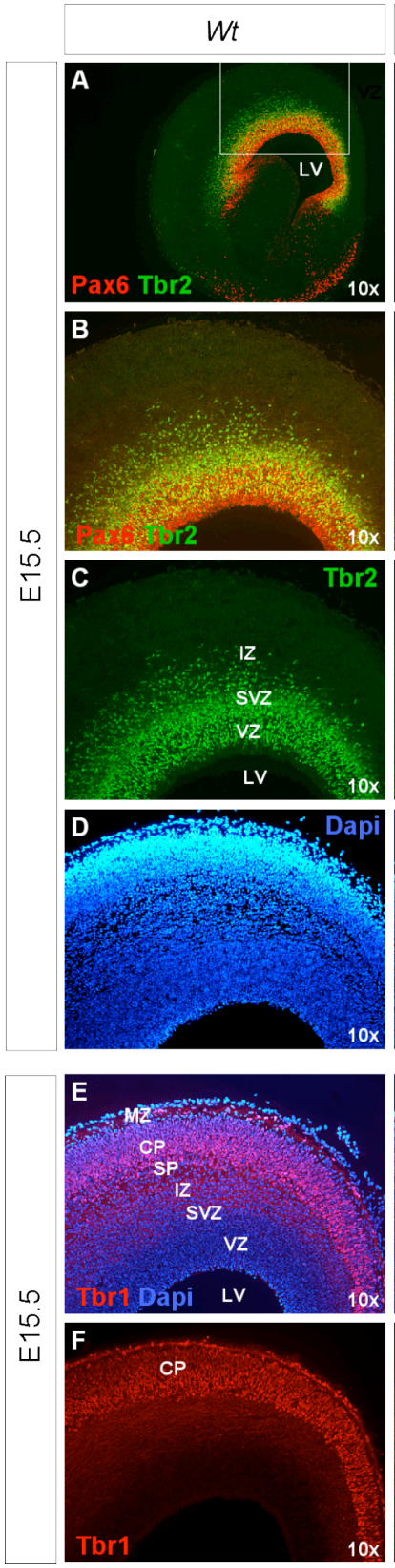

Geminif $^{f l / f l} ;$ Em $\times 1^{\text {IRESCre }}$
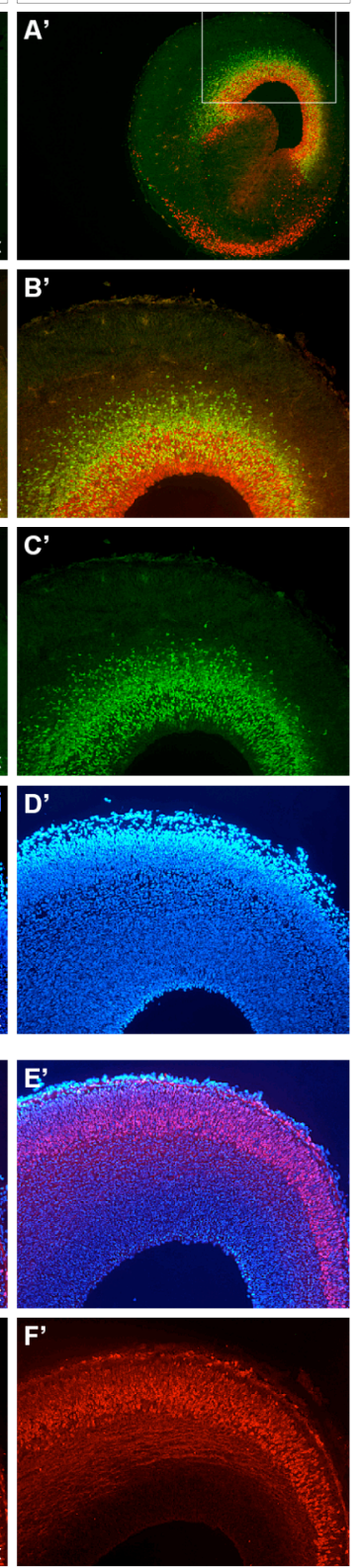

b

E15.5

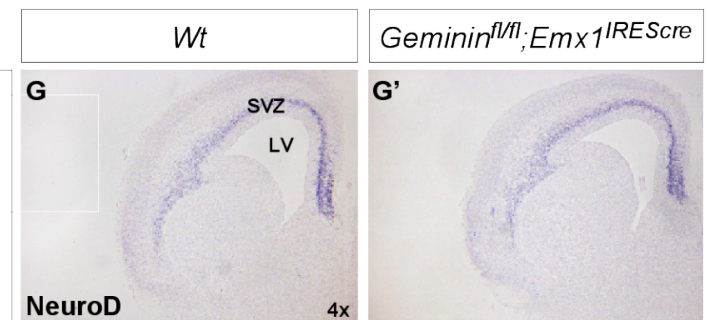

NeuroD $4 x$

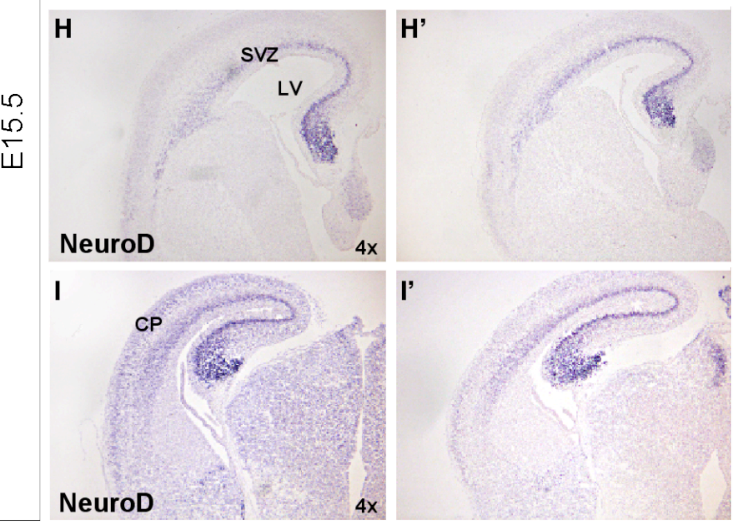

NeuroD

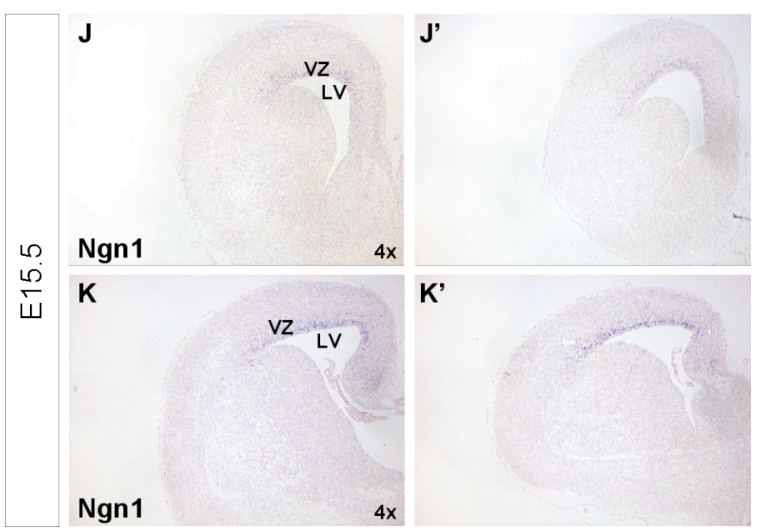

Abbildung 24. Expression von Pax6, Tbr2, Tbr1, NeuroD und Ngn1 im Cortex von E15.5 Wt- und cKOMäusen. (a) IHC von coronalen Gefrierschnitten mit Anti-Pax6 (rot; A, A', B, B'; Kästen in A, A' sind in größerer Vergrößerung in B und B' dargestellt) und Anti-Tbr2 (grün; B, B', C, C'; Dapi in blau; D, D') und IHC mit Anti-Tbr1 (rot; E, E', F, F'; Dapi in blau). (b) ISH von NeuroD (G bis I') und Ngn1 (J bis K') auf coronalen Gewebeschnitten von E15.5 Mausembryonen (CP, cortikale Platte; IZ, intermediäre Zone; LV, Lateraler Ventrikel; VZ, Ventrikulrzone; SP, Subplatte; SVZ, Subventrikularzone).

In der cortikalen Expressionskaskade folgt auf die Expression von Tbr2 die des proneuralen Gens NeuroD. Die Expressionsanalyse von NeuroD in den GemininMutanten war im Rahmen dieser Arbeit zudem von Interesse, da NeuroD sowie auch das proneurale Gen Ngn1 der transkriptionellen Aktivierung durch Brg1 unterliegen und Brg1 selbst als Interaktionspartner von Geminin charakterisiert wurde (Seo et al., 2005b; Seo et al., 2005a). Die Expression von NeuroD ist in der oberen SVZ und in der dem Ventrikel 
zugewandten Seite der IZ zu vermerken (Abbildung 24; G, G', H, H', I, I'). Die vergleichende ISH-Analyse in E15.5 mit einer gegen NeuroD-mRNA gerichteten Sonde offenbarte keine Abweichungen der NeuroD-Expression im Telencephalon von Wt- und cKO-Mäusen (Abbildung 24; G, G', H, H', I, I'). Ebenso ist das Expressionsmuster des Brg1-regulierten proneuralen Gens Ngn1 in der Mutante unverändert und in Mäusen beider Genotypen auf die VZ beschränkt (Abbildung 24; J, J', K, K').

Tbr1 ist in postmitotischen Neuronen in der basalen IZ, der SP, der CP und der MZ exprimiert und folgt in der Expressionsabfolge der Aktivierung von NeuroD (Hevner et al., 2001; Hevner et al., 2006). Im Cortex Geminin-inaktivierter Mäuse sind keine morphologischen Veränderungen in der cortikalen Platte zu erkennen und das Expressionslevel von Tbr1 ist in E15.5 vergleichbar mit dem von Wt-Mäusen.

Der Verlust der Funktion von Geminin hat scheinbar keine signifikante Auswirkung auf den Vorgang der Formation der neocortikalen Schichten, welche durch die sequentielle Expressionsabfolge von Pax6, Ngn2, Tbr2, NeuroD und Tbr1 beschrieben wurde. Zudem konnte keine reprimierende Wirkung von Geminin auf die Brg1-Zielgene Ngn1 und NeuroD in dem Maus-Modell des Stadiums E15.5 nachgewiesen werden.

\section{Deletion von Geminin in cortikalen Vorläuferzellen verändert nicht die Expression von Sox 2}

Das Protein Sox2 dient der Erhaltung neuronaler Vorläuferzellen in dem Status der Proliferation. Es wird in neuroepithelialen Stammzellen und Vorläuferzellen in der VZ exprimiert (Bani-Yaghoub et al., 2006) und zeigt dort in E12.5 zu 90\% eine Co-Expression mit Geminin-positiven Zellen (Spella et al., 2007). Bei der Entwicklung der Neuralplatte im Huhn wurde gezeigt, dass Geminin an der Induktion der Sox2-Expression durch Interaktion mit dem SWI/SNF-Komplex beteiligt ist (Papanayotou et al., 2008). Außerdem gilt Sox2 als direktes Zielgen von Pax6 (Wen et al., 2008).

Um zu analysieren, ob die Inaktivierung von Geminin in den proliferierenden Zellen des Cortex einen Einfluss auf die Expression von Sox2 hat, wurde eine ISH mit einer gegen Sox2-mRNA gerichteten Sonde vorgenommen. Die Expression von Sox2 ist im Telencephalon von Wt-Mäusen in der VZ des Cortex, der MGE und der LGE zu beobachten (Abbildung 25, A, B, C). Im Vergleich zu der ISH der Gewebeschnitte von E15.5 WtTieren ist in Gehirnschnitten mutanter Tiere keine veränderte Sox2-Expression zu verzeichnen (Abbildung 25, A', B', C'). Die Deletion von Geminin im Neocortex hat während der frühen neocortikalen Entwicklung bis E15.5 keinen Einfluss auf die Initiierung der Expression von Sox2. 


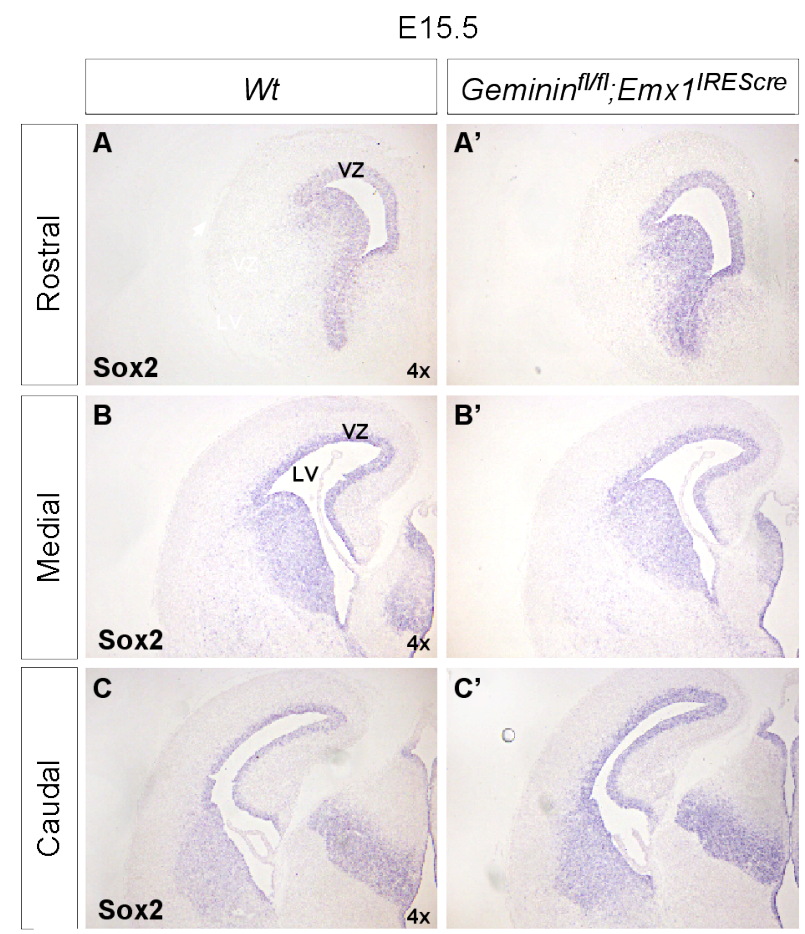

Abbildung 25. Expression von Sox2 in Wt- und Geminin $^{\text {fl/fil }} ; E m \times 1^{\text {IRESCre }}$-Mäusen. ISH von Sox2 auf coronalen Gehirnschnitten des Stadiums E15.5 von Wt- $(\mathrm{A}, \mathrm{B}, \mathrm{C})$ und Geminin-defizienten Mäusen (A', $\left.B^{\prime}, C^{\prime}\right)$.

\section{Die tangentiale Migration von Interneuronen ist in Geminin-defizienten Embryonen nicht beeinträchtigt}

Aus dem Pallium gehen hauptsächlich glutamaterge cortikale Neurone hervor, während aus dem Subpallium überwiegend GABAerge Interneurone hervorgehen. GAD1 (engl. "glutamic acid decarboxylase 1") ist ein entscheidendes Element bei der Synthese des inhibitorischen Neurotransmitters GABA und ist selbst Zielgen verschiedener DIxHomeodomän-Proteine. In Ngn2 ${ }^{-/}$- und Pax6 $6^{\mathrm{Sey} / \mathrm{Sey}}$-Mausmutanten wurde die erhöhte Einwanderung GAD1-positiver Neurone in den Neocortex beobachtet (Chapouton et al., 1999). Um zu prüfen, ob die tangentiale Migration von Vorläuferzellen der Interneurone in den Geminin-Mausmutanten beeinträchtigt ist, wurde eine ISH mit GAD1 durchgeführt. Wie der Abbildung 26 zu entnehmen ist, war die Expression von GAD1 in der GE, im Thalamus (Th) und zu einem geringen Level in der PP nachzuweisen (Abbildung 26). Zwischen Wt- und Geminin ${ }^{f l / f l} ; E m \times 1^{\text {IREScre }}$-Mäusen wurde kein abweichendes Expressionsmuster registriert. In Stadien der frühen neocortikalen Entwicklung scheint der Verlust von Geminin keinen Einfluss auf die Einwanderung von Interneuronen aus der GE zu haben.

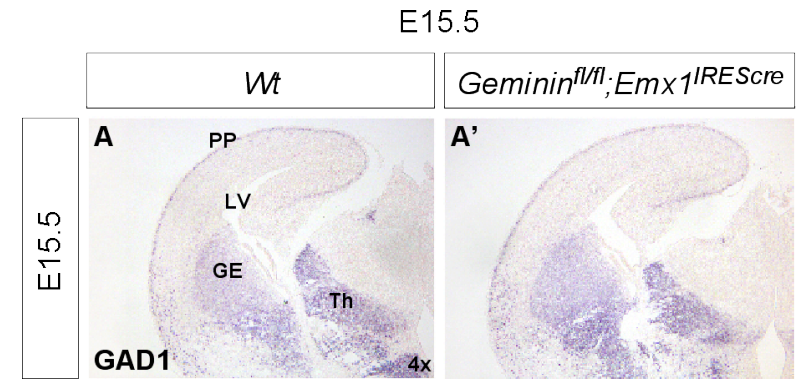

Abbildung 26. Identische Expressionsmuster von GAD1 im Telencephalon von Wt- und Geminin-Mausmutanten. ISH von GAD1 auf coronalen Schnitten von E15.5 Maus-Embryonen (GE, Eminentia ganglionaris; LV, lateraler Ventrikel; PP, Präplatte;Th, Thalamus). 
Zusammenfassend wurde bei konditionaler Inaktivierung des Geminin-Gens im dorsalen Telencephalon der Maus kein signifikanter Phänotyp der neocortikalen Entwicklung bis E15.5 entdeckt. Sowohl die Verteilung der Zellen in den Phasen des Zellzyklus, wie auch die sequentielle Aktivierung der analysierten Transkriptionsfaktoren in den verschiedenen Schichten des sich bildenden Cortex (Tabelle 1) war im Vergleich zu Wt-Embryonen unverändert. Der Funktionsverlust von Geminin zeigte in der Periode der Neurogenese keinen Effekt auf die proliferierenden und postmitotischen Zellpopulationen bei Bildung des cerebralen Neocortex.

\begin{tabular}{llll} 
Abbildung & Marker & Spezifität & Expression in E15.5 (Wt) \\
\hline 18 & H3P & $\begin{array}{l}\text { Zellen in M-Phase, Aktivierung } \\
\text { des G } / \text { M-Phase-Kontrollpunktes }\end{array}$ & VZZ \\
18 & BrdU 30 Min. & Zellen in S-Phase, DNA-Synthese & VZ, SVZ \\
20 & TUNEL & Apoptotische Zellen & \\
16 & Geminin & & VZ, SVZ \\
19 & Ki67 & Proliferierende Zellen & VZ, SVZ \\
19 & TuJ1 & Primär differenzierte Neurone & SVZ, IZ, CP \\
$24 b$ & Ngn1 & Vorläuferzellen der neuronalen Linie & VZ \\
25 & Sox2 & Vorläuferzellen & VZ,SVZ \\
22 & Pax6 & Vorläuferzellen / Radiale Gliazellen & VZ,SVZ \\
23 & Ngn2 & Vorläuferzellen der neuronalen Linie & VZ, SVZ \\
$24 b$ & NeuroD & Vorläuferzellen der neuronalen Linie & SVZ \\
$24 a$ & Tbr2 & Intermediäre Vorläuferzellen & VZ, SVZ, (IZ) \\
$24 a$ & Tbr1 & Postmitotische Zellen der & CP \\
& & neuronalen Linie & \\
\hline 26 & GAD1 & Interneurone & PP, GE, Th \\
\hline
\end{tabular}

Tabelle 1. Liste der verwendeten Marker und deren spezifische Expression im Cortex von E15.5 WtEmbryonen. Der spezifische Zelltyp und die spezifische Schicht im Cortex, in der der jeweilige Marker exprimiert wird, ist ebenso angegeben wie auch ein Verweis auf die entsprechende Abbildung in dieser Arbeit, welche die Expression des Markers zeigt (CP, Cortikale Platte; GE, Eminentia ganglionaris; IZ, Intermediäre Zone; PP, Präplatte; SVZ, Subventrikularzone; VZ, Ventrikularzone; Th, Thalamus). 


\section{Anreicherung von GFAP-positiven Zellen bei Abwesenheit von Geminin}

Da die konditionale Inaktivierung von Geminin im Cortex von Mäusen keine Auswirkung auf das Schicksal der neuronalen Zelllinie zeigte, wurde im Folgenden analysiert, ob das gliogene Schicksal der Zellen beeinflusst war. Da der Übergang von Neuro- zu Gliogenese ab E18 erfolgt, wurden die IHC-Analysen zunächst mit Gewebeschnitten von Mäusen des postnatalen Stadiums P10 durchgeführt. Während die bisherige Analyse von E15.5 Embryonen hauptsächlich auf coronalen Gewebeschnitten vorgenommen worden war, wurde die Analyse von P10 Mäusen zudem auch mit sagittalen Schnitten durchgeführt wie im Folgenden dargestellt. Die sagittale Betrachtungsweise ermöglicht einen Überblick des Genexpressionslevels in den verschiedenen Regionen des ZNS von rostral nach caudal und veranschaulicht ggf. graduelle Abstufungen. Die Detektion von Zellen der Astroglialinie erfolgte mit dem für primär differenzierte Astrocyten spezifischen AntiGFAP Antikörper und die Detektion von terminal differenzierten Neuronen mit Anti-NeuN.

Die Anzahl mit NeuN markierter Projektionsneurone im Neocortex war in den Geminindefizienten Mäusen im Vergleich zu Wt-Tieren nicht signifikant verändert (Abbildung 27, D, D', F, F'). Es wurde zudem keine veränderte Expression von NeuN und GFAP im Hippocampus und in der SVZ von beobachtet (Daten nicht gezeigt). Im Cortex von Mäusen mit konditional inaktiviertem Geminin war jedoch eine deutliche Anreicherung GFAP-positiver Astrocyten in der Schicht I (Abbildung 27, B', C') zu verzeichnen. In dieser Schicht war die Expression von GFAP um bis zu 200\% höher als im Cortex vergleichbarer $W t$-Tiere. Überdies wurde auch eine Zunahme von Astrocyten im Corpus Callosum (CC; Abbildung 27, E') registriert, wobei die davon ausgehenden Astrocyten auch in die Schicht VI des cerebralen Cortex hineinreichten. Das Erscheinungsbild der GFAPpositiven Zellen entsprach dabei der typisch filamentösen Morphologie von Astrocyten.

In Wt-Mäusen erscheinen die ersten GFAP-positiven Astrocyten um E18.5. Um ggf. eine vorzeitige Initiierung der GFAP-Expression zu registrieren, wurden IHC-Analysen der Stadien E16.5, E17.5 und E18.5 vorgenommen. Es wurde dabei keine frühzeitige oder gesteigerte Expression von GFAP-positiven Astrogliazellen im Cortex Geminin-defizienter Embryonen wahrgenommen (Daten nicht gezeigt).

Zusammenfassend resultierte der Verlust der Aktivität von Geminin durch konditionale Inaktivierung mit $E m \times 1^{1 R E S c r e}$ in postnatalen Stadien in keiner Veränderung der Anzahl NeuN-positiver, neuronaler Projektionsneurone. Im cerebralen Cortex von P10 Geminindefizienten Mausmutanten wurde jedoch in eine signifikante Anreicherung GFAP-positiver Astrocyten dokumentiert. 
a P10 Sagittal

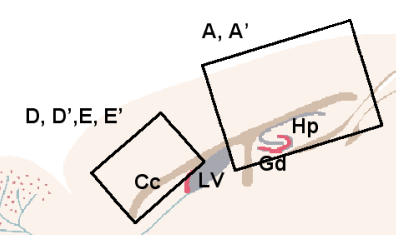

b

P10
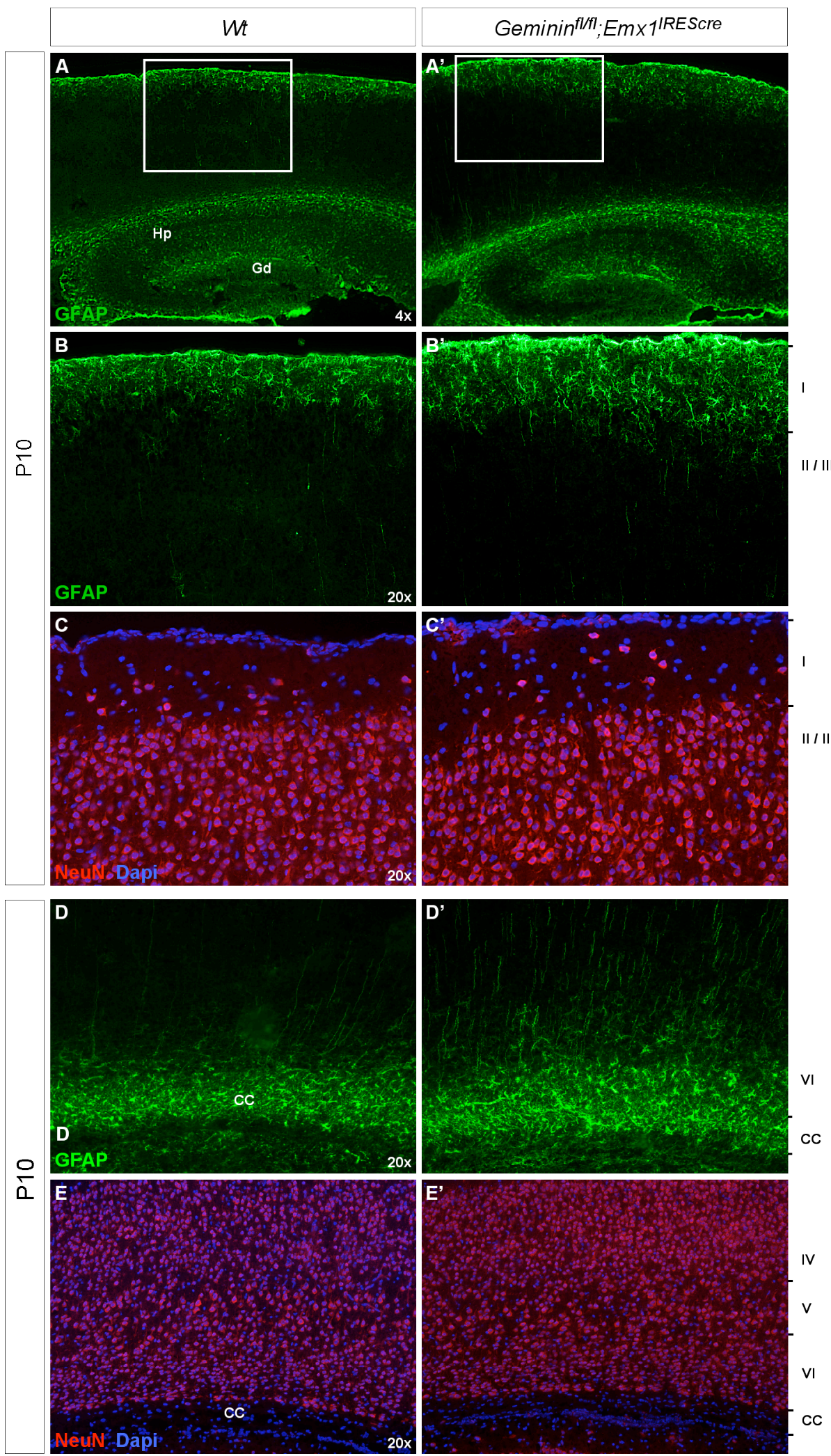
Abbildung 27. Anreicherung von Astrocyten im Cortex Geminin-defizienter Mausmutanten. (a) Schematische Darstellung eines sagittalen Schnittes durch das Gehirn einer Maus im Stadium P10. Die Kästen verweisen auf die entsprechenden Abbildungen in (b). (b) IHC mit Anti-GFAP (grün; A, A', B, B', D, D') und Anti-NeuN (rot; C, C', E, E'; Dapi in blau) im Cortex von P10 Wt- und mutanten Gehirnen. Weiße Kästen in $A$ und $A^{\prime}$ markieren den vergrößerten Bereich, der in $B$ und $B^{\prime}$ dargestellt ist. Abbildungen $A$ bis $C^{\prime}$ zeigen den Ausschnitt der oberen Schicht I; Abbildungen D bis E' stellen den Bereich der unteren cortikalen Schichten einschließlich des Corpus Callosum (CC) dar (Gd, Gyrus dentatus; Hp, Hippocampus; LV, Lateraler Ventrikel). 


\section{Diskussion}

Die embryonale Entwicklung involviert zahlreiche Zellteilungen und die Spezifizierung von zellulären Identitäten, um einen vollständigen und komplexen Organismus zu generieren. Der Prozess umfasst sowohl die Steuerung von Mechanismen, welche die konkrete Zuweisung eines zellulären Schicksals gewährleisten, als auch den korrekten Zeitpunkt dieser Determination. Die Embryonalentwicklung bedarf somit der engen Kontrolle von Zellproliferation und -differenzierung. Geminin wurde als ein Schlüsselelement der embryonalen Entwicklung charakterisiert, welches das koordinierte Zusammenspiel verschiedener Moleküle reguliert. Während Geminin zum einen die genomische Integrität durch Regulation der DNA-Replikationslizenzierung im Zellzyklus aufrechterhält, ist es zum anderen durch Kontrolle des neuralen Zellschicksals auch an der Zelldifferenzierung beteiligt.

Mit der vorliegenden Studie konnte das Verständnis der Rolle Geminins in der Entwicklung des dem ZNS untergeordnetem Telencephalon erweitert werden. Während Geminin in der Periode der Neurogenese keine entscheidende Bedeutung hat, besitzt es ab E18 eine entscheidende funktionale Rolle bei der Determination von Zellen der Astroglialinie. Des Weiteren wurde mit der Modifikation durch SUMO eine neue posttranslationale Modifikation des Geminin-Proteins identifiziert.

\section{Geminin ist ein neues Zielprotein der SUMOylierung}

Mit der Entdeckung von posttranslationalen Modifikationen wurde das Verständnis der funktionalen Diversität von Proteinen bedeutend erhöht. Die SUMOylierung hat in erster Linie Einfluss auf die Interaktion eines Proteins mit anderen Proteinen oder regulatorischen DNA-Elementen oder beeinflusst die Konformation des Proteins. Im Rahmen dieser Arbeit konnte gezeigt werden, dass humanes Geminin ein Substrat der Modifikation mit SUMO ist, und sowohl in vitro als auch in vivo in Säugerzellen sumoyliert werden kann. Das für die Konjugation von SUMO erforderliche Lysin im Geminin-Protein konnte jedoch nicht ausfindig gemacht werden.

Da der Prozess der SUMOylierung hochdynamisch und reversibel ist, sind de facto nur wenige Proteine entweder konstitutiv oder nach Erhalt bestimmter Signale quantitativ sumoyliert. Die Detektion von SUMO-konjugierten Substraten gestaltet sich oft als sehr schwierig, da nur ein kleiner Prozentsatz der zellulären SUMO-Substrate zu einer bestimmten Zeit in modifizierter Form vorliegt. Transiente SUMOylierungen werden bei Standardpräparationen oft nicht erfasst. Ausschließlich abundante Proteine wie RanGAP1, die stabil modifiziert vorliegen, können mit den gegebenen Detektionsmethoden 
erfasst werden (Mahajan et al., 1997; Matunis et al., 1996). Der Nachweis von sumoyliertem Geminin war in vivo nur bei Überexpression von Geminin und SUMO1 und Anreicherung mit Nickel-Agarose möglich. Endogenes, an SUMO1 konjugiertes Geminin konnte nicht visualisiert werden. HeLa 6xHis-SUMO1-Zellen exprimieren 6xHis-SUMO1 nur auf geringem Niveau (Girdwood et al., 2003) und eine Vielzahl von SUMO1Substraten wird mit Geminin um die Konjugation von SUMO1 konkurriert haben. Sofern also die in geringer Anzahl von SUMO1 vorhandenen Moleküle an die zellulären Zielproteine gebunden haben, verblieben nur wenige Moleküle für eine Konjugation an das endogene Geminin-Protein. Erst die Anreicherung von Geminin vermochte die Anzahl konjugierter Moleküle von Geminin an SUMO1 in dem Zellkultursystem kompetetiv zu erhöhen, so dass die Modifikation letztlich visualisiert werden konnte.

\section{Regulation der Funktion von Geminin durch posttranslationale Modifikationen}

Für das humane Geminin-Protein wurde eine weitere posttranslationale Modifikation in Form von Phosphorylierung beschrieben (Kulartz et al., 2003; Kulartz et al., 2004). Der funktionale Mechanismus dieser Modifikation bei der Regulation von Geminin ist noch vollkommen unaufgeklärt. Die Phosphorylierung kann auf die SUMOylierung von Geminin einen positiven Effekt haben, indem sie durch das Einfügen einer lokalen negativen Ladung die Bindung von Ubc9 induziert und damit die Konjugation an SUMO verstärkt wird, wie am Beispiel von MEF2A erläutert wurde (Hietakangas et al., 2006). Die Phosphorylierung kann jedoch auch wie für c-Fos beschrieben (Bossis et al., 2005) negative Konsequenzen haben, sofern die Anheftung der Phosphatgruppe in unmittelbarer Nähe eines SUMO-Akzeptorlysins stattfindet. Die Anheftung von SUMO wäre folglich nicht möglich.

Geminin wurde auch als Substrat der Modifikation mit Ubiquitin beschrieben, welches die Degradation bzw. Inaktivierung von Geminin in Abhängigkeit vom Zellzyklus einleitet (McGarry and Kirschner, 1998; Li and Blow, 2004; Benjamin et al., 2004). Ubiquitin bindet zumeist unspezifisch an Lysinreste des Zielproteins. Ubiquitin und SUMO könnten beide denselben Lysinrest als Akzeptor im Substratprotein besitzen, so dass sie in wechselseitigem Antagonismus stünden, wie auch am Beispiel von PCNA belegt wurde (Hoege et al., 2002). In einer Studie von p53 wurde auf der anderen Seite gezeigt, dass die Ubiquitinylierung die Anheftung von SUMO an ein anderes Lysin sogar verstärkt, indem die Rekrutierung von SUMO-E3-Ligasen bewirkt wird (Carter et al., 2007). Dieser Mechanismus wäre eine Erklärung für die beschriebene Inaktivierung von Geminin während der M-Phase des Zellzyklus (Li and Blow, 2004; Hodgson et al., 2002). Das Geminin-Protein erfährt eine transiente Polyubiquitinylierung, wird möglicherweise mit SUMO modifiziert und verbleibt aufgrund dessen in der $\mathrm{G}_{1}$-Phase inaktiv. Derartige Annahmen bedürfen 
jedoch weiterführender Analysen wie z. B. der Untersuchung von modifiziertem Geminin in Abhängigkeit der Zellzyklus-Phasen in einem System synchronisierter Zellen.

\section{Funktionale Rolle der SUMOylierung von Geminin}

Geminin interagiert bei der Kontrolle von Zellproliferation und -differenzierung mit verschiedenen Proteinen. Die Modifikation von Geminin mit SUMO1 vermag möglicherweise durch sterische Hinderung die Interaktion mit bestimmten Bindepartnern stören, während anderen die Bindung ermöglicht wird. Auf der anderen Seite vermag die SUMOylierung eine Konformationsänderung des Geminin-Proteins bewirken, so dass die Interaktion mit bestimmten Bindepartnern erst ermöglicht wird, während andere Partner an der Assoziation zu Geminin gehindert werden. Sofern die kovalente Bindung von SU$\mathrm{MO}$ an das Substrat keine konformativen Änderungen bewirkt, können neue Interaktionen auch durch SUMO selbst geschehen. In C. elegans wurde der SUMOylierung beispielsweise eine essentielle Rolle in der Regulation der Hox-Gene zugesprochen (Zhang et al., 2004). Da Geminin ebenfalls in der Regulation der Hox-Genexpression involviert ist, könnte diese Regulation erst durch die Konjugation von SUMO1 durchführbar sein.

Da der Prozess der SUMOylierung hochdynamisch und reversibel ist, ermöglicht die Modifikation mit SUMO zudem einen schnellen Wechsel des funktionalen Status von Geminin im Zellzyklus, welcher bei der Regulation der Replikation erforderlich ist.

Ebenso vermag die SUMOylierung ein Rolle bei der Steuerung des Transports von Geminin zwischen Kern und Cytoplasma spielen, welcher in Ei-Extrakten von Xenopus, im Huhn und für humanes Geminin nachgewiesen wurde (Luo et al., 2007; Hodgson et al., 2002; Boos et al., 2006). Wie jedoch auch RanGAP1 in Hefen und Pflanzen nicht durch SUMO modifiziert wird, kann auch Geminin nicht in allen Spezies der SUMOylierung unterliegen.

\section{Substrat-Spezifität der SUMOylierung}

SUMO wird an die meisten Substrate an ein Lysin (K) in dem Akzeptormotiv $\psi-K-x-[D / E]$ gebunden, jedoch gibt es noch weitere Faktoren, die bei der Selektion des Substrats bestimmend sind. Neben dem Lysin ist das Glutamat $(E)$ in dem Konsensusmotiv die am nächsten hochkonservierte Position. Im Fall von einigen SUMO-Substraten reduziert die Mutation des konservierten Glutamats zu Aspartat (D) signifikant die SUMOylierung, obwohl andere K-x-D Sequenzen wiederum sumoyliert werden. Das PCNA-Protein weist beispielsweise zwei SUMOylierungsmotive auf, von denen das eine konform zu der typischen Konsensussequenz ist, das andere aber eine für die SUMOylierung untypische Sequenz darstellt (Hoege et al., 2002). Andere SUMO-Substrate, wie Daxx und Smad4, 
enthalten kein typisches SUMO-Akzeptormotiv (Jang et al., 2002; Chang et al., 2005) und wieder andere werden immer noch sumoyliert, obwohl alle Konsenussequenzen mutiert sind. Die beiden vorhergesagten Konsensusmotive von humanem Geminin mögen zwar der SUMOylierungsmaschinerie zugängig sein, müssen aber nicht die entscheidenden Stellen für die Konjugation von SUMO1 darstellen. Da kein vollständiger Verlust der Modifikation von Geminin mit SUMO beobachtet wurde, vermag SUMO bei Abwesenheit des Akzeptorlysins möglicherweise auf ein benachbartes Lysin übergesprungen sein. SUMO kann zudem an mehrere Lysine des Geminin-Proteins konjugiert sein. Zur weiteren Analyse bedürfte es der Konstruktion von Doppel- bzw. Tripelmutanten, bei denen zwei bzw. drei Lysine zu Arginin mutiert sind. Wie im Fall des Daxx-Proteins war die Mutation von 9 Lysinen nicht ausreichend, um die SUMOylierung zu verhindern. Erst der Austausch von 13 Lysinen zu Arginin führte zum vollständigen Verlust der SUMOylierung (Lin et al., 2006). Ein Geminin-Konstrukt ohne jedes Lysin sollte letztlich die Modifikation mit SUMO vollständig verhindern.

Basierend auf den Ergebnissen und Erkenntnissen der vorliegenden Arbeit ergeben sich eine Reihe interessanter Fragestellungen im Hinblick auf die funktionale Rolle der SUMOylierung von Geminin. Da mehrere Interaktionspartner von Geminin charakterisiert worden sind, stellt sich die Frage, inwiefern die SUMO-Modifikation die Bindung an das jeweilige interagierende Protein zulässt oder inhibiert. Die nicht durch SUMO1 modifizierbare Lysin-Mutante von Geminin würde neben der unmodifizierten Form ein bedeutendes Hilfsmittel bei der Aufklärung der Rolle von Geminin in der Regulation der verschiedenen Proteine und regulatorischen DNA-Elemente darstellen. Weiterführende Untersuchungen sind erforderlich, um die Rolle von sumoyliertem Geminin bei der Kontrolle von Zellproliferation und -differenzierung $\mathrm{zu}$ entschlüsseln. Sumoyliertes Geminin vermag zudem eine funktionale Rolle bei der neuronalen Entwicklung zukommen, da der Modifikation mit SUMO in den letzten Jahren vermehrt auch eine Rolle bei der Regulation neuronaler Mechanismen, wie der von Glutamat-Rezeptoren zugeschrieben wurde (Tang et al., 2005; Martin et al., 2007). 


\section{Phänotyp-Analyse der konditional inaktivierten Geminin-Mäuse}

Um einen Einblick in die Funktion von Geminin während der cortikalen Entwicklung im Telencephalon zu erlangen, wurde eine Strategie zur konditionalen Inaktivierung von Geminin in vivo entwickelt. Zur Generierung des konditionalen Knockout-Konstruktes wurde im Rahmen dieser Arbeit die Methode des „Recombineering“ angewendet.

Die spezifische Inaktivierung der Expression des Geminin-Gens mit Emx $1^{\text {IREScre }}$ im Bereich des dorsalen Telencephalon wurde anhand ISH von Geminin-mRNA gezeigt und stimmte mit der Expressionsdomäne von Emx1 $1^{\text {RESCre }}$ überein (vergleiche Gorski et al., 2002). Homozygote Geminif ${ }^{f / f t} ; E m \times 1^{\text {IREScre }}$ Embryonen und adulte Mäuse wiesen keine morphologischen Aberrationen auf, verhielten sich normal und waren fertil.

\section{Inaktivierung von Geminin erlaubt die normale Proliferation von cortikalen Vorläuferzellen}

Die Zellzyklusparameter in der frühen neocortikalen Entwicklung bestimmen die Anzahl der ausdifferenzierten Neurone im Cortex. Im Cortex Geminin-defizienter Embryonen konnte während der Neurogenese keine veränderte Verteilung der proliferierenden Vorläuferzellen in den einzelnen Phasen des Zellzyklus festgestellt werden. In E13.5 und E15.5 mutanten Embryonen befanden sich ebenso viele Zellen in der S-Phase des Zellzyklus wie in vergleichbaren Wt-Embryonen. Ebenso wurde kein signifikanter Unterschied in der Anzahl und Lokalisation H3P-positiver Zellen in der $\mathrm{G}_{2} / \mathrm{M}$-Phase des Zellzyklus dokumentiert. Es war keine erhöhte Apoptoserate gegeben und das Verhältnis proliferierender Vorläuferzellen zu postmitotischen Zellen war unverändert, so dass daraus resultierend entsprechend auch keine veränderte Anzahl von Neuronen in postnatalen Stadien verzeichnet wurde.

Im Gegensatz zu den Funktionsverluststudien von Geminin in humanen Zellkultursystemen und in Drosophila (Melixetian et al., 2004; Zhu et al., 2004; Quinn et al., 2001; Mihaylov et al., 2002; Yoshida et al., 2004) resultierte die konditionale Inaktivierung von Geminin in cortikalen Vorläuferzellen nicht in Rereplikation und einem Zellzyklusarrest in der $\mathrm{G}_{2} / \mathrm{M}$-Phase. Wie jedoch auch in der Knockout-Situation resultierte die Herunterregulierung von Geminin in HeLa- und MCF10A-Zellen mittels RNA Interferenz nicht in Rereplikation und Zellzyklusarrest. In diesen Zellen inhibiert Geminin in der S-Phase nicht die Funktion des Replikationsfaktors Cdt1, sondern das Level von Cdt1 unterliegt der Regulation redundanter Mechanismen wie Ubiquitinylierung und Proteolyse (Kulartz and Knippers, 2004; Nishitani et al., 2004; Sugimoto et al., 2004; Machida and Dutta, 2007). Während Geminin in der S-Phase an das Chromatin gebunden bleibt, läuft die Synthese und Degradation von Cdt1 durch $\mathrm{SCF}^{\mathrm{Skp} 2}$ ab. Erst sofern Cdt1 in der $\mathrm{G}_{2}$-Phase im 
Überschuss produziert wird oder der Degradation entgeht, verhindert Geminin den Zugang von Cdt1 zur Replikationsmaschinerie (Arias and Walter, 2005). Ein vergleichbarer Mechanismus vermag auch in den cortikalen Vorläuferzellen abgelaufen sein, da die Eliminierung von Geminin bis E15.5 keinen nachweisbaren Effekt auf die Zellzyklusparameter hatte.

Zusammenfassend hatte die Deletion von Geminin im dorsalen Telencephalon keinen signifikanten Effekt auf den mitotischen Zellzyklus während der Neurogenese. Geminin scheint in dieser Periode von E10 bis E15.5 nicht an der Entscheidung, aus dem Zellzyklus auszutreten oder eine weitere Runde durch den Zellzyklus zu laufen, beteiligt zu sein.

\section{Die frühe neuronale Differenzierung in der Maus hängt nicht von Geminin ab}

Die Expression des Pax6-Transkriptionsfaktors ist auf eine Subpopulation der cortikalen Vorläuferzellen in der VZ und SVZ, den neuroepithelialen und radialen Gliazellen beschränkt (Götz et al., 1998). Mittels GST-Pull-Down Experiment und CoImmunpräzipitation in Säugerzellen wurde im Rahmen dieser Arbeit die physikalische Interaktion von Pax6 und Geminin in vitro und in vivo belegt. Obwohl bisher nicht analysiert wurde, ob auch bei der neocortikalen Entwicklung eine Interaktion der beiden Proteine gegeben ist, deutet die Co-Lokalisation von Geminin und Pax6 in Zellen der VZ und SVZ und in adulten Stammzellen (Spella et al., 2007) auf eine biologisch signifikante Interaktion hin. Im Cortex Geminin-inaktivierter Mäuse wurde jedoch während der frühen neocortikalen Entwicklung keine Repression oder Erhöhung der Genexpressionslevel von Pax6 und dem Pax6-reguliertem Gen Ngn2 (Scardigli et al., 2003) festgestellt. Zudem wies die Morphologie des geschichteten Neocortex von Geminin-deletierten Mäusen keine bestimmten Aberrationen auf wie z. B. bei Abwesenheit von Pax6 dokumentiert wurde (Götz et al., 1998; Estivill-Torrus et al., 2002; Malatesta et al., 2000). Bei konditionaler Inaktivierung von Pax6 äußert sich der Phänotyp so im Besonderen in Defekten bei der Formation der unteren cortikalen Schichten (Tuoc, 2008). Bei Überexpression von Pax6 wurde demgegenüber eine Anreicherung radialer Gliazellen verzeichnet (Heins et al., 2002) und die Expression von Ngn2 ist in den Pax6-Mutanten entsprechend herunterreguliert (Stoykova et al., 2000). Da derartige Merkmale nicht bei Abwesenheit von Geminin dokumentiert wurden, hat Geminin somit in der Phase der frühen neuronalen Entwicklung des Neocortex bis E15.5 keine reprimierende oder aktivierende Wirkung auf Pax6.

Neben der Untersuchung der Expression von Pax6 und Ngn2 erbrachte auch die Expressionsanalyse von weiteren Cortex-spezifischen Markern der neuronalen Zelllinie 
(Tbr1/2, NeuroD etc.) und dem Marker für Interneurone (GAD1) in E15.5 und in postnatalen Stadien keine signifikanten Unterschiede zwischen Wt- und cKO-Mäusen. Geminin ist somit offenbar nicht für die Bildung von Neuronen und Interneuronen in der frühen neuronalen Entwicklung und für die Spezifizierung der cortikalen Schichten erforderlich.

\section{Geminins Rolle in der Neuralinduktion}

Die Expression von Geminin ist in den neuroepithelialen Zellen der Neuralplatte, des sich formierenden Cortex und in den cortikalen Vorläuferzellen der Maus gegeben. Die Deletion des gefloxten Geminin-Gens mit Emx $1^{\text {IREScre }}$ erfolgte ab E9.5 in den neuroepithelialen Stammzellen des Cortex und im Laufe der weiteren Entwicklung auch in den cortikalen Vorläuferzellen der VZ und SVZ (Gorski et al., 2002). Die konditionale Inaktivierung von Geminin lag somit zu Beginn der Neurogenese vor. Die neuroepithelialen Zellen der Neuralplatte, aus denen aber alle Zellen des ZNS hervorgehen, hatten jedoch noch nicht die Deletion des Geminin-Gens erfahren.

In Xenopus resultierte die Herunterregulierung von Geminin vor beginnender Formation der Neuralplatte in der Repression der Sox2-Genexpression (Seo et al., 2005a). Die Überexpression von Geminin führte dagegen zur Expansion des Neuralgewebes, indiziert durch die erhöhte Expression von Sox2 (Boos et al., 2006). Auch im Huhn konnte gezeigt werden, dass Geminin in koordinierter Zusammenarbeit mit dem SWI/SNF-Komplex zu Beginn der Entwicklung der Neuralplatte die Expression des Sox2-Gens aktiviert (Papanayotou et al., 2008). In der Maus erfolgt die Formation der Neuralplatte in E7.5. Im Cortex von Geminin ${ }^{f / f f l} ; E m \times 1^{\text {IREScre }}$ Mäusen wurde demzufolge keine Veränderung der Sox2-Expression registriert, da die Inaktivierung von Geminin durch Emx $1^{\text {IREScre }}$ erst erfolgte, nachdem die Aktivierung der Sox2-Expression durch Geminin und die Bildung der Neuralplatte bereits vollzogen war. Der beschriebene Mechanismus der Gemininregulierten Sox2-Aktivität ist offenbar spezifisch für die Neuralinduktion. Obgleich eine CoLokalisation von Geminin und Sox2 auch bei der Bildung des murinen Neocortex aufgewiesen wurde (Spella et al., 2007), scheint in der Periode der Neurogenese die Regulation der Sox2-Expression Geminin-unabhängigen Mechanismen zu unterliegen. So wurde u. a. gezeigt, dass die Aktivierung von Sox2 in der SVZ während der späten neuronalen Entwicklung direkt durch Pax6 gesteuert wird (Wen et al., 2008). 


\section{Inhibition der Gliogenese in der Periode der Neurogenese}

Bei konditionaler Inaktivierung des Geminin-Gens im dorsalen Telencephalon wurde im Rahmen dieser Arbeit eine Anreicherung GFAP-positiver Zellen in postnatalen Stadien beobachtet. GFAP zählt zu dem Typ III Intermediärfilament-Proteinen und ist spezifisch für Zellen der Astroglialinie als Marker für Astrogenese (Reeves et al., 1989). Die Expression von GFAP ermöglicht jedoch nicht die Unterscheidung von primär und terminal differenzierten Astrocyten. Zudem exprimieren auch viele embryonale und adulte Vorläuferzellen des ZNS GFAP. Die Charakterisierung dieser zellulären Subtypen ist noch relativ ungeklärt. In den P10 Geminin-Mausmutanten wurde sowohl eine Anreicherung bereits determinierter GFAP-positiver Astrocyten in der MZ als auch im Corpus Callosum vermerkt. Die Differenzierung in GFAP-positive Zellen erfolgte jedoch nicht frühzeitig. Geminin ist somit bei der Entscheidung der Vorläuferzellen, das gliogene Schicksal anzunehmen, involviert.

Während der Neurogenese von E10 bis etwa E18 gehen aus den multipotenten Vorläuferzellen des Neocortex Neurone hervor, die die Cytokine CTNF (engl. „ciliary neurotrophic factor"), LIF (engl. „leukemia inhibitor factor") und CT-1 (Cardiotrophin-1) sekretieren (reviewed in Miller and Gauthier, 2007; Guillemot, 2007). Diese induzieren zusammen mit BMP2 und Notch-Liganden ab E18 die Gliogenese, welche die Bildung von Astrocyten aus den entsprechenden Vorläuferzellen einbezieht. Um eine vorzeitige Einleitung der Gliogenese zu verhindern, bedarf es während der Neurogenese von E10 bis E18 zunächst der Repression der durch die extrinsischen Faktoren induzierten Signalwege. Ein Mechanismus zur Repression der Gliogenese involviert das proneurale bHLH-Protein Ngn1. Ebenso wie Ngn2 fördert dieses Mitglied der bHLH-Gruppe von Transkriptionsfaktoren nicht nur die Differenzierung in Neurone, sondern es dient gleichzeitig auch der Repression des gliogenen Schicksals in den Vorläuferzellen.

Die von den neu gebildeten Neuronen sekretierten Faktoren wie CT-1 aktivieren zunächst den JAK/STAT-Signalweg. Der Transkriptionsfaktor STAT3 formiert in diesem Zuge mit Smad1 und dem Co-Aktivator p300/CBP einen Komplex, der an den Promotor des GFAPbzw. S100 $\beta$-Gens bindet und die Expression der Gene initiiert. Die Transaktivierung dieser Gene wird dabei während der Neurogenese durch das bHLH-Protein Ngn1 reprimiert. Ngn1 assoziiert an p300/CBP, so dass der Co-Aktivator in Beschlag genommen wird und nicht mehr für die Komplexbildung und Aktivierung von STAT3 verfügbar ist. Als Konsequenz ist die Gliogenese inhibiert (Abbildung 28a; Sun et al., 2001). Innerhalb der Vorläuferzellen fördert Ngn1 somit die Differenzierung in Neurone und inhibiert die Zellen gleichzeitig, sich zu Astrocyten weiterzuentwickeln. 


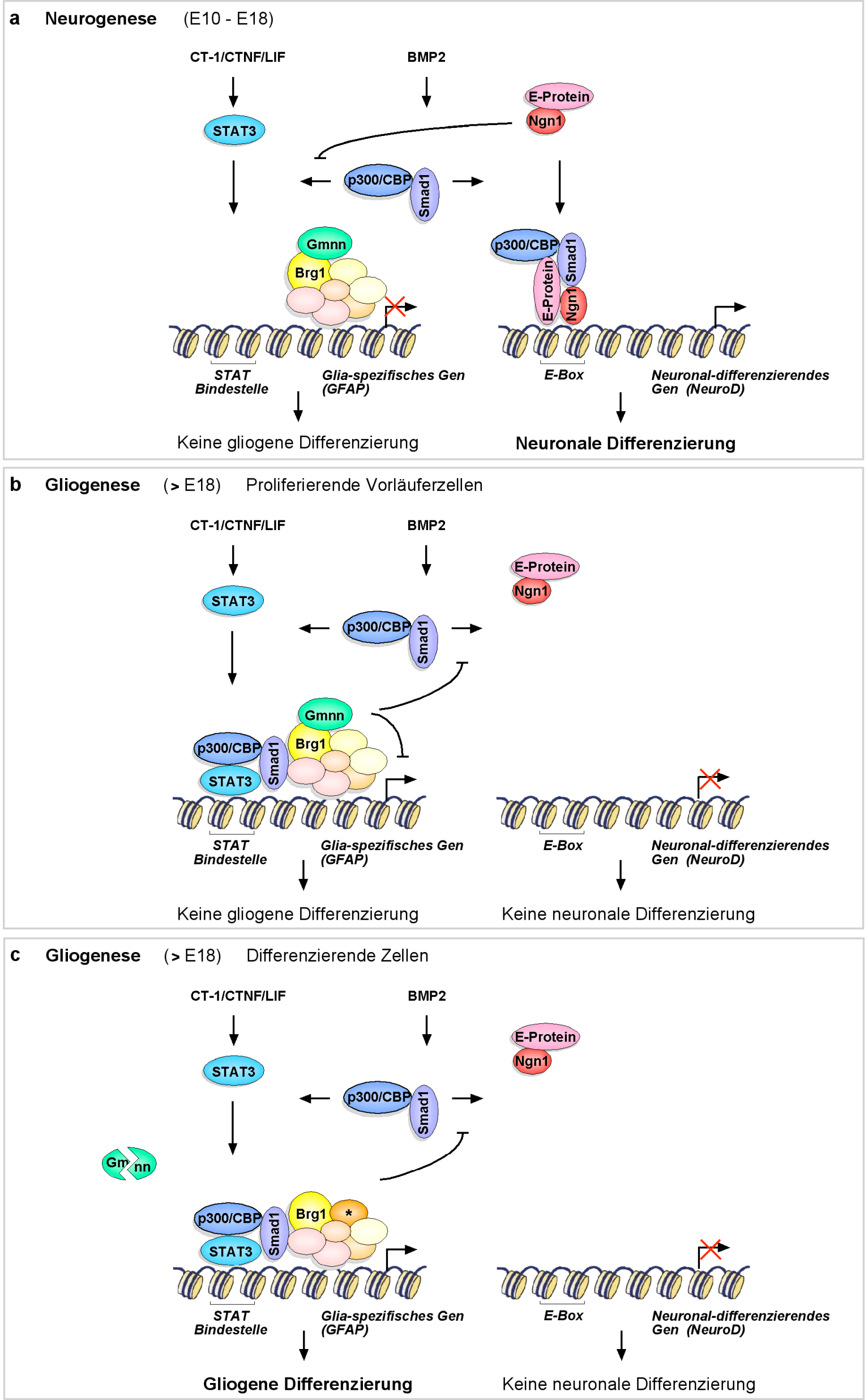


Abbildung 28. Vereinfachtes Modell der Regulationsmechanismen bei der Neuralinduktion und der Neurogenese und Gliogenese im Cortex. (a) Der Co-Aktivator p300/CBP und Smad1 assoziieren während der Neurogenese von E10 bis E18 mit Ngn1 an neuronal-spezifischen Promotoren wie von NeuroD und aktivieren deren Transkription (rechts). Die neu gebildeten Neurone sekretieren dann die Cytokine CT-1, CTNF und LIF, welche zusammen mit BMP2 den JAK/STAT-Signalweg und Smad1 aktivieren. Ngn1 inhibiert in dieser Phase die Aktivierung von Glia-spezifischen Genen wie GFAP, indem es STAT3 von der Aktivierung von p300/CBP-Smad1 abhält. Die Differenzierung in Gliazellen wird damit während der Neurogenese verhindert (links; verändert nach Sun et al., 2001). (b) Geminin (Gmnn) reprimiert während der Gliogenese in gliogenen Vorläuferzellen die Aktivierung der GFAP-Expression durch Inhibition des SWI/SNF-Komplexes, welcher mit p300/CBP, Smad1 und STAT3 auf dem Chromatin assoziiert ist. Diese Regulation schließt möglicherweise auch die Repression der Aktivität von Ngn1 ein. Die Differenzierung in gliogene Zellen ist folglich reprimiert. (c) Um die gliogene Differenzierung einzuleiten, erfolgt vermutlich der Austausch von Untereinheiten des SWI/SNF-Komplexes (markiert durch *), so dass Geminin die Transkriptionsaktivierung des GFAPGens nicht länger reprimiert. Vermutlich besitzt der SWI/SNF-Komplex auch eine Funktion auf dem Chromatin von neuronal-differenzierenden Genen, das aber zur Vereinfachung des Modells in diesem Rahmen nicht dargestellt wurde.

Dieser Mechanismus ist in den Mausmutanten auch ohne funktionales Geminin abgelaufen, da keine vorzeitige Initiierung der Gliogenese durch Anreicherung GFAP-positiver Zellen vor E18 beobachtet wurde. Da aber eine deutlich höhere Anzahl von Astrogliazellen in postnatalen Stadien registriert wurde, vermag Geminin möglicherweise erst ab E18, beim Übergang von Neurogenese zu Gliogenese, und in der weiteren Entwicklung eine entscheidende Rolle zukommen, indem Geminin die Inhibition des gliogenen Zellschicksals vermittelt.

\section{Geminins Rolle in der Regulation der Gliogenese}

Die Gliogenese im murinen Cortex erfordert ebenso die Repression von neuronalen Signalen wie in der Periode der Neurogenese die Inhibition von gliogenen Signalen erforderlich ist. Es bedarf somit zeitlich kontrollierter Mechanismen, welche die Aktivität der proneuralen bHLH-Proteine mit Einleitung der Gliogenese unterdrücken.

In einer dieser Arbeit vorausgegangenen Studie wurde die inhibitorische Wirkung von Geminin auf die proneuralen Gene belegt (Seo et al., 2005a). In Xenopus und proliferierenden P19-Zellen aus der Maus wurde dabei gezeigt, dass Ngn1 an die E-Box von spezifischen Genen bindet. Um die Expression der Zielgene zu initiieren, ist die Transaktivierung durch Brg1, der katalytischen Untereinheit des SWI/SNF-Komplexes, erforderlich, so dass letztlich die Differenzierung der Zellen eingeleitet werden kann (Seo et al., 2005b). Geminin inhibiert die Interaktion zwischen den bHLH-Proteinen und Brg1 (Seo et al., 2005a). Die neuronalen Vorläuferzellen verbleiben infolgedessen in dem Status der Proliferation, so dass Geminin der Aufrechterhaltung des undifferenzierten Zellstatus dient und damit den Zeitpunkt der Differenzierung der neuronalen Vorläuferzellen kontrollieren kann. Ein analoger, über den SWI/SNF-Komplex vermittelter 
Mechanismus vermag auch bei der Gliogenese im murinen Cortex stattfinden, der jedoch die Expression von Glia-spezifischen Genen wie GFAP reguliert (Abbildung 28b). Da die Neurogenese in dieser Phase der Entwicklung bereits herunterreguliert ist, könnte Geminin oder Brg1 zeitgleich die Inhibition von Ngn1 und weiteren Mitgliedern der bHLHFamilie vermitteln (Abbildung 28b), ohne dass sich der Funktionsverlust von Geminin in den Mausmutanten auf die neuronale Zellpopulation auswirkt.

Brg1 wird ab E13 in der cortikalen VZ exprimiert (Matsumoto et al., 2006), so dass ab diesem Stadium die Expressionsdomänen von Geminin und Brg1 überlappen und eine Interaktion durch die räumliche Nähe ermöglicht wird. Die konditionale Inaktivierung von Brg1 mit Nestin ${ }^{C r e}$ resultierte im Gegensatz zum Funktionsverlust von Geminin in einer Abnahme von GFAP-positiven Zellen. Die Gliogenese war bei Abwesenheit von Brg1 herunterreguliert, wohingegen die Expression von Markern neuronaler Vorläuferzellen erhöht war (Matsumoto et al., 2006). Die Analysen in der Maus konnten damit bestätigen, dass Brg1 nicht wie in Xenopus und P19-Zellen für die Expressionsaktivierung von proneuralen bHLH-Genen verantwortlich ist, sondern dass Brg1 in der Maus ein bestimmender Faktor bei der Differenzierung und/oder Reifung von Astrocyten und Oligodendrocyten ist. Brg1 reprimiert die Entscheidung zu dem neurogenen Schicksal einer gliogenen Vorläuferzelle und erhält sie dagegen in einem Status aufrecht, der ihr erlaubt, das Schicksal einer Gliazelle anzunehmen und auf entsprechende gliogene Signale zu reagieren.

Den Ergebnissen der vorliegenden Arbeit zufolge gewinnt die Interaktion zwischen Geminin und Brg1 erst in der Phase der Gliogenese an Bedeutung wie in dem Modell in Abbildung 28b veranschaulicht. Geminin vermag in proliferierenden Zellen durch Inhibition von Brg1 die Transkription des GFAP-Gens und möglicherweise weiteren Gliaspezifischen Genen wie $S 100 \beta$ verhindern. Bei konditionaler Inaktivierung von Geminin im Cortex war die Repression des SWI/SNF-Komplexes folglich aufgehoben und zuvor reprimierte Transkriptionsfaktoren wurden aktiviert, so dass das GFAP-Gen im Überschuss exprimiert wurde. Geminin dient somit der Aufrechterhaltung des proliferierenden Zellstatus, indem es die Aktivität von Brg1 kontrolliert.

Dieser Mechanismus kann in direkter Verbindung mit dem erläuterten JAK/STATSignalweg stehen, da gezeigt wurde, dass bei der Signalgebung durch das Cytokin IL-6 (Interleukin-6) Brg1 den Transkriptionsfaktor STAT3 auf das Chromatin IL-6-induzierbarer Gene rekrutiert (Ni and Bremner, 2007). In dem vorgeschlagenen Modell sind sowohl Brg1 als Komponente des SWI/SNF-Komplex wie auch STAT3 und der Co-Aktivator p300/CBP mit dem Chromatin des GFAP-Gens assoziiert, dessen transkriptionelle Aktivierung durch Geminin blockiert wird (Abbildung 28b). Geminin vermag die Aktivierung 
der Transkription dabei entweder direkt oder durch Rekrutierung von Co-Repressoren oder HDACs (Histon-Deacetylasen) inhibieren.

Die Zusammensetzung der Untereinheiten des SWI/SNF-Komplexes unterscheidet sich in proliferierenden und postmitotischen Zellen (Lessard et al., 2007). Die Bindung von Geminin an Brg1 könnte somit durch Modifikation oder Austausch der Untereinheiten des SWI/SNF-Komplexes aufgelöst werden (Abbildung 28c, Markierung der ausgetauschten SWI/SNF-Untereinheit durch *), so dass Geminin in Folge keine inhibitorische Wirkung mehr auf Brg1 hat. Die Expression des GFAP-Gens wird aktiviert und die gliogene Differenzierung eingeleitet (Abbildung 28c). Die Expression von Geminin ist außerdem auf proliferierende Zellen beschränkt (Spella et al., 2007) und mit Austritt der Zellen aus dem Zellzyklus erfolgt die Degradation oder Inaktivierung des Geminin-Proteins (McGarry and Kirschner, 1998; Li and Blow, 2004). In Folge der Abwesenheit von Geminin würde Brg1 nicht länger an seiner Funktion der Transkriptionsaktivierung gehindert werden und der Prozess der gliogenen Differenzierung kann ablaufen (Abbildung 28c).

Möglicherweise involviert der durch Geminin regulierte Mechanismus in der Gliogenese auch Pax6 und Sox2. Beide Transkriptionsfaktoren werden in dieser Phase der Entwicklung des Neocortex in GFAP-positiven gliogenen Vorläuferzellen und primären Astrocyten exprimiert (Sakurai and Osumi, 2008). Es wird angenommen, dass die Transkriptionsfaktoren an der Reifung von Astrocyten beteiligt sind. Wie bereits erwähnt hat Geminin keinen Effekt auf die Expression von Pax6 und Sox2 in der frühen neocortikalen Entwicklung. Da aber eine Anreicherung GFAP-positiver Zellen in postnatalen Stadien verzeichnet wurde, vermag Geminin einen Einfluss auf die Steuerung von Pax6 und Sox2 während der späten Entwicklung haben. Da Geminin bei Einleitung der Differenzierung in Astrogliazellen nicht mehr verfügbar ist, kann die Aktivität von Pax6 und Sox2 und das Schicksal dieser Zellen, Glia zu werden, nicht mehr durch Geminin reprimiert werden. Eine eingehendere Expressionsanalyse von Pax6, Sox2 und Markern der gliogenen Zelllinie wie $S 100 \beta$ in postnatalen Stadien der Geminin ${ }^{f / f / f \mid} ; E m \times 1^{\text {IREScre }}$ Linie würde in diesem Rahmen Aufschluss über den Regulationsmechanismus durch Geminin geben.

In einer weiteren Studie wurde zudem belegt, dass p300/CBP auch ein Interaktionspartner von Pax6 ist. Phosphoryliertes Pax6 transaktiviert den Co-Aktivator, dessen Interaktion mit Pax6 daraufhin verstärkt wird und in Folge wird die Expression der Zielgene aktiviert (Kim et al., 2006). Obwohl die funktionale Relevanz dieser Interaktion im ZNS bisher ebenso wenig analysiert wurde wie die Interaktion von Geminin und Pax6 im ZNS, wäre ein biologisch signifikanter Regulationsmechanismus im neocortikalen Gewebe dennoch denkbar. Geminin könnte als Teil des Komplexes von Pax6, p300/CBP und 
SWI/SNF eine regulatorische Funktion bei der Repression des gliogenen Zellschicksals haben. Inwiefern Geminin die funktionalen Eigenschaften des Komplexes beeinflusst, bliebe zu klären.

Brg1 wurde des Weiteren in einer cDNA Microarray Analyse von Transkripten in der Linse von Pax6-überexprimierenden transgenen Mäusen gefunden (Chauhan et al., 2002). Brg1 und Pax6 weisen im Auge überlappende Expressionsdomänen auf. Der Promotor des Brg1-Gens enthält mindestens drei Bindestellen für Pax6 und die Expression von Brg1 ist in den transgenen Pax6-Mäusen hochreguliert, so dass eine direkte Regulation von Brg1 durch Pax6 im Auge plausibel ist (Chauhan et al., 2002). In einer weiterführenden Studie wurde zudem belegt, dass Pax6 Brg1 rekrutiert, die Chromatin-Remodellierung des $\alpha \mathrm{A}-K r y s t a l l i n-L o k u s$ der Linse zu initiieren (Yang et al., 2006b). Die Interaktion von Brg1 und Pax6 ist im Neocortex bisher nicht untersucht worden. Sofern Geminin aber eine inhibitorische Wirkung auf den SWI/SNF-Komplex ausübt, könnte diese durch die Pax6vermittelte Chromatin-Remodellierung des Komplexes aufgehoben werden, so dass in Folge die Differenzierung der Zellen in Astrogliazellen eingeleitet wird.

Eine Option zu weiterführenden Analysen des Schicksals Geminin-deletierter Zellen ist die in vitro Kultivierung so genannter Neurosphären (Reynolds and Weiss, 1992). Neurale Stamm- oder Vorläuferzellen würden isoliert, expandiert und ausgezählt werden, um die verschiedenen Subtypen Geminin-defizienter Zellen zu quantifizieren bzw. zu charakterisieren. Zellzyklusparameter und die Aktivierung von Kontrollpunkten des Zellzyklus könnte durch die Verwendung von spezifischen Markern (H3P, Ki67, Cycline, Cdks etc.) untersucht werden. Außerdem könnte vermutlich eine Tendenz der Zellen zur Differenzierung in Astrogliazellen visualisiert werden, deren stufenweise Differenzierung mittels Expressionsanalyse mit entsprechenden Markern (S100 $\beta$, Cd44 etc.) verfolgt werden könnte.

\section{Geminins Rolle in der Embryonalentwicklung}

Die Spezifizierung des Schicksals einer Zelle involviert, bezogen auf ein besonderes Schicksal, die reziproke Aktivierung von Genen und die Repression von Genen alternativer Schicksale. Viele Transkriptionsfaktoren können sowohl das eine Schicksal positiv regulieren als auch zugleich eine negative Wirkung auf das alternative Schicksal haben. Geminin wurde durch Interaktion mit dem SWI/SNF-ChromatinRemodellierungskomplex als ein Schlüsselelement beim Übergang von proliferierenden Vorläuferzellen zu differenzierenden Zellen charakterisiert (Seo et al., 2005a).

Geminin hat während der Neurogenese von E10 bis E18 keinen Effekt auf die neuronale Differenzierung. Mit Beginn der Gliogenese ab E18 bewirkt Geminin aber offenbar die 
Aufrechterhaltung des proliferierenden Zellstatus, indem es die Differenzierung in GFAPpositive Astrogliazellen reprimiert. Der durch Geminin vermittelte Prozess führt möglicherweise zur Unterscheidung von neuronalen Vorläuferzellen und intermediären Subklassen, welche sich zwischen dem Stadium einer Stammzelle und einem bestimmten Stadium von Vorläuferzelle befinden. Die Mechanismen bezüglich der räumlichen und zeitlichen Kontrolle dieser Regulation sind bisher nur unzureichend verstanden.

Wie am Beispiel von Ngn1 verdeutlicht, ist das proneurale bHLH-Protein bei der Aktivierung von Genen für die neuronale Differenzierung erforderlich und ebenso an der Repression des gliogenen Zellschicksals beteiligt. Die Regulation dieser unabhängigen Prozesse wird vermutlich durch bestimmte Domänen des Ngn-Proteins gewährleistet. Auch im Fall von Geminin verdeutlicht die molekulare Struktur des Proteins seinen multifunktionalen Charakter. Während einige Bindepartner miteinander konkurrieren werden, binden andere simultan an Geminin. Der Effekt von Geminin bei in vivo Überexpressionsoder Funktionsverluststudien hat sich oftmals als Dosis-abhängiger Effekt erwiesen. Die Ergebnisse vorausgegangener Studien deuten darauf hin, dass das Verhältnis des Expressionslevels von Geminin gegenüber den Interaktionspartnern die Funktionalität von Geminin zu entscheiden vermag wie z. B. anhand der Regulation der Cdt1-Aktivität gezeigt wurde (Lutzmann et al., 2006). Geminin wird neben der zeitlichen Kontrolle der Produktion von GFAP-positiven Zellen im murinen Cortex simultan auch die Regulation des Zellzyklus durch Interaktion mit anderen Proteinen kontrollieren.

Im Rahmen der vorliegenden Arbeit wurde ein weiterer konditionaler Knockout der transgenen Geminin-Linie mit der Cre Rekombinase unter der Kontrolle des $T$ (brachyury) Promotors und mit einer Mauslinie, bei der die Expression der Cre Rekombinase durch das Msd (mesodermal) Enhancer-Element des Delta1-Gens gesteuert wurde (Beckers et al., 2000), vorgenommen (Daten nicht gezeigt). Beide regulatorischen Elemente werden im Allgemeinen in der frühen Embryonalentwicklung im mesodermalen Gewebe aktiviert, aus denen die Somiten hervorgehen, welche später u. a. zu Wirbeln und Muskeln differenzieren. T-Cre Mäuse deletierten das konditionale Geminin-Allel bereits im Primitivstreifen, während die Expression von Msd-Cre um E7 im paraxialen Mesoderm des Primitivstreifens aktiviert wird und später in den Somiten erhalten bleibt. Wie aber auch bei der Geminin ${ }^{f / f f l} ; E m \times 1^{\mid R E S c r e}$ Linie keine offensichtlichen Abnormalitäten in Morphologie und im Verhalten der transgenen Tiere festgestellt wurde, so erbrachte auch die Untersuchung der mit $T$ - und Msd-Cre deletierten Mäuse keinen Hinweis auf einen offensichtlichen Phänotyp (Daten nicht gezeigt). Obwohl Geminin an der Regulation der Hox-Gene und -Proteine bei der axialen Musterung beteiligt ist, konnten keine homeotischen Transformationen der Wirbel in den transgenen Tieren nachgewiesen werden. 
Obgleich Geminin nach vollständiger Inaktivierung in der Maus eine bedeutende Rolle in den ersten embryonalen Zellteilungen zugeschrieben wurde (Gonzalez et al., 2006; Hara et al., 2006), konnte in der vorliegenden Arbeit bei konditionaler Inaktivierung von Geminin kein gravierender Effekt registriert werden. Während die ersten Teilungen der ES-Zellen eines Embryos die Präsenz von Geminin verlangen, scheint sie während der weiteren Entwicklung zu einem komplexen Organismus entbehrlich zu sein. Die Funktion Geminins vermag in diesem Fall durch andere regulatorische Proteine kompensiert worden sein, wie beispielsweise für Ngn2 angenommen wird (Fode et al., 2000). Der dahinter stehende Mechanismus wird dabei in Abhängigkeit von dem jeweiligen Zelltyp stehen. Während Geminin bei der Neurogenese entbehrlich ist, ist es in der Periode der Gliogenese ein entscheidender Faktor bei der Aufrechterhaltung des proliferierenden Zellstatus und verhindert die Differenzierung in Astrogliazellen. 


\section{Zusammenfassung}

Während der embryonalen Entwicklung muss für den Übergang von der Zellproliferation zur -differenzierung eine präzise Koordination und zeitliche Kontrolle gewährleistet sein. Geminin wurde als multifunktionales Protein charakterisiert, das in der Regulation der DNA-Replikationslizenzierung, Chromatin-Remodellierung, Transkriptionsregulation und in der Kontrolle des neuralen Zellschicksals involviert ist.

Die Interaktion mit verschiedenen Bindepartnern ermöglicht Geminin die zeitgleiche Kontrolle von Zellproliferation und -differenzierung. Während einige Faktoren simultan an Geminin binden können, stehen andere in direkter Kompetition um die Bindungsdomänen. Mit der SUMOylierung wurde eine neue posttranslationale Modifikation des GemininProteins identifiziert, die den Ausgangpunkt der Analyse neuer Regulationsmechanismen von Geminin und sumoyliertem Geminin in der Kontrolle der zellulären Prozesse darstellt.

Bei der Entwicklung des murinen Neocortex regulieren epigenetische Veränderungen in der Zelltyp-spezifischen Genexpression den Übergang von neurogenen zu überwiegend gliogenen Phasen der Differenzierung von Vorläuferzellen. Die regulatorischen Eigenschaften dieses Übergangs sind bislang nur unzureichend aufgeklärt.

Der Transkriptionsfaktor Pax6 wurde als ein Schlüsselelement bei der Neurogenese, der Formation der cortikalen Schichten und regionalen Musterung des Telencephalons charakterisiert. Im Rahmen dieser Arbeit wurde die Interaktion von Geminin mit Pax6 in vitro und in vivo nachgewiesen. Um den Effekt von Geminin auf die Regulation von Pax6 und die Rolle Geminins bei der cortikalen Entwicklung näher zu untersuchen, wurde ein konditionaler Knockout des Geminin-Gens in der Maus generiert. Die Inaktivierung von Geminin wurde dabei in den neuronalen Vorläuferzellen des dorsalen Telencephalons zu Beginn der Neurogenese vorgenommen. Der Funktionsverlust von Geminin hatte in Periode der Neurogenese keinen Effekt auf Pax6 und Pax6-regulierte Zielgene. Ebenso hatte es keine abnormale Formation der cortikalen Schichten zur Folge. In postnatalen Stadien der Maus resultierte die Deletion von Geminin im Cortex jedoch in einer deutlichen Anreicherung GFAP-positiver Astrogliazellen.

Geminin dient ab E18 in der Phase der Gliogenese der Aufrechterhaltung des proliferierenden Zellstatus, indem es die Vorläuferzellen inhibiert, das Schicksal von Astrogliazellen anzunehmen. Diese zeitlich koordinierte Regulation vermag die Interaktion von Geminin mit dem SWI/SNF-Komplex und den Komponenten des JAK-STAT-Signalweges zu involvieren. Die vorliegende Studie konnte somit das Verständnis der bisher unbeschriebenen Rolle Geminins in der Entwicklung des murinen Neocortex erweitern. 


\section{Material und Methoden}

\section{Molekularbiologische Methoden}

\section{Isolierung von Plasmid-DNA aus E.coli}

Um bis zu $20 \mu \mathrm{g}$ Plasmid-DNA aus E. coli Bakterien zu isolieren, wurden $4 \mathrm{ml}$ LB-Medium mit den Bakterienzellen angeimpft und das QIAprep $^{\circledR}$ Spin Miniprep Kit (Qiagen) verwendet. Für die Gewinnung größerer DNA-Mengen von bis zu $500 \mu \mathrm{g}$ wurde eine $100 \mathrm{ml}-$ Kultur inokuliert und das QIAfilter ${ }^{\circledR}$ Spin Plasmid Maxi Kit (Qiagen) benutzt. Beide Systeme basieren auf dem Prinzip der alkalischen Lyse (Birnboim and Doly, 1979). Die Inokulation erfolgte in beiden Fällen unter Zugabe des entsprechenden Antibiotikums $(100 \mu \mathrm{g} / \mathrm{ml}$ Ampicillin; $50 \mu \mathrm{g} / \mathrm{ml}$ Kanamycin; $25 \mu \mathrm{g} / \mathrm{ml}$ Chloramphenicol). Die Zellen wurden für 12 bis 16 Stunden unter kontinuierlicher Schüttelbewegung bei $37^{\circ} \mathrm{C}$ inkubiert. Die Isolierung der Plasmid-DNA wurde entsprechend den Angaben des Herstellers durchgeführt. Das DNAPellet wurde in $\mathrm{dH}_{2} \mathrm{O}$ eluiert oder aufgenommen und für 10 Minuten bei $37^{\circ} \mathrm{C}$ gelöst.

\section{Extraktion von genomischer DNA aus murinem Gewebe}

Zur Gewinnung von genomischer DNA aus Mausgewebe wurde dieses unter Zugabe von $475 \mu \mathrm{l}$ Lysepuffer (100 mM Tris $\mathrm{HCl} p H$ 8,0, $5 \mathrm{mM}$ EDTA, $200 \mathrm{mM} \mathrm{NaCl}, 0,2 \%$ SDS) und $25 \mu$ Proteinase $\mathrm{K}(10 \mathrm{mg} / \mathrm{ml}$ in $50 \mathrm{mM}$ Tris $\mathrm{HCl} \mathrm{pH} 8,0$ und 1,5 M Kalziumacetat) in ein Reaktionsgefäß gegeben. Je nach Anteil des Gewebes erfolgt eine Inkubation bei $55^{\circ} \mathrm{C}$ für 2 bis 16 Stunden. Um eventuelle unlysierte Rückstände loszuwerden, wurde das Lysat für 5 Minuten bei 13.000 rpm zentrifugiert. Zur Fällung der DNA wurde der Überstand in ein neues Reaktionsgefäß, in das zuvor $350 \mu \mathrm{l}$ Isopropanol pipettiert wurden, transferiert. Es erfolgte eine weiterer Zentrifugationsschritt für 5 Minuten bei $13.000 \mathrm{rpm}$, um die DNA zu pelletieren. Der Überstand wurde verworfen und das Pellet wurde mit $500 \mu \mathrm{l}$ 70\%igem EtOH gewaschen. Nach einem letzten Zentrifugationsschritt für 5 Minuten bei 13.000 rpm wurde das DNA-Pellet für 2 bis 5 Minuten bei RT getrocknet, anschließend in 50 bis 200

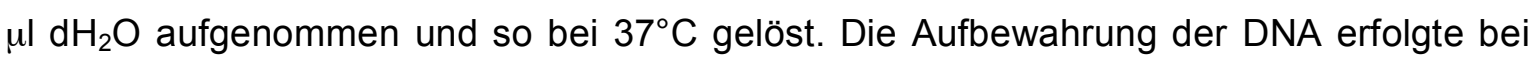
$-20^{\circ} \mathrm{C}$.

\section{DNA Extraktion - Phenol-Chloroform-Fällung}

Um bei einer Transfektion eine optimale Aufnahme von DNA in die zu transfizierenden Zellen zu gewährleisten, sollten die DNA weitestgehend frei von Unreinheiten wie Proteinen etc. sein. Zur Entfernung dieser Bestandteile wurde die DNA daher einer 
Phenol-Chloroform-Fällung unterzogen. Zu der DNA wurde ein Volumen PhenolChloroform-Isoamylalkohol im Mengenverhältnis 25:24:1 gegeben, 15 Sekunden gevortext und anschließend für 2 Minuten bei 13.200 rpm zentrifugiert. Die obere, wäßrige Phase, die DNA enthaltend, wurde in ein neues Reaktionsgefäß transferiert und die untere Phase mit den Proteinen und dem Phenol wurde verworfen. Im nächsten Schritt wurde ein Volumen Chloroform-Isoamylalkohol (24:1 (v/v)) zugegeben und der Vorgang des Vortexens und der Zentrifugation, wie oben geschildert, wiederholt. Die obere Phase wurde wiederum in ein neues Reaktionsgefäß überführt, zu dem 1/10 Volumen $3 \mathrm{M}$ Natriumacetat $(\mathrm{pH} 5,2)$, ein Volumen $100 \% \mathrm{EtOH}$ und $1 \mu \mathrm{l} 10 \mathrm{mg} / \mathrm{ml}$ Glycogen gegeben wurde. Die Fällung der DNA wurde für 30 Minuten bei $-20^{\circ} \mathrm{C}$ durchgeführt. Danach wurde für 15 Minuten bei $4^{\circ} \mathrm{C}$ zentrifugiert, der Überstand abgenommen und das Pellet mit $1 \mathrm{ml}$ 70\% Ethanol zur Reduzierung von Salzen gewaschen. Nach einer Zentrifugationszeit von 5 Minuten bei $13.200 \mathrm{rpm}$ wurde der Ethanol unter der Sterilbank abpipettiert, und das Pellet bei RT getrocknet. Die Plasmid-DNA wurde in einer angemessenen Menge RNasefreiem $\mathrm{H}_{2} \mathrm{O}$ aufgenommen.

\section{Konzentrationsbestimmung von Nukleinsäuren}

Die Konzentrationsbestimmung der Nukleinsäuren erfolgte mit dem NanoDrop ${ }^{\circledR}$ ND-1000 Spektrophotometer (Peqlab) oder mit dem BioPhotometer (Eppendorf) bei einer Wellenlänge von $260 \mathrm{~nm}$. Zur Ermittlung des Reinheitsgrades wurde zusätzlich die Optische Dichte (OD) bei $280 \mathrm{~nm}$ gemessen und der Quotient aus OD $260 \mathrm{~nm}$ und OD 280 $\mathrm{nm}$ gebildet. Das Verhältnis der Extinktionen sollte bei reiner Nukleinsäure zwischen 1,8 und 2,0 liegen. Abweichungen von diesen Werten wiesen auf Verunreinigungen der Proben mit Proteinen hin.

\section{Polymerasekettenreaktion - Amplifikation von DNA}

Zur selektiven Amplifikation von DNA wurde die Polymerasekettenreaktion (PCR) angewandt. Als Template-DNA wurden sowohl Plasmide wie auch genomische DNA verwendet. Die optimale Annealing-Temperatur wurde mit der Schmelztemperatur der Primer abgeglichen. Um eine minimale Fehlerrate in der Sequenz des PCR-Produktes zu gewährleisten, wurde für Standard-Amplifikationen die Pwo DNA-Polymerase (Roche) verwendet, welche im Vergleich zu der Taq-Polymerase eine zehnfach geringere Fehlerrate besitzt und welche mit einer 3'-5'-Exonukleaseaktivität mit einer Korrekturlesefunktion versehen ist. Für die Genotypisierung von murinem Gewebe wurde die GoTaq ${ }^{\circledR}$ DNAPolymerase (Promega) benutzt. Alle Polymerasen wurden unter Zugabe von je 10 pmol Sense- und Antisense-Primer (Tabelle 3) und 20 mM dNTPS (Genecraft) gemäß den Angaben des Herstellers verwendet. Die Durchführung der PCRs wurde in einem 
Mastercycler ${ }^{\circledR}$ Gradient (Eppendorf) unter Verwendung des in Tabelle 2 aufgezeigten Temperaturprogramms durchgeführt.

Die Primer für PCRs wurden generiert und mit Hilfe des Oligo Calculator (http://www.basic.northwestern.edu/biotools/oligocalc.html) kontrolliert. Das Programm überprüft die Komplementarität der Oligonukleotid-Primer zueinander und berechnet deren physikalische Konstante. Die in Tabelle 3 aufgeführten Primer wurden von der IBA GmbH (Göttingen) und Operon (Köln) generiert.

\begin{tabular}{llll} 
Schritt & Temperatur & Dauer & Anzahl der Zyklen \\
\hline 1. Initiale Denaturierung & $94^{\circ} \mathrm{C}$ & 5 Minuten & 1 \\
\hline 2. Denaturierung & $94^{\circ} \mathrm{C}$ & 30 Sekunden & \\
Annealing & $55-65^{\circ} \mathrm{C}$ & 45 Sekunden & $28-35$ \\
Elongation & $72^{\circ} \mathrm{C}$ & 45 Sekunden & \\
\hline 3. Finale Elongation & $72^{\circ} \mathrm{C}$ & $5-10$ Minuten & 1 \\
\hline
\end{tabular}

Tabelle 2. Temperaturprogramm des Thermocyclers für die DNA-Amplifikation. Die AnnealingTemperatur variiert in Abhängigkeit der Schmelztemperatur der für die PCR verwendeten Primer.

\section{Mutagenese}

Mittels der gerichteten Punktmutagenese wurde ein Lysin jeweils durch ein Arginin ersetzt. Zur Generierung von Punktmutationen in einem Plasmid-DNA-Insert wurden zwei etwa 30 bp lange Oligonukleotide (Tabelle 3) verwendet, welche mit dem Abschnitt um die kodierende Sequenz des zu mutierenden Lysins identisch waren. Die Amplifikation der DNA mittels PCR wurde, wie bereits erläutert, und unter Verwendung der PhusionPolymerase (New England Biolabs), durchgeführt. Die PCR-Produkte wurden zur Entfernung der Template-DNA für eine Stunde bei $37^{\circ} \mathrm{C}$ mit $1 \mu \mathrm{l}(10 \mathrm{U} / \mu \mathrm{l})$ Dpnl verdaut und anschließend in E. coli Zellen transformiert.

\section{Aufreinigung von PCR-Produkten}

Um die mittels PCR amplifizierten DNA-Fragmente für eine Klonierung von unspezifischen Produkten und verbliebenen Primern etc. zu reinigen, wurde eine Aufreinigung vorgenommen. Sie erfolgte unter Verwendung des QIAquick $^{\circledR}$ PCR Purification Kits (Qiagen) entsprechend den Angaben des Herstellers. 


\begin{tabular}{|c|c|c|c|}
\hline Primer & $\begin{array}{l}\text { Orien- } \\
\text { tierung }\end{array}$ & Tag & Sequenz \\
\hline \multicolumn{4}{|c|}{ Klonierung von pGEX-KT-hGem } \\
\hline hGem1 & Sense & EcoRI & CCGGAATTCCGATGAATCCCAGTATGAAGC \\
\hline hGem2 & Antisense & Xhol & CCGCTCGAGTCATATACATGGCTTTGCATC \\
\hline \multicolumn{4}{|c|}{ Recombineering } \\
\hline A & Sense & $\begin{array}{l}\text { Notl, } \\
\text { Hpal }\end{array}$ & $\begin{array}{l}\text { ATAAGAATGCGGCCGCGTTAACGAGCATCTTGC- } \\
\text { CAGTTAAT }\end{array}$ \\
\hline $\mathrm{B}$ & Antisense & Spel & GACTAGTCTCTGGAAGAGGTCACCGAG \\
\hline C & Sense & Kpnl & GGGGTA CCCAGCTTGGTCTTGTGTTTGC \\
\hline $\mathrm{D}$ & Antisense & $\begin{array}{l}\text { Sall, } \\
\text { Ndel }\end{array}$ & ACGCGTCGACCATATGCTGTAACAATGGCACAGTGTC \\
\hline$E$ & Sense & BamHI & CGGGATCCGACACTGTGCCATTGTTACAG \\
\hline $\mathrm{F}$ & Antisense & Notl & $\begin{array}{l}\text { ATAAGAATGCGGCCGCCACACAGTGCACAGAAGAG- } \\
\text { CAG }\end{array}$ \\
\hline G & Sense & Kpnl & GGGGTACCGGATACAGCACTGTGGAC \\
\hline $\mathrm{H}$ & Antisense & $\begin{array}{l}\text { Sall, } \\
\text { Ndel }\end{array}$ & ACGCGTCGACCATATGGATACCTTCTGACAGCTACAG \\
\hline I & Sense & BamHI & CGGGATCCAGGTCTCATTACAGATGGTTG \\
\hline $\mathrm{J}$ & Antisense & Notl & ATAAGAATGCGGCCGCGTGCAGATACAAATAGCTG \\
\hline $\mathrm{K}$ & Sense & Kpnl & GTCCCAAGGAGAACGCTGAAG \\
\hline L & Antisense & Sall & GAAAAGCGACAGGCAGTTGAG \\
\hline M & Sense & BamHI & GAAACATCGCATCGAGCGAGC \\
\hline $\mathrm{N}$ & Antisense & Notl & CAGCGCATCGCCTTCTATC \\
\hline $\mathrm{Y}$ & Sense & Spel & GACTAGTCTGCTTCTCTACAGCTTCC \\
\hline Z & Antisense & BamHI & CGGGATCCCAAACCTGGCAACCCTTCTC \\
\hline 5'LoxP5' & Sense & & GTACCAGGAACTGAGCTGAG \\
\hline 5'LoxP3' & Antisense & & CAAGCGTATACTCCGTTCAC \\
\hline \multicolumn{4}{|c|}{ Southern Blot Analyse } \\
\hline SP5'Sonde_5' & Sense & & GAGAAGCAAGCAAGCAAAC \\
\hline SP5'Sonde_3' & Antisense & & GATTCAACGACGCCAGAACG \\
\hline SP3'Sonde_5' & Sense & & GCAGTAAGTTTCCCTATTGAGC \\
\hline SP3'Sonde_3' & Antisense & & CACAGGTGAGTAGATCTGGTG \\
\hline \multicolumn{4}{|c|}{ Genotypisierung } \\
\hline Cre_5' & Sense & & ATGCTTCTGTCCGTTTGCCG \\
\hline Cre_3' & Antisense & & СCTGTTTTGCACGTTCACCG \\
\hline Neo_5' & Sense & & CAGCTGTGCTCGACGTTGTCACTG \\
\hline Neo_3' & Antisense & & CCATGATATTCGGCAAGCAGGCATCG \\
\hline \multicolumn{4}{|l|}{ Mutagenese } \\
\hline hGem (K8R) & Sense & & $\begin{array}{l}\text { GAATCCCAGTATGAAGCAGAGACAAGAAGAAATCA- } \\
\text { AAGG }\end{array}$ \\
\hline hGem (K8R) & Antisense & & $\begin{array}{l}\text { CTCTTTGATTTCTTCTTGTCTCTGCTTCATACTGG- } \\
\text { GATTC }\end{array}$ \\
\hline
\end{tabular}




\begin{tabular}{|c|c|c|c|}
\hline hGem (K27R) & Sense & & CCAAGAAGAACTCTGAGGATGATTCAGCCTTCTG \\
\hline hGem (K27R) & Antisense & & CAGAAGGCTGAATCATCCTCAGAGTTCTTCTTGG \\
\hline hGem (K50R) & Sense & & GTCCGCAGGCTTGTCCAGAAGGAAACATCGGAATGAC \\
\hline hGem (K50R) & Antisense & & GTCATTCCGATGTTTCCTTCTGGACAAGCCTGCGGAC \\
\hline hGem (K52R) & Sense & & CAGGCTTGTCCAAAAGGAGACATCGGAATGACCAC \\
\hline hGem (K52R) & Antisense & & GTGGTCATTCCGATGTCTCCTTTTGGACAAGCCTG \\
\hline hGem (K100R) & Sense & & $\begin{array}{l}\text { CCATCCTCTCAGTATTGGAGGGAAGTGGCAGAAA- } \\
\text { AACG }\end{array}$ \\
\hline hGem (K100R) & Antisense & & CGTTTTTCTGCCACTTCCCTCCAATACTGAGAGGATGG \\
\hline hGem (K108R) & Sense & & GTGGCAGAAAAACGGAGAAGGGCGCTGTATGAAGCAC \\
\hline hGem (K108R) & Antisense & & GTGCTTCATACAACGCCCTTCTCCGTTTTTCTGCCAC \\
\hline hGem (K127R) & Sense & & CATAAAGAAATTGAACAAAGGGACAATGAAATTG \\
\hline hGem (K127R) & Antisense & & CAGAAGGCTGAATCATCCTCAGAGTTCTTCTTGG \\
\hline hGem (K135R) & Sense & & GAAATTGCCCGCCTGAGAAAGGAGAATAAAGAACTGG \\
\hline hGem (K135R) & Antisense & & CCAGTTCTTTATTCTCCTTTCTCAGGCGGGCAATTTC \\
\hline hGem (K136R) & Sense & & GAAATTGCCCGCCTGAAAAGGGAGAATAAAGAACTGG \\
\hline hGem (K136R) & Antisense & & CCAGTTCTTTATTCTCCCTTTTCAGGCGGGCAATTTC \\
\hline $\begin{array}{l}\text { hGem } \\
\text { (K135R,K136R) }\end{array}$ & Sense & & GAAATTGCCCGCCTGAGAAGGGAGAATAAAGAACTGG \\
\hline $\begin{array}{l}\text { hGem } \\
\text { (K135R,K136R) }\end{array}$ & Antisense & & CCAGTTCTTTATTCTCCСTTCTCAGGCGGGCAATTTC \\
\hline hGem (18-209) & Sense & & CCGGAATTCCGATGAATAGTTCTGTCCCAAGAAG \\
\hline hGem (1-69) & Antisense & Notl & ATAGTTTAGCGGCCGCGACAATAACCCCAGGGCTG \\
\hline hGem (161-209) & Sense & Notl & $\begin{array}{l}\text { ATAAGAATGCGGCCGCTGAACCTCTGGATAATTT- } \\
\text { GAATC }\end{array}$ \\
\hline \multicolumn{4}{|c|}{ Sequenzierungen } \\
\hline pGEX.ss & Sense & & GGGCTGGCAAGCCACGTTTGGTG \\
\hline pGEX.as & Antisense & & CCGGGAGCTGCATGTGTCAGAGG \\
\hline pFLAG.ss & Sense & & GCAGAGCTCGTTTAGTGAACC \\
\hline pCMV.ss & Sense & & GATCCGGTACTAGAGGAACTGAAAAAC \\
\hline pL253.ss & Sense & & CAGCATAGCCAGGTCAAGC \\
\hline mGem.ss & Sense & & CCAAGGTATTTTGTGTGTTTAG \\
\hline mGem.as & Antisense & & CAGGTGGGTGAGAGGAGAG \\
\hline Exon_1.ss & Sense & & CAGAGACTGCACGCACCTTG \\
\hline Exon_1.as & Antisense & & CACAGAGACAGTGTCGGAC \\
\hline Exon_5.ss & Sense & & CTGTTGCAGCTCAGGGATC \\
\hline Exon_7.ss & Sense & & CATGAGGTGTGGGACGCAC \\
\hline
\end{tabular}

Tabelle 3. Liste der verwendeten Primer. 


\section{DNA-Elektrophorese und -Elution aus Agarose-Gelen}

Um DNA-Fragmente von Restriktionsverdauen zu analysieren oder um selektiv einzelne Fragmente zu isolieren, wurden Agarose-Gele vorbereitet. Die organische Substanz Ethidiumbromid interkaliert mit einzelnen Molekülen zwischen den Basen der DNADoppelhelix, wodurch sich das Anregungsspektrum von Ethidiumbromid verändert. Infolgedessen wird die Fluoreszenz der Substanz durch Anregung mit UV-Licht stark erhöht. Die Lichtintensität ist dabei proportional zur vorhandenen DNA-Menge.

0,8-1,5\% (w/v) Agarose (Invitrogen) wurde in 1× TBE-Puffer aufgekocht und nach Zugabe von Ethidiumbromid in einer Endkonzentration von $0,3 \mu \mathrm{g} / \mathrm{ml}$ zur Polymerisation in eine Gelkammer gegossen. Der Bereich der DNA-Auftrennung hängt dabei von der AgaroseKonzentration ab (Tabelle 4). Die DNA-Proben wurden mit 6× DNA-Ladepuffer $(0,25 \%$ (w/v) Bromophenolblau, 0,25\% (w/v) Xylencyanol FF, 30\% (v/v) Glycerol in $\mathrm{dH}_{2} \mathrm{O}$ ) versetzt und auf das Agarose-Gel geladen. Die Elektrophorese wurde bei $70 \mathrm{~V}(1-7 \mathrm{~V} / \mathrm{cm})$ in $1 \times$ TBE-Puffer durchgeführt. Die mit Ethidiumbromid gefärbte DNA wurde unter UV-Licht bei einer Wellenlänge von $258 \mathrm{~nm}$ visualisiert. Zur Selektion der spezifischen DNAFragmente wurde die DNA von unspezifischen Produkten gereinigt. Dazu wurden die Banden der gewünschten Größe mit einem Skalpell aus dem Gel isoliert und in ein zuvor abgewogenes Eppi gegeben. Das Gewicht des Gelfragmentes wurde durch erneutes Wiegen ermittelt. Derartige präparative Gele wurden unter UV-Licht bei einer Wellenlänge von $300 \mathrm{~nm}$ und mit geringerer Intensität isoliert, um die Bildung von Thymidin-Dimeren und Strangbrüchen zu vermeiden. Zur Aufreinigung der DNA aus dem Gel wurde das Zentrifugationsprotokoll des QIAquick ${ }^{\circledR}$ Gel Purification Kits (Qiagen) in Übereinstimmung mit den Angaben des Herstellers benutzt.

\section{Agarose-Konzentration [\% w/v ] DNA Fragmentlänge [kb]}

\begin{tabular}{ll}
\hline 0,5 & $1-30$ \\
0,7 & $0,8-12$ \\
1,0 & $0,5-7$ \\
1,2 & $0,4-6$ \\
1,5 & $0,2-3$ \\
2,0 & $0,1-2$ \\
\hline
\end{tabular}

Tabelle 4. Agarose-Konzentrationen und die davon abhängigen FragmentlängenTrenn-bereiche von DNA (Mülhardt, 2000). 


\section{Analytischer und präparativer Restriktionsverdau von DNA}

Zur Linearisierung, Herstellung der Klonierungsstellen von Plasmid-DNA-Vektoren und zum Verdau von PCR-Fragmenten wurden je $\mu \mathrm{g}$ DNA $10 \mathrm{U}$ des entsprechenden Restriktionsenzyms gemäß den Angaben des Herstellers (New England Bioloabs, Roche) eingesetzt. Sofern BSA erforderlich war, wurde dieses in einer Endkonzentration von 100 $\mu \mathrm{g} / \mathrm{ml}$ zugegeben. Der enzymatische Verdau durch die Endonukleasen wurde für 2 Stunden bei $37^{\circ} \mathrm{C}$ durchgeführt. Präparative Verdaue von Endstücken von DNA-Fragmenten erforderten eine Inkubation über Nacht bei RT für etwa 20 Stunden. Die DNA wurde in jedem Fall anschließend unter Verwendung des QIAquick ${ }^{\circledR}$ PCR Purification Kits (Qiagen) aufgereinigt. Sofern bei Doppelverdauen beide Enzyme dieselben Bedingungen erforderten, wurde der Verdau in einem Reaktionsansatz durchgeführt. Andernfalls wurden die Verdaue in sequentieller Abfolge vorgenommen, wobei die DNA zwischen den beiden Verdauen mit dem QIAquick ${ }^{\circledR}$ PCR Purification Kit (Qiagen) aufgereinigt wurde. Für analytische Restriktionsverdaue wurden nur jeweils 0,2 bis $0,4 \mu \mathrm{g}$ DNA eingesetzt und für eine Stunde bei $37^{\circ} \mathrm{C}$ verdaut. Die verdauten Fragmente wurden sowohl bei einem analytischen wie auch bei einem präparativen Verdau auf ein 1\%iges (w/v) Agarose-Gel geladen und deren Größe ermittelt. Im Falle von präparativen Verdauen wurde das gewünschte DNA-Fragment aus dem Gel isoliert und aufgereinigt.

\section{Dephosphorylierung von DNA-Fragmenten}

Klonierungsvektoren wurden mit dem Enzym Alkalischer Phosphatase (Roche) dephosphoryliert. Das Enzym hydrolisiert die 5'-Phosphat-Gruppe an der DNASchnittstelle und verhindert mit dieser Modifikation die Religation des Vektor mit sich selbst. 20 ng Plasmid-DNA wurde mit je 1 U (1 U/ul) Alkalischer Phophatase und 1/10 Volumen 10x Dephosphorylierungspuffer gemischt und für 30 Minuten bei $37^{\circ} \mathrm{C}$ inkubiert. Zur Inaktivierung der Enzymaktivität wurde der Reaktionsansatz für 10 Minuten bei $65^{\circ} \mathrm{C}$ inkubiert. Anschließend wurde die DNA mit dem QIAquick ${ }^{\circledR}$ PCR Purification Kit (Qiagen) aufgereinigt.

\section{Ligation}

Zur Ligation von Vektor und Insert wurde die T4 DNA Ligase (MBI Fermentas) verwendet. Ausgehend von einer Vektor-DNA-Menge von 25 bis $50 \mathrm{ng}$ wurde die zu verwendete Menge an Insert-DNA nach folgender Formel (Mülhardt, 2000) berechnet:

Masse $_{\text {Insert }}[\mathrm{ng}]=5 \times$ Masse $_{\text {Vektor }}[\mathrm{ng}] \times$ Länge $_{\text {Insert }}[\mathrm{bp}] /$ Länge Vektor $[\mathrm{bp}]$ 
Die Ligation wurde in einem Gesamtvolumen von 10ul durchgeführt. Es wurde $1 \mu \mathrm{l}$ T4 DNA Ligase (3 $\mathrm{U} / \mu \mathrm{l}), 1 \mu \mathrm{l}$ 10× Ligationspuffer (MBI Fermentas), die entsprechenden Mengen DNA sowie $10 \mathrm{mM}$ ATP verwendet. Die Inkubation erfolgte für eine Stunde bei RT oder über Nacht bei $16^{\circ} \mathrm{C}$.

\begin{tabular}{|c|c|c|c|c|}
\hline Name & Vektor & Insert & Verwendung & Referenz \\
\hline pCMV3 & $\begin{array}{l}\text { pCMV3 (Clon- } \\
\text { tech) }\end{array}$ & - & $\begin{array}{l}\text { Allgemeine Klo- } \\
\text { nierungen }\end{array}$ & Clontech \\
\hline pGEX-KT & $\begin{array}{l}\text { pGEX-KT } \\
\text { (Amersham } \\
\text { Biosciences) }\end{array}$ & GST-Tag & Proteinexpression & $\begin{array}{l}\text { Amersham } \\
\text { Biosciences }\end{array}$ \\
\hline pGEX-KT-hGem & $\begin{array}{l}\text { pGEX-KT } \\
\text { (Amersham } \\
\text { Biosciences) }\end{array}$ & $\begin{array}{l}\text { GST-Geminin } \\
\text { (human) }\end{array}$ & Proteinexpression & Diese Arbeit \\
\hline pFLAG-CMV ${ }^{\mathrm{TM}}-2$ & $\begin{array}{l}\text { pFLAG- } \\
\text { CMV }^{\mathrm{TM}}-2 \\
\text { (Sigma) }\end{array}$ & FLAG-Taq & SUMOylierung & Sigma \\
\hline $\begin{array}{l}\text { pFLAG-CMV }{ }^{\top M}-2- \\
\text { hGem }\end{array}$ & $\begin{array}{l}\text { pFLAG- } \\
\text { CMV }^{\mathrm{TM}}-2 \\
\text { (Sigma) }\end{array}$ & $\begin{array}{l}\text { FLAG-Geminin } \\
\text { (human) }\end{array}$ & SUMOylierung & Diese Arbeit \\
\hline pCS2 & pCS2+ & - & $\begin{array}{l}\text { Negativ-Kontrolle } \\
\text { Co-IP }\end{array}$ & \\
\hline pCS2-Pax6-FLAG & pCS2+FLAG & Pax6-FLAG & Co-IP & \\
\hline RPCIP711F02244Q2 & pPAC4 & $\mathrm{RPCl}-21$ 244F2 & $\begin{array}{l}\text { Recombineering - } \\
\text { genomische DNA }\end{array}$ & $\begin{array}{l}\text { imaGenes, } \\
\text { RZPD }\end{array}$ \\
\hline PL253 & pBluescript & MC1-HSV-TK & $\begin{array}{l}\text { Recombineering - } \\
\text { Retrieving }\end{array}$ & $\begin{array}{l}\text { (Liu et al., } \\
2003 \text { ) }\end{array}$ \\
\hline PL451 & pBluescript & $\begin{array}{l}\text { Frt-PGK-em7- } \\
\text { neo-Frt-LoxP }\end{array}$ & $\begin{array}{l}\text { Recombineering - } \\
\text { Targeting }\end{array}$ & $\begin{array}{l}\text { (Liu et al., } \\
2003 \text { ) }\end{array}$ \\
\hline PL452 & pBluescript & $\begin{array}{l}\text { LoxP-PGK-em7- } \\
\text { neo-bpA-LoxP }\end{array}$ & $\begin{array}{l}\text { Recombineering - } \\
\text { Targeting }\end{array}$ & $\begin{array}{l}\text { (Liu et al., } \\
2003 \text { ) }\end{array}$ \\
\hline PL256-LRneo (Z3) & pBluescript & $\begin{array}{l}\text { LoxP-Frt-PGK- } \\
\text { em7-neo-bpA- } \\
\text { Frt-LoxP im Ge- } \\
\text { minin Genlokus }\end{array}$ & $\begin{array}{l}\text { Recombineering - } \\
\text { konditionales } \\
\text { Knockout Kon- } \\
\text { strukt }\end{array}$ & Diese Arbeit \\
\hline pBS ${ }^{\circledast} / 1$ KS-Cux2 & $\mathrm{pBS}^{\circledR} \| \mathrm{KS}$ & Cux2 (Maus) & $\mathrm{ISH}$ & $\begin{array}{l}\text { Abteilungs- } \\
\text { stock }\end{array}$ \\
\hline pGEM ${ }^{\circledR} T$ easy-Er81 & pGEM $^{\circledR} T$ easy & Er81 (Maus) & ISH & $\begin{array}{l}\text { Abteilungs- } \\
\text { stock }\end{array}$ \\
\hline pT7T3-GAD1 & pT7T3 & GAD1 (Maus) & ISH & $\begin{array}{l}\text { Abteilungs- } \\
\text { stock }\end{array}$ \\
\hline $\mathrm{pBS}^{\circledR} \mathrm{II} \mathrm{KS}-$ Geminin & $\mathrm{pBS}^{\circledR} \| \mathrm{KS}$ & Geminin (Maus) & $\mathrm{ISH}$ & $\begin{array}{l}\text { Abteilungs- } \\
\text { stock }\end{array}$ \\
\hline $\mathrm{pBS}^{\circledR}$ II KS-NeuroD & $\mathrm{pBS}^{\circledR} \| \mathrm{KS}$ & NeuroD (Maus) & $\mathrm{ISH}$ & $\begin{array}{l}\text { Abteilungs- } \\
\text { stock }\end{array}$ \\
\hline
\end{tabular}




\begin{tabular}{|c|c|c|c|c|}
\hline pGEM $^{\circledR} 3 Z f(+)-N g n 1$ & pGEM $^{\circledR} 3 Z f(+)$ & Ngn1 (Maus) & ISH & $\begin{array}{l}\text { Abteilungs- } \\
\text { stock }\end{array}$ \\
\hline pGEM $^{\circledR} 3-N g n 2$ & pGEM $^{\circledR} 3$ & Ngn2 (Maus) & ISH & $\begin{array}{l}\text { Abteilungs- } \\
\text { stock }\end{array}$ \\
\hline pBS ${ }^{\circledR} / \mid$ KS-Pax6 & $\mathrm{pBS}^{\circledR} \| \mathrm{KS}$ & Pax6 (Maus) & $\mathrm{ISH}$ & $\begin{array}{l}\text { Abteilungs- } \\
\text { stock }\end{array}$ \\
\hline pBS ${ }^{\circledR}||$ KS-Sox2 & $\mathrm{pBS}^{\circledR} \| \mathrm{KS}$ & Sox2 (Maus) & $\mathrm{ISH}$ & $\begin{array}{l}\text { Abteilungs- } \\
\text { stock }\end{array}$ \\
\hline $\begin{array}{l}\text { pcDNA3-6xHis- } \\
\text { SUMO1 }\end{array}$ & pcDNA3 & SUMO1 & SUMOylierung & $\begin{array}{l}\text { (Girdwood et } \\
\text { al., 2003) }\end{array}$ \\
\hline pcDNA3-SUMO1-HA & pcDNA3-HA & SUMO1 & SUMOylierung & $\begin{array}{l}\text { (Desterro et } \\
\text { al., 1998) }\end{array}$ \\
\hline pEYFP-SUMO1- $\triangle \mathrm{C} 4$ & $\begin{array}{l}\text { pEYFP } \\
\text { (Clontech) }\end{array}$ & $\begin{array}{l}\text { Konjugierbares } \\
\text { SUMO1 }\end{array}$ & SUMOylierung & $\begin{array}{l}\text { Melchior, F. } \\
\text { unveröffent- } \\
\text { licht }\end{array}$ \\
\hline pEYFP-SUMO1- $\Delta C 7$ & $\begin{array}{l}\text { pEYFP } \\
\text { (Clontech) }\end{array}$ & $\begin{array}{l}\text { Unkonjugierbares } \\
\text { SUMO1 }\end{array}$ & $\begin{array}{l}\text { Negativ-Kontrolle } \\
\text { SUMOylierung }\end{array}$ & $\begin{array}{l}\text { Melchior, F. } \\
\text { unveröffent- } \\
\text { licht }\end{array}$ \\
\hline pcDNA3.1-PIAS1 & pcDNA3.1(+) & PIAS1 (human) & SUMOylierung & Diese Arbeit \\
\hline $\begin{array}{l}\text { pcDNA3-FLAG-HA- } \\
\text { SENP1 }\end{array}$ & $\begin{array}{l}\text { pcDNA3- } \\
\text { FLAG-HA }\end{array}$ & SENP1 & DeSUMOylierung & (Bailey, 2003) \\
\hline $\begin{array}{l}\text { pcDNA3-FLAG-HA- } \\
\text { SENP1 C603S }\end{array}$ & $\begin{array}{l}\text { pcDNA3- } \\
\text { FLAG-HA }\end{array}$ & $\begin{array}{l}\text { SENP1 C603 } \\
\text { mutiert zu S }\end{array}$ & DeSUMOylierung & (Bailey, 2003) \\
\hline pcDNA3.1(+) & pcDNA3.1(+) & & $\begin{array}{l}\text { Allgemeine } \\
\text { Klonierungen }\end{array}$ & Invitrogen \\
\hline pcDNA3.1-hGem & pcDNA3.1(+) & Geminin (human) & SUMOylierung & Diese Arbeit \\
\hline $\begin{array}{l}\text { pcDNA3.1-hGem } \\
\text { (K8R) }\end{array}$ & pcDNA3.1(+) & $\begin{array}{l}\text { Geminin K8 mu- } \\
\text { tiert zu R }\end{array}$ & SUMOylierung & Diese Arbeit \\
\hline $\begin{array}{l}\text { pcDNA3.1-hGem } \\
\text { (K27R) }\end{array}$ & pcDNA3.1(+) & $\begin{array}{l}\text { Geminin K27 } \\
\text { mutiert zu R }\end{array}$ & SUMOylierung & Diese Arbeit \\
\hline $\begin{array}{l}\text { pcDNA3.1-hGem } \\
\text { (K50R) }\end{array}$ & pcDNA3.1(+) & $\begin{array}{l}\text { Geminin K50 } \\
\text { mutiert zu R }\end{array}$ & SUMOylierung & Diese Arbeit \\
\hline $\begin{array}{l}\text { pcDNA3.1-hGem } \\
\text { (K52R) }\end{array}$ & pcDNA3.1(+) & $\begin{array}{l}\text { Geminin K52 } \\
\text { mutiert zu R }\end{array}$ & SUMOylierung & Diese Arbeit \\
\hline $\begin{array}{l}\text { pcDNA3.1-hGem } \\
\text { (K100R) }\end{array}$ & pcDNA3.1(+) & $\begin{array}{l}\text { Geminin K100 } \\
\text { mutiert zu R }\end{array}$ & SUMOylierung & Diese Arbeit \\
\hline $\begin{array}{l}\text { pcDNA3.1-hGem } \\
\text { (K108R) }\end{array}$ & pcDNA3.1(+) & $\begin{array}{l}\text { Geminin K108 } \\
\text { mutiert zu R }\end{array}$ & SUMOylierung & Diese Arbeit \\
\hline $\begin{array}{l}\text { pcDNA3.1(+)hGem } \\
\text { (K127R) }\end{array}$ & pcDNA3.1(+) & $\begin{array}{l}\text { Geminin K127 } \\
\text { mutiert zu R }\end{array}$ & SUMOylierung & Diese Arbeit \\
\hline $\begin{array}{l}\text { pcDNA3.1-hGem } \\
\text { (K135R) }\end{array}$ & pcDNA3.1(+) & $\begin{array}{l}\text { Geminin K135 } \\
\text { mutiert zu R }\end{array}$ & SUMOylierung & Diese Arbeit \\
\hline $\begin{array}{l}\text { pcDNA3.1-hGem } \\
\text { (K136R) }\end{array}$ & pcDNA3.1(+) & $\begin{array}{l}\text { Geminin K136 } \\
\text { mutiert zu R }\end{array}$ & SUMOylierung & Diese Arbeit \\
\hline
\end{tabular}




\begin{tabular}{lllll}
$\begin{array}{l}\text { pcDNA3.1-hGem } \\
(\text { K135R, K136R) }\end{array}$ & pcDNA3.1(+) & $\begin{array}{l}\text { Geminin K135 } \\
\text { und K136 mutiert } \\
\text { zu jeweils R }\end{array}$ & SUMOylierung & Diese Arbeit \\
$\begin{array}{l}\text { pcDNA3.1-hGem } \\
(18-209)\end{array}$ & pcDNA3.1 $(+)$ & $\begin{array}{l}\text { Geminin As 18- } \\
209\end{array}$ & SUMOylierung & Diese Arbeit \\
$\begin{array}{l}\text { pcDNA3.1-hGem (1- } \\
69 ; 161-209)\end{array}$ & pcDNA3.1(+) & $\begin{array}{l}\text { Geminin As 1-69 } \\
\text { fusioniert an As } \\
161-209\end{array}$ & SUMOylierung & Diese Arbeit \\
\hline
\end{tabular}

Tabelle 5. Plasmidvektoren und im Rahmen dieser Arbeit verwendete und erstellte Plasmidkonstrukte. A, Arginin; As, Aminosäure; C, Cystein; Co-IP, Co-Immunpräzipitation; IHC, Immunhistochemie; ISH, In situ Hybridisierung; K, Lysin; S, Serin.

\section{Herstellung chemisch kompetenter E. coli Bakterien}

Zur Herstellung chemisch kompetenter Zellen (Tabelle 6) wurde eine einzelne Kolonie $E$. coli HB101 in 5 ml LB-Medium (1\% (w/v) Bacto-Agar, 0,5\% (w/v) Hefeextrakt, 1\% (w/v) $\mathrm{NaCl}$ in $\mathrm{dH}_{2} \mathrm{O}$ ) inokuliert und über Nacht bei $37^{\circ} \mathrm{C}$ unter kontinuierlicher Bewegung bei $250 \mathrm{rpm}$ geschüttelt. Jeweils $2,5 \mathrm{ml}$ von der Übernacht-Kultur wurden in je $50 \mathrm{ml}$ LB-Medium transferiert und bei $37^{\circ} \mathrm{C}$ im Schüttler bis zu einer Optischen Dichte $\left(\mathrm{OD}_{600}\right)$ von 0,6 bis 0,7 inkubiert. Die Zellsuspensionen wurden in $50 \mathrm{ml}-F a l c o n s$ überführt und bei $2.000 \mathrm{rpm}$ für 10 Minuten bei $4^{\circ} \mathrm{C}$ zentrifugiert (Heraeus, Rotor: Sorvall SS34). Die beiden Pellets wurden in jeweils $25 \mathrm{ml}$ eisgekühltem $50 \mathrm{mM} \mathrm{CaCl}_{2}$ resuspendiert und erneut für 10 Minuten bei $2.000 \mathrm{rpm}$ und $4^{\circ} \mathrm{C}$ pelletiert. Des Weiteren wurden die Pellets in $3 \mathrm{ml} 50$ $\mathrm{mM} \mathrm{CaCl}{ }_{2}$ aufgenommen, resuspendiert und es wurde Glycerol zugegeben, so dass eine Endkonzentration von 10\% Glycerol gegeben war. Die kompetenten Zellen wurden auf Eis à $50 \mu \mathrm{l}$ in $1,5 \mathrm{ml}$ Eppendorf-Gefäße aliquotiert und sofort in flüssigem Stickstoff eingefroren. Die Lagerung fand bei $-80^{\circ} \mathrm{C}$ statt.

\section{Transformation in chemisch kompetente E. coli Bakterien}

Die Transformation von Plasmid-DNA (Tabelle 5) in chemisch kompetente E. coli Bakterien des Stammes HB101 (Tabelle 6) erfolgte mittels Hitzeschock. Ein Aliquot der kompetenten Zellen wurde auf Eis aufgetaut und sofort zu der zu transformierenden DNA pipettiert. Nach Mischen der Suspension durch Auf-und Abpipettieren wurden die Zellen für 30 Minuten auf Eis inkubiert. Der Hitzeschock erfolgte für 45 Sekunden bei $42^{\circ} \mathrm{C}$ im Heizblock. Es wurde für eine Minute auf Eis inkubiert, damit sich die Membranporen der Zellen wieder schließen konnten, und $950 \mu$ LB-Medium wurden hinzugefügt. Bei $37^{\circ} \mathrm{C}$ wurden die Bakterien für 30 bis 45 Minuten zur Erholung von der Behandlung im Heizblock geschüttelt und anschließend bei $3.000 \mathrm{rpm}$ für 2 Minuten pelletiert. $800 \mu \mathrm{l}$ des Überstandes wurden abgenommen, das Zellpellet in den verbliebenen $200 \mu$ l Medium 
resuspendiert und auf LB-Agar ausplattiert. Zur Selektion der Bakterienkolonien waren, in Abhängigkeit von dem Resistenzgen der DNA, die LB-Agarplatten zuvor mit dem entsprechenden Antibiotikum versehen worden (100 $\mu \mathrm{g} / \mathrm{ml}$ Ampicillin, $50 \mu \mathrm{g} / \mathrm{ml}$ Kanamycin oder $25 \mu \mathrm{g} / \mathrm{ml}$ Chloramphenicol).

\begin{tabular}{lll} 
Name & Verwendung & Herkunft \\
\hline BL21 & Proteinexpression & Invitrogen \\
BL21 rossetta & Proteinexpression & Novagen \\
BL21-CodonPlus ${ }^{\circledR}$ (DE3)-RIL & Proteinexpression & Invitrogen \\
DH5 $\alpha$ & Vermehrung von Plasmid-DNA & Invitrogen \\
DH10B & Vermehrung von Plasmid-DNA & E. Herzog \\
HB101 & Vermehrung von Plasmid-DNA & Abteilungsstock \\
SW102 & Recombineering & (Warming et al., 2005) \\
SW105 & Recombineering (Arabinose- & (Warming et al., 2005) \\
& induzierbares Flpe Gen & \\
SW106 & Recombineering (Arabinose- & (Warming et al., 2005) \\
& induzierbares Cre Gen & \\
\hline
\end{tabular}

Tabelle 6. Liste der gebrauchten Bakterienstämme.

\section{Herstellung von elektrokompetenten E. coli Bakterien}

Zur Generierung von elektrokompetenten Zellen wurde eine einzelne Kolonie E. coli Bakterien in 2× $10 \mathrm{ml}$ LB-Medium inokuliert und über Nacht bei $220 \mathrm{rpm}$ unter schüttelnden Bewegungen wachsen gelassen. Die Kulturen wurden benutzt, um daraufhin $2 \times 1$ I LB-Medium anzuimpfen, welche bis zu einer $\mathrm{OD}_{600}$ von 0,6 bis 0,7 inkubiert wurden. Die Zellen wurden für 20 Minuten auf Eis gekühlt und dann durch Zentrifugation bei $5000 \times \mathrm{g}$ für 20 Minuten bei $4^{\circ} \mathrm{C}$. pelletiert. Sie wurden in einem Verhältnis von $1: 1$, bezogen auf das initiale Volumen der Kultur, mit vorgekühltem $\mathrm{dH}_{2} \mathrm{O}$ vorsichtig gewaschen und erneut zentrifugiert. Im Anschluss wurden die Bakterien im Verhältnis 1:10, 1:50 und 1:500 mit vorgekühltem $10 \%$ igem Glycerol in $\mathrm{dH}_{2} \mathrm{O}$ gewaschen. Die Zentrifugation erfolgte jedes Mal bei $5500 \times g$ für 10 Minuten bei $4^{\circ} \mathrm{C}$. Letztlich wurden die Zellen in einem gleichen Volumen 10\% Glycerol resuspendiert und in $50 \mu$-Aliquots unterteilt. Die Aliquots wurden unmittelbar in flüssigen Stickstoff eingefroren und zur Aufbewahrung bei $-80^{\circ} \mathrm{C}$ gelagert. 


\section{Transformation in elektrokompetente E. coli Bakterien}

Elektrokompetente E.coli Bakterien wurden auf Eis aufgetaut und mit 1 bis $4 \mu$ l eines Ligationsansatzes oder 1 bis $50 \mathrm{ng}$ Plasmid-DNA versetzt. Das Gemisch wurde in Elektroporationsküvetten (Biorad E.coli Pulser ${ }^{\mathrm{TM}}$ Cuvette Nr.1652089) pipettiert und die Elektroporation wurde mit einem Genepulser ${ }^{\mathrm{TM}}$ (BioRad) bei einer Spannung von 1,8 kV und $25 \mu \mathrm{F}$ und einem Widerstand von $200 \Omega$ durchgeführt. Die Zeitkonstante sollte für eine effiziente Transformation zwischen 3,8 und 4,6 Millisekunden liegen. Nach erfolgter Elektroporation wurden $950 \mu$ L LB-Medium zu den Zellen gegeben und sie wurden für 30 Minuten bei $37^{\circ} \mathrm{C}$ in einem Schüttler inkubiert. 10 bis $50 \mu \mathrm{l}$ der Zellsuspension wurden auf eine getrocknete LB-Agarplatte mit dem entsprechenden Antibiotikum gegeben, abhängig von dem Resistenzgen der DNA. Sofern der gesamte Ansatz ausplattiert werden sollte, wurde er zuvor für 2 Minuten bei 3.000 rpm zentrifugiert, $800 \mu \mathrm{l}$ des Überstandes wurden verworfen und der verbleibende Anteil wurde ausplattiert. Die Platten wurden zur Kultivierung der Bakterien bei $37^{\circ} \mathrm{C}$ inkubiert (Dower et al., 1988).

\section{Sequenzierung}

Die Sequenzierung unter Verwendung des Taq Dye Deoxy Terminator Kits (Perkin Elmer) und des ABI Prism 377 DNA Sequenziergerätes (Applied Biosystems) wurde entweder freundlicherweise in der Abteilung Molekulare Zellbiologie von Sigurd Hille umgesetzt oder von der GATC Biotech (Konstanz). Die Sequenzanalyse erfolgte mit der Sequencher ${ }^{\mathrm{TM}}$ Software (Gene Codes Corporation). Die Datenanalyse wurde durch Abgleich mit verschiedenen Datenbanken des National Center for Biotechnology Information (NCBI, http://www.ncbi.nih.org), des exPASy (http://www.expasy.org) Molecular Biology Servers (http://www.ensembl.org/index/html) und Ensembl vorgenommen. Die zu Sequenzierungen verwendeten Primer sind in Tabelle 3 aufgelistet.

\section{Generierung eines konditionalen Knockout-Konstruktes mittels Recombineering}

Zur Generierung eines konditionalen Knockout-Konstruktes wurde die Methode des „Recombineering“ (engl. „Recombination-mediated genetic engineering”) angewandt. Der E. coli Stamm SW102 ist ein von DH10B E. coli Zellen modifizierter Bakterienstamm, der einen defekten $\lambda$-(Lambda) Prophagen enthält. Das Operon des Phagen codiert für die Gene exo, beta und gam, welche unter der Kontrolle des temperatursensitiven $\lambda$-Repressors (c/857) stehen, welcher durch Erhöhung der Temperatur auf $42^{\circ} \mathrm{C}$ induziert werden kann. Die Phagen-spezifischen Proteine bewirken die Rekombination in den 
E. coli Zellen (Zhang et al., 2000; Muyrers et al., 2001; Copeland et al., 2001). Der bedeutendste Vorteil dieser Methode besteht darin, dass der Gebrauch von in geeigneter Weise positionierten Restriktionsschnittstellen umgangen wird, denn bei der konventionellen genetischen Konstruktion eines Knockout-Konstruktes ist die Modifikation der DNA oft durch die Verfügbarkeit einzigartiger Schnittstellen beeinträchtig.

\section{Isolierung von P1-Phagen Artifiziellen Chromoson-PAC aus E.coli}

Zur Isolierung von großen DNA-Konstrukten von über $10 \mathrm{~kb}$ wie dem des P1 Prophagen abgeleiteten Bakteriellen Artifiziellen Chromosoms (PAC), bedurfte es einem von der herkömmlichen DNA-Isolierung abweichenden Verfahren. Es wurden die Puffer des QIAprep ${ }^{\circledR}$ Miniprep Kit (Qiagen) eingesetzt, jedoch wurden die Säulen vermieden, da diese ungeeignet für derartig große DNA-Konstrukte sind. Eine $5 \mathrm{ml}$-Bakterienkultur wurde inokuliert, über Nacht wachsen gelassen und am nächsten Tag die Zellen durch Zentrifugation bei 5000 rpm pelletiert. Von den zur Selektion der PAC-Klone genutzten Antibiotika wurden im Vergleich zur Kultivierung von gewöhnlicher Plasmid-DNA geringere Konzentrationen eingesetzt $(50 \mu \mathrm{g} / \mathrm{ml}$ Ampicillin; $25 \mu \mathrm{g} / \mathrm{ml}$ Kanamycin; 12,5 $\mu \mathrm{g} / \mathrm{ml}$ Chloramphenicol; $12,5 \mu \mathrm{g} / \mathrm{ml}$ Tetracyclin). Das Zellpellet wurde in $250 \mu \mathrm{l}$ Puffer P1 resuspendiert und nach Zugabe von $250 \mu$ I Puffer P2 vorsichtig gemischt und zur Lyse für 5 Minuten bei RT inkubiert. Anschließend wurden $350 \mu$ l Puffer N3 hinzugegeben und es wurde eine Inkubationszeit von 5 Minuten auf Eis eingehalten. Anschließend wurde zweimal für je 5 Minuten bei 13.200 rpm zentrifugiert, wobei der Überstand jedes Mal in ein neues Reaktionsgefäß überführt wurde. Zur Fällung der DNA wurden $750 \mu$ Isopropanol zu dem Lysat gegeben und das Gemisch wurde für 10 Minuten auf Eis inkubiert. Nach erneuter Zentrifugation für 10 Minuten bei 13.200 rpm wurde der Überstand verworfen und das verbliebene DNA-Pellet wurde mit $1 \mathrm{ml}$ 70\% EtOH gewaschen. Die DNA wurde letztlich in $50 \mu \mathrm{l} \mathrm{TE}$ aufgenommen und bei $37^{\circ} \mathrm{C}$ gelöst. Für Transformationen wurden ausschließlich frisch präparierte PAC-DNA eingesetzt.

\section{Konstruktion der Retrieving- und Targeting-Vektoren}

Zur Klonierung des Retrieving-Vektors wurde zunächst das Screening einer Maus PACBank (imaGenes, früher RZPD, Maus PAC-Bank (RPCl-21) Nr.711, Stamm: 129S6/SvEvTac) durchgeführt. Das Verfahren wurde mittels einer eigens hergestellten Sonde des offenen Leserahmens des Geminin-Lokus gemäß den Anweisungen des Herstellers der Bank durchlaufen (Osoegawa et al., 2000). Positive Klone wurden mittels PCR analysiert, ob die vollständige bedeutende genomische Region zur Generierung des Targeting-Vektors in den Klonen beinhaltet war. Die PCRs wurden mit dem Primerpaar A 
und $\mathrm{B}$, welche ein Fragment in der Region abwärts des genomischen Geminin-Lokus amplifizierten und den Primern $Y$ und $Z$ durchgeführt, welche ein Fragment in der Region aufwärts des Lokus amplifizierten. Sämtliche für die Klonierung des Retrieving und der Mini-Targeting-Vektoren verwendete Primer sind in Tabelle 3 aufgelistet. Die Amplifikationen wurden unter Verwendung des PAC-Klons als Template ausgeführt. Um Mutationsereignisse auszuschließen wurden die PCRs ausschließlich mit der Pwo DNAPolymerase durchgeführt. Des Weiteren wurden die PCR-Produkte mit den entsprechenden Restriktionsenzymen verdaut. Das mit Primer A und B amplifizierte Fragment von $410 \mathrm{bp}$ ist homolog zu einer Region aufwärts des ersten Exons. Primer B wurde zusätzlich eine einzigartige Restriktionsschnittstelle (Hpal) angefügt, welche ansonsten nicht in dem genomischen Geminin-Lokus vorhanden ist. Zur Generierung von einem homologen Fragment abwärts vom letzten Exon des Geminin-Lokus wurden Primer $Y$ und $Z$ eingesetzt, welche ein PCR-Produkt von 385 bp erzeugten. Der Retrival-Vektor wurde durch Ligation der verdauten PCR-Fragmente A, B (Notl, Spel) und Y, Z (Spel, BamHI) mit dem PL253-Vektor (Notl, BamHI) generiert. Der Vektor basiert auf dem pBluescript-Vektor und enthält eine durch den MC1-Promotor gesteuerte ThymidinKinase-(TK) Kassette, welcher der Negativ-Selektion in den ES-Zellen dient.

Der erste Mini-Targeting-Vektor wurde durch Ligation der PCR-Fragmente C, D (379 bp; Kpnl, Sall) und E, F (420 bp; BamHI, Notl) mit dem PL452-Vektor (Kpnl, Notl) hergestellt. Der Vektor beinhaltet eine Neomycin-(Neo) Kassette, welche zur Positiv-Selektion genutzt wird. Die Kassette wird von zwei LoxP-Sequenzen flankiert. Die Expression des NeoGens unterliegt der Regulation durch den prokaryontischen em7-Promotor und dem eukaryotischen PgK-Promotor. Zur Identifikation von korrekt klonierten Konstrukten mittels Restriktionsanalyse wurde mit Primer $\mathrm{F}$ abwärts von der linken LoxP-Stelle eine zusätzliche Ndel-Schnittstelle hinzugefügt.

Für den zweiten Mini-Targeting-Vektor wurden die PCR-Produkte G, H (400 bp; Kpnl, Sall) und I, J (385 bp; BamHI, Notl) mit dem PL451-Vektor (Kpnl, Notl) ligiert. Der Vektor trägt ebenfalls eine Neo-Kassette, welche jedoch von zwei Frt-Sequenzen (engl. „Flpe recognition targets"), die Erkennungssequenzen für die Flpe Rekombinase sind. Außerdem befindet sich abwärts von der einen Frt-Sequenz eine weitere LoxP-Sequenz

\section{Transformation von PAC- und Plasmid-DNA in den E. coli Stamm SW102}

Von einer einzelnen Kolonie des E. coli Bakterienstammes SW102 (Warming et al., 2005) wurde eine $5 \mathrm{ml}$-Kultur angeimpft. Die Inkubation erfolgte über Nacht bei $32^{\circ} \mathrm{C}$ in einem Schüttler. Die Kultur wurde am folgenden Tag 1:50 in 25 ml LB Medium verdünnt und für 3 bis 5 Stunden bei $32^{\circ} \mathrm{C}$ inkubiert, bis die Bakterien eine $\mathrm{OD}_{600}$ von 0.6 erzielt hatten. 
Daraufhin wurden sie für wenige Minuten in einem Eisbad heruntergekühlt. Alle weiteren Schritte erfolgten bei $4^{\circ} \mathrm{C}$. Die Bakteriensuspension wurde in $50 \mathrm{ml}$-Falcons überführt. Die Bakterien wurden durch Zentrifugation für 5 Minuten bei $5000 \mathrm{rpm}$ und $4^{\circ} \mathrm{C}$ pelletiert. Der Überstand wurde entfernt und zu dem Pellet wurde $1 \mathrm{ml}$ eisgekühltes $10 \%$ iger Glycerol gegeben und durch vorsichtige Schüttelbewegungen im Eisbad darin resuspendiert. Diese Suspension wurde in ein Reaktionsgefäß transferiert und für 20 Sekunden bei 13.200 rpm und $4^{\circ} \mathrm{C}$ zentrifugiert. Der Überstand wurde entfernt und das Pellet wurde erneut in $1 \mathrm{ml}$ 10\%iges Glycerol aufgenommen, resuspendiert und abzentrifugiert. Nachdem der Überstand wiederum abgenommen wurde, wurde das Bakterienpellet in dem verbliebenem Rest 10\%igem Glycerol aufgenommen. Die nun elektrokompetenten Bakterien wurden mit der zu transformierenden DNA gemischt und für 5 Minuten auf Eis inkubiert. Die Elektroporation wurde wie bereits angegeben durchgeführt. Die Bakterien wurden anschließend auf LB-Agarplatten mit dem entsprechenden selektiven Antibiotikum ausplattiert und für 18 bis 24 Stunden bei $32^{\circ} \mathrm{C}$ inkubiert.

\section{Retrieving und Targeting}

Zur Aktivierung der Genexpression des defekten Lambda-Prophagen bedarf es einer Hitzeschockinduktion. Für das Retrieving wurden die den PAC-Klon bereits beinhaltenden SW102-Zellen wie zuvor beschrieben kultiviert und bis zu einer ${ } D_{600}$ von 0.6 wachsen gelassen. Von der $25 \mathrm{ml}$-Kultur wurden $10 \mathrm{ml}$ in ein Falcon überführt und für 15 Minuten bei $42^{\circ} \mathrm{C}$ in einem Wasserbad unter leichten Schüttelbewegungen inkubiert. Dieser Hitzeschock ermöglicht den Bakterien die Herstellung der zur Rekombination erforderlichen Proteine. Der verbleibende Anteil der initialen Kultur diente der Kontrolle und wurde weiterhin bei $32^{\circ} \mathrm{C}$ inkubiert. Induzierte und uninduzierte Bakterien wurden anschließend durch vorsichtige Schüttelbewegungen für einige Minuten in einem Eisbad heruntergekühlt und wie zuvor beschrieben transformiert. Für das Retrieving wurde der modifizierte Retrieving-Vektor PL253 vor der Transformation mit Hpal linearisiert. Für das erste und zweite Targeting wurden die Kassetten aus dem modifizierten PL452- und PL451-Vektor mittels Restriktionsverdau mit Kpnl und Notl ausgeschnitten und mit Hilfe einer Gelextraktion aufgereinigt. Es wurden sowohl Einzel- als auch Co-Elektroporationen durchgeführt. Es wurden 1 bis $10 \mathrm{ng}$ Plasmid-DNA, 1 bis $5 \mu \mathrm{g}$ frisch präparierte Plasmid-DNA oder 100 ng einer aufgereinigten Targeting-Kassette zur Elektroporation eingesetzt. Die Kultivierung der Bakterien erfolgte bei $32^{\circ} \mathrm{C}$.

Von mehreren Bakterienkolonien wurde die DNA mittels Mini-Präparation aufgereinigt und einer Restriktionsanalyse unterzogen. Beim Retrieving wurde mit Ampicilin selektiert, beim Targeting aufgrund der Resistenz des Neo-Gens mit Kanamycin. 
Die Repression des RecBCP Proteins in den SW102-Zellen fördert das Vorkommen von Laufkreis-Replikation (engl. „rolling circle replication”), welche die Synthese von multiplen Kopien des Plasmids bedeutet. Um zu gewährleisten, dass sich ausschließlich eine Kopie des Retrieving- bzw. Targeting-Vektors in den Bakterienzellen befindet, wurde daher eine Retransformation von $1 \mathrm{ng}$ DNA in DH10B Zellen vorgenommen.

\section{Entfernung der Neo-Kassette}

Zur Entfernung der mit dem ersten Mini-Targeting-Vektors inserierten Neo-Kassette und zur Überprüfung der Funktionalität der LoxP- und Frt-Stellen wurde das TargetingKonstrukt in die Stämme SW106 und SW105 transformiert. Der Bakterienstamm SW106 beinhaltet das Gen für die Cre Rekombinase, Stamm SW105 trägt das Flpe Rekombinase-Gen. Beide Gene stehen unter der Kontrolle des Arabinose-induzierbaren AraC und $P_{B A D}$ Promotors und können so durch Zugabe von Arabinose in das Kulturmedium zur Expression der Rekombinasen induziert werden.

Zu Beginn wurde eine 10 ml-Kultur des Bakterienstammes SW105 oder SW106 in LB-Medium angeimpft und über Nacht bei $32^{\circ} \mathrm{C}$ wachsen gelassen. Die Kultur wurde 1:50 in $100 \mathrm{ml}$ LB-Medium verdünnt und für etwa 2 bis 3 Stunden bis zu einer $\mathrm{OD}_{600}$ von 0.4 bis 0.5 bei $180 \mathrm{rpm}$ inkubiert. Im Folgenden wurden $10 \mathrm{ml}$ der Kultur mit $100 \mu \mathrm{l} 10 \% \mathrm{~L}(+)$ Arabinose (Sigma Nr.A-3256), so dass eine Endkonzentration von 0.1\% gegeben war. Die Bakteriensuspension wurde zur Induktion der Cre bzw. Flpe Rekombinase für eine Stunde bei $32^{\circ} \mathrm{C}$ und $180 \mathrm{rpm}$ in einem Wasserbad inkubiert. Als Kontrolle dienten $10 \mathrm{ml}$ des uninduzierten Rests der 100 ml-Kultur. Des Weiteren wurden die Bakterien, Kontrolle sowie induzierte Bakterien wie bereits zuvor beschrieben, elektrokompetent gemacht und zur Transformation verwendet.

\section{Gen-Targeting in murinen ES Zellen und Produktion der Chimären}

Der Geminin cKO-Vektor wurde mit Hpal linearisiert und einer Phenol-Chloroform-Fällung unterzogen. $30 \mu \mathrm{g}$ des gereinigten Konstruktes wurden in MPI-II ES Zellen elektroporiert. Die positive Selektion der ES Zellen erfolgte in den ersten 2 bis 4 Tagen durch Zugabe von $2 \mathrm{mM}$ Ganciclovir, die negative Selektion erfolgte über eine Dauer von 10 Tagen mittels Zugabe von $250 \mu \mathrm{g} / \mathrm{ml}$ Geneticin (G418) in das ES-Kulturmedium. Die Expression des Neomycin-Gens verleiht Resistenz gegenüber Geneticin. Durch Zugabe dieses Antibiotikums in das ES-Zellmedium dient die Neo-Kassette der Selektion von Zellen mit positiven Rekombinationsereignissen. Da die Neo-Kassette von Frt-Sequenzen flankiert wird, kann nach Rekombination des Targeting-Konstruktes in den ES-Zellen bzw. nach 
Produktion der Maus-Chimären die Neo-Kassette durch Expression der Flpe Rekombinase wieder deletiert werden.

ES-Zellkolonien, welche die Selektion überlebten, wurden in 96-Well-Plastten trypsiniert, auf so genannten „Feeder-Zellen“ in 24-Well-Platten ausplattiert und für weitere 9 Tage kultiviert. Zum Schluß wurden die ES-Zellen auf gelatinisierte Platten transferiert und die DNA extrahiert. Die DNA wurde zur Southern Blot Analyse verwendet, um zu überprüfen, ob das cKO-Konstrukt erfolgreich in das ES-Zell-Genom inseriert worden war. Die DNA der ES-Zellen wurden dazu wie zuvor erläutert aufgearbeitet. ES-Zellen mit korrekt inseriertem Konstrukt wurden zur Aggregation mit CD-1 $1 /$ ICR Embryonen im MorulaStadium (16 Zellen) gegeben und bis zum Blastozystenstadium in Brutschränken inkubiert. Aggregierte Blastozysten wurden dann in den Ovidukt von scheinschwangeren Empfängermäusen transferiert.

\section{Southern Blot}

\section{Restriktionsverdau von genomischer DNA}

Die Reaktionen wurden in einem Gesamtvolumen von $50 \mu \mathrm{l}$ angesetzt. Zu 5 bis $10 \mu \mathrm{g}$ genomischer DNA wurde das entsprechende Restriktionsenzym in einer Endkonzentration von $10 \mathrm{U}$ pro $\mu \mathrm{g}$ DNA sowie der adequate Puffer gegeben. Des Weiteren wurden $2 \mu \mathrm{l}$ RNase A (1 mg/ml in $10 \mathrm{mM}$ Tris $\mathrm{HCl}$ pH 7,5, Roche Nr.109142) hinzugegeben, so dass die Endkonzentration $40 \mathrm{ng} / \mu \mathrm{l}$ betrug. Der Reaktionsansatz wurde bei angemessener Temperatur für 8 bis 16 Stunden inkubiert. Um eine vollständige Verdauung der DNA zu gewährleisten, wurde nach dieser Inkubationszeit eine weiteres Aliquot Enzym (5 U/ $\mathrm{g}$ DNA) zu der DNA gegeben und der Reaktionsansatz wurde für weitere 2 bis 3 Stunden inkubiert.

\section{Agarose-Gelelektrophorese}

Zur Auftrennung der verdauten DNA wurde ein 0,7\%iges Agarose-Gel mit 0,5× TBE (45 mM Tris-Borate, 1 mM EDTA, pH 8.0) und Ethidiumbromid in einer Endkonzentration von $0,3 \mu \mathrm{g} / \mathrm{ml}$ vorbereitet. Sofern die verdaute DNA bei $4^{\circ} \mathrm{C}$ aufbewahrt wurde, wurde sie vor dem Beladen des Gels für 2 Minuten bei $56^{\circ} \mathrm{C}$ erhitzt. Die Proben wurden mit der entsprechenden Menge an 6× DNA-Ladepuffer (25\% Ficoll, 100 mM EDTA, 0.05\% Bromophenolblau) versetzt und die Elektrophorese wurde für cirka 19 Stunden bei $30 \mathrm{~V}$ $(<1 \mathrm{~V} / \mathrm{cm})$ durchgeführt. Danach wurden der Teil des Gels oberhalb der Taschen und alle weiteren unbenötigten Teile abgeschnitten. Die Orientierung des Gels wurde durch Abschneiden eine Ecke markiert. Unter UV-Licht wurde ein Photo des Gels, zusammen mit einem der Markierung dienenden Lineal, aufgenommen. Vor dem Blotten wurde das 
Gel zunächst in eine Plastikkammer überführt. Das Gel wurde unter kontinuierlicher Schüttelbewegung in 0,25 M HCl depuriniert. Im Folgenden wurde das $\mathrm{Gel}$ mit $\mathrm{dH}_{2} \mathrm{O}$ gewaschen und für 40 Minuten in eine Denaturierungslösung $(1,5 \mathrm{M} \mathrm{NaCl}, 0,5 \mathrm{M} \mathrm{NaOH})$ gegeben. Die kontrollierte Behandlung mit Säure und die darauf folgende alkalische Denaturierung der DNA bewirkt, dass die DNA-Stränge an den depurinierten Strängen brechen, resultierend in kleineren, leichter $\mathrm{zu}$ transferierenden Fragmenten. Diese Behandlung ist besonders von Bedeutung, wenn DNA-Fragmente von über $10 \mathrm{~kb} z u$ transferieren sind. Das Gel wurde erneut mit $\mathrm{dH}_{2} \mathrm{O}$ gewaschen und für 40 Minuten in eine Neutralisierungslösung $(1,5 \mathrm{M} \mathrm{NaCl}, 1 \mathrm{M}$ Tris $\mathrm{HCl}, \mathrm{pH}$ 7,2) gegeben. Zuletzt wurde das Gel für mindestens 20 Minuten in $20 \times \operatorname{SSC}(0,3 \mathrm{M}$ Natriumcitrat, $3 \mathrm{M} \mathrm{NaCl}, \mathrm{pH} 7,0)$ geschwenkt. Zwischenzeitlich wurde die Nylonmembran (Genescreen ${ }^{\mathrm{TM}}$ Hybridization Transfer Membrane, PerkinElmer ${ }^{\mathrm{TM}}$ Life Sciences) in $\mathrm{dH}_{2} \mathrm{O}$ gegeben und anschließend für mindestens 20 Minuten in 20x SSC äquilibriert, bis sich die Membran einheitlich hellgrau, ohne verbleibende weiße Stellen zu hinterlassen, verfärbt hatte.

\section{Aufbau des Kapillar-Blotsystems}

Beim Kapillar-Blot ist die treibende Kraft ein Flüssigkeitsstrom, der von einem Reservoir ausgehend von unten durch das Gel weiter durch die Membran zu einem Stapel saugfähigen Materials läuft. Dieser Strom zieht die DNA aus dem Gel mit, die dann in den Maschen der Membran hängen bleibt. Das Whatman-Papier wurde dazu zuvor in 20x SSC getränkt. Die zu transferiernde DNA sollte sich im Gel oben befinden, d. h. es galt das Gel zu wenden. Dazu wurden zwei Glasplatten mit 70\%igem EtOH gesäubert und das Gel wurde mit Hilfe dieser gewendet. Nachdem auch die Membran und zwei weitere Lagen Whatman-Papier aufgelegt worden waren, wurden verbliebene Luftblasen zwischen Papier und Glasplatten durch Rollen mit einer angefeuchteten Pipette entfernt. Das Blotten wurde für 24 bis 48 Stunden in 20x SSC durchgeführt. Vor dem Entfernen des Gels wurden zur Orientierung die Taschen auf der Membran mit einem Bleistift markiert.

\section{Vernetzung von DNA und Membran}

Zur Vernetzung von DNA und Membran wurde die Membran auf zwei Whatman-Papieren liegend für eine Minute mit UV-Licht bestrahlt $\left(0,5 \mathrm{~J} / \mathrm{cm}^{2}\right.$, Fluo Link). Des Weiteren wurde die Membran für 2 Stunden bei $80^{\circ} \mathrm{C}$ in einem Vakuumofen gebacken.

\section{Markierung der DNA-Sonde und Aufreinigung}

Die DNA-Sonde wurde entsprechend den Anweisungen des Rediprime II Random Prime Labelling Kits (GE Healthcare) mit $\left[\alpha{ }^{32} \mathrm{P}\right]$-dCTP (Amersham Biosciences) radioaktiv markiert. Die Sonde wurde den Angaben des Herstellers entsprechend über die ProbeQuant G-50 Sephadex Micro Columns (GE Healthcare) aufgereinigt. Die spezifische 
Aktivität der radioaktiv markierten DNA wurde durch Messung mit einem LS1701 Scintillation Counter (BeckMan) ermittelt. Die Sonde wurde ausschließlich zur Hybridierung mit einer Membran eingesetzt, sofern sie eine spezifische Aktivität von mindestens 800.000 $\mathrm{cpm} / \mathrm{ul}$ besaß.

\section{Prähybridisierung und Hybridisierung}

Die Membranen wurden in Glasröhren transferiert und für 30 Minuten in vorgewärmten $2 \times$ SSC mit $0.5 \%$ SDS bei $65^{\circ} \mathrm{C}$ unter rotierender Bewegung gewaschen. Die Prähybridisierung erfolgte in etwa $0.1 \mathrm{ml}$ vorgewärmter Prähybridisierungslösung $/ \mathrm{cm}^{2}$ Membran (5× Denhardt's Lösung, 5x SSPE, 0,5\% SDS, $100 \mu \mathrm{g} / \mathrm{ml}$ Hering-Testis-DNA (Sigma, Nr. D6898); 100× Denhardt's Lösung (2\% (w/v) Ficoll 400, 2\% (w/v) Polyvinylpyrrolidon, 2\% (w/v) Kälberserum (Sigma, Fraktion V); 20× SSPE $(3 \mathrm{M} \mathrm{NaCl}, 0,2 \mathrm{M}$ $\mathrm{NaH}_{2} \mathrm{PO}_{4}, 20 \mathrm{mM}$ EDTA, pH 7.0). Die Prähybridisierung wurde für mindestens 2 Stunden bei $65^{\circ} \mathrm{C}$ durchgeführt. Zur Hybridisierung wurde die Prähybridierungslösung verworfen und durch frische Prähybridisierungslösung einschließlich der radioaktiv markierten Sonde ersetzt $\left(1 \times 10^{6} \mathrm{cpm} / \mathrm{ml}\right)$. Die Hybridisierung von Sonde und der auf der Membran vernetzten DNA fand unter rotierender Bewegung bei $65^{\circ} \mathrm{C}$ über Nacht statt. Die Hybridisierungslösung wurde anschließend im flüssigen Radioaktivabfall entsorgt. Die Membran wurde zweimal mit je einem Flaschenvolumen für je 30 Minuten mit auf $65^{\circ} \mathrm{C}$ vorgewärmten $2 \times$ SSC, 0,5\% SDS gewaschen. Es folgte ein weiterer Waschschritt von 30 Minuten mit vorgewärmten 0,1× SSC, 0,5\% SDS. Im Anschluß wurde die Membran für etwa 30 Minuten auf Whatman Papier an der Luft getrocknet.

\section{Autoradiographie}

Zur Detektion der radioaktiv markierten DNA-Sonde auf dem Blot wurden zunächst die Ecken der Membran mit Klebeband auf Whatman Papier fixiert und mit Frischhaltefolie eingewickelt. Der Blot wurde so in eine Filmkassette gelegt und unter Ausschluss von Licht wurde ein Röntgenfilm (Biomax MR Film, Kodak) aufgelegt. Die Dauer der Exponierung wurde in Abhängigkeit von der Sonde empirisch ermittelt. In der Regel wurde ein Film für mindestens 5 Tage bei $-80^{\circ} \mathrm{C}$ exponiert. Die Entwicklung des Filmes erfolgte mit der Curix 60 Entwicklermaschine (Agfa).

\section{Zellbiologische Methoden}

\section{Transiente Transfektion}

Zur transienten Transfektion von Gewebekulturzellen (Tabelle 7) mittels Lipofektion wurde das Lipofectamine ${ }^{\text {TM }} 2000$ (Invitrogen) Reagenz verwendet. Mindestens 24 Stunden vor 
der Transfektion wurde dazu eine angemessene Anzahl von Zellen auf die entsprechenden Gewebekulturschalen passagiert, so dass am Tage der Transfektion eine Konfluenz von 85-95\% vorlag. Die Zellen wurden in DMEM-10-Medium (DMEM mit 4 mM L-Glutamin, 4,5 mg/ml Glukose (Invitrogen), 10\% FCS, $2 \mathrm{mM} \mathrm{L-Glutamin)} \mathrm{bei} 37^{\circ} \mathrm{C}$ und in luftgesättigter Atmosphäre kultiviert. Zur Transfektion wurde ausschließlich einer PhenolChloroform-Fällung unterzogene Plasmid-DNA verwendet. Die DNA wurde in Opti-MEM ${ }^{\circledR}$ । (Invitrogen) Medium verdünnt. Lipofectamine ${ }^{\mathrm{TM}} 2000$ wurde folglich den Angaben des Herstellers eingesetzt. Die Mengen und Volumina an DNA, Medium und Lipofectamine sind in Tabelle 8 aufgeführt. Die Zellen wurden nach erfolgter Transfektion 24 bis 48 Stunden bei $37^{\circ} \mathrm{C}, 5 \% \mathrm{CO}_{2}$ in luftgesättigter Atmosphäre inkubiert.

\begin{tabular}{lll} 
Name & Beschreibung & Referenz \\
\hline HeLa & Human Cervixcarcinom-Zellen & \\
HeLa 6xHis-SUMO1 & $\begin{array}{l}\text { Human Cervixcarcinom-Zellen, stabil } \\
\text { 6xHis-SUMO1 exprimierend }\end{array}$ & (Girdwood et al., 2003) \\
& Embryonale Stammzellen der Maus & P. Gruss, MPI bpc, Göttingen \\
\hline
\end{tabular}

Tabelle 7. Liste der verwendeten Zelllinien.

\begin{tabular}{|c|c|c|c|}
\hline Gewebekulturschale & $\begin{array}{l}\text { Vol. } \\
\text { Kulturmedium }\end{array}$ & $\begin{array}{l}\text { Menge DNA in Vol. } \\
\text { Opti-MEM }^{\circledR} \text { I Medium }\end{array}$ & 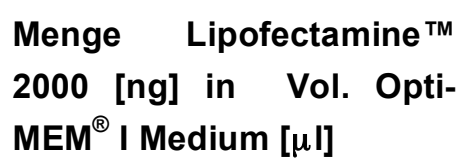 \\
\hline 24-Well-Platte & $500 \mu l$ & $0,8 \mu \mathrm{g}$ in $50 \mu \mathrm{l}$ & $1,5 \mu \mathrm{l}$ in $50 \mu \mathrm{l}$ \\
\hline 12-Well-Platte & $2 \mathrm{ml}$ & $1,6 \mu \mathrm{g}$ in $100 \mu \mathrm{l}$ & $3 \mu \mathrm{l}$ in $100 \mu \mathrm{l}$ \\
\hline 100-mm-Schale & $10 \mathrm{ml}$ & $24 \mu \mathrm{g}$ in $1,5 \mathrm{ml}$ & $45 \mu \mathrm{l}$ in $1,5 \mathrm{ml}$ \\
\hline
\end{tabular}

Tabelle 8. Verwendete Volumina von Medium und Lipofectamine ${ }^{\mathrm{TM}}$ und Mengen an DNA für transiente Transfektionen. Die Volumina und DNA-Mengen sind in Abhängigkeit der Größe der Gewebekulturschale dargestellt.

\section{Proteinbiochemische Methoden}

\section{Expression und Aufreinigung rekombinanter Proteine}

Für die Expression von GST-Tag fusionierten Proteinen wurde die cDNA des entsprechenden Gens in den Leserahmen des GST-Tags kloniert. Eine das Plasmid tragende Kolonie E. coli Bakterien (Tabelle 5) wurde in $5 \mathrm{ml}$ LB-Medium mit dem 
entsprechenden Antibiotikum inokuliert und für etwa 10 Stunden bei $37^{\circ} \mathrm{C}$ und $180 \mathrm{rpm}$ wachsen gelassen. Die Kultur wurde 1:20 in $100 \mathrm{ml}$ LB-Medium verdünnt und weiterhin unter den beschriebenen Bedingungen über Nacht inkubiert. $50 \mathrm{ml}$ der Vorkultur wurden jeweils zu 1 I vorgewärmtem LB-Medium mit dem entsprechenden Antibiotikum gegeben und bis zu einer $\mathrm{OD}_{600}$ von 0,6 bis 0,7 wachsen gelassen. Zur Kontrolle wurde ein $1 \mathrm{ml}-$ Aliquot entnommen, durch Zentrifugation pelletiert und der Überstand verworfen. Das Pellet wurde in $100 \mu \mathrm{l} 1 \times$ SDS-Ladepuffer (siehe unten) resuspendiert und für 5 Minuten bei $95^{\circ} \mathrm{C}$ gekocht (Input). Die Expression des Proteins wurde durch Zugabe von $1 \mathrm{mM}$ IPTG

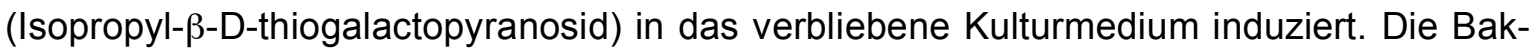
terienkultur wurde für 4 bis 5 Stunden bei $25^{\circ} \mathrm{C}$ und $150 \mathrm{rpm}$ inkubiert. Die Zellen wurden dann durch Zentrifugation für 25 Minuten bei $5.000 \mathrm{rpm}$ und $4^{\circ} \mathrm{C}$ pelletiert. Der Überstand wurde vorsichtig dekantiert und verworfen. Das Pellet wurde in dem verbliebenen Medium resuspendiert und in ein $50 \mathrm{ml}$-Falcon überführt. Es folgte ein weiterer Zentrifugationsschritt für 25 Minuten bei $4.000 \mathrm{rpm}$ und $4^{\circ} \mathrm{C}$ und der Überstand wurde wiederum verworfen. Das Falcon mit dem Pellet wurde in flüssigen Stickstoff gegeben über Nacht bei $80^{\circ} \mathrm{C}$ eingefroren. Am folgenden Tag wurde das Pellet auf Eis aufgetaut und in $8,5 \mathrm{ml}$ Resuspensionspuffer (50 mM Tris $\mathrm{HCl}, \mathrm{pH}$ 7,5, 500 mM NaCl, 2 mM EDTA, 5 mM DTT, frisch zugebenes $1 \mathrm{mM}$ PMSF und 1:25 Complete $^{\mathrm{TM}}$-EDTA Protease Inhibitor, Roche) resuspendiert. Es wurde $1 \mathrm{ml}(10 \mathrm{mg} / \mathrm{ml})$ Lysozym hinzugegeben und für eine Stunde auf Eis inkubiert. Nach 50 Minuten Inkubation wurden zudem $50 \mu \mathrm{l}(1 \mathrm{mg} / \mathrm{ml})$ DNasel und 50 $\mu \mathrm{l}(1 \mathrm{mg} / \mathrm{ml})$ RNase zu der Suspension gegeben. Es folgte eine einstündige Zentrifugation bei $30.000 \times g$ und $4^{\circ} \mathrm{C}$. Zur Vorbereitung der Glutathion-Sepharose 4B Kugeln (Amersham Biosciences) wurden diese dreimal mit PBS gewaschen und so mit PBS verdünnt, dass der Anteil der Kugeln etwa 50\% betrug. Das Zelllysat wurde dann zu $2 \mathrm{ml}$ der gewaschenen Glutathion-Sepharose Kugeln gegeben und für 2 Stunden bei $4^{\circ} \mathrm{C}$ unter rotierendenden Bewegungen inkubiert. Das Lysat wurde dann auf eine vorgewaschene $10 \mathrm{ml}$-Säule (Pierce) gegeben und dreimal mit je $10 \mathrm{ml}$ Waschpuffer $(50 \mathrm{mM}$ Tris $\mathrm{HCl}, \mathrm{pH} \mathrm{7,5,1 \textrm {M }}$ $\mathrm{NaCl}, 2 \mathrm{mM}$ EDTA, 1:25 Complete $^{\mathrm{TM}}$-EDTA Protease Inhibitor) gewaschen. Die Elution der Proteine erfolgte durch Zugabe $3 \mathrm{ml}$ Elutionspuffer $(20 \mathrm{mM}$ Glutathion in $100 \mathrm{mM}$ Tris $\mathrm{HCl} \mathrm{pH}$ 8.0, 1:25 Complete $^{\mathrm{TM}}$-EDTA Protease Inhibitor). Die Proteine wurden in Transportpuffer (20 mM Hepes, pH 7,3,110 mM KOAc, 2 mM Mg(OAc) 2,1 mM EGTA, 1 mM DTT, 1:25 Complete $^{\mathrm{TM}}$-EDTA Protease Inhibitor, 0,05\% Tween 20) dialysiert. Die Proteinkonzentrationen wurden mit Hilfe des Bradford-Tests (siehe unten) ermittelt. Aufgereinigte Proteine wurden in flüssigem Stickstoff schockgefroren und bei $-80^{\circ} \mathrm{C}$ gelagert. 


\section{Thrombin-Spaltung von GST-fusionierten Proteinen}

Zur Entfernung des GST-Taqs wurden GST-fusionierte Proteine mit der Thrombin Protease (Amersham Biosciences) geschnitten. Zur Trennung wurde das Protein in $950 \mu \mathrm{l}$ 1× PBS zusammen mit $50 \cup$ Thrombin auf die Glutathion-Sepharose 4B Kugeln in einer Säule geladen und über Nacht bei $4^{\circ} \mathrm{C}$ inkubiert. Die Reaktion wurde durch Zugabe von 1 mM PMSF gestoppt und das Protein durch Zugabe von 1× PBS von den Kugeln eluiert.

\section{GST-Pull-Down Analyse}

Protein-Protein Interaktionen wurden mit einer in vitro GST-Pull-Down Analyse belegt. An GST-fusioniertes Geminin wurden an Glutathione-Sepharose 4B Kugeln (Amersham) gebunden. $50 \mu \mathrm{l}$ der Kugeln wurde in einem Reaktionsgefäß mit $500 \mu \mathrm{l}$ of Pull-Down Bindepuffer $(20 \mathrm{mM}$ Tris $\mathrm{HCl}$ pH 7.5, $100 \mathrm{mM} \mathrm{NaCl}, 1 \mathrm{mM}$ EDTA, 0.1\% Nonidet P-40, $1 \mathrm{mM}$ frisch hinzugegebenes PMSF) gewaschen. Die Kugeln wurden durch Zentrifugation für wenige Sekunden bei $4.000 \mathrm{rpm}$ herunterzentrifugiert und der Überstand wurde verworfen. Zur Bindung an die Kugeln wurden $40 \mu \mathrm{g}$ rekombinantes GST-Geminin oder GST-Protein in $500 \mu \mathrm{l}$ of Bindepuffer und bei $4^{\circ} \mathrm{C}$ über Nacht rotieren gelassen. Nachdem der Überstand wiederum verworfen wurde, wurden die Kugeln zur Entfernung von ungebundenem Protein mit $500 \mu \mathrm{l}$ Bindepuffer gewaschen. Anschließend wurden $40 \mu \mathrm{l}$ des in vitro transkribierten und translatierten Pax6-Proteins zu den GST-Geminin- und GSTgekoppelten Kugeln gegeben. Die Kugeln wurden für eine Stunde bei $4^{\circ} \mathrm{C}$ und unter rotierenden Bewegungen inkubiert und danach dreimal mit Bindepuffer gewaschen. Danach wurden sie dreimal mit Pull-Down Waschpuffer $(20 \mathrm{mM}$ Tris $\mathrm{HCl}$ pH 7.5, $150 \mathrm{mM}$ $\mathrm{NaCl}, 1 \mathrm{mM}$ EDTA, 0.1\% Nonidet P-40, 1 mM frisch hinzugegebenes PMSF) gewaschen. Die abzentrifugierten Kugeln wurden zur Elution der Proteine in einem gleichen Volumen $2 \times$ SDS-Ladepuffer aufgenommen und für 7 Minuten bei $95{ }^{\circ} \mathrm{C}$ gekocht. Die Proben wurden auf ein SDS-Gel geladen und die Elektrophorese wurde bei $20 \mathrm{~mA}$ vorgenommen. Das Gel wurde getrocknet und über Nacht mit einem BioMax X-ray Film (Kodak) bei $-80^{\circ} \mathrm{C}$ exponiert und mit der Curix 60 Entwicklermaschine (Agfa) entwickelt.

\section{In vitro Transkription/Translation}

Zur in vitro Transkription und Translation wurde das TNT Retikulocyten System (Promega) eingesetzt. Für einen Reaktionsansatz wurden $2 \mu \mathrm{g}$ Plasmid-DNA, $4 \mu \mathrm{l}$ TNT Reaktionspuffer, $2 \mu \mathrm{l}$ Aminosäuren-Mix ohne Methionin, $4 \mu \mathrm{l}\left[{ }^{35} \mathrm{~S}\right]-$ Methionin (Amersham Biosciences), 1,5 $\mu$ l TNT RNA-Polymerase, $50 \mu l$ Retikulocyten-Lysat mit der entsprechenden Menge DEPC- $\mathrm{H}_{2} \mathrm{O}$ in einem Gesamtvolumen von $100 \mu \mathrm{l}$ angesetzt und für 2 Stunden bei $30^{\circ} \mathrm{C}$ inkubiert. 


\section{Generierung von Gesamt-Proteinextrakten}

Zur Herstellung von Gesamtzellextrakten aus Gewebekulturzellen wurden diese zunächst zweimal mit eisgekühltem PBS gewaschen und in einem angemessenen Volumen 2× SDS-Ladepuffer (125 mM Tris, 4\% SDS, 20\% Glycerin, 0,002\% Bromphenolblau, pH 6.8) lysiert. Die Zugabe von DTT (Dithiothreitol) zu dem Ladepuffer erfolgte in jedem Fall unmittelbar vor der Zelllyse. Die Endkonzentration von DTT sollte bei $100 \mathrm{mM}$ liegen. Es erfolgte eine fünfminütige Inkubation der Zellsuspension bei $95^{\circ} \mathrm{C}$ im Thermoblock zur Denaturierung der Proteine. Des Weiteren wurden die Zellen zum Aufbrechen der genomischen DNA einer Behandlung für 10 Minuten im Ultraschallbad unterzogen. Die Zelllysate wurden entweder bei $-20^{\circ} \mathrm{C}$ gelagert oder für die Western Blot Analyse unmittelbar auf ein SDS-Gel geladen. Unmittelbar vor dem Beladen des Gels wurden die Proben zur Denaturierung für 5 Minuten bei $95^{\circ} \mathrm{C}$ gekocht.

\section{Konzentrationsbestimmung von Proteinen nach Bradford}

Der Bradford-Test dient der Ermittlung der Konzentration an Proteinen in einer Lösung. Die Hauptkomponente der Bradford-Reagenz Coomassie Brilliant Blue G-250 verschiebt bei Bindung an Proteine das Absorptionsmaximum der Farbe. Ohne gebundenes Protein liegt es bei einer Wellenlänge von $465 \mathrm{~nm}$, mit Protein bei $595 \mathrm{~nm}$ vor. Entsprechend ist die Zunahme der Absorption bei $595 \mathrm{~nm}$ ein Maß für die Proteinkonzentration der Lösung. Die Farbentwicklung ist nach 2 Minuten beendet (Rehm, 2002). Zur Kalibrierung wurde vor der eigentlichen Messung eine Verdünnungsreihe mit Rinderserumalbumin (BSA)

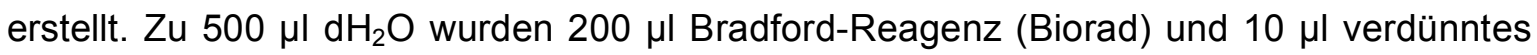
BSA bzw. $10 \mu \mathrm{l} \mathrm{zu} \mathrm{messender} \mathrm{Proteinextrakt} \mathrm{gegeben} \mathrm{und} \mathrm{gemischt.} \mathrm{Die} \mathrm{Messung}$ erfolgte nach 2 Minuten Inkubation im Photometer bei der Wellenlänge von $595 \mathrm{~nm}$.

\section{SDS-Polyacrylamidgelelektrophorese (SDS-PAGE)}

Zur Herstellung der SDS-Gele wurden die Glassplatten, Spacer und Kämme gesäubert und mit 70\%igem EtOH behandelt. Das Trenngel (Tabelle 9) wurde zwischen die Glasplatten gegossen und mit Isopropanol überschichtet, um zur Beschleunigung der Polymerisation einen Luftabschluß zu gewährleisten. Nach abgeschlossener Polymerisation des Trenngels wurde der Isopropanol entfernt. Das Sammelgel (Tabelle 9) wurde auf das Trenngel gegossen und es wurde ein Kamm zwischen die Glasplatten eingeführt. Trennund Sammelgel bestehen aus denselben Komponenten, mit Ausnahme des speziellen $4 \times$ Trenngel-Puffers (1,5 M Tris, 0,4\% SDS, pH 8,8) bzw. des $4 \times$ Sammelgel-Puffers (0,5 M Tris, 0,4\% SDS, pH 6,8). Ammonium Persulfat (APS, $10 \%$ (w/v) Stock-Lösung in $\mathrm{dH}_{2} \mathrm{O}$ ) und TEMED (Fluka, Buchs, Schweiz) wurden erst direkt vor dem Gießen der Gele 
hinzugegeben, da diese Reagenzien unmittelbar die Polymerisation des Acrylamids einleiteten. Nachdem das Gel vollständig ausgehärtet war, wurde es in die entsprechende Vorrichtung der Gelkammer (Tank Blot Chamber, Biorad) eingespannt, welche dann mit 1× Elektrophorese-Puffer (12,5 mM Tris, 96 mM Glycin, 0,05\% SDS) gefüllt wurde. Der Kamm wurde entfernt und die Taschen wurden unter Verwendung einer HamiltonGlasnadel mit Puffer ausgespült. 4 bis $5 \mu$ les MagicMark ${ }^{\text {TM }}$ XP Western Protein Standards (Invitrogen, Nr. LC5602) wurde neben den Proben mit der Glasnadel auf das SDS-Gel geladen. Ein Gel wurde bei 20 mA laufen gelassen, bei zwei Gelen je Kammer wurde die Stromstärke auf $40 \mathrm{~mA}$ erhöht.

\begin{tabular}{llll|ll} 
Trenngel & $\mathbf{7 , 5} \%$ & $\mathbf{1 0 \%}$ & $\mathbf{1 2 \%}$ & Sammelgel & $\mathbf{5 \%}$ \\
\hline $\begin{array}{l}30 \% \text { Acrylamid- } \\
\text { Bisacrylamid }\end{array}$ & $2,5 \mathrm{ml}$ & $3,3 \mathrm{ml}$ & $4 \mathrm{ml}$ & $\begin{array}{l}30 \% \text { Acrylamid- } \\
\text { Bisacrylamid }\end{array}$ & $670 \mu \mathrm{l}$ \\
$4 \times$ Trenngelpuffer & $2,5 \mathrm{ml}$ & $2,5 \mathrm{ml}$ & $2,5 \mathrm{ml}$ & $4 \times$ Sammelgelpuffer & $1 \mathrm{ml}$ \\
$\mathrm{dH}_{2} \mathrm{O}$ & $4,9 \mathrm{ml}$ & $4,1 \mathrm{ml}$ & $3,4 \mathrm{ml}$ & $\mathrm{dH}_{2} \mathrm{O}$ & $2,3 \mathrm{ml}$ \\
$10 \%$ APS & $100 \mu \mathrm{l}$ & $100 \mu \mathrm{l}$ & $100 \mu \mathrm{l}$ & $10 \%$ APS & $40 \mu \mathrm{l}$ \\
TEMED & $4 \mu \mathrm{l}$ & $4 \mu \mathrm{l}$ & $4 \mu \mathrm{l}$ & TEMED & $4 \mu \mathrm{l}$ \\
\hline
\end{tabular}

Tabelle 9. Komponenten und Mengenangaben für Trenn- und Sammelgel für je zwei SDS-PAGE-Gele.

\section{Western Blot Analyse}

\section{Elektrophoretischer Transfer der Proteine}

Für die Western Blot Analyse (Kyhse-Andersen, 1984) wurden jeweils vier Stücke Whatman Papier mit den Abmaßen 8,5 × 6,5 cm sowie ein Stück Nitrozellulosemembran (Potran BA 85, Schleicher und Schuell) zurecht geschnitten. Das Whatman Papier wurde zunächst in den Transfer-Puffer (3,9 mM Glycerine, $48 \mathrm{mM}$ Tris, 0,037\% SDS, $20 \% \mathrm{MeOH}$ ) getaucht und anschließend wurden jeweils zwei Stücke auf jede Seite der Transfer-Kassette gelegt. Die Membran wurde ebenfalls in Transfer-Puffer äquilibriert, auf die weiße Seite (Richtung Kathode) gelegt und mit einer Pinzette wurde durch vorsichtiges Streichen über die Membran Blasen entfernt. Das SDS-Polyacrylamid-Gel wurde aus der Elektrophoresekammer genommen, das Sammelgel entfernt und das Trenngel auf die Membran transferiert. Die Transfer-Kassette wurde geschlossen und in die mit TransferPuffer gefüllte Blotkammer überführt. Nachdem die Kühlbox ebenfalls in die Kammer eingebracht worden war, konnte der Deckel geschlossen und die Kammer an ein Spannungsregler angeschlossen werden. Die Übertragung der Proteine aus dem SDSGel auf die Nitrozellulosemembran erfolgte für 3 Stunden bei $30 \mathrm{~V}$. 


\section{Ponceau-Färbung der Proteine}

Auf einem Schwenkgerät wurde die Membran für etwa 5 Sekunden mit Ponceau $S$ (2\% (w/v) Ponceau S in 30\% (w/v) Trichloressigsäure und 30\% (w/v) Salicylsulfonsäure (2-Hydroxy-5-sulfobenzoesäure)) gefärbt, um die Proteine reversibel sichtbar zu machen und damit den erfolgreichen Transfer zu bestätigen. Außerdem konnte so vermerkt werden, ob in etwa gleiche Proteinmengen auf das Gel geladen worden waren. Die Membran wurde durch drei- bis viermaliges Waschen mit $1 \times$ Waschpuffer $A$ wieder entfärbt. 10× Waschpuffer $\mathrm{A}(100 \mathrm{mM}$ Tris $\mathrm{HCl}$ pH 7.4, 9\% $\mathrm{NaCl}$ ) wurde erst unmittelbar vor Gebrauch zum Waschen der Membran im Mengenverhältnis 1:10 verdünnt und es wurde 0,05\% Tween-20 zugegeben, da Tween-20 in Gegenwart von Licht schnell zerfällt. Der Waschvorgang wurde zur Aufnahme eines Bildes der Ponceau-Färbung unterbrochen.

\section{Applikation der primären und sekundären Antikörper}

Vor der Reaktion eines Blots mit Antikörpern werden die unspezifischen Proteinbindungsstellen der Blotmembran mit einem Blocker, in diesem Fall entfettetes Milchpulver, abgesättigt. Die Inkubation der Membran erfolgte dazu für eine Stunde auf einem Schwenkgerät bei RT in Block-Puffer. Die Membran wurde über Nacht bei $4^{\circ} \mathrm{C}$ und kontinuierlicher Schwenkbewegung mit dem primären Antikörper (Tabelle 10) in 1× Waschpuffer A, mit Milchpulver versetzt, inkubiert. Nicht gebundene, überschüssige Antikörper wurden am darauf folgenden Tag durch Waschen für 10 Minuten mit $1 \times$ Waschpuffer $A$ (10 mM Tris $\mathrm{HCl} \mathrm{pH} \mathrm{7.4,0,9 \%} \mathrm{NaCl,} \mathrm{0.05 \%} \mathrm{Tween-20),} \mathrm{zweimaliges} \mathrm{Waschen} \mathrm{für} \mathrm{je}$ 10 Minuten mit Waschpuffer B $(0,9 \% \mathrm{NaCl}, 0,5 \%$ Triton-X-100, 0,2\% SDS) und weitere 10 Minuten Waschen mit 1× Waschpuffer A entfernt. Zum Nachweis der primären Antikörper wurden Sekundärantikörper mit HRP (engl. „horseradish peroxidase“; Meerrettich-Peroxidase) gekoppelt verwendet (Tabelle 10). Die Inkubation mit dem zweiten Antikörper erfolgte für 45 Minuten bei RT. Abschließend wurden die zuvor aufgeführten Waschschritte wiederholt.

\section{Chemilumineszente Detektion der Proteine}

Die Membranen wurden auf Frischhaltefolie überführt und damit bedeckt, um ein Austrocknen zu verhindern. Zur Detektion der an HRP-gekoppelten Antikörper wurden Luminol und Oxidant des SuperSignal ${ }^{\circledR}$ West Pico Chemiluminescent Substrate Kits (Pierce, Nr. 34080) oder des SuperSignal® West Femto Maximum Sensitivity Subsrate (Pierce) im Verhältnis 1:1 in einem Eppi gemischt und auf die wieder freigelegte Membran pipettiert. Nach 5 Minuten Inkubationsdauer wurde die Detektion mittels Lumi-Imager ${ }^{\text {TM }}$ (Boehringer-Mannheim) eingeleitet. Die Auswertung geschah mit der LumiAnalyst ${ }^{\mathrm{TM}} 3.0$ Image Analysis Software (Boehringer-Mannheim). Als Belichtungszeit wurden zunächst 10 Sekunden gewählt und der Intensität des Signals entsprechend bei der nächsten 
Aufnahme entweder eine niedrigere oder höhere Belichtungszeit gesetzt, um eine möglichst optimale Darstellung der detektierten Proteinbanden zu erhalten. Alternativ wurden die Membranen mit CL-XPosure ${ }^{\mathrm{TM}}$ Filmen (Pierce) exponiert. Die Entwicklung erfolgte in diesem Fall mit der Curix 60 Entwicklermaschine (Agfa).

\section{Strippen und Rehybridisierung von Nitrozellulose-Membranen}

Die Bindung zwischen Antikörper und Antigen kann durch Hitze und unter denaturierenden Bedingungen gelöst werden, da die ionischen Wechselwirkungen zwischen Protein und Antikörper aufgehoben werden. Mit Proteinen beladene Nitrozellulosemembranen können mehrfach zur Western Blot Analyse mit verschiedenen Antikörpern verwendet werden. Strippen bezeichnet das Entfernen eines spezifisch gebundenen Antikörpers, um eine weitere Nachweisreaktion mit einem zweiten spezifischen Antikörper durchführen zu können. Die Membran wurde zunächst in einer Glaskammer in 1× Waschpuffer A getränkt und dann für 30 Minuten bei $50^{\circ} \mathrm{C}$ im Western Blot Strippingpuffer unter leichten Schwenkbewegungen inkubiert. Zu je $50 \mathrm{ml}$ Western Blot Strippingpuffer (25 mM $\mathrm{Na}_{2} \mathrm{HPO}_{4}, 25 \mathrm{mM} \mathrm{NaH} \mathrm{PO}_{4}, 2 \%$ SDS) wurden dabei zuvor $350 \mu \mathrm{l} \beta$-Mercaptoethanol gegeben. Anschließend wurde die Membran in eine neue Kammer überführt und dreimal für je 5 Minuten und danach dreimal für je 10 Minuten in $1 \times$ Waschpuffer $A$ geschwenkt. Die Nitrozellulose war danach bereit für die Inkubation mit einem weiteren Antikörper.

\section{Co-Immunpräzipitation}

Zur Untersuchung von Protein-Protein-Interaktionen in vivo wurde eine CoImmunpräzipitation durchgeführt. Hierzu wurden HeLa-Zellen in 100 mm-Gewebekulturschalen kultiviert, so dass sie zum Zeitpunkt der Transfektion eine ungefähre Konfluenz von 80 bis $90 \%$ hatten. 16 Stunden nach Transfektion der Zellen wurde MG132 (Sigma), ein Inhibitor der 26S Untereinheit des Proteasoms, in einer Endkonzentration von $10 \mu \mathrm{M}$ appliziert, um eine vorzeitige Degradierung der Proteine zu verhindern. Die Zellen wurden daraufhin für weitere 8 Stunden inkubiert. Die Zellernte und Immunpräzipitation erfolgte dann mittels des FLAG ${ }^{\circledR}$ Tagged Protein Immunoprecitpitation Kits (Sigma). Die Prozedur wurde entsprechend den Angaben des Herstellers durchgeführt, einschließlich des optionalen Waschschrittes zur Entfernung jeglichen ungebundenen Antikörpers. Die Elution des Proteins wurde mit 2x SDS-Ladepuffer vorgenommen. 


\begin{tabular}{|c|c|c|c|c|}
\hline Antikörper & $\begin{array}{l}\text { Herkunft und } \\
\text { Typ }\end{array}$ & Hersteller/Quelle & $\begin{array}{l}\text { Verdünnung } \\
\text { IHC }\end{array}$ & $\begin{array}{l}\text { Verdünnung } \\
\text { WB }\end{array}$ \\
\hline \multicolumn{5}{|l|}{ Primärantikörper } \\
\hline Anti-BrdU & $\begin{array}{l}\text { Maus } \\
\text { Monoklonal }\end{array}$ & Roche & $1: 20$ & \\
\hline Anti-FLAG & $\begin{array}{l}\text { Kaninchen } \\
\text { Polyklonal }\end{array}$ & Sigma & & $1: 1.000$ \\
\hline Anti-Geminin (FL-209) & $\begin{array}{l}\text { Kaninchen } \\
\text { Polyklonal }\end{array}$ & $\begin{array}{l}\text { Santa Cruz } \\
\text { sc-13015 }\end{array}$ & & 1:1.000 \\
\hline Anti-GFAP & $\begin{array}{l}\text { Kaninchen } \\
\text { Polyklonal }\end{array}$ & $\begin{array}{l}\text { DakoCytomation } \\
\text { Z0334 }\end{array}$ & $1: 300$ & \\
\hline Anti-GST & $\begin{array}{l}\text { Maus } \\
\text { Monoklonal }\end{array}$ & Novagen & & 1:10.000 \\
\hline Anti-HA & $\begin{array}{l}\text { Ratte } \\
\text { Monoklonal }\end{array}$ & Roche & & $1: 500$ \\
\hline Anti-His-Tag & $\begin{array}{l}\text { Maus } \\
\text { Monoklonal }\end{array}$ & Novagen $70796-3$ & & $1: 1.000$ \\
\hline Anti-H3P & Maus & Cell Signaling & $1: 100$ & \\
\hline Anti-Ki67 & Kaninchen & Abcam Ab15580 & $1: 250$ & \\
\hline Anti-NeuN & Maus & Millipore & $1: 200$ & \\
\hline Anti-Pax6 & Maus & DSHB & $1: 200$ & \\
\hline Anti-Tbr1 & $\begin{array}{l}\text { Kaninchen } \\
\text { Polyklonal }\end{array}$ & $\begin{array}{l}\text { Chemicon } \\
\text { AB9616 }\end{array}$ & $1: 500$ & \\
\hline Anti-Tbr2 & $\begin{array}{l}\text { Kaninchen } \\
\text { Polyklonal }\end{array}$ & $\begin{array}{l}\text { Chemicon } \\
\text { AB9618 }\end{array}$ & $1: 1.000$ & \\
\hline Anti-TuJ1 & $\begin{array}{l}\text { Maus } \\
\text { Monoklonal }\end{array}$ & Covance & $1: 500$ & \\
\hline Anti-RanGAP tail & Ziege & $\begin{array}{l}\text { Bossis, G. } \\
\text { unveröffenticht }\end{array}$ & & $1: 7.500$ \\
\hline \multicolumn{5}{|l|}{ Sekundärantikörper } \\
\hline Anti-Kaninchen-HRP & Ziege & Covance & & $1: 10.000$ \\
\hline Anti-Maus-HRP & Ziege Polyklonal & Dianova & & $1: 5.000$ \\
\hline Anti-Ziege-HRP & $\begin{array}{l}\text { Kaninchen } \\
\text { Polyklonal }\end{array}$ & Abcam & & $1: 7.500$ \\
\hline Anti-Ratte-HRP & Ziege Polyklonal & Dianova & & $1: 5.000$ \\
\hline $\begin{array}{l}\text { Anti-Kaninchen-Alexa } \\
488\end{array}$ & Ziege & MoBiTec & & 1:1.000 \\
\hline $\begin{array}{l}\text { Anti-Kaninchen-Alexa } \\
594\end{array}$ & Ziege & MoBiTec & & $1: 1.000$ \\
\hline Anti-Maus-Alexa 488 & Ziege & MoBiTec & & $1: 1.000$ \\
\hline Anti-Maus-Alexa 594 & Ziege & MoBiTec & & $1: 1.000$ \\
\hline
\end{tabular}

Tabelle 10. Liste der verwendeten Antikörper. Herkunft, Typ und Hersteller der Antikörper sind ebenso angegeben wie die benutzte Verdünnung bei Immunhistochemie (IHC) und Western Blot (WB) Analyse. 


\section{TUNEL-Test}

Zur Detektion von apoptotischen Zellen wurde ein TUNEL- (engl. „Terminal deoxynucleotidyltransferase-mediated dUTP-biotin nick end labeling") Test durchgeführt (Gavrieli et al., 1992). Während der Apoptose wird der DNA-Strang des Zellkerns durch die Aktivität von Endonukleasen fragmentiert. Das verwendete TUNEL-Reagenz (ApoTag® Red In Situ Apoptosis Detection Kit (Chemicon Nr.S7165) markiert die DNA an den Strangbrüchen am 3'-Hydroxy-Ende. Das die Reaktion katalysierende Enzym trägt die Bezeichnung Terminale Desoxynukleotidyl-Transferase (TdT). Es bewirkt unabhängig von der DNAVorlage die Polymerisation der Fluorescein-gekoppelten Nukleotide an den freien 3'-Hydroxy-Enden, so dass eine rote Färbung unter dem Fluoreszenzmikroskop visualisiert werden kann. Der TUNEL-Test wurde auf Gefrierschnitten und entsprechend den Angaben des Herstellers des ApoTag ${ }^{\circledR}$ Red In Situ Apoptosis Detection Kit durchgeführt. Die Schnitte wurden anschließend in Vectashield Mounting Medium mit DAPI (Vector Laboratories Nr.H-1200, 1,5 $\mu \mathrm{g} / \mathrm{ml}$ DAPI) eingebettet. Die Fluoreszenzmikroskopie wurde mit einem BX-60 Fluoreszenz-Mikroskop (Olympus) durchgeführt.

\section{In vitro SUMOylierung}

Um Proteine auf die Modifikation mit SUMO1 zu untersuchen, wurde eine in vitro SUMOylierungsreaktion durchgeführt (Pichler et al., 2002). Dazu wurde $1 \mu \mathrm{g}$ des

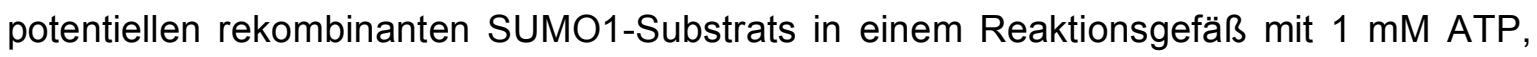
$68 \mathrm{nM}$ Aos1/Uba2, 28 nM, Ubc9, 4,4 $\mu \mathrm{M}$ SUMO1 und wahlweise PIAS1, PIAS3 oder 7,75 nM GST-RanBP2 $\Delta$ FG in Transportpuffer (20 mM Hepes, pH 7,3, $110 \mathrm{mM} \mathrm{KOAc,}$ $2 \mathrm{mM} \mathrm{Mg}(\mathrm{OAc})_{2}$, $1 \mathrm{mM}$ EGTA, $1 \mathrm{mM}$ DTT, $1 \mu \mathrm{g} / \mathrm{ml}$ Leupetin, $1 \mu \mathrm{g} / \mathrm{ml}$ Aprotinin, $1 \mu \mathrm{g} / \mathrm{ml}$ Pepstatin, 0,05\% Tween 20) und 0,2 mg/ml Ovalbumin verdünnt. Es folgte eine Inkubation für 30 Minuten bei $30^{\circ} \mathrm{C}$. Die Reaktionen wurden durch Zugabe von $2 \times$ SDS-Ladepuffer abgestoppt. Die rekombinanten Proteine wurden freundlicherweise von Prof. Dr. F. Melchior und T. Lampe aus der Abteilung Biochemie I der Universität Göttingen zur Verfügung gestellt.

\section{In vivo SUMOylierung}

Mittels Bindung an eine Nickel-Agarose-Matrix und unter stark denaturierenden Bedingungen können an 6xHis-SUMO1 konjugierte Proteine aufgereinigt und analysiert werden. Die Zellen einer $100 \mathrm{~mm}$-Platte wurden dazu zweimal mit eiskaltem PBS gewaschen und bei RT mit Hilfe eines Zellschabers in jeweils $6 \mathrm{ml}$ Guanidiumhydrochlorid-Puffer (GuHCl-Puffer; $6 \mathrm{M}$ Guanidium Hydrochlorid, $100 \mathrm{mM} \mathrm{Na} 2 \mathrm{HPO}_{4} / \mathrm{NaH}_{2} \mathrm{PO}_{4}$, $10 \mathrm{mM}$ Tris $\mathrm{HCl} \mathrm{pH}$ 8.0) lysiert. Zum Aufbrechen der Zellen wurde bei $50 \%$ Kraft und 
$50 \%$ Output Kontrolle für eine Minute mit Ultraschall behandelt. Durch Zentrifugation für 25 Minuten bei $20.000 \times \mathrm{g}$ und $4^{\circ} \mathrm{C}$ wurden unlysierte Rückstände pelletiert und es wurde ausschließlich der Überstand für das weitere Verfahren verwendet. Ein Aliquot des Überstandes von $200 \mu \mathrm{l}$ wurde als Input-Kontrolle aufgehoben und einer $\mathrm{MeOH} / \mathrm{CHCl}_{3}$ Präzipitation (siehe unten) unterzogen. Zu dem verbliebenen Überstand wurden $160 \mu \mathrm{l}$ Nickel-NTA Kügelchen (Qiagen), welche zuvor zweimal mit GuHCl-Puffer gewaschen worden waren sowie $30 \mu \mathrm{l} 2 \mathrm{M}$ Imidazol (Sigma) gegeben, so dass eine Endkonzentration des Imidazols von etwa $10 \mathrm{mM}$ vorlag. Das Lysat wurde so für 3 Stunden bei RT bei rotierender Bewegung mit den Kügelchen zu deren Beladung inkubiert. Im Anschluss wurden die Kügelchen zunächst für 10 Minuten mit $10 \mathrm{mM}$ Imidazol in $1,2 \mathrm{ml} \mathrm{GuHCl}$ Puffer gewaschen. Es folgten weitere Waschschritte für jeweils 10 Minuten mit je 1,2 ml Harnstoff-Puffer pH 8,0, (8 M Harnstoff, 100 mM Na $2 \mathrm{HPO}_{4} / \mathrm{NaH}_{2} \mathrm{PO}_{4}, 10 \mathrm{mM}$ Tris $\mathrm{HCl} \mathrm{pH}$ 8,0 bzw. pH 6,3) Harnstoff-Puffer pH 6,3, Harnstoff-Puffer pH 6,3 mit 0,2\% Triton-X-100, Harnstoff-Puffer pH 6,3 mit 0,1\% Triton-X-100 und erneut mit Harnstoff-Puffer pH 6,3. In jedem Fall wurden zuvor $10 \mathrm{mM}$ Imidazol zu dem Puffer zugegeben. Abschließend wurde nach dem letzten Waschschritt der verbliebene Puffer mit einer Glasspritze (Hamilton) entfernt. Die Elution gebundener Proteine wurde durch Kompetition mit $250 \mathrm{mM}$ Imidazol in 2x SDS-Ladepuffer durchgeführt. Nach 10 Minuten Inkubation bei rotierender Bewegung wurden die Kügelchen in dem Puffer für 6 Minuten bei $95^{\circ} \mathrm{C}$ gekocht und das Eluat wurde letztlich in ein neues Reaktionsgefäß transferiert. Die Proben wurden bis zu einer Woche bei RT aufbewahrt und ansonsten bei $-20^{\circ} \mathrm{C}$ gelagert.

\section{Methanol-Chloroform- $\left(\mathrm{MeOH} / \mathrm{CHCl}_{3}\right)$ Präzipitation}

Zur Gewinnung von Proteinextrakten von in GuHCl-Puffer lysierten Proben wurde eine $\mathrm{MeOH} / \mathrm{CHCl}_{3}$-Präzipitation vorgenommen, um die Proteine von ungewünschten Bestandteilen zu reinigen und um die Proteine anzukonzentrieren. $\mathrm{Zu}$ dem initialen Volumen wurden zunächst 4 Volumen $\mathrm{MeOH}$ und 2 Volumen $\mathrm{CHCl}_{3}$ pipettiert und gemischt. Die Proben wurden für 10 Sekunden bei $9.000 \times g$ zentrifugiert. Es wurden weiterhin 3 Volumen $\mathrm{dH}_{2} \mathrm{O}$ zu dem Gemisch hinzugegeben und für eine Minute gevortext. Es folgte eine Zentrifugation für 5 Minuten bei ebenfalls $9.000 \times \mathrm{g}$. Die Proteine befanden sich daraufhin in der intermediären Phase, so dass die obere Phase verworfen wurde. Nach Zugabe von 3 Volumen $\mathrm{MeOH}$ wurde wiederum gemischt und für 2 Minuten bei $9.000 \times g$ zentrifugiert. Der Überstand wurde verworfen und das verbliebene Zellpellet wurde bei RT getrocknet. Es wurde in $50 \mu \mathrm{l} 2 \times$ SDS-Ladepuffer gelöst und für 10 Minuten bei $95^{\circ} \mathrm{C}$ gekocht. 


\section{Histologische Methoden}

\section{BrdU-Perfusion von Mäusen}

BrdU (5'-Bromo-2'-deoxyuridin) ist ein chemisches Analogon des Nukleosids Thymidin. Phosphoryliert kann es kann anstelle des Nukleotids Desoxythymidintriphosphat bei der DNA-Synthese in neu synthetisierte DNA inkorporiert werden. BrdU dient daher der Markierung von proliferierenden Zellen und kann durch Bindung eines spezifischen Antikörpers immunhistochemisch nachgewiesen werden. Für die BrdU-Perfusion von Mäusen wurden unmittelbar vor der Injektion $14 \mathrm{mg}$ BrdU (Roche Nr.10280879001) in $1 \mathrm{ml}$ PBS gelöst und für etwa 5 Minuten bei $37^{\circ} \mathrm{C}$ inkubiert und ggf. gevortext, bis sich das Pulver gelöst hatte. Je $10 \mathrm{~g}$ Körpergewicht wurden $100 \mu \mathrm{l}$ der BrdU-Lösung intraperitoneal in das Muttertier injiziert.

\section{Einbetten in Kryomatrix}

Zur Herstellung von Gefrierschnitten wurde das einzubettende Gewebe zunächst in 4\% PFA bei $4^{\circ} \mathrm{C}$ fixiert (Kopf E12.5, E13.5 und Gehirn E15.5 für jeweils 2 Stunden, E16.5: 2,5 Stunden, P10: 5 Stunden). Das PFA wurde durch dreimaliges Waschen mit PBS für je 20 Minuten aus dem Gewebe entfernt. Des Weiteren wurde es zur Äquilibration in eine $25 \%$ ige Sucroselösung überführt. Sobald das Gewebe abgesunken war, wurde es in Kryomatrix (Tissue Freezing Medium ${ }^{\circledR}$ Einbettmedium, Leica) gegeben, auf Trockeneis darin eingefroren und anschließend bei $-20^{\circ} \mathrm{C}$ gelagert.

\section{Anfertigung von Gefrierschnitten}

Aus präpariertem Gewebe und Gehirnen wurde mit Hilfe eines Kryotoms 8 bis $10 \mu \mathrm{m}$ dicke Schnitte angefertigt. Die Schnitte wurden auf Objektträger aufgezogen, für etwa eine halbe Stunde bei $32^{\circ} \mathrm{C}$ trocknen gelassen und anschließend bis zur weiteren Verwendung bei $-80^{\circ} \mathrm{C}$ aufbewahrt.

\section{Einbetten in Paraffin}

Gehirne der Stadien P10 und und P15 wurden über Nacht in PFA fixiert. Das PFA wurde durch dreimaliges Waschen mit PBS für je eine Stunde entfernt. Des Weiteren wurden durch Waschen der Gehirne mit $0,86 \% \mathrm{NaCl}$ für 3 Stunden Salzkristalle entfernt. Die Waschlösung wurde ebenfalls jede Stunde gewechselt. Im Folgenden sind die einzelnen Schritte der Dehydrierung aufgeführt, welche bei $4^{\circ} \mathrm{C}$ vorgenommen wurden. 
$2 \times 15$ Minuten $50 \%$ EtOH

2× 15 Minuten $70 \%$ EtOH

$3 \times 20$ Minuten $80 \%$ EtOH

$3 \times 30$ Minuten $90 \% \mathrm{EtOH}$

4× 30 Minuten $96 \%$ EtOH

Die Gehirne wurden über Nacht in Isopropanol gelassen und anschließend erfolgte bei RT die Infiltration des Gewebes mit Paraffin wie im Folgenden beschrieben.

30 Minuten $25 \%$ Toluol / $75 \%$ Isopropanol

30 Minuten $50 \%$ Toluol / 50\% Isopropanol

30 Minuten $75 \%$ Toluol / 25\% Isopropanol

$2 \times 1$ Stunde $100 \%$ Toluol

Die Gehirne wurden danach zunächst erneut in frisches 100\%iges Toluol überführt und darin so lange belassen, bis sie leicht glasig aussahen. Anschließend wurden sie in Paraffin gegeben und für 3 Tage bei $60^{\circ} \mathrm{C}$ aufbewahrt. Das Paraffin wurde jeden Tag gewechselt, um das Toluol vollständig auszuwaschen. Die Gehirne wurden zum Schluß mit einer Einbettmaschine in Blöcken fixiert und bei $4^{\circ} \mathrm{C}$ zur Aufbewahrung gelagert.

\section{Anfertigung von Paraffinschnitten}

Die in Paraffin eingebetteten Gehirne wurden mit Hilfe eines Mikrotoms in $10 \mu \mathrm{m}$ dicke Schnitte geschnitten. Die in einem handwarmen Wasserbad gestreckten Schnitte wurden auf Objekträger aufgezogen und über Nacht bei $37^{\circ} \mathrm{C}$ getrocknet. Bis zur weiteren Verarbeitung wurden sie auf $4^{\circ} \mathrm{C}$ gelagert.

\section{BrdU Immunfluoreszenzfärbung}

Gefrierschnitte von murinem Gewebe wurden zweimal für 5 Minuten bei RT in PBS gewaschen. Es folgte eine Inkubation von 30 Minuten in $2 \mathrm{~N} \mathrm{HCl}$ bei $37^{\circ} \mathrm{C}$. Die Schnitte wurden anschließend zweimal für je 5 Minuten in $0.1 \mathrm{M}$ Natriumtetraboratpuffer gewaschen. Der pH-Wert dieses Puffers wurde zuvor mit $1 \mathrm{M}$ Borsäure auf 8,5 adjustiert. Nach einer einstündigen Inkubation der Gewebeschnitte in Blocklösung $(0,2 \%$ BSA, 0,04\% Tween in PBS) wurde der Anti-BrdU Antikörper (Roche) in einer 1:20 Verdünnung in Blocklösung appliziert. Die Inkubation erfolgte über Nacht bei $4^{\circ} \mathrm{C}$. Alle weiteren Schritte erfolgten gemäß dem Verfahren von gewöhnlichen Immunfluoreszenzfärbungen wie im Folgenden erläutert. 


\section{Indirekte Immunfluoreszenzfärbung}

Zu Beginn der indirekten Immunfluoreszenz wurden die mit Gewebeschnitten versehenen Objektträger dreimal für je 5 Minuten mit PBS gewaschen. In Abhängigkeit vom Primärantikörper wurden die Schnitte im folgenden Schritt zum Aufspüren der Antigene für 5 Minuten in Antigen-Demaskierungslösung (Vector Laboratories) in der Mikrowelle gekocht. In allen anderen Fällen wurden die Schnitte zur Absättigung von unspezifischen Bindungen für eine Stunde in Blocklösung (10\% FCS oder 10\% NGS mit 0,1\% Tween-20 oder $0,1 \%$ Triton-X-100 jeweils in PBS) inkubiert. Die Inkubation mit dem Primärantikörper (Tabelle 10) erfolgte in der entsprechenden Verdünnung in Blocklösung über Nacht in einer Feuchtkammer bei $4^{\circ} \mathrm{C}$. Am nächsten Tag wurden die Schnitte zunächst dreimal für je 5 Minuten mit PBS gewaschen und für 45 Minuten unter Ausschluß von Licht mit dem verdünnten Fluorophor-gekoppelten Sekundärantikörper (Tabelle 10) bei RT inkubiert. Es folgte erneut ein dreimaliges Waschen mit PBS und abschließend wurden die Gewebeschnitte in Vectashield $\AA$ Mounting Medium mit DAPI (Vector Laboratories) eingebettet. Die Deckgläschen wurden mit Nagellack versiegelt. Aufnahmen der Fluoreszenzmarkierten Schnitte wurden mit dem BX-60 Fluoreszenzmikroskop (Olympus) und der Cell^P Software (Olympus) erstellt.

\section{Herstellung von DIG-markierten Antisense-RNA-Sonden}

Um die Expression von spezifischer RNA im Gewebe zu visualisieren, kann mittels in vitro Transkription die cDNA des Interesses in RNA umgeschrieben und dabei mit einer Markierung versehen werden. Digoxigenin-11-UTP (DIG) ist ein derartiger Marker, der später im Gewebe mit einem $\alpha$-DIG-Alkalische Phosphatase Antikörper nachgewiesen werden kann. Zur Transkription wird linearisierte Plasmid-DNA verwendet, da die Linearisierung mit dem Restriktionsenzym einen 5'-Überhang hinterlässt, welcher die RNA-Polymerase daran hindert, „umzudrehen“ und einen Sense-Strang zu synthetisieren. Die Transkriptionsreaktion beinhaltete $1 \mu \mathrm{g}$ linearisiertes Plasmid, $2 \mu \mathrm{l} 10 \times$ Transkriptionspuffer (Roche), $2 \mu$ 10× DIG RNA Labeling Mix (Roche), $2 \mu \mathrm{l}$ RNasin (40 U/ul) und $1 \mu \mathrm{l}$ der entsprechenden RNA-Polymerase (SP6, T3 oder T7). Die Reaktion wurde mit RNase-freiem DEPC- $\mathrm{H}_{2} \mathrm{O}$ auf ein Gesamtvolumen von $20 \mu \mathrm{l}$ aufgefüllt und für 2 Stunden bei $37^{\circ} \mathrm{C}$ inkubiert. Zur Entfernung von nicht inkorporierten Nukleotiden wurde die Sonde über ProbeQuant G50 Mikrosäulen (GE Healthcare) aufgereinigt. Das Volumen des Transkriptionsansatzes wurde dazu mit DEPC- $\mathrm{H}_{2} \mathrm{O}$ auf $50 \mu \mathrm{l}$ aufgefüllt. Ein $5 \mu \mathrm{l}$ Aliquot der Sonde wurde zur Überprüfung der korrekten Größe auf einem Agarose-Gel aufgetragen. Die finale Konzentration sollte bei $100 \mu \mathrm{g} / \mu \mathrm{l}$ liegen. Anschließend wurde sie entweder zur sofortigen Verwendung für die In situ Hybridisierung mit 
Prähybridisierungspuffer 1:100 verdünnt und zur Denaturierung für 5 Minuten bei $95^{\circ} \mathrm{C}$ gekocht oder bis zur weiteren Verwendung bei $-20^{\circ} \mathrm{C}$ eingefroren.

\section{In situ Hybridisierung von Gefrierschnitten}

Die Gewebeschnitte wurden zuerst in 4\% PFA in PBS und DEPC- $\mathrm{dH}_{2} \mathrm{O}$ pH 7,8 für 15 Minuten bei $4^{\circ} \mathrm{C}$ gewaschen. Danach wurde zweimal für je 5 Minuten mit $1 \times$ PBS gewaschen. Um das Gewebe für die Sonden zugängig zu machen, wurde mit $20 \mu \mathrm{g} / \mathrm{ml}$ Proteinase $\mathrm{K}$ in Proteinase K-Puffer $\left(50 \mathrm{mM}\right.$ Tris $\mathrm{HCl}$ pH 8,0, $5 \mathrm{mM}$ EDTA in DEPC- $\mathrm{dH}_{2} \mathrm{O}$, autoklaviert) inkubiert. Für Schnitte des Stadiums E12.5 und E13.5 wurden für 3 Minuten mit Proteinase $\mathrm{K}$ behandelt, für E15.5 Schnitte für 3,5 Minuten und für P10 für 10 Minuten. Des Weiteren wurden die Schnitte für 5 Minuten mit 1\% Glycin in PBS und zweimal für je 5 Minuten in PBS gewaschen. Zur Postfixierung erfolgte eine Inkubation von 20 Minuten in 4\% PFA und 0,2\% Glutaraldehyd in PBS. Die Prähybridisierung erfolgte für mindestens 2 Stunden in Prähybridisierungspuffer (50\% (v/v) Formamid 5× SSC pH 4,5, 1\% (w/v) Blockpulver (Roche), $5 \mathrm{mM}$ EDTA, 0,1\% (v/v) Tween-20, 0,1\% (w/v) CHAPS, 0,1 $\mu \mathrm{g} / \mathrm{ml}$ Heparin, $1 \mathrm{mg} / \mathrm{ml}$ Transfer-RNA in DEPC- $\mathrm{dH}_{2} \mathrm{O}$ ) in einer mit 2× SSC pH 4,5/50\% Formamid gefüllten Feuchtkammer bei $70^{\circ} \mathrm{C}$. Danach wurde der Puffer durch Prähybridisierungspuffer mit der 1:100 verdünnten Sonde ersetzt. Die Hybridisierung fand über Nacht bei $70^{\circ} \mathrm{C}$ statt. Am nächsten Tag wurden die Schnitte zunächst für 5 Minuten in 2x SSC $(\mathrm{pH} 4,5)$ überführt. Es folgte dreimal ein Waschschritt von je 30 Minuten bei $65^{\circ} \mathrm{C}$ in $2 \times \mathrm{SSC} \mathrm{pH} \mathrm{4,5/50 \%} \mathrm{Formamid.} \mathrm{Danach} \mathrm{wurden} \mathrm{die} \mathrm{Schnitte} \mathrm{zweimal} \mathrm{für} \mathrm{jeweils}$ 10 Minuten und bei RT in KTBT $(50 \mathrm{mM}$ Tris $\mathrm{HCl} \mathrm{pH}$ 7,5, $150 \mathrm{mM} \mathrm{NaCl}, 10 \mathrm{mM} \mathrm{KCl}$, $10 \%$ (w/v) Tween-20) gewaschen. Um unspezifische Bindestellen des Antikörpers abzudecken, wurden die Gewebeschnitte für 2 Stunden bei RT in Blockreagenz (2\% inaktiviertes FCS in KTBT) inkubiert. Der Anti-Digoxigenin-AP ( $F_{a b}$ Fragmente) Antikörper (Roche) wurde in dem Blockreagenz verdünnt und über Nacht bei $4^{\circ} \mathrm{C}$ inkubiert. Es folgten zunächst drei Waschschritte à jeweils 5 Minuten bei RT mit KTBT, auf die drei weitere Waschschritte mit KTBT à jeweils 30 Minuten folgten. Anschließend wurden die Schnitte in NTMT (100mM Tris $\mathrm{HCl}$ pH 9,5, $10 \mathrm{mM} \mathrm{NaCl}, 50 \mathrm{mM} \mathrm{MgCl} 2,1 \% / \mathrm{v} / \mathrm{v}$ ) Tween-20, $1 \mathrm{mM}$ Levamisol) überführt und dreimal für je 5 Minuten bei RT darin gewaschen. Die Färbung mit NTMT/NBT/BCIP (100 mM Tris $\mathrm{HCl}$ pH 9,5, $10 \mathrm{mM} \mathrm{NaCl}$, $50 \mathrm{mM} \mathrm{MgCl} 2,1 \% / \mathrm{v} / \mathrm{v}$ ) Tween-20, $50 \mu \mathrm{M}$ Levamisol, 2\% (v/v) NBT/BCIP) wurde dann für 30 Minuten bei RT bis über Nacht bei $4^{\circ} \mathrm{C}$ durchgeführt. Die Schnitte wurden nach erfolgter Färbung viermal für je 5 Minuten in PBT gewaschen und dann in Mowiol $(4-88$ (Roth) eingedeckelt. Die Aufbewahrung erfolgte bei RT. 


\section{Cresylviolettfärbung von Paraffinschnitten}

Cresylviolett ist ein Farbstoff, der an basophile Verbindungen wie RNA und DNA bindet und daher Nukleoli und Ribosomen blau oder violett färbt. Da derartige Zellorganellen im Nervengewebe nur im Nervenzellkörper vorhanden sind, nicht aber an dessen Fortsätzen, wie Axone und Dendriten, werden nur die Zellkörper angefärbt. Die Menge, Form und Verteilung des Farbstoffs variiert in verschiedenen Typen von Neuronen. Paraffinschnitte von Gewebe wurden zur Färbung mit Cresylviolett (1,5\% Cresylviolett in Acetatpuffer (10 mM Natriumacetat, $10 \mathrm{mM}$ Essigsäure in $\mathrm{dH}_{2} \mathrm{O}$ )) den im Folgenden aufgeführten Prozess schrittweise unterzogen.

\begin{tabular}{ll} 
Histosol & $2 \times 5$ Minuten \\
Histosol & 3 Minuten \\
$100 \% \mathrm{EtOH}$ & 2 Minuten \\
$90 \% \mathrm{EtOH}$ & 2 Minuten \\
$70 \% \mathrm{EtOH}$ & 2 Minuten \\
$50 \% \mathrm{EtOH}$ & 2 Minuten \\
$\mathrm{d} \mathrm{H}_{2} \mathrm{O}$ & 2 Minuten \\
$50 \% \mathrm{Kaliumdisulfit}$ & 15 Minuten \\
$\mathrm{dH} \mathrm{H}_{2} \mathrm{O}$ & 1 Minute \\
$\mathrm{d} \mathrm{H}_{2} \mathrm{O}$ & 1 Minute \\
$\mathrm{Cresylviolett}$ & 10 Minuten \\
$\mathrm{Acetatpuffer}$ & $3 \times 1$ Minute \\
$0,14 \%$ Essigsäure & 30 Sekunden \\
$\mathrm{dH} \mathrm{H}_{2} \mathrm{O}$ & 1 Minute Objektträger auf- und abbewegen \\
$70 \%$ EtOH & 30 Sekunden oder länger \\
$100 \%$ EtOH & $2 \times 2$ Minuten \\
\hline $\mathrm{Histosol}$ & 10 Minuten oder länger \\
\hline
\end{tabular}

Die Objekte wurden anschließend in Eukitt (Kindler) eingedeckelt und bei RT aufbewahrt. 


\section{Literaturverzeichnis}

Anderson, S.A., Eisenstat, D.D., Shi, L. and Rubenstein, J.L. (1997) Interneuron migration from basal forebrain to neocortex: dependence on Dlx genes. Science, 278, 474476.

Angevine, J.B., Jr. and Sidman, R.L. (1961) Autoradiographic study of cell migration during histogenesis of cerebral cortex in the mouse. Nature, 192, 766-768.

Anthony, T.E., Klein, C., Fishell, G. and Heintz, N. (2004) Radial glia serve as neuronal progenitors in all regions of the central nervous system. Neuron, 41, 881-890.

Arias, E.E. and Walter, J.C. (2005) Replication-dependent destruction of Cdt1 limits DNA replication to a single round per cell cycle in Xenopus egg extracts. Genes Dev, 19, 114-126.

Bailey, D. (2003) Characterization of the Localization and Proteolytic Activity of the SUMO-specific Protease, SENP1. Journal of Biological Chemistry, 279, 692-703.

Bani-Yaghoub, M., Tremblay, R.G., Lei, J.X., Zhang, D., Zurakowski, B., Sandhu, J.K., Smith, B., Ribecco-Lutkiewicz, M., Kennedy, J., Walker, P.R. and Sikorska, M. (2006) Role of Sox2 in the development of the mouse neocortex. Dev Biol, 295, 52-66.

Bayer, P., Arndt, A., Metzger, S., Mahajan, R., Melchior, F., Jaenicke, R. and Becker, J. (1998) Structure determination of the small ubiquitin-related modifier SUMO-1. J Mol Biol, 280, 275-286.

Bayer, S.A., Altman, J., Russo, R.J., Dai, X.F. and Simmons, J.A. (1991) Cell migration in the rat embryonic neocortex. J Comp Neurol, 307, 499-516.

Bayer, S.A., Altman. J. (1991) Neocortical Development. New York: Raven Press.

Beckers, J., Caron, A., Hrabe de Angelis, M., Hans, S., Campos-Ortega, J.A. and Gossler, A. (2000) Distinct regulatory elements direct delta1 expression in the nervous system and paraxial mesoderm of transgenic mice. Mech Dev, 95, 23-34.

Behar, T., Ma, W., Hudson, L. and Barker, J.L. (1994) Analysis of the anatomical distribution of GAD67 mRNA encoding truncated glutamic acid decarboxylase proteins in the embryonic rat brain. Brain Res Dev Brain Res, 77, 77-87.

Benjamin, J.M., Torke, S.J., Demeler, B. and McGarry, T.J. (2004) Geminin has dimerization, Cdt1-binding, and destruction domains that are required for biological activity. J Biol Chem, 279, 45957-45968.

Birnboim, H.C. and Doly, J. (1979) A rapid alkaline extraction procedure for screening recombinant plasmid DNA. Nucleic Acids Res, 7, 1513-1523.

Bohren, K.M., Gabbay, K.H. and Owerbach, D. (2007) Affinity chromatography of native SUMO proteins using His-tagged recombinant UBC9 bound to Co2+-charged talon resin. Protein Expr Purif, 54, 289-294. 
Bohren, K.M., Nadkarni, V., Song, J.H., Gabbay, K.H. and Owerbach, D. (2004) A M55V polymorphism in a novel SUMO gene (SUMO-4) differentially activates heat shock transcription factors and is associated with susceptibility to type I diabetes mellitus. J Biol Chem, 279, 27233-27238.

Boos, A., Lee, A., Thompson, D.M. and Kroll, K.L. (2006) Subcellular translocation signals regulate Geminin activity during embryonic development. Biol Cell, 98, 363-375.

Bossis, G., Malnou, C.E., Farras, R., Andermarcher, E., Hipskind, R., Rodriguez, M., Schmidt, D., Muller, S., Jariel-Encontre, I. and Piechaczyk, M. (2005) Downregulation of c-Fos/c-Jun AP-1 dimer activity by sumoylation. Mol Cell Biol, 25, 6964-6979.

Bossis, G. and Melchior, F. (2006) SUMO: regulating the regulator. Cell Div, 1, 13.

Carter, S., Bischof, O., Dejean, A. and Vousden, K.H. (2007) C-terminal modifications regulate MDM2 dissociation and nuclear export of p53. Nat Cell Biol, 9, 428-435.

Chang, C.C., Lin, D.Y., Fang, H.I., Chen, R.H. and Shih, H.M. (2005) Daxx mediates the small ubiquitin-like modifier-dependent transcriptional repression of Smad4. J Biol Chem, 280, 10164-10173.

Chapouton, P., Gärtner, A. and Gštz, M. (1999) The role of Pax6 in restricting cell migration between developing cortex and basal ganglia. Development, 126, 5569-5579.

Chauhan, B.K., Reed, N.A., Yang, Y., Cermłk, L., Reneker, L., Duncan, M.K. and Cvekl, A. (2002) A comparative cDNA microarray analysis reveals a spectrum of genes regulated by Pax6 in mouse lens. Genes Cells, 7, 1267-1283.

Copeland, N.G., Jenkins, N.A. and Court, D.L. (2001) Recombineering: a powerful new tool for mouse functional genomics. Nat Rev Genet, 2, 769-779.

Del Bene, F., Tessmar-Raible, K. and Wittbrodt, J. (2004) Direct interaction of geminin and Six3 in eye development. Nature, 427, 745-749.

Desterro, J.M., Rodriguez, M.S. and Hay, R.T. (1998) SUMO-1 modification of IkappaBalpha inhibits NF-kappaB activation. Mol Cell, 2, 233-239.

Desterro, J.M., Rodriguez, M.S., Kemp, G.D. and Hay, R.T. (1999) Identification of the enzyme required for activation of the small ubiquitin-like protein SUMO-1. J Biol Chem, 274, 10618-10624.

Dower, W.J., Miller, J.F. and Ragsdale, C.W. (1988) High efficiency transformation of E. coli by high voltage electroporation. Nucleic Acids Res, 16, 6127-6145.

Ellis, H.M., Yu, D., DiTizio, T. and Court, D.L. (2001) High efficiency mutagenesis, repair, and engineering of chromosomal DNA using single-stranded oligonucleotides. Proc Natl Acad Sci U S A, 98, 6742-6746.

Englund, C., Fink, A., Lau, C., Pham, D., Daza, R.A., Bulfone, A., Kowalczyk, T. and Hevner, R.F. (2005) Pax6, Tbr2, and Tbr1 are expressed sequentially by radial glia, intermediate progenitor cells, and postmitotic neurons in developing neocortex. $J$ Neurosci, 25, 247-251. 
Eriksson, P.S., Perfilieva, E., Bjork-Eriksson, T., Alborn, A.M., Nordborg, C., Peterson, D.A. and Gage, F.H. (1998) Neurogenesis in the adult human hippocampus. Nat Med, 4, 1313-1317.

Estivill-Torrus, G., Pearson, H., van Heyningen, V., Price, D.J. and Rashbass, P. (2002) Pax6 is required to regulate the cell cycle and the rate of progression from symmetrical to asymmetrical division in mammalian cortical progenitors. Development, 129, 455-466.

Eward, K. L., Obermann, E. C., Shreeram, S., Loddo, M., Fanshawe, T., Williams, C., Jung, H. I., Prevost, A. T., Blow, J. J., Stoeber, K., Williams, G. H. (2004) DNA replication licensing in somatic and germ cells. J Cell Sci, 117, 5875-86.

Fode, C., Ma, Q., Casarosa, S., Ang, S.L., Anderson, D.J. and Guillemot, F. (2000) A role for neural determination genes in specifying the dorsoventral identity of telencephalic neurons. Genes Dev, 14, 67-80.

Francis, N.J., Saurin, A.J., Shao, Z. and Kingston, R.E. (2001) Reconstitution of a functional core polycomb repressive complex. Mol Cell, 8, 545-556.

Gavrieli, Y., Sherman, Y. and Ben-Sasson, S.A. (1992) Identification of programmed cell death in situ via specific labeling of nuclear DNA fragmentation. J Cell Biol, 119, 493-501.

Geiss-Friedlander, R. and Melchior, F. (2007) Concepts in sumoylation: a decade on. Nat Rev Mol Cell Biol, 8, 947-956.

Gilbert, S.F. (2000) Developmental Biology.

Girdwood, D., Bumpass, D., Vaughan, O.A., Thain, A., Anderson, L.A., Snowden, A.W., Garcia-Wilson, E., Perkins, N.D. and Hay, R.T. (2003) P300 transcriptional repression is mediated by SUMO modification. Mol Cell, 11, 1043-1054.

Glotzer, M., Murray, A.W. and Kirschner, M.W. (1991) Cyclin is degraded by the ubiquitin pathway. Nature, 349, 132-138.

Götz, M. and Huttner, W.B. (2005) The cell biology of neurogenesis. Nat Rev Mol Cell Biol, 6, 777-788.

Götz, M., Stoykova, A. and Gruss, P. (1998) Pax6 controls radial glia differentiation in the cerebral cortex. Neuron, 21, 1031-1044.

Gonzalez, M.A., Tachibana, K.E., Adams, D.J., van der Weyden, L., Hemberger, M., Coleman, N., Bradley, A. and Laskey, R.A. (2006) Geminin is essential to prevent endoreduplication and to form pluripotent cells during mammalian development. Genes Dev, 20, 1880-1884.

Gorski, J.A., Talley, T., Qiu, M., Puelles, L., Rubenstein, J.L. and Jones, K.R. (2002) Cortical excitatory neurons and glia, but not GABAergic neurons, are produced in the Emx1-expressing lineage. J Neurosci, 22, 6309-6314.

Gotz, M. and Barde, Y.A. (2005) Radial glial cells defined and major intermediates between embryonic stem cells and CNS neurons. Neuron, 46, 369-372.

Gould, E. (2007) How widespread is adult neurogenesis in mammals? Nat Rev Neurosci, 8, 481-488. 
Gould, E., Reeves, A.J., Graziano, M.S. and Gross, C.G. (1999) Neurogenesis in the neo cortex of adult primates. Science, 286, 548-552.

Gould, E., Vail, N., Wagers, M. and Gross, C.G. (2001) Adult-generated hippocampal and neocortical neurons in macaques have a transient existence. Proc Natl Acad Sci U S A, 98, 10910-10917.

Graham, V., Khudyakov, J., Ellis, P. and Pevny, L. (2003) SOX2 functions to maintain neural progenitor identity. Neuron, 39, 749-765.

Guillemot, F. (2007) Cell fate specification in the mammalian telencephalon. Prog Neurobiol, 83, 37-52.

Guillemot, F., Molnar, Z., Tarabykin, V. and Stoykova, A. (2006) Molecular mechanisms of cortical differentiation. Eur J Neurosci, 23, 857-868.

Gupta, A., Tsai, L.H. and Wynshaw-Boris, A. (2002) Life is a journey: a genetic look at neocortical development. Nat Rev Genet, 3, 342-355.

Hara, K., Nakayama, K.I. and Nakayama, K. (2006) Geminin is essential for the development of preimplantation mouse embryos. Genes Cells, 11, 1281-1293.

Hardeland, U., Steinacher, R., Jiricny, J. and Schar, P. (2002) Modification of the human thymine-DNA glycosylase by ubiquitin-like proteins facilitates enzymatic turnover. Embo J, 21, 1456-1464.

Hartfuss, E., Galli, R., Heins, N. and Gotz, M. (2001) Characterization of CNS precursor subtypes and radial glia. Dev Biol, 229, 15-30.

Haubensak, W., Attardo, A., Denk, W. and Huttner, W.B. (2004) Neurons arise in the basal neuroepithelium of the early mammalian telencephalon: a major site of neurogenesis. Proc Natl Acad Sci U S A, 101, 3196-3201.

Hay, R.T. (2005) SUMO: a history of modification. Mol Cell, 18, 1-12.

Heins, N., Cremisi, F., Malatesta, P., Gangemi, R.M., Corte, G., Price, J., Goudreau, G., Gruss, P. and Gotz, M. (2001) Emx2 promotes symmetric cell divisions and a multipotential fate in precursors from the cerebral cortex. Mol Cell Neurosci, 18, 485502.

Heins, N., Malatesta, P., Cecconi, F., Nakafuku, M., Tucker, K.L., Hack, M.A., Chapouton, P., Barde, Y.A. and Götz, M. (2002) Glial cells generate neurons: the role of the transcription factor Pax6. Nat Neurosci, 5, 308-315.

Hevner, R.F., Hodge, R.D., Daza, R.A. and Englund, C. (2006) Transcription factors in glutamatergic neurogenesis: conserved programs in neocortex, cerebellum, and adult hippocampus. Neurosci Res, 55, 223-233.

Hevner, R.F., Shi, L., Justice, N., Hsueh, Y., Sheng, M., Smiga, S., Bulfone, A., Goffinet, A.M., Campagnoni, A.T. and Rubenstein, J.L. (2001) Tbr1 regulates differentiation of the preplate and layer 6 . Neuron, 29, 353-366.

Hietakangas, V., Anckar, J., Blomster, H.A., Fujimoto, M., Palvimo, J.J., Nakai, A. and Sistonen, L. (2006) PDSM, a motif for phosphorylation-dependent SUMO modification. Proc Natl Acad Sci U S A, 103, 45-50. 
Hodgson, B., Li, A., Tada, S. and Blow, J.J. (2002) Geminin becomes activated as an in hibitor of Cdt1/RLF-B following nuclear import. Curr Biol, 12, 678-683.

Hoege, C., Pfander, B., Moldovan, G.L., Pyrowolakis, G. and Jentsch, S. (2002) RAD6dependent DNA repair is linked to modification of PCNA by ubiquitin and SUMO. Nature, 419, 135-141.

Iulianella, A., Vanden Heuvel, G. and Trainor, P. (2003) Dynamic expression of murine Cux2 in craniofacial, limb, urogenital and neuronal primordia. Gene Expr Patterns, $3,571-577$.

Jan, Y.N. and Jan, L.Y. (1994) Genetic control of cell fate specification in Drosophila peripheral nervous system. Annu Rev Genet, 28, 373-393.

Jang, M.S., Ryu, S.W. and Kim, E. (2002) Modification of Daxx by small ubiquitin-related modifier-1. Biochem Biophys Res Commun, 295, 495-500.

Johnson, E.S. (2004) Protein modification by SUMO. Annu Rev Biochem, 73, 355-382.

Johnson, E.S. and Gupta, A.A. (2001) An E3-like factor that promotes SUMO conjugation to the yeast septins. Cell, 106, 735-744.

Johnson, E.S., Schwienhorst, I., Dohmen, R.J. and Blobel, G. (1997) The ubiquitin-like protein $S m t 3 p$ is activated for conjugation to other proteins by an Aos $1 p / U b a 2 p$ heterodimer. Embo J, 16, 5509-5519.

Kagey, M., Melhuish, T. and Wotton, D. (2003) The polycomb protein Pc2 is a SUMO E3. Cell, 113, 127-137.

Kahyo, T., Nishida, T. and Yasuda, H. (2001) Involvement of PIAS1 in the sumoylation of tumor suppressor p53. Mol Cell, 8, 713-718.

Kim, E.A., Noh, Y.T., Ryu, M.J., Kim, H.T., Lee, S.E., Kim, C.H., Lee, C., Kim, Y.H. and Choi, C.Y. (2006) Phosphorylation and transactivation of Pax 6 by homeodomaininteracting protein kinase 2. J Biol Chem, 281, 7489-7497.

Koyano-Nakagawa, N., Wettstein, D. and Kintner, C. (1999) Activation of Xenopus genes required for lateral inhibition and neuronal differentiation during primary neurogenesis. Mol Cell Neurosci, 14, 327-339.

Kriegstein, A.R. and Gotz, M. (2003) Radial glia diversity: a matter of cell fate. Glia, 43, $37-43$.

Kroll, K.L. (2007) Geminin in embryonic development: coordinating transcription and the cell cycle during differentiation. Front Biosci, 12, 1395-1409.

Kroll, K.L., Salic, A.N., Evans, L.M. and Kirschner, M.W. (1998) Geminin, a neuralizing molecule that demarcates the future neural plate at the onset of gastrulation. Development, $125,3247-3258$.

Krubitzer, L. and Kaas, J. (2005) The evolution of the neocortex in mammals: how is phenotypic diversity generated? Curr Opin Neurobiol, 15, 444-453.

Kulartz, M., Hiller, E., Kappes, F., Pinna, L.A. and Knippers, R. (2004) Protein kinase CK2 phosphorylates the cell cycle regulatory protein Geminin. Biochem Biophys Res Commun, 315, 1011-1017. 
Kulartz, M. and Knippers, R. (2004) The replicative regulator protein geminin on chromatin in the HeLa cell cycle. J Biol Chem, 279, 41686-41694.

Kulartz, M., Kreitz, S., Hiller, E., Damoc, E.C., Przybylski, M. and Knippers, R. (2003) Expression and phosphorylation of the replication regulator protein geminin. Biochem Biophys Res Commun, 305, 412-420.

Kyhse-Andersen, J. (1984) Electroblotting of multiple gels: a simple apparatus without buffer tank for rapid transfer of proteins from polyacrylamide to nitrocellulose. J Biochem Biophys Methods, 10, 203-209.

Lapenta, V., Chiurazzi, P., van der Spek, P., Pizzuti, A., Hanaoka, F. and Brahe, C. (1997) SMT3A, a human homologue of the $S$. cerevisiae SMT3 gene, maps to chromosome 21 qter and defines a novel gene family. Genomics, 40, 362-366.

Lee, C., Hong, B., Choi, J.M., Kim, Y., Watanabe, S., Ishimi, Y., Enomoto, T., Tada, S. and Cho, Y. (2004) Structural basis for inhibition of the replication licensing factor Cdt1 by geminin. Nature, 430, 913-917.

Lessard, J., Wu, J.I., Ranish, J.A., Wan, M., Winslow, M.M., Staahl, B.T., Wu, H., Aebersold, R., Graef, I.A. and Crabtree, G.R. (2007) An essential switch in subunit composition of a chromatin remodeling complex during neural development. Neuron, $55,201-215$.

Li, A. and Blow, J.J. (2004) Non-proteolytic inactivation of geminin requires CDKdependent ubiquitination. Nat Cell Biol, 6, 260-267.

Lin, D.Y., Huang, Y.S., Jeng, J.C., Kuo, H.Y., Chang, C.C., Chao, T.T., Ho, C.C., Chen, Y.C., Lin, T.P., Fang, H.I., Hung, C.C., Suen, C.S., Hwang, M.J., Chang, K.S., Maul, G.G. and Shih, H.M. (2006) Role of SUMO-interacting motif in Daxx SUMO modification, subnuclear localization, and repression of sumoylated transcription factors. Mol Cell, 24, 341-354.

Liu, P., Jenkins, N.A. and Copeland, N.G. (2003) A highly efficient recombineering-based method for generating conditional knockout mutations. Genome Res, 13, 476-484.

Luo, L., Uerlings, Y., Happel, N., Asli, N.S., Knoetgen, H. and Kessel, M. (2007) Regulation of geminin functions by cell cycle-dependent nuclear-cytoplasmic shuttling. Mol Cell Biol, 27, 4737-4744.

Luo, L., Yang, X., Takihara, Y., Knoetgen, H. and Kessel, M. (2004) The cell-cycle regulator geminin inhibits Hox function through direct and polycomb-mediated interactions. Nature, 427, 749-753.

Lutzmann, M., Maiorano, D. and MŽchali, M. (2006) A Cdt1-geminin complex licenses chromatin for DNA replication and prevents rereplication during $S$ phase in Xenopus. EMBO J, 25, 5764-5774.

Machida, Y.J. and Dutta, A. (2007) The APC/C inhibitor, Emi1, is essential for prevention of rereplication. Genes Dev, 21, 184-194.

Mahajan, R., Delphin, C., Guan, T., Gerace, L. and Melchior, F. (1997) A small ubiquitinrelated polypeptide involved in targeting RanGAP1 to nuclear pore complex protein RanBP2. Cell, 88, 97-107. 
Malatesta, P., Hack, M.A., Hartfuss, E., Kettenmann, H., Klinkert, W., Kirchhoff, F. and Gotz, M. (2003) Neuronal or glial progeny: regional differences in radial glia fate. Neuron, 37, 751-764.

Malatesta, P., Hartfuss, E. and Gotz, M. (2000) Isolation of radial glial cells by fluorescentactivated cell sorting reveals a neuronal lineage. Development, 127, 5253-5263.

Marin, O. and Rubenstein, J.L. (2003) Cell migration in the forebrain. Annu Rev Neurosci, 26, 441-483.

Martin, S., Wilkinson, K.A., Nishimune, A. and Henley, J.M. (2007) Emerging extranuclear roles of protein SUMOylation in neuronal function and dysfunction. Nat Rev Neurosci, 8, 948-959.

Matsumoto, S., Banine, F., Struve, J., Xing, R., Adams, C., Liu, Y., Metzger, D., Chambon, P., Rao, M.S. and Sherman, L.S. (2006) Brg1 is required for murine neural stem cell maintenance and gliogenesis. Dev Biol, 289, 372-383.

Matunis, M.J., Coutavas, E. and Blobel, G. (1996) A novel ubiquitin-like modification modulates the partitioning of the Ran-GTPase-activating protein RanGAP1 between the cytosol and the nuclear pore complex. J Cell Biol, 135, 1457-1470.

McConnell, S.K. (1995) Constructing the cerebral cortex: neurogenesis and fate determination. Neuron, 15, 761-768.

McGarry, T.J. and Kirschner, M.W. (1998) Geminin, an inhibitor of DNA replication, is degraded during mitosis. Cell, 93, 1043-1053.

Melchior, F. (2000) SUMO-nonclassical ubiquitin. Annu Rev Cell Dev Biol, 16, 591-626.

Melixetian, M., Ballabeni, A., Masiero, L., Gasparini, P., Zamponi, R., Bartek, J., Lukas, J. and Helin, K. (2004) Loss of Geminin induces rereplication in the presence of functional p53. J Cell Biol, 165, 473-482.

Mihaylov, I.S., Kondo, T., Jones, L., Ryzhikov, S., Tanaka, J., Zheng, J., Higa, L.A., Minamino, N., Cooley, L. and Zhang, H. (2002) Control of DNA replication and chromosome ploidy by geminin and cyclin A. Mol Cell Biol, 22, 1868-1880.

Miller, F. and Gauthier, A. (2007) Timing Is Everything: Making Neurons versus Glia in the Developing Cortex. Neuron, 54, 357-369.

Minty, A., Dumont, X., Kaghad, M. and Caput, D. (2000) Covalent modification of p73alpha by SUMO-1. Two-hybrid screening with p73 identifies novel SUMO-1interacting proteins and a SUMO-1 interaction motif. J Biol Chem, 275, 3631636323.

Misson, J.P., Edwards, M.A., Yamamoto, M. and Caviness, V.S., Jr. (1988) Identification of radial glial cells within the developing murine central nervous system: studies based upon a new immunohistochemical marker. Brain Res Dev Brain Res, 44, 95-108.

Miyata, T., Kawaguchi, A., Saito, K., Kawano, M., Muto, T. and Ogawa, M. (2004) Asymmetric production of surface-dividing and non-surface-dividing cortical progenitor cells. Development, 131, 3133-3145. 
Molyneaux, B.J., Arlotta, P., Menezes, J.R. and Macklis, J.D. (2007) Neuronal subtype specification in the cerebral cortex. Nat Rev Neurosci, 8, 427-437.

Montanari, M., Boninsegna, A., Faraglia, B., Coco, C., Giordano, A., Cittadini, A. and Sgambato, A. (2005) Increased expression of geminin stimulates the growth of mammary epithelial cells and is a frequent event in human tumors. J Cell Physiol, 202, 215-222.

Mülhardt, C. (2000) Der Experimentator: Molekularbiologie. Spektrum Akadem. Verlag

Mukhopadhyay, D. and Dasso, M. (2007) Modification in reverse: the SUMO proteases. Trends Biochem Sci, 32, 286-295.

Muller, S., Hoege, C., Pyrowolakis, G. and Jentsch, S. (2001) SUMO, ubiquitin's mysterious cousin. Nat Rev Mol Cell Biol, 2, 202-210.

Muyrers, J.P., Zhang, Y. and Stewart, A.F. (2001) Techniques: Recombinogenic engineering--new options for cloning and manipulating DNA. Trends Biochem Sci, 26, 325331.

Nakagawa, Y. and O'Leary, D.D. (2003) Dynamic patterned expression of orphan nuclear receptor genes RORalpha and RORbeta in developing mouse forebrain. Dev Neurosci, 25, 234-244.

Ni, Z. and Bremner, R. (2007) Brahma-related gene 1-dependent STAT3 recruitment at IL-6-inducible genes. J Immunol, 178, 345-351.

Nieto, M., Monuki, E.S., Tang, H., Imitola, J., Haubst, N., Khoury, S.J., Cunningham, J., Gotz, M. and Walsh, C.A. (2004) Expression of Cux-1 and Cux-2 in the subventricular zone and upper layers II-IV of the cerebral cortex. J Comp Neurol, 479, 168180.

Nishitani, H., Lygerou, Z. and Nishimoto, T. (2004) Proteolysis of DNA replication licensing factor Cdt1 in S-phase is performed independently of geminin through its $\mathrm{N}$ terminal region. J Biol Chem, 279, 30807-30816.

Nishitani, H., Lygerou, Z., Nishimoto, T. and Nurse, P. (2000) The Cdt1 protein is required to license DNA for replication in fission yeast. Nature, 404, 625-628.

Noctor, S.C., Flint, A.C., Weissman, T.A., Wong, W.S., Clinton, B.K. and Kriegstein, A.R. (2002) Dividing precursor cells of the embryonic cortical ventricular zone have morphological and molecular characteristics of radial glia. J Neurosci, 22, 3161-73.

Noctor, S.C., Martinez-Cerdeno, V., Ivic, L. and Kriegstein, A.R. (2004) Cortical neurons arise in symmetric and asymmetric division zones and migrate through specific phases. Nat Neurosci, 7, 136-144.

Okorokov, A.L., Orlova, E.V., Kingsbury, S.R., Bagneris, C., Gohlke, U., Williams, G.H. and Stoeber, K. (2004) Molecular structure of human geminin. Nat Struct Mol Biol, $11,1021-1022$.

Olave, I., Wang, W., Xue, Y., Kuo, A. and Crabtree, G.R. (2002) Identification of a polymorphic, neuron-specific chromatin remodeling complex. Genes Dev, 16, 25092517. 
Osoegawa, K., Tateno, M., Woon, P.Y., Frengen, E., Mammoser, A.G., Catanese, J.J., Hayashizaki, Y. and de Jong, P.J. (2000) Bacterial artificial chromosome libraries for mouse sequencing and functional analysis. Genome Res, 10, 116-128.

Papanayotou, C., Mey, A., Birot, A.M., Saka, Y., Boast, S., Smith, J.C., Samarut, J. and Stern, C.D. (2008) A Mechanism Regulating the Onset of Sox2 Expression in the Embryonic Neural Plate. PLoS Biol, 6, e2.

Pichler, A., Gast, A., Seeler, J.S., Dejean, A. and Melchior, F. (2002) The nucleoporin RanBP2 has SUMO1 E3 ligase activity. Cell, 108, 109-120.

Pichler, A., Knipscheer, P., Oberhofer, E., van Dijk, W.J., Korner, R., Olsen, J.V., Jentsch, S., Melchior, F. and Sixma, T.K. (2005) SUMO modification of the ubiquitinconjugating enzyme E2-25K. Nat Struct Mol Biol, 12, 264-269.

Qian, X., Shen, Q., Goderie, S.K., He, W., Capela, A., Davis, A.A. and Temple, S. (2000) Timing of CNS cell generation: a programmed sequence of neuron and glial cell production from isolated murine cortical stem cells. Neuron, 28, 69-80.

Quinn, L.M., Herr, A., McGarry, T.J. and Richardson, H. (2001) The Drosophila Geminin homolog: roles for Geminin in limiting DNA replication, in anaphase and in neurogenesis. Genes Dev, 15, 2741-2754.

Rakic, P. (1995) A small step for the cell, a giant leap for mankind: a hypothesis of neocortical expansion during evolution. Trends Neurosci, 18, 383-388.

Ramón y Cajal S. (1913) Contribución al conocimiento de la neuroglia del cerebro humano. Trab. Lab. Invest. Biol., 255-315

Rechsteiner, M. and Rogers, S.W. (1996) PEST sequences and regulation by proteolysis. Trends Biochem Sci, 21, 267-271.

Reeves, S.A., Helman, L.J., Allison, A. and Israel, M.A. (1989) Molecular cloning and primary structure of human glial fibrillary acidic protein. Proc Natl Acad Sci U S A, 86, 5178-5182.

Rehm, H. (2002) Der Experimentator: Proteinbiochemie/Proteomics.

Reynolds, B.A. and Weiss, S. (1992) Generation of neurons and astrocytes from isolated cells of the adult mammalian central nervous system. Science, 255, 1707-1710.

Rogers, S., Wells, R. and Rechsteiner, M. (1986) Amino acid sequences common to rapidly degraded proteins: the PEST hypothesis. Science, 234, 364-368.

Roukos, V., Iliou, M.S., Nishitani, H., Gentzel, M., Wilm, M., Taraviras, S. and Lygerou, Z. (2007) Geminin cleavage during apoptosis by caspase-3 alters its binding ability to the SWI/SNF subunit Brahma. J Biol Chem, 282, 9346-9357.

Rubenstein, J.L., Shimamura, K., Martinez, S. and Puelles, L. (1998) Regionalization of the prosencephalic neural plate. Annu Rev Neurosci, 21, 445-477.

Sakurai, K. and Osumi, N. (2008) The neurogenesis-controlling factor, Pax6, inhibits proliferation and promotes maturation in murine astrocytes. J Neurosci, 28, 4604-4612.

Sauer, B. (1998) Inducible gene targeting in mice using the Cre/lox system. Methods, 14 , 381-392. 
Sauer, F.C. (1935) Mitosis in the neural tube. J Comp Neurol, 62, 377-405.

Saxena, S., Yuan, P., Dhar, S.K., Senga, T., Takeda, D., Robinson, H., Kornbluth, S., Swaminathan, K. and Dutta, A. (2004) A dimerized coiled-coil domain and an adjoining part of geminin interact with two sites on Cdt1 for replication inhibition. Mol Cell, 15, 245-258.

Scardigli, R., Bäumer, N., Gruss, P., Guillemot, F. and Le Roux, I. (2003) Direct and concentration-dependent regulation of the proneural gene Neurogenin2 by Pax6. Development, 130, 3269-3281.

Scholzen, T. and Gerdes, J. (2000) The Ki-67 protein: from the known and the unknown. J Cell Physiol, 182, 311-322.

Schuurmans, C., Armant, O., Nieto, M., Stenman, J.M., Britz, O., Klenin, N., Brown, C., Langevin, L.M., Seibt, J., Tang, H., Cunningham, J.M., Dyck, R., Walsh, C., Campbell, K., Polleux, F. and Guillemot, F. (2004) Sequential phases of cortical specification involve Neurogenin-dependent and -independent pathways. EMBO J, 23, 2892-2902.

Seo, S., Herr, A., Lim, J.W., Richardson, G.A., Richardson, H. and Kroll, K.L. (2005a) Geminin regulates neuronal differentiation by antagonizing Brg1 activity. Genes Dev, 19, 1723-1734.

Seo, S., Richardson, G.A. and Kroll, K.L. (2005b) The SWI/SNF chromatin remodeling protein Brg1 is required for vertebrate neurogenesis and mediates transactivation of Ngn and NeuroD. Development, 132, 105-115.

Shen, T.H., Lin, H.K., Scaglioni, P.P., Yung, T.M. and Pandolfi, P.P. (2006) The mechanisms of PML-nuclear body formation. Mol Cell, 24, 331-339.

Song, J., Durrin, L.K., Wilkinson, T.A., Krontiris, T.G. and Chen, Y. (2004) Identification of a SUMO-binding motif that recognizes SUMO-modified proteins. Proc Natl Acad Sci U S A, 101, 14373-14378.

Spella, M., Britz, O., Kotantaki, P., Lygerou, Z., Nishitani, H., Ramsay, R.G., Flordellis, C., Guillemot, F., Mantamadiotis, T. and Taraviras, S. (2007) Licensing regulators Geminin and Cdt1 identify progenitor cells of the mouse CNS in a specific phase of the cell cycle. Neuroscience, 147, 373-387.

Stoykova, A. and Gruss, P. (1994) Roles of Pax-genes in developing and adult brain as suggested by expression patterns. J Neurosci, 14, 1395-1412.

Stoykova, A., Treichel, D., Hallonet, M. and Gruss, P. (2000) Pax6 modulates the dorsoventral patterning of the mammalian telencephalon. J Neurosci, 20, 8042-8050.

Subramanian, L., Benson, M.D. and Iniguez-Lluhi, J.A. (2003) A synergy control motif within the attenuator domain of CCAAT/enhancer-binding protein alpha inhibits transcriptional synergy through its PIASy-enhanced modification by SUMO-1 or SUMO-3. J Biol Chem, 278, 9134-9141.

Sugimoto, N., Tatsumi, Y., Tsurumi, T., Matsukage, A., Kiyono, T., Nishitani, H. and Fujita, M. (2004) Cdt1 phosphorylation by cyclin A-dependent kinases negatively regulates its function without affecting geminin binding. J Biol Chem, 279, 19691-19697. 
Sun, Y., Nadal-Vicens, M., Misono, S., Lin, M.Z., Zubiaga, A., Hua, X., Fan, G. and Greenberg, M.E. (2001) Neurogenin promotes neurogenesis and inhibits glial differentiation by independent mechanisms. Cell, 104, 365-376.

Tachibana, K.E., Gonzalez, M.A., Guarguaglini, G., Nigg, E.A. and Laskey, R.A. (2005) Depletion of licensing inhibitor geminin causes centrosome overduplication and mitotic defects. EMBO Rep, 6, 1052-1057.

Tada, S., Li, A., Maiorano, D., Mechali, M. and Blow, J.J. (2001) Repression of origin assembly in metaphase depends on inhibition of RLF-B/Cdt1 by geminin. Nat Cell Biol, 3, 107-113.

Takahashi, T., Nowakowski, R.S. and Caviness, V.S., Jr. (1993) Cell cycle parameters and patterns of nuclear movement in the neocortical proliferative zone of the fetal mouse. J Neurosci, 13, 820-833.

Takahashi, Y., Kahyo, T., Toh, E.A., Yasuda, H. and Kikuchi, Y. (2001) Yeast Ull1/Siz1 is a novel SUMO1/Smt3 ligase for septin components and functions as an adaptor between conjugating enzyme and substrates. J Biol Chem, 276, 48973-48977.

Tang, Z., El Far, O., Betz, H. and Scheschonka, A. (2005) Pias1 interaction and sumoylation of metabotropic glutamate receptor 8. J Biol Chem, 280, 38153-38159.

Tatham, M.H., Jaffray, E., Vaughan, O.A., Desterro, J.M., Botting, C.H., Naismith, J.H. and Hay, R.T. (2001) Polymeric chains of SUMO-2 and SUMO-3 are conjugated to protein substrates by SAE1/SAE2 and Ubc9. J Biol Chem, 276, 35368-35374.

Thépaut, M., Maiorano, D., Guichou, J. F., Augé, M. T., Dumas, C., Méchali, M., Padilla, A. (2004) Crystal structure of the coiled-coil dimerization motif of geminin: structural and functional insights on DNA replication regulation. J Mol Biol, 342, 275-87.

Tuoc, T. (2008) Pax6-dependent mechanisms in mammalian corticogenesis. Max-PlanckInsitute for Biophysical Chemistry, Dept. Molecular Cell Biology, Göttingen.

Uchimura, Y. (2004) Overproduction of eukaryotic SUMO-1- and SUMO-2-conjugated proteins in Escherichia coli. Analytical Biochemistry, 331, 204-206.

Vijay-Kumar, S., Bugg, C.E. and Cook, W.J. (1987) Structure of ubiquitin refined at $1.8 \mathrm{~A}$ resolution. J Mol Biol, 194, 531-544.

Walther, C. and Gruss, P. (1991) Pax-6, a murine paired box gene, is expressed in the developing CNS. Development, 113, 1435-1449.

Wang, W., Xue, Y., Zhou, S., Kuo, A., Cairns, B.R. and Crabtree, G.R. (1996) Diversity and specialization of mammalian SWI/SNF complexes. Genes Dev, 10, 21172130.

Warming, S., Costantino, N., Court, D.L., Jenkins, N.A. and Copeland, N.G. (2005) Simple and highly efficient $B A C$ recombineering using galK selection. Nucleic Acids Res, 33, e36.

Watakabe, A., Ichinohe, N., Ohsawa, S., Hashikawa, T., Komatsu, Y., Rockland, K.S. and Yamamori, T. (2007) Comparative analysis of layer-specific genes in Mammalian neocortex. Cereb Cortex, 17, 1918-1933. 
Weissman, T., Noctor, S.C., Clinton, B.K., Honig, L.S. and Kriegstein, A.R. (2003) Neurogenic radial glial cells in reptile, rodent and human: from mitosis to migration. Cereb Cortex, 13, 550-559.

Wen, J., Hu, Q., Li, M., Wang, S., Zhang, L., Chen, Y. and Li, L. (2008) Pax6 directly modulate Sox2 expression in the neural progenitor cells. Neuroreport, 19, 413-417.

Wilson, S.W. and Rubenstein, J.L. (2000) Induction and dorsoventral patterning of the telencephalon. Neuron, 28, 641-651.

Wohlschlegel, J.A., Dwyer, B.T., Dhar, S.K., Cvetic, C., Walter, J.C. and Dutta, A. (2000) Inhibition of eukaryotic DNA replication by geminin binding to Cdt1. Science, 290, 2309-2312.

Wohlschlegel, J. A., Kutok, J. L., Weng, A. P., Dutta, A. (2002) Expression of geminin as a marker of cell proliferation in normal tissues and malignancies. Am J Pathol, 161, 267-73.

Xouri, G., Lygerou, Z., Nishitani, H., Pachnis, V., Nurse, P. and Taraviras, S. (2004) Cdt1 and geminin are down-regulated upon cell cycle exit and are over-expressed in cancer-derived cell lines. Eur J Biochem, 271, 3368-3378.

Yanagi, K., Mizuno, T., Tsuyama, T., Tada, S., lida, Y., Sugimoto, A., Eki, T., Enomoto, T. and Hanaoka, F. (2005) Caenorhabditis elegans geminin homologue participates in cell cycle regulation and germ line development. J Biol Chem, 280, 19689-694.

Yang, S.H., Galanis, A., Witty, J. and Sharrocks, A.D. (2006a) An extended consensus motif enhances the specificity of substrate modification by SUMO. Embo J, 25, 5083-5093.

Yang, Y., Stopka, T., Golestaneh, N., Wang, Y., Wu, K., Li, A., Chauhan, B.K., Gao, C.Y., Cveklova, K., Duncan, M.K., Pestell, R.G., Chepelinsky, A.B., Skoultchi, A.I. and Cvekl, A. (2006b) Regulation of alphaA-crystallin via Pax6, c-Maf, CREB and a broad domain of lens-specific chromatin. Embo J, 25, 2107-2118.

Yoshida, K., Oyaizu, N., Dutta, A. and Inoue, I. (2004) The destruction box of human Geminin is critical for proliferation and tumor growth in human colon cancer cells. Oncogene, 23, 58-70.

Yoshida, K., Takisawa, H. and Kubota, Y. (2005) Intrinsic nuclear import activity of geminin is essential to prevent re-initiation of DNA replication in Xenopus eggs. Genes Cells, 10, 63-73.

Zhang, H., Smolen, G., Palmer, R., Christoforou, A., Van Den Heuvel, S. and Haber, D. (2004) SUMO modification is required for in vivo Hox gene regulation by the Caenorhabditis elegans Polycomb group protein SOP-2. Nat Genet, 36, 507-511.

Zhang, Y., Muyrers, J.P., Testa, G. and Stewart, A.F. (2000) DNA cloning by homologous recombination in Escherichia coli. Nat Biotechnol, 18, 1314-1317.

Zhu, W., Chen, Y. and Dutta, A. (2004) Rereplication by depletion of geminin is seen regardless of p53 status and activates a G2/M checkpoint. Mol Cell Biol, 24,7140-50.

Zimmer, C., Tiveron, M.C., Bodmer, R. and Cremer, H. (2004) Dynamics of Cux2 expression suggests that an early pool of SVZ precursors is fated to become upper cortical layer neurons. Cereb Cortex, 14, 1408-1420. 


\section{Lebenslauf}

\section{Persönliche Angaben}

Yvonne Uerlings

Unter den Linden 5

37085 Göttingen

Fon: 0551-7975554

Mobil: 0170-8390857

E-mail: yuerlin@gwdg.de

Geburtstag: 19. Februar 1980

Geburtsort: Göttingen

Staatsangehörigkeit: Deutsch

Familienstand: ledig

Seit $10 / 2004$

\section{Beruflicher Werdegang}

Dissertation „Die Funktion von Geminin beim Übergang von Neuro- zu Gliogenese in der Maus" am Max-Planck-Institut für biophysikalische Chemie in Göttingen, Abteilung Molekulare Zellbiologie, Forschungsgruppe Entwicklungsbiologie

\section{Universitäre Bildung}

$02 / 2004-09 / 2004$

Diplomarbeit „Zellzyklus und Hox-Gen-Regulation” am Max-Planck-Institut für biophysikalische Chemie in Göttingen

$10 / 1999-01 / 2004$

08/1992 - 06/1999

Diplom-Studium der Biologie an der Georg-August-Universität Göttingen, Hauptfach Entwickungsbiologie, Nebenfächer Biochemie und Zoologie

\section{Schulische Bildung}

Gymnasium, Otto-Hahn-Gymnasium in Göttingen, Abschluss mit Abitur, Hauptfächer Biologie, Mathematik und Englisch

08/1986 - 06/1992

Grundschule in Adelebsen

\section{Praktika und Arbeitserfahrung}

$09 / 1999-12 / 2003$

Wissenschaftliche Assistentin bei DeveloGen Biopharmazeutische Firma, Abteilung „Functional Genomics I In vitro Validation" (Pankreaskrebs- und Diabetes-Programm)

Praktikum bei DeveloGen, Abteilung „Assay Development”

Praktikum im Institut für Biochemie der Georg-AugustUniversität in Göttingen 


\section{Zusatzqualifikationen}

\section{Sprachen}

Englisch, verhandlungssicher in Wort und Schrift

Französisch, Grundkenntnisse

\section{Computerkenntnisse}

Gute Kenntnisse in MS-Office, Photoshop, Freehand

\section{Persönliche Interessen}

Sport, Tae Bo, Reiten, Klettern, Skifahren, Reisen

\section{Veröffentlichungen}

„Regulation of Geminin functions by cell cycle-dependent nuclear-cytoplasmic shuttling" Lingfei Luo, Yvonne Uerlings, Nicole Happel, Naisana S. Asli, Hendrik Knoetgen and Michael Kessel. Molecular and Cellular Biology (2007) 